UNIVERSITÉ DU QUÉBEC

\author{
THÈSE PRÉSENTÉE À \\ L'UNIVERSITÉ DU QUÉBEC À CHICOUTIMI \\ COMME EXIGENCE PARTIELLE \\ DU DOCTORAT EN INGÉNIERIE
}

par

Stephan Brettschneider

\title{
CONTRIBUTION TO STUDY OF VISIBLE \\ DISCHARGE INITIATION AND DEVELOPMENT ON \\ THE ICE SURFACE
}

\section{CONTRIBUTION À L'ÉTUDE DE L'APPARITION ET DU DÉVELOPPEMENT DES DÉCHARGES VISIBLES \\ À LA SURFACE DE LA GLACE}




\section{Bibliothèque}

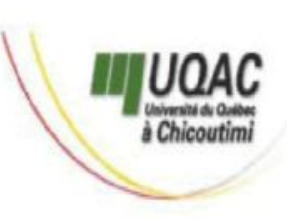

\section{Mise en garde/Advice}

Afin de rendre accessible au plus Motivated by a desire to make the grand nombre le résultat des results of its graduate students' travaux de recherche menés par ses research accessible to all, and in étudiants gradués et dans l'esprit des accordance with the rules règles qui régissent le dépôt et la governing the acceptation and diffusion des mémoires et thèses diffusion of dissertations and produits dans cette Institution, theses in this Institution, the I'Université du Québec à Université du Québec à Chicoutimi (UQAC) est fière de Chicoutimi (UQAC) is proud to rendre accessible une version make a complete version of this complète et gratuite de cette œuvre. work available at no cost to the reader.

L'auteur conserve néanmoins la The author retains ownership of the propriété du droit d'auteur qui copyright of this dissertation or protège ce mémoire ou cette thèse. thesis. Neither the dissertation or Ni le mémoire ou la thèse ni des thesis, nor substantial extracts from extraits substantiels de ceux-ci ne it, may be printed or otherwise peuvent être imprimés ou autrement reproduced without the author's reproduits sans son autorisation. permission. 


\section{ABSTRACT}

The present study aims to further the knowledge of the fundamental processes of electrical discharges along ice surfaces. The understanding of these phenomena may help to develop numerical tools for prediction of flashover on icecovered insulators and to improve the design of $\mathrm{HV}$ insulators for application to power networks in cold regions. Despite the numerous investigations on the electrical performance of industrial insulators under icing conditions, there still exist major gaps in comprehensive studies on the subject. Such fundamental studies on electrical insulation performance under atmospheric icing conditions consist one of the main objectives of the NSERC/Hydro Quebec/UQAC Chair on Atmospheric Icing of Power Network Equipment (CIGELE).

Sophisticated ultra high-speed photographic techniques were applied in order to observe and analyse the very fast processes of visible discharge initiation and development on the ice surface during the first nanoseconds. In addition, measurements of the $50 \%$ lightning impulse breakdown voltage and waveform measurements of voltage and current were realised. A physical model with two hemispherical capped electrodes, half submerged in ice, was used for the experiments, to which lighting impulse voltage was applied. The effects of various parameters were investigated: Environmental parameters (freezing water conductivity, ice temperature, ice surface uniformity, cooling rate, type of ice accumulation), electrical parameters (voltage polarity, voltage waveform, electric field during cooling period) and geometrical parameters (electrode distance, electrode curvature radius, electrode axis orientation).

The investigations show that streak photography is an adequate technique to study the very fast visible discharge processes along ice surfaces under various conditions. The study reveals that different regimes govern the ice surface discharge process in the early stages, depending on the ice temperature and the distance between the electrodes. Numerical data is provided on critical conditions of discharge initiation, time delay between start of pre-discharge activities and occurrence of breakdown, as well as on velocity of discharge development. In spite of the fact that the experimental conditions (simplified physical models under impulse voltage) did not perfectly portray the actual situation on power networks under icing conditions (complex-shaped insulators under ac or dc voltages), some

good correspondences between previous field observations of power failures and the present laboratory investigations can be identified. 


\section{RÉSUMÉ}

Le présent travail a pour objectif d'améliorer la connaissance des processus fondamentaux de décharges électriques à la surface de la glace. La compréhension de ces phénomènes peut aider à développer des outils numériques pour la prédiction des contournements des isolateurs recouverts de glace et à améliorer la conception des isolateurs à haute tension pour des applications dans des réseaux de transport d'énergie électrique dans les régions froides. Malgré un grand nombre d'études relatives à la performance électrique des isolateurs industriels sous des conditions givrantes, peu de travaux ont traité des processus fondamentaux. Dans ce contexte, ce projet de recherche a été initié par la Chaire CRSNG/Hydro-Québec/UQAC sur le givrage atmosphérique des équipements des réseaux électriques (CIGELE), dont les activités visent à accroître les connaissances de ces phénomènes.

Dans cette étude expérimentale, des technologies sophistiquées de photographie à ultra haute vitesse sont appliquées dans le but d'observer et d'analyser pendant les premières nanosecondes les processus extrêmement rapides de l'apparition et du développement de décharge visible à la surface de la glace. Un modèle physique, qui consiste en deux électrodes métalliques à moitié submergées dans la glace, est utilisé pour les expériences. Des tensions d'essai en forme de choc de foudre sont appliquées. Les effets de plusieurs paramètres sont étudiés: conductivité de l'eau, température de la glace, uniformité de la surface de glace, taux de refroidissement, type d'accumulation de glace, polarité de la tension, forme d'onde, champ électrique pendant la période de refroidissement, distance entre les électrodes, rayon de courbure des électrodes, orientation de l'axe des électrodes.

Les résultats montrent que la technologie des appareils photo à balayage de fente est adéquate pour l'étude des premières décharges visibles à la surface de la glace. Les expériences révèlent qu'il existe différents régimes pour les premières étapes des processus de décharge à la surface de la glace en fonction de la température de la glace et de la distance entre les électrodes. Des valeurs numériques sont relevées pour les conditions critiques de l'amorçage des décharges, pour la durée entre l'apparition des premières décharges et le contournement, ainsi que pour la vitesse de développement des décharges à la surface de la glace. Malgré le fait que les conditions expérimentales (modèle physique simplifié, tension en forme de choc de foudre) ne reproduisent pas parfaitement la situation d'une ligne de transport d'énergie électrique à haute tension (isolateur avec des formes complexes, tension sinusoïdale), des similitudes peuvent être identifiées entre les observations de terrain pendant des coupures de courant et des expériences en laboratoire. 


\section{ZUSAMMENFASSUNG}

Die vorliegende Arbeit möchte einen Beitrag zur Erweiterung der Grundlagenkenntnisse über die elektrischen Entladungserscheinungen auf Eisoberflächen leisten. Das Verständnis dieser Phänomene erscheint notwendig für die Entwicklung von Computerprogrammen zur Simulation und Vorhersage von Überschlägen von vereisten Hochspannungsisolatoren wie auch für den Entwurf neuer Isolatortypen, die auf die klimatischen Verhältnisse in Kälteregionen angepasst sind. Obwohl sich zahlreiche Forschungsarbeiten mit der Problematik von Überschlägen an vereisten Hochspannungsisolatoren befassen, gehen nur sehr wenige Veröffentlichungen auf die zugrundeliegenden Prozesse von Entstehung und Entwicklung der elektrischen Entladungserscheinungen ein. Vor diesem Hintergrund wurde die hier präsentierte Forschungsarbeit im Rahmen der Aktivitäten des Lehrstuhls für Vereisungserscheinungen von Komponeten der Energieübertragungssysteme an der "Université du Québec à Chicoutimi", Kanada, ins Leben gerufen.

In dieser Studie, die sich vorrangig auf praktische Experimente stützt, wurden spezielle Hochgeschwindigkeitskameras verwendet, um die ersten Nanosekunden der Entstehung und des Wachstums der schnell ablaufenden Entladungserscheinungen auf der Eisoberfläche zu beobachten. Für die Versuche wurde ein Model benutzt, welches aus zwei Metallelektroden besteht, die zur Hälfte in Eis eingetaucht sind. Impulsspannungen vom Typ "Blitzstoßspannung" wurden angelegt. Die nachfolgende Aufzählung nennt die Parameter, die untersucht wurden: Leitfähigkeit des Eiswassers, Eistemperatur, Gleichmässigkeit der Eisoberfläche, Abkühlungsgeschwindigkeit, Spannungspolarität, Spannungsform, Eisbildung mit elektrischen Feld, Elektrodenabstand, Elektrodenradius, Ausrichtung der Elektrodenachse.

Die Versuchsergebnisse belegen, dass Hochgeschwindigkeitsfotografie mittels einer "Streak-Kamera" eine angemessene Verfahrensweise ist, um die Entstehung und Entwicklung der ersten sichtbaren Entladungserscheinungen auf der Eisoberfläche zu untersuchen. Es konnte gezeigt werden, dass die elektrischen Entladungen nach verschiedenen Grundprinzipien ablaufen - in Abhängigkeit von Eistemperatur und Elektrodenabstand. Spannungsschwellenwerte der Entladungsentstehung, Zeitdauer zwischen Entladungsentstehung und elektrischem Überschlag sowie die Fortpflanzungsgeschwindigkeit der Entladungen auf der Eisoberfläche konnten gemessen werden. Obgleich für die Versuche mehrere Vereinfachungen vorgenommen werden mussten, um die Situation von vereisten Hochspannungsisolatoren im Labor nachzubilden, lassen sich einige interessante Übereinstimmungen zwischen Versuchergebnissen und Feldbeobachtungen während Eisstürmen aufzeigen. 


\section{PREFACE}

"About 12 years ago, Professor Urey, the discoverer of deuterium, came to see our laboratory. When he learnt that we were working on the electrical properties of ice crystals, he asked astonished: 'What, isn't there everything known about ice?' "

H. Graenicher, opening keynote,

International Symposium on Physics of Ice, September 1968 [92]

Today, 44 years after this comment of an astonished Professor Urey, ice research is still an actual topic in many aspects - and some characteristics of this substance are still a mystery to the scientific community.

Ice - or in a more general sense we should speak of water, as ice is only the solid state of this substance - is one of the most amazing matter in nature. Some examples for its exceptional behaviour may be the density characteristic, which reaches its highest value in liquid state, or the high value of its permittivity constant. In the temperature range of natural life on our planet, water does appear in all its different chemical states - solid, liquid, gaseous or mixtures of several states at the same time. This adds even more complexity to any investigation of this substance, as it may be expected that its behaviour will be influenced by the different chemical states. Perhaps this study can add some more aspects to describe this interesting substance, whereas it has to be admitted that we are still far from understanding it entirely.

The interest for studying the impact of atmospheric icing on power network equipment awoke as early as in the seventies at the University of Québec in Chicoutimi (UQAC). Growing research activities led to the creation of the "Research Group on Atmospheric Environment Engineering (GRIEA)" in 1983. During the past years, development continued and a peak in research and their recognition could be reached with creation of the "NSERC/Hydro-Québec/UQAC Chair on Atmospheric Icing of Power Network Equipment (CIGELE)" in September 1997. One of the objectives of this research institution is to further fundamental understanding of electrical insulation performance under atmospheric icing conditions. In this framework, a project related to discharge initiation and development on the ice surface was initiated by CIGELE, under the direction of Professor M. Farzaneh and in co-operation with Professor K. D. Srivastava from the University of British Columbia (UBC). It was a great pleasure for me to get the opportunity to participate in this project as a Ph.D.-student. A very interesting task 
was assigned to me, and I could learn a lot throughout the whole period of this Ph.D.-Thesis. However, I would not have been able to take part in this project without another co-operation that brought me first to the University of Québec in Chicoutimi. I had the chance to carry out my final research project, which is a part of the German engineering diploma, at this institution in the framework of a scientific co-operation between Professor M. Farzaneh of UQAC and Professor A. J. Schwab as well as Professor A. M. Miri of the University of Karlsruhe. Therefore, I owe my recognition to them for giving me the chance to participate in this cooperation and to do my diploma project at the University of Québec in Chicoutimi.

This Ph.D. Thesis was carried out in a very practical way. It presented a real challenge and numerous hours were spent in the two high voltage laboratories (often early in the morning or late in the evening in order to avoid disturbing colleagues who did working in the same rooms, as the camera requires total darkness). However, the research may just have started at this point. More experiments may be carried out, different physical models may be explored, mathematical and numerical models may be established, and theories on type and characteristics of the different discharge processes may be developed. I hope that this work may have succeeded in proving that this technology transfer into the field of ice research is possible, and that doors have been opened for future research towards the roots of the physical phenomena on ice surfaces. It is your power, dear reader, to make this ruling and perhaps to pass the opened doors in order to continue this research.

Chicoutimi, October 6, 2000

Stephan Brettschneider 


\section{ACKNOWLEDGEMENTS}

This work was carried out within the framework of the NSERC/HydroQuébec/UQAC Industrial Chair on Atmospheric Icing of Power Network Equipment (CIGELE) at the University of Québec in Chicoutimi, in collaboration with the University of British Colombia.

A single person cannot accomplish a project like the present one. I would like to express my grateful recognition to all of the numerous people - friends and colleagues - who offered their assistance and accompaniment throughout the whole project. It may be impossible to name all of them at this place, however, I would like to express my deepest gratitude in particular to:

Professor Masoud Farzaneh and Professor K.D. Srivastava, respectively my director and co-director of the thesis,

for their guidance, presence, patience and confidence that they offered me at any time during the project;

Professor Abderrahmane Beroual, Dr. William A. Chisholm, Professor René Chouinard, and Dr. Pierre Couture, for their participation in the evaluation committee;

Sylvain Desgagnés, Claudio Furnari, Dr. S. Li, and Simon Pilote, for their technical help and assistance during the ultra high-speed recordings;

Rabah Chaarani and Cyril Guesdon, for their patient support at each appearance of another inexplicable bug in the computer system;

Jean Talbot and Melanie Tremblay, for their advises, encouragement and help to render my texts legible;

My parents,

for their constant moral support and all their energy that they have put into my education, which enabled me to get to the point where I am today. 


\section{TABLE OF CONTENTS}

Title page

Page:

Abstract

Résumé (in French)

Zusammenfassung (in German)

Preface

Acknowledgements

TABLE OF CONTENTS

viii

List of Abbreviations and Symbols___ xiii

List of Figures__ XV

List of Tables_ $\quad x x$

List of Conference Contributions Arising from this Ph.D. Project___ xxii

\section{CHAPTER 1 INTRODUCTION}

1.1 General Context: Problem of Flashover on Ice-covered Insulators 2

1.2 State of the Art in Research on Flashover Performance of Ice-covered Insulators

1.3 Objectives of this Research Project

1.4 Methodology

\section{CHAPTER 2 LITERATURE REVIEW}

2.1 Introduction to Chapter 2

2.2 Related Fundamentals on Ice Physics

2.2.1 General Characteristics of Ice under Consideration of the Conditions in the Present Study

2.2.2 Electric Conductivity of Ice

2.2.3 Ice Surface Characteristics

2.2.4 Charge Storage in Ice

2.2.5 Influence of Electric Field on Ice Formation 
2.3 Related Fundamentals on Electrical Discharges__ 29

2.3.1 Generation of Charges _ 29

2.3.2 Different Types of Electrical Discharges _ $\quad 30$

2.3.2.1 Townsend Process__ 31

2.3.2.2 Streamer Process _ 32

2.3.3 Discharge Characteristics for Short Distances__

2.4. Surface Discharges

2.4.1 Discharge Activity on Synthetic Surfaces__ $\quad 37$

2.4.1.1 Mechanism of Surface Charge Accumulation and Discharge Initiation_ 38

2.4.1.2 Main Characteristics of Discharges on Synthetic Surfaces__ $\quad 40$

2.4.1.3 Propagation Velocity of Surface Discharges__ $\quad 46$

2.4.1.4 Application of Ultra High-speed Photography _ $\quad 47$

2.4.2 Discharge Activity on Ice Surfaces__ 48

2.4.3 Discharge Propagation in Water and on its Surface__ 52

2.5 Conclusions of Chapter 2

\section{CHAPTER 3 EXPERIMENTAL SET-UP AND PROCEDURES}

3.1 Introduction to Chapter 3ـ_ 59

3.2 Test Equipment

3.2.1 Ultra High-speed Imaging System _ $\quad 60$

3.2.2 Cold Chamber__ $\quad 63$

3.2.3 High Voltage Generator__ 64

3.2.4 Measuring System__ 67

3.3 Physical Model

3.3.1 Geometric Configurations__ $\quad 69$

3.3.2 Electric Field Conditions

3.3.3 Procedure of Ice Formation_

3.4 Experimental Parameters $\quad 76$

3.4.1 Freezing Water Conductivity__

3.4.2 Ice Temperature__

3.4.3 Voltage Waveform _ 81

3.4.4 Voltage Polarity _ 82

3.4.5 Electrode Distance___ 83

3.4.6 Electrode Curvature Radius__ $\quad 84$

3.4.7 Electrode Axis Orientation__ $\quad 84$

3.4.8 Ice Surface Uniformity___ 85 
3.4.9 Cooling Rate 85

3.4.10 Ice Accumulation Process 86

3.5 Test Procedures 88

3.5.1 Basic Principle of Streak Photography__ 88

3.5.2 Interpretation of Streak Recordings___ $\quad 89$

3.5.3 Definition of the Instant of Breakdown on the Streak Recordings_ $\quad 91$

3.5.4 Determination of $50 \%$ Lightning Impulse Breakdown Voltage__ $\quad 92$

3.5.5 Interpretation of Current Waveforms __ 93

3.6 Error Discussions__ $\quad 96$

3.6.1 Accuracy in the Determination of $50 \%$ Breakdown Voltage__ $\quad 96$

3.6.2 Temperature Characteristics of Current Shunt__ $\quad 97$

3.6.3 Time Resolution of Digitising Oscilloscope___ $\quad 98$

3.6.1 Time Resolution of the Streak Camera__ $\quad 98$

3.6.5 Oscillations in the Streak Recordings___ $\quad 99$

\section{CHAPTER 4 STUDY OF CRITICAL BREAKDOWN VOLTAGES}

4.1 Introduction to Chapter 4 107

4.2 Experimental Results__ 109

4.2.1 $\mathrm{U}_{50 \%}$ Values 109

4.2.2 Surface Photographs 114

4.3 Discussion and Analysis 116

4.3.1 Comparison of Different Materials 116

4.3.2 Effect of Freezing Water Conductivity__ 117

4.3.3 Effect of Ice Temperature__ 120

4.3.4 Effect of Voltage Polarity _ 122

4.3.5 Effect of Voltage Waveform 124

4.3.6 Effect of Electrode Curvature Radius $\quad 125$

4.3.7 Effect of Electrode Axis Orientation_ 126

4.3.8 Effect of Ice Surface Uniformity_ 127

4.3.9 Effect of Cooling Rate $\quad 132$

4.3.10 Electric Field during Cooling Period___ 134

4.4 Conclusions of Chapter 4_ 136

CHAPTER 5 STUDY OF VISIBLE DISCHARGE DEVELOPMENT

5.1 Introduction to Chapter 5 
5.2 Discharge Development in an Air Gap and along Synthetic Surfaces__ 141

5.3 Verifications of Experimental Methodology _ 143

5.3.1 Discharge Path _ 144

5.3.2 Repeatability of the Experiments__ 147

5.4 Ultra High-speed Photographic Observations for Ice Surfaces without

Artificial Air Gap_ $\quad 149$

5.4.1 Experimental Results $\quad 149$

5.4.1.1 Ice samples with Electrode Distance of $7 \mathrm{~mm} \quad 149$

5.4.1.2 Ice samples with Electrode Distance of $18 \mathrm{~mm} \quad 152$

5.4.2 Discussion and Analysis__ 157

5.4.2.1 Comparison of Different Materials_ $\quad 157$

5.4.2.2 Effect of Freezing Water Conductivity_ $\quad 159$

5.4.2.3 Effect of Ice Temperature__ 162

5.4.2.4 Effect of Voltage Polarity__ 165

5.4.2.5 Effect of Electrode Distance _ 167

5.4.2.6 Effect of Electrode Curvature Radius $\quad 170$

5.4.2.7 Effect of Electrode Axis Orientation $\quad 172$

5.4.2.8 Discharge Propagation Velocity _ 173

5.4.2.9 Effect of Steepness of Voltage Rise___ 177

5.5 Ultra High-speed Photographic Observations for Ice Surfaces

with Air Gaps_ 179

5.5.1 Experimental Results $\quad 179$

5.5.1.1 Ice Samples with Artificial Air Gap_ 179

5.5.1.2 Ice Samples with Natural Air Gaps__ 183

5.5.2 Discussion and Analysis $\quad 185$

5.5.2.1 Effect of Ice Temperature__ 185

5.5.2.2 Effect of Air Gap Location_ 187

5.5.2.3 Discharge Initiation for Ice Surfaces with Artificial Air Gap__ 190

5.5.2.4 Effect of Cooling Rate__ 191

5.5.2.5 Effect of Electric Field during Cooling Period__ 194

5.5.2.6 Effect of Type of Ice Accumulation Process___ 195

5.6 Conclusions of Chapter 5__ 196

\section{CHAPTER 6 STUDY OF VOLTAGE AND CURRENT WAVEFORMS}

6.1 Introduction to Chapter 6_ 201

6.2 Waveform Recordings of the Breakdown Process__ 203

6.2.1 Experimental Results for Ice Surfaces without Artificial Air Gap__ 203

6.2.2 Experimental Results for Ice Surfaces with Artificial Air Gap_ 206 
6.2.3 Discussion and Analysis

6.3 Waveform Recordings of Pre-discharge Activity _ 209

6.3.1 Experimental Results

6.3.2 Discussion and Analysis

6.4 Conclusions of Chapter 6

\section{CHAPTER 7 GENERAL CONCLUSIONS AND RECOMMENDATIONS FOR FUTURE WORK}

7.1 General Conclusions 218

7.2 Recommendations for Future Work 228

REFERENCES 233

\section{APPENDICES}

A1 Phase Diagrams of Ice 246

A2 Technical Data of Streak Camera 248

A3 Technical Data of Climate Chamber 249

A4 Elements of HV Impulse Generator 251

A5 Technical Data of Digitising Oscilloscope 253 A6 Specifications of Overvoltage Protection 256

A7 Design Parameters for Capacitive HV Measuring Divider 257

A8 Design Parameters for Current Shunts

A9 Connection of the Sub-systems in the Experimental Test Set-up 258

A10 Correction of Freezing Water Conductivity in Function of Temperature 260 A11 Non-linear Regression Analysis of the Effect of Freezing Water Conductivity on Critical Breakdown Voltage 


\title{
LIST OF ABBREVIATIONS AND SYMBOLS
}

\author{
ac Alternating current \\ dc Direct current \\ cha. Conductive channel as discharge path \\ CIGELE NSERC/Hydro-Québec/UQAC Chair on Atmospheric Icing of Power \\ Network Equipment \\ ESDD Equivalent salt deposit density \\ gro. Empty groove as discharge path \\ hor. Horizontal electrode axis orientation \\ HV High voltage \\ LI Lightning impulse voltage (1.2/50 $\mu \mathrm{s})$ \\ $\mathrm{NaCl}$ Sodium chloride \\ neg. Negative voltage polarity \\ orient. Electrode axis orientation of the test model \\ pol. Voltage polarity \\ pos. Positive voltage polarity \\ SDD Salt deposit density \\ UBC University of British Columbia \\ UQAC University of Québec in Chicoutimi \\ ver. Vertical electrode axis orientation
}

$\begin{array}{ll}a & \text { Distance of air gap from HV electrode [mm] } \\ d & \text { Distance between electrodes [mm] } \\ \mathbf{E} & \text { Electric field [V/m] } \\ \mathbf{g} & \text { Air gap length [mm] } \\ \mathbf{l} & \text { Current [mA] } \\ \mathrm{I}_{\text {ddc }} & \text { Dielectric displacement current [mA] } \\ \mathrm{I}_{\text {pdi }} & \text { Pre-discharge current impulse [mA] } \\ \mathrm{I}_{\text {pbc }} & \text { Pre-breakdown current [mA] } \\ \mathrm{r} & \text { Electrode curvature radius [mm] } \\ \mathrm{s} & \text { Standard deviation of } \mathrm{U}_{50 \%}[\mathrm{kV}] \\ \mathrm{t} & \text { Time [ns] } \\ \mathrm{t}_{\text {breakdown }} & \text { Time to breakdown [ns] } \\ \mathrm{t}_{\text {sweep }} & \text { Sweep period of streak camera [ns] } \\ \mathrm{t}_{\text {rame }} & \text { Exposure time of framing photograph [ns] } \\ \mathrm{t}_{\text {interf. }} & \text { Time between two framing photographs [ns] }\end{array}$


$\mathrm{t}_{1} \quad$ Front time [ $\left.\mu \mathrm{s}\right]$

$\mathrm{t}_{2} \quad$ Time to half value $\mu \mathrm{s}$ ]

$t_{\text {cooling }} \quad$ Duration of cooling period [ $h$ ]

$T_{\text {cooling }}^{\text {cooling }}$

$T_{\text {test }}$

Temperature inside climate chamber during cooling period $\left[{ }^{\circ} \mathrm{C}\right]$

$U_{\text {cooling }}$ Ice Temperature during test $\left[{ }^{\circ} \mathrm{C}\right]$

$\mathrm{U}_{50 \%} \quad 50 \%$ lightning impulse breakdown voltage [kV]

$\alpha \quad$ First Townsend coefficient

$\delta \quad$ Correction factor for freezing water conductivity as a function of temperature

$\varepsilon_{\mathrm{r}} \quad$ Relative electric permittivity

$\gamma \quad$ Second Townsend coefficient

$\sigma \quad$ Freezing water conductivity $[\mathrm{S} / \mathrm{m}]$

(Conductivity of liquids is often given in " $\mu \mathrm{S} / \mathrm{cm}$ ". The relation between the two units is: $1 \mu \mathrm{S} / \mathrm{cm}=1 \times 10^{-4} \mathrm{~S} / \mathrm{m}$ )

Several units are given using prefixes to avoid very large or very small numerical values. The following list shows the units concerned:

Distance $(a, d, g, r)$ :

Current $\left(I, I_{d d c}, I_{p d i}, I_{p b c}\right)$ :

Voltage $\left(U_{\text {cooling }}, U_{50 \%}\right)$ :

Time $\left(t, t_{\text {breakdown }}, t_{\text {sweep }}, t_{\text {rame }}, t_{\text {intert. }}\right)$ :

$1 \mathrm{~mm}=10^{-3} \mathrm{~m}$
$1 \mathrm{~mA}=10^{-3} \mathrm{~A}$
$1 \mathrm{kV}=10^{3} \mathrm{~V}$
$1 \mathrm{~ns}=10^{-9} \mathrm{~s}$
$1 \mu \mathrm{s}=10^{-6} \mathrm{~s}$ 


\section{LIST OF FIGURES}

Fig. 1-1: Appearance of visible discharge activities on the surface and at the

ends of an ice-covered high voltage insulator

Page: 3

Fig. 2-1: Hexagonal structure of ice type "Ih" [75]__ 16

Fig. 2-2: Unrelaxed surface bilayer of ice [75] $\quad 21$

Fig. 2-3: Streamer discharge causing a field enhancement in front of and behind the electron avalanche [4]

Fig. 2-4: Creation of secondary avalanches by emission of photons out of the primary streamer [4]

Fig. 2-5: Breakdown curves for sphere-plane configuration as a function

of gap length [67] 36

Fig. 3-1: Experimental set-up combining ultra high-speed imaging system, cold chamber, high voltage generator and measuring system

Fig. 3-2: Schematic diagram of the imaging system

Fig. 3-3: Experimental set-up with the streak camera in front of the cold chamber

Fig. 3-4: Waveform of a lightning impulse voltage [50] $\quad 65$

Fig. 3-5: Equivalent electric circuit of the high voltage impulse generator__ $\quad 66$

Fig. 3-6: Photograph of the real set-up of the high voltage impulse generator 66

Fig. 3-7: Connections of the oscilloscope to the experimental set-up__ $\quad 68$

Fig. 3-8: Vertical section of the physical model_ $\quad 71$

Fig. 3-9: Still photographs of ice model__

Fig. 3-10: Numerical simulation for electric field distribution of the physical model $(\mathrm{d}=18 \mathrm{~mm} ; \mathrm{r}=6 \mathrm{~mm})[108]$ 72

Fig. 3-11: Electric field values between the electrodes for an applied voltage of $1 \mathrm{~V}$

Fig. 3-12: Different steps for the preparation of the ice samples

Fig. 3-13: Orientation of the streak photographs in this study

Fig. 3-14: Processed versions of a streak recording

Fig. 3-15: Determination of the instant of breakdown

Fig. 3-16: Typical waveform recording for voltage and current

Fig. 3-17: Observed impulses on the current waveform recordings 73

Fig. 3-18: Focus image recorded with the streak camera (showing two lines

Fig. 3-19: Recordings with streak camera accidentally adjusted to focus 74 mode 
Fig. 4-1: Surface still photographs as a function of cooling rate $\left(\sigma=30 \times 10^{-4} \mathrm{~S} / \mathrm{m}\right.$;

$\mathrm{T}=-12^{\circ} \mathrm{C}$; pol.=pos.; $\mathrm{d}=18 \mathrm{~mm}$; $\mathrm{r}=6 \mathrm{~mm}$; orient.=hor.)

Fig. 4-2: Surface still photographs as a function the ice accumulation process $\left(\sigma=30 \times 10^{-4} \mathrm{~S} / \mathrm{m} ; \mathrm{T}=-12^{\circ} \mathrm{C}\right.$; pol.=neg.; $\mathrm{d}=18 \mathrm{~mm} ; \mathrm{r}=6 \mathrm{~mm}$; orient.=hor.)

Fig. 4-3: $50 \%$ lightning impulse breakdown voltage for different materials (pol.=pos.; $d=7 \mathrm{~mm} ; \mathrm{r}=6 \mathrm{~mm}$; orient.=hor.)

Fig. 4-4: $50 \%$ lightning impulse voltages for ice surface without artificial air gap as a function of freezing water conductivity $y, \sigma$, and ice temperature, $T$ ( $\mathrm{d}=18 \mathrm{~mm}$; $\mathrm{r}=6 \mathrm{~mm}$; orient.=hor.) 118

Fig. 4-5: $50 \%$ lightning impulse breakdown voltage as a function of voltage polarity for different temperatures $\left(\sigma=30 \times 10^{-4} \mathrm{~S} / \mathrm{m}\right.$; $d=18 \mathrm{~mm} ; \mathrm{r}=6 \mathrm{~mm}$; orient.=hor.)

Fig. 4-6: $50 \%$ breakdown voltages as a function of the voltage waveform $\left(\sigma=30 \times 10^{-4} \mathrm{~S} / \mathrm{m} ; \mathrm{T}=-12^{\circ} \mathrm{C}\right.$; pol.=neg.; $\mathrm{d}=18 \mathrm{~mm} ; \mathrm{r}=6 \mathrm{~mm}$; orient. $=$ hor.)

Fig. 4-7: $50 \%$ breakdown voltages as a function of electrode curvature radius $\left(\sigma=30 \times 10^{-4} \mathrm{~S} / \mathrm{m} ; \mathrm{d}=18 \mathrm{~mm}\right.$; orient.=hor.) 126

Fig. 4-8: $50 \%$ breakdown voltages as a function of ice surface uniformity $\left(\sigma=30 \times 10^{-4} \mathrm{~S} / \mathrm{m} ; \mathrm{d}=18 \mathrm{~mm} ; \mathrm{r}=6 \mathrm{~mm}\right.$; orient.=hor.) 129

Fig. 4-9: $50 \%$ breakdown voltages as a function of surface material and for different surface conditions $\left(\sigma_{\text {ice }}=30 \times 10^{-4} \mathrm{~S} / \mathrm{m} ; \mathrm{T}=-12^{\circ} \mathrm{C} ; \mathrm{pol} .=\mathrm{pos}\right.$; $\mathrm{d}=18$ $\mathrm{mm} ; \mathrm{r}=6 \mathrm{~mm}$ )

Fig. 4-10: $50 \%$ breakdown voltages as a function of cooling rate $\left(\sigma=30 \times 10^{-4} \mathrm{~S} / \mathrm{m}\right.$; $\mathrm{T}=-12^{\circ} \mathrm{C}$; pol.=pos.; $\mathrm{d}=18 \mathrm{~mm} ; \mathrm{r}=6 \mathrm{~mm}$; orient.=hor.)

Fig. 5-1: Discharge development in an air gap ( $T=20^{\circ} \mathrm{C}$; pol.=pos.; $d=7 \mathrm{~mm} ; r=6$ $\mathrm{mm}$; orient.=ver.; $\mathrm{t}_{\text {sweep }}=100 \mathrm{~ns}$ )

Fig. 5-2: Series of framing recordings showing the temporal discharge development in an air gap ( $T=-12^{\circ} \mathrm{C}$; pol.=pos.; $d=7 \mathrm{~mm} ; \mathrm{r}=6 \mathrm{~mm}$; orient.=hor.; $t_{\text {rame }}=10 \mathrm{~ns}$; $\mathrm{t}_{\text {interf. }}=0 \mathrm{~ns}$ ) 142

Fig. 5-3: Discharge development along the surface of a Teflon spacer $\left(T=20^{\circ} \mathrm{C}\right.$; pol.=pos.; $d=7 \mathrm{~mm} ; \mathrm{r}=6 \mathrm{~mm}$; orient.=ver.; $\mathrm{t}_{\text {sweep }}=50 \mathrm{~ns}$ )

Fig. 5-4: Photographs of discharge staying inside the conductive channel $\left(\sigma=30 \times 10^{-4} \mathrm{~S} / \mathrm{m} ; \mathrm{T}=0^{\circ} \mathrm{C}\right.$; pol.=pos.; $d=18 \mathrm{~mm} ; \mathrm{r}=6 \mathrm{~mm}$; orient.=hor.; path=cha.)

Fig. 5-5: Streak recordings for the two proposed measures to keep the discharge on a straight line $\left(\sigma=30 \times 10^{-4} \mathrm{~S} / \mathrm{m} ; \mathrm{T}=-12^{\circ} \mathrm{C}\right.$; pol.=pos.; $\mathrm{d}=18 \mathrm{~mm} ; \mathrm{r}=6 \mathrm{~mm}$; orient.=hor.; $\mathrm{t}_{\text {sweep }}=50 \mathrm{~ns}$ )

Fig. 5-6: Photographs of a discharge propagating along the surface of the ice $\left(\sigma=30 \times 10^{-4} \mathrm{~S} / \mathrm{m} ; \mathrm{T}=-12^{\circ} \mathrm{C}\right.$; pol.=pos.; $\mathrm{d}=18 \mathrm{~mm}$; $\mathrm{r}=6 \mathrm{~mm}$; orient.=hor.; path $=$ cha.) 
Fig. 5-7: Streak recordings for similar test conditions carried out in different laboratories (pol.=pos.; $d=7 \mathrm{~mm}$; $r=6 \mathrm{~mm}$; orient.=hor.; $\left.t_{\text {sweep }}=50 \mathrm{~ns}\right)$

Fig. 5-8: Comparison of a streak recording with a framing recording for similar experimental conditions $\left(\sigma=30 \times 10^{-4} \mathrm{~S} / \mathrm{m} ; \mathrm{T}=0^{\circ} \mathrm{C}\right.$; pol.=pos.; $\mathrm{d}=18 \mathrm{~mm}$; $\mathrm{r}=6 \mathrm{~mm}$; orient.=hor.; path=cha.; $\mathrm{a}=0 \mathrm{~mm}$ )

Fig. 5-9: Streak recordings as a function of freezing water conductivity, $\sigma$ $\left(\mathrm{T}=-12^{\circ} \mathrm{C}\right.$ or $\mathrm{T}_{\mathrm{ubc}}=-20^{\circ} \mathrm{C}$; $\mathrm{d}=7 \mathrm{~mm} ; \mathrm{r}=6 \mathrm{~mm}$; orient.=hor.; $\left.t_{\text {sweep }}=50 \mathrm{~ns}\right)$

Fig. 5-10: Streak recordings as a function of ice temperature, $T\left(\sigma=2.5 \times 10^{-4} \mathrm{~S} / \mathrm{m}\right.$ or $\sigma_{\text {ubc }}=1 \times 10^{-4} \mathrm{~S} / \mathrm{m} ; \mathrm{d}=7 \mathrm{~mm} ; \mathrm{r}=6 \mathrm{~mm}$; orient.=hor.; $\mathrm{t}_{\text {sweep }}=50 \mathrm{~ns}$ )

Fig. 5-11: Streak recordings as a function of freezing water conductivity, $\sigma$ $\left(T=-12^{\circ} \mathrm{C}\right.$ or $T_{u b c}=-20^{\circ} \mathrm{C}$; $d=18 \mathrm{~mm} ; \mathrm{r}=6 \mathrm{~mm}$; orient.=hor.; $t_{\text {swees }}=50 \mathrm{~ns}$ )

Fig. 5-12: Streak recordings as a function of ice temperature, $\mathrm{T}\left(\sigma=2.5 \times 10^{-4} \mathrm{~S} / \mathrm{m}\right.$ or $\sigma_{\mathrm{ubc}}=1 \times 10^{-4} \mathrm{~S} / \mathrm{m} ; \mathrm{d}=18 \mathrm{~mm} ; \mathrm{r}=6 \mathrm{~mm}$; orient.=hor.; $\left.\mathrm{t}_{\text {sweep }}=50 \mathrm{~ns}\right)$

Fig. 5-13: Series of framing recordings showing the very fast temporal discharge development along the surface of the ice $\left(\sigma=30 \times 10^{-4} \mathrm{~S} / \mathrm{m}\right.$; $\mathrm{T}=-12^{\circ} \mathrm{C}$; pol.=pos.; $\mathrm{d}=18 \mathrm{~mm} ; \mathrm{r}=6 \mathrm{~mm}$; orient.=hor.; $\mathrm{t}_{\text {trame }}=10 \mathrm{~ns}$; $\mathrm{t}_{\text {intertr }}=0 \mathrm{~ns}$ )

Fig. 5-14: Streak recordings as a function of electrode distance, $\mathrm{d}\left(\mathrm{T}=-12^{\circ} \mathrm{C}\right.$ or $\mathrm{T}_{\mathrm{ubc}}=-20^{\circ} \mathrm{C}$; pol. $=$ pos.; $\mathrm{r}=6 \mathrm{~mm}$; orient. $=$ hor.; $\mathrm{t}_{\text {sweep }}=50 \mathrm{~ns}$ )

Fig. 5-15: Streak recordings as a function of electrode curvature radius, $r$ $\left(\sigma=2.5 \times 10^{-4} \mathrm{~S} / \mathrm{m} ; \mathrm{T}=-12^{\circ} \mathrm{C} ; \mathrm{d}=18 \mathrm{~mm} ; \mathrm{r}=6 \mathrm{~mm}\right.$; orient.=hor.; $t_{\text {sweep }}=50 \mathrm{~ns}$ )

Fig. 5-16: Streak recordings for increased electrode curvature radius as a function of freezing water conductivity and ice temperature (pol.=pos.; $d=18 \mathrm{~mm} ; \mathrm{r}=15.5 \mathrm{~mm}$; orient.=hor.; $\mathrm{t}_{\text {sweep }}=50 \mathrm{~ns}$ )

Fig. 5-17: Streak Recordings as a function of electrode axis orientation $\left(\sigma=30 \times 10^{-4} \mathrm{~S} / \mathrm{m} ; \mathrm{T}=0^{\circ} \mathrm{C} ; \mathrm{d}=18 \mathrm{~mm} ; \mathrm{r}=6 \mathrm{~mm} ; \mathrm{t}_{\text {sweep }}=200 \mathrm{~ns}\right.$ )

Fig. 5-18: Discharge development for different materials (pol.=pos.; $d=7 \mathrm{~mm}$; $r=6 \mathrm{~mm})$

Fig. 5-19: Comparison of streak recordings of Teflon surface and ice surface for similar electrode configuration (pol.=pos.; $d=18 \mathrm{~mm}$; $r=6 \mathrm{~mm}$; $t_{\text {sweep }}=50 \mathrm{~ns}$ )

Fig. 5-20: Time to breakdown as a function of freezing water conductivity, $\sigma$ ( $\mathrm{T}=-12^{\circ} \mathrm{C}$ or $\mathrm{T}_{\mathrm{ubc}}=-20^{\circ} \mathrm{C} ; \mathrm{d}=7 \mathrm{~mm} ; \mathrm{r}=6 \mathrm{~mm}$; orient.=hor.)

Fig. 5-21: Time to breakdown as a function of freezing water conductivity, $\sigma$ ( $\mathrm{T}=-12^{\circ} \mathrm{C}$ or $\mathrm{T}_{\mathrm{ubc}}=-20^{\circ} \mathrm{C} ; \mathrm{d}=18 \mathrm{~mm} ; \mathrm{r}=6 \mathrm{~mm}$; orient.=hor.)

Fig. 5-22: Time to breakdown as a function of ice temperature, $T\left(\sigma=2.5 \times 10^{-4} \mathrm{~S} / \mathrm{m}\right.$ or $\sigma_{\mathrm{ubc}}=1 \times 10^{-4} \mathrm{~S} / \mathrm{m} ; \mathrm{d}=7 \mathrm{~mm} ; \mathrm{r}=6 \mathrm{~mm}$; orient.=hor.) 
Fig. 5-23: Time to breakdown as a function of ice temperature, $T\left(\sigma=2.5 \times 10^{-4} \mathrm{~S} / \mathrm{m}\right.$ or $\sigma_{\mathrm{ubc}}=1 \times 10^{-4} \mathrm{~S} / \mathrm{m} ; \mathrm{d}=18 \mathrm{~mm} ; \mathrm{r}=6 \mathrm{~mm}$; orient.=hor.)

Fig. 5-24: Schematic representation of the streak recordings presented in

Fig 5-12b $\left(\sigma=2.5 \times 10^{-4} \mathrm{~S} / \mathrm{m}\right.$ or $\sigma_{\mathrm{ubc}}=1 \times 10^{-4} \mathrm{~S} / \mathrm{m} ; \mathrm{d}=18 \mathrm{~mm} ; \mathrm{r}=6 \mathrm{~mm}$; orient.=hor.; $t_{\text {sweep }}=50 \mathrm{~ns}$ )

Fig. 5-25: Time to breakdown as a function of electrode curvature radius, $r$ $\left(\sigma=2.5 \times 10^{-4} \mathrm{~S} / \mathrm{m} ; \mathrm{T}=-12^{\circ} \mathrm{C} ; \mathrm{d}=18 \mathrm{~mm}\right.$; orient.=hor. $)$

Fig. 5-26: Time to breakdown as a function of electrode axis orientation $\left(\sigma=30 \times 10^{-4} \mathrm{~S} / \mathrm{m} ; \mathrm{T}=0^{\circ} \mathrm{C} ; \mathrm{d}=18 \mathrm{~mm}\right)$

Fig. 5-27: Speed of discharge growth as a function of freezing water conductivity, $\sigma\left(\mathrm{T}=-12^{\circ} \mathrm{C}\right.$; pol.=pos.; $\mathrm{d}=7 \mathrm{~mm}$; $\mathrm{r}=6 \mathrm{~mm}$; orient.=hor.)

Fig. 5-28: Streak recordings as a function of the steepness of voltage rise $\left(\sigma=30 \times 10^{-4} \mathrm{~S} / \mathrm{m} ; \mathrm{T}=-12^{\circ} \mathrm{C}\right.$; pol.=pos.; $\mathrm{d}=7 \mathrm{~mm} ; \mathrm{r}=6 \mathrm{~mm}$; orient.=hor.)

Fig. 5-29: Parallel streak recordings and surface still photographs for ice samples with an artificially introduced air gap $\left(\sigma=30 \times 10^{-4} \mathrm{~S} / \mathrm{m} ; \mathrm{d}=18 \mathrm{~mm} ; \mathrm{r}=6 \mathrm{~mm}\right.$; orient.=hor.; $\mathrm{t}_{\text {sweep }}=50 \mathrm{~ns}$ )

Fig. 5-30: Series of framing recordings of the discharge development for an air gap located in front of the HV electrode $\left(\sigma=30 \times 10^{-4} \mathrm{~S} / \mathrm{m} ; \mathrm{T}=0^{\circ} \mathrm{C}\right.$; pol.=pos.; $d=18 \mathrm{~mm}$; $r=6 \mathrm{~mm}$; orient.=hor.; $a=0 \mathrm{~mm}$; no channel or groove; $\mathrm{t}_{\text {rame }}=10 \mathrm{~ns} ; \mathrm{t}_{\text {intertr }}=50 \mathrm{~ns}$ )

Fig. 5-31: Streak recordings as a function of temperature, $T$, for central air gap $\left(\sigma=30 \times 10^{-4} \mathrm{~S} / \mathrm{m} ; d=18 \mathrm{~mm} ; \mathrm{r}=6 \mathrm{~mm}\right.$; orient.=hor.; path=cha.; $a=9 \mathrm{~mm}$; $t_{\text {sweep }}=50 \mathrm{~ns}$ )

Fig. 5-32: Streak recordings as a function of air gap location, a $\left(\sigma=30 \times 10^{-4} \mathrm{~S} / \mathrm{m}\right.$; $T=-12^{\circ} \mathrm{C}$; $d=18 \mathrm{~mm} ; \mathrm{r}=6 \mathrm{~mm}$; orient.=hor.; path=gro.; $\left.\mathrm{t}_{\text {sweep }}=50 \mathrm{~ns}\right)$

Fig. 5-33: Streak recordings for ice models with artificial air gap showing visible pre-discharge phenomena $\left(\sigma=30 \times 10^{-4} \mathrm{~S} / \mathrm{m} ; \mathrm{d}=18 \mathrm{~mm}\right.$; $\mathrm{r}=6 \mathrm{~mm}$; orient.=hor.)

Fig. 5-34: Streak recordings as a function of cooling rate $\left(\sigma=30 \times 10^{-4} \mathrm{~S} / \mathrm{m}\right.$; $\mathrm{T}=-12^{\circ} \mathrm{C}$; pol.=pos.; $\mathrm{d}=18 \mathrm{~mm}$; $\mathrm{r}=6 \mathrm{~mm}$; orient.=hor.; path=gro.; $t_{\text {sweep }}=50 \mathrm{~ns}$ )

Fig. 5-35: Streak recordings as a function the ice accumulation process

$\left(\sigma=30 \times 10^{-4} \mathrm{~S} / \mathrm{m} ; \mathrm{T}=-12^{\circ} \mathrm{C}\right.$; pol.=neg.; $\mathrm{d}=18 \mathrm{~mm} ; \mathrm{r}=6 \mathrm{~mm}$; orient.=hor.; path=gro.; $\mathrm{t}_{\text {sweep }}=50 \mathrm{~ns}$ )

Fig. 5-36: Time to breakdown values as a function of ice temperature, $T$, for a centrally located air gap $\left(\sigma=30 \times 10^{-4} \mathrm{~S} / \mathrm{m} ; \mathrm{T}=-12^{\circ} \mathrm{C} ; \mathrm{d}=18 \mathrm{~mm}\right.$; $\mathrm{r}=6 \mathrm{~mm}$; orient. $=$ hor.)

Fig. 5-37: Time to breakdown as a function of ice temperature, $T$, for different ice surface conditions $\left(\sigma=30 \times 10^{-4} \mathrm{~S} / \mathrm{m}\right.$; pol.=neg.; $d=18 \mathrm{~mm} ; r=6 \mathrm{~mm}$; orient.=hor.) 
Fig. 5-38: Time to breakdown values as a function of air gap location, a $\left(\sigma=30 \times 10^{-4} \mathrm{~S} / \mathrm{m} ; \mathrm{T}=-12^{\circ} \mathrm{C} ; \mathrm{d}=18 \mathrm{~mm} ; \mathrm{r}=6 \mathrm{~mm}\right.$; orient.=hor.)

Fig. 5-39: Time to breakdown as a function of cooling rate $\left(\sigma=30 \times 10^{-4} \mathrm{~S} / \mathrm{m}\right.$; $\mathrm{T}=-12^{\circ} \mathrm{C}$; pol.=pos.; $\mathrm{d}=18 \mathrm{~mm} ; \mathrm{r}=6 \mathrm{~mm}$; orient.=hor.)

Fig. 6-1: Waveform recordings for very late breakdown $(\mathrm{d}=18 \mathrm{~mm} ; \mathrm{r}=6 \mathrm{~mm}$; orient=hor.)

Fig. 6-2: Waveform recordings as a function of freezing water conductivity, $\sigma$ ( $\mathrm{T}=-12^{\circ} \mathrm{C}$; pol.=pos.; $\mathrm{d}=18 \mathrm{~mm}$; $\mathrm{r}=6 \mathrm{~mm}$; orient=hor.)

Fig. 6-3: Waveform recordings as a function of freezing water conductivity, $\sigma$ ( $\mathrm{T}=-12^{\circ} \mathrm{C}$; pol.=neg.; $\mathrm{d}=18 \mathrm{~mm} ; \mathrm{r}=6 \mathrm{~mm}$; orient=hor.)

Fig. 6-4: Waveform recordings as a function of ice surface conditions $\left(\sigma=30 \times 10^{-4} \mathrm{~S} / \mathrm{m} ; \mathrm{T}=-12^{\circ} \mathrm{C}\right.$; pol.=pos.; $\mathrm{d}=18 \mathrm{~mm} ; \mathrm{r}=6 \mathrm{~mm}$; orient=hor.)

Fig. 6-5: Recording of a pre-discharge current impulse $\left(\sigma=30 \times 10^{-4} \mathrm{~S} / \mathrm{m} ; \mathrm{T}=-4^{\circ} \mathrm{C}\right.$; pol.=neg.; $d=18 \mathrm{~mm} ; \mathrm{r}=6 \mathrm{~mm}$; orient=hor.) 209

Fig. 6-6: Waveform recordings with pre-discharge current impulses as a function of voltage polarity $\left(\sigma=30 \times 10^{-4} \mathrm{~S} / \mathrm{m} ; \mathrm{T}=-12^{\circ} \mathrm{C}\right.$; $\mathrm{d}=18 \mathrm{~mm}$; $\mathrm{r}=6 \mathrm{~mm}$; orient=hor.)

Fig. A-1: Phase diagram of ice as a function of pressure (showing the different crystalline ice structures) [48]

Fig. A-2: Phase diagram of a water/ $/ \mathrm{NaCl}$-solution as a function of $\mathrm{NaCl}$ concentration [99]

Fig. A-3: Relative permittivity of ice as a function of temperature and frequency [118] 247

Fig. A-4: Coaxial design of current shunts 258

Fig. A-5: Internal circuit of the current shunt 259

Fig. A-6: Actual experimental set-up in the laboratory 260

Fig. A-7: Complete experimental set-up with the interconnection of the different systems 261

Fig. A-8: Curves of measurement and equations resulting from regression analysis for critical breakdown voltage as a function of freezing water conductivity 


\section{LIST OF TABLES}

Table 3-1: Specifications for a lightning impulse voltage (International

Page:

Standard IEC 60-2 [50]) 65

Table 3-2: Variable parameters during the test series 76

Table 3-3: Chosen values of the freezing water conductivity _

Table 3-4: Chosen values for the ice temperature $\quad 79$

Table 3-5: Chosen distances between the electrodes__

Table 3-6: Electrode curvature radii__ 84

Table 3-7: Different locations of the artificial air gap_

Table 3-8: Experimental parameters for different cooling rates__ $\quad 86$

Table 3-9: Chosen ice accumulation processes__ $\quad 87$

Table 3-10: Accuracy of time resolution of digitising oscilloscope__ $\quad 98$

Table 3-11: Accuracy of time resolution of streak recordings as a function of slit width

99

Table 4-1: $50 \%$ lightning impulse breakdown voltage as a function of freezing water conductivity, $\sigma$, for ice surfaces without artificial air gap ( $\mathrm{T}=-12^{\circ} \mathrm{C}$; $\mathrm{d}=18 \mathrm{~mm} ; \mathrm{r}=6 \mathrm{~mm}$; orient.=hor.)

Table 4-2: $50 \%$ lightning impulse breakdown voltage as a function of freezing water conductivity, $\sigma$, for ice surfaces without artificial air gap ( $\mathrm{T}=-4^{\circ} \mathrm{C} ; \mathrm{d}=18 \mathrm{~mm} ; \mathrm{r}=6 \mathrm{~mm}$; orient.=hor.)

Table 4-3: $50 \%$ lightning impulse breakdown voltage as a function of freezing water conductivity, $\sigma$, for ice surfaces without artificial air gap $\left(\mathrm{T}=0^{\circ} \mathrm{C} ; \mathrm{d}=18 \mathrm{~mm} ; \mathrm{r}=6 \mathrm{~mm}\right.$; orient.=hor.)

Table 4-4: $50 \%$ lightning impulse breakdown voltages as a function of electrode curvature radius, $r$, for different temperatures, $T$, and for ice surfaces without artificial air gap $\left(\sigma=30 \times 10^{-4} \mathrm{~S} / \mathrm{m}\right.$; $d=18 \mathrm{~mm}$; orient.=hor.)

Table 4-5: $50 \%$ lightning impulse breakdown voltage as a function of electrode axis orientation $\left(\sigma=80 \times 10^{-4} \mathrm{~S} / \mathrm{m} ; \mathrm{T}=0^{\circ} \mathrm{C}\right.$; pol.=pos.; $=18 \mathrm{~mm}, \mathrm{r}=6 \mathrm{~mm}$ )

Table 4-6: $50 \%$ lightning impulse breakdown voltage as a function of temperature, $\mathrm{T}$, for vertical electrode axis orientation $\left(\sigma=80 \times 10^{-4} \mathrm{~S} / \mathrm{m}\right.$; pol.=pos.; $\mathrm{d}=18 \mathrm{~mm} ; \mathrm{r}=6 \mathrm{~mm}$; orient.=ver. $)$

Table 4-7: $50 \%$ lightning impulse breakdown voltage as a function of ice surface condition $\left(\sigma=30 \times 10^{-4} \mathrm{~S} / \mathrm{m} ; \mathrm{T}=-12^{\circ} \mathrm{C} ; \mathrm{d}=18 \mathrm{~mm} ; \mathrm{r}=6 \mathrm{~mm}\right.$; orient.=hor.)

Table 4-8: $50 \%$ lightning impulse breakdown voltage as a function of ice 
surface condition $\left(\sigma=30 \times 10^{-4} \mathrm{~S} / \mathrm{m} ; \mathrm{T}=0^{\circ} \mathrm{C} ; \mathrm{d}=18 \mathrm{~mm} ; \mathrm{r}=6 \mathrm{~mm}\right.$; orient.=hor.)

Table 4-9: $50 \%$ lightning impulse breakdown voltage as a function of cooling rate $\left(\sigma=30 \times 10^{-4} \mathrm{~S} / \mathrm{m} ; \mathrm{T}=-12^{\circ} \mathrm{C}\right.$; pol.=pos.; $d=18 \mathrm{~mm} ; \mathrm{r}=6 \mathrm{~mm}$; orient.=hor.)

Table 4-10: $50 \%$ lightning impulse breakdown voltage as a function of ice accumulation process $\left(\sigma=30 \times 10^{-4} \mathrm{~S} / \mathrm{m} ; \mathrm{T}=-12^{\circ} \mathrm{C}\right.$; pol.=pos.; $\mathrm{d}=18 \mathrm{~mm} ; \mathrm{r}=6 \mathrm{~mm}$; orient.=hor.)

Table 4-11: Equations describing the effect of the freezing water conductivity on the critical breakdown voltage for the two ice surface conditions $(\mathrm{d}=18 \mathrm{~mm} ; \mathrm{r}=6 \mathrm{~mm})$

Table 6-1: Appearance of "pre-discharge current impulses" as a function of ice surface condition $\left(\sigma=30 \times 10^{-4} \mathrm{~S} / \mathrm{m} ; \mathrm{T}=-12^{\circ} \mathrm{C}\right.$; $d=18 \mathrm{~mm} ; \mathrm{r}=6 \mathrm{~mm}$; orient.=hor.)

Table A-1: Temperature range of climate chamber 248

Table A-2: Technical data of streak camera 249

Table A-3: Elements of high voltage generator 251

Table A-4: Technical specifications of oscilloscope 253

Table A-5: Specifications of overvoltage suppressor 256

Table A-6: Design parameters for the low voltage capacitor of capacitive voltage divider 257

Table A-7: Specifications for the current shunt 259

Table A-8: Correction factor $\delta$ for water conductivity as a function of the temperature

Table A-9: Measured conductivity values before and after adding $0.2 \mathrm{~g}$ of $\mathrm{NaCl}$ to $0.25 \ell$ of de-ionised water 263

Table A-10: Equations resulting from regression analysis of the effect of freezing water conductivity on critical breakdown voltage

Table A-11: Final results of non-linear regression analysis 266 266 


\section{LIST OF CONFERENCE CONTRIBUTIONS ARISING FROM THIS PH.D. PROJECT}

S. Brettschneider, M. Farzaneh, K.D. SRivastava, "Influence of Micro Air-gaps in the Ice Surface on the Electrical Discharge Development", Proceedings of IWAIS 2000, Chester, UK, June 2000.

S.Brettschneider, M.Farzaneh, K.D.Srivastava, S.Y.LI, "Study of Ice Surface Breakdown Using Ultra High-Speed Photography", Proceedings of 56th Eastern Snow Conference, Fredericton, Canada, pp.23-30, June 1999.

M. Farzaneh, S. Brettschneider, K.D. Srivastava, "Study of Visible Discharge Onset and Development on Ice Surfaces", Proceedings of IEEE International Symposium on Electrical Insulation ISEI 2000, pp.216-221, Anaheim, USA, April 2000.

M.Farzaneh, S.Brettschneider, K.D.Srivastava, S.LI, "Impulse Breakdown Performance of the Ice Surface", Proceedings of 11th International Symposium on High-Voltage Engineering (ISH), Vol.4, pp.341-344, London, UK, August 1999.

M.Farzaneh, S.Brettschneider, K.D.Srivastava, S.LI, "Ultra High-Speed Photographic Observations of Discharge Development along the Ice Surface", Proceedings of 11 th International Symposium on High-Voltage Engineering (ISH), Vol.3, pp.297-300, London, UK, August 1999. 


\section{CHAPTER 1}

\section{INTRODUCTION}




\section{CHAPTER 1}

\section{INTRODUCTION}

\subsection{General Context: Problem of Flashover on Ice-covered Insulators}

Continuous supply with electric power has become one of the major foundations of industrialised societies. Various technologies of modern life, such as communication, transportation, heating, cooking, health care etc., rely solely on electricity in order to work, and any outage will often cause major problems. In most cases, the electric energy is not produced in the vicinity of consumption (urban areas), but outside, where enough energy and space is available. Particularly, hydroelectric power stations are often located in remote areas. Electric energy transmission systems, using high voltage, are necessary to carry electric power over long distances. As it is almost impossible to store large amounts of electric energy (at least from practical and commercial viewpoints), these networks have to be in continuous operation. 
Snow and ice accretion on components of electric power networks can obstruct their operation and lead to power failures. They can be classified roughly in two different groups: Mechanical and electrical phenomena. A manifestation of the second category is flashover of ice-covered insulators, which was reported from various countries in the scientific literature (Section 1.2). The electrical insulation capability of the insulators is drastically reduced by ice formation. The presence of small air gaps and polluting particles in the ice may provoke the onset of partial discharges. Figure 1-1 shows the appearance of a local arc on the surface of an industrial insulator covered with wet-grown ice. Under certain meteorological conditions, these pre-discharges may lead to the creation of stable arcs and to flashover even under service voltages.

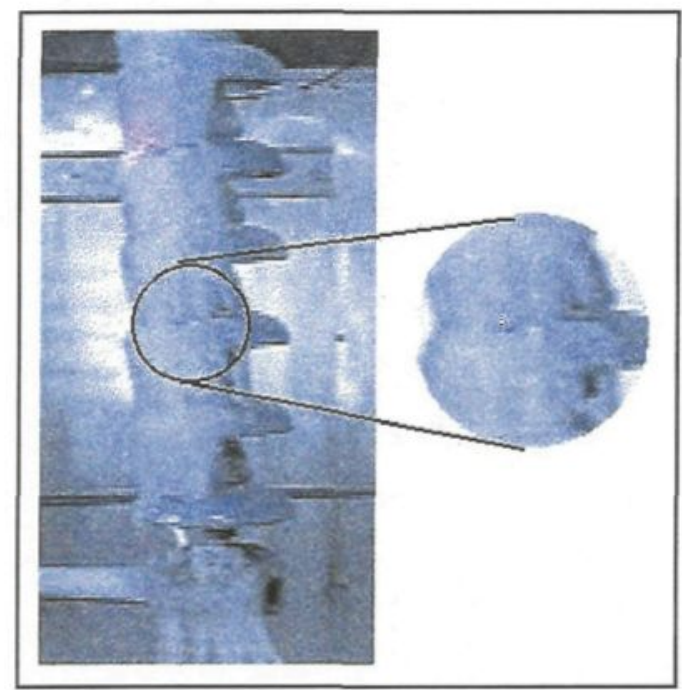

Fig. 1-1: Appearance of visible discharge activities on the surface and at the ends of an ice-covered high voltage insulator 
Whereas, in the recent past, an important number of investigations were carried out on the flashover performance of actual insulators under icing conditions (Section 1.2), little research activity has been dedicated to the fundamental processes of discharge initiation and early development along ice surfaces. However, the understanding of the origins of ice surface discharges and their characteristics may be beneficial for the design of new insulators, and for the development of numerical tools to predict and prevent flashover on ice-covered insulators. In this context, the present study was primarily carried out to contribute to the understanding of these fundamental physical processes.

As flashover on ice-covered insulators presents the practical problem and the motivation for the accomplishment of this Ph.D. Thesis, related research in this field is summarised briefly in the next section. Afterwards, the objectives of this study are listed and the methodologies to achieve these objectives are presented. Finally, the structure of the succeeding chapters is briefly described.

\subsection{State of the art in Research on Flashover Performance of Ice- covered Insulators}

The field of research on the flashover performance of ice-covered insulators is quite young. The first investigations date back only about 30 years [55] [77]. 
Since then, a number of worthwhile and valuable studies on the subject were carried out in various countries (for example [15] [25] [28] [37] [39] [53] [71] [109] [110]). They can be divided into two groups: Field studies [15] [25] [39] [109] and laboratory investigations [25] [28] [37] [53] [71] [109] [110]. The effects of several parameters such as air temperature [15], type, thickness and uniformity of ice [25] [28], nature and polarity of applied voltage [37] [71], conductivity of freezing precipitation [25] [28] [53], as well as insulator parameters such as type, leakage and arcing distances [53] [110] on the withstand voltage of insulators were investigated. Reviews of most of the studies on the subject were published recently [26] [27].

The Research Group on Atmospheric Environment Engineering (GRIEA), attached to of the Applied Science Department at the Université du Québec à Chicoutimi, has worked on this research field for over 25 years. One of its objectives is to advance the knowledge on the influence of atmospheric icing on structures, and more particularly, on overhead power transmission lines. With the creation of the NSERC/Hydro-Québec/UQAC Chair on Atmospheric Icing Of Power Network Equipment (CIGELE) in September 1997, the activities of GRIEA have gained even more importance and particular attention is focused on fundamental studies on electrical insulation performance under atmospheric icing conditions. The studies recently undertaken and the ongoing activity aim to characterise volume and surface conductivity of ice [24], identify flashover characteristics and 
flashover mechanisms of ice surfaces [33] [36] [116], calculate electric field distribution [35], and develop models for the prediction of the flashover performance of insulators under icing conditions [38]. Also, the results obtained in the framework of this Ph.D. were the subject of several conference publications (see list at the beginning of this thesis).

Two papers are reviewed to summarise the results of the research activity on flashover of ice-covered insulators. The first study [25] combines results from field observations and laboratory investigations, whereas the second paper [26] reviews laboratory investigations of the past years. The following conclusions may be retained:

- The presence of ice on insulators provokes dramatic loss of electrical strength, which may lead to insulator flashover and consequent power outages under certain conditions;

- Two forms of ice accretion can be identified in the field, depending on the amount of freezing rain precipitation: Separated icicles are observed for weak precipitation, whereas the insulator gets totally covered by the ice if precipitation exceeds a certain level;

- A precipitation of $40 \mathrm{~mm}$ of freezing rain corresponds to an artificial ice accumulation with a radial thickness of $1 \mathrm{~cm}$ on a rotating monitoring cylinder;

- Wet grown ice is considered more dangerous than dry grown ice; 
- Besides other factors, the amount, type, uniformity of the ice build-up, the conductivity of freezing water, and voltage polarity are identified to have a significant influence on the flashover voltage;

- Increasing wind velocity leads to an increase in withstand voltage due to the more non-uniform ice distribution, as wind velocity influences the deviation angle of icicles

- For short insulator strings (arcing distance less than $82 \mathrm{~cm}$ ), the maximum withstand voltage increases almost linearly with arcing distance;

- Maximum withstand voltage decreases with increasing ice thickness, but tends to saturate for a thickness of about $3 \mathrm{~cm}$;

- Increasing freezing water conductivity up to $80 \times 10^{-4} \mathrm{~S} / \mathrm{m}$ decreases the maximum withstand voltage. On the other hand, for a relatively high conductivity level of $150 \mu \mathrm{S} / \mathrm{cm}$, discharge activities during accretion hinder ice accumulation and increase withstand voltage;

- A wet uniform ice cover of $2 \mathrm{~cm}$ thickness, formed from water of about $80 \mu \mathrm{S} / \mathrm{cm}$, is equivalent to an ESDD (Equivalent Salt Density Deposit) of $0,13 \mathrm{mg} / \mathrm{cm}^{2}$ on polluted insulators. 


\subsection{Objectives of this Research Project}

To further understanding of the flashover processes on ice-covered HV insulators, the present Ph.D. Thesis was initiated to study the fundamental physical processes of discharge initiation, mechanisms of local arc formation and development, as well as flashover characteristics on ice surfaces under various surface conditions, and to provide experimental data on these processes. In particular, the present project aimed to analyse the early stages of the very fast visible discharge processes along the ice surface. Therefore, the experimental method of ultra high-speed photography, which was already used in various other research fields, was applied. The following objectives were fixed:

- Observation of development of the first nanoseconds of visible discharges on the ice surface;

- Determination of influence of nature and polarity of applied voltage on initiation and development of visible discharges on the ice surface;

- Determination of modes and time to breakdown of the different discharge types on the ice surface;

- Identification of fundamental mechanisms causing the formation and propagation of partial discharges on the ice surface. 


\subsection{Methodology}

This study concerns principally laboratory experiments in cold chambers. A physical model with a simplified geometry was used as actual HV insulators have a complex structure, and they are composed of several different materials. The model allows investigating the influence of each individual parameter separately. Several experimental test series were carried out using different methodologies, listed below:

- Determination of $50 \%$ lightning impulse breakdown voltage according to IEC 507 ;

- Recording of visible discharge development during the first nanoseconds using ultra high-speed photography;

- Measurement of voltage and current waveforms.

No international standards yet exist for the test of the electrical performance of industrial ice-covered insulators. In order to perform most reliable and repeatable tests in this context, experiments were based on the available standard IEC 507 for polluted insulators [51] and standard IEC $60-2$ for HV test techniques [50], as adapted by researchers of UQAC [25] [26] [28].

The major tools for visual observations of the very fast processes of discharge initiation and development are ultra high-speed cameras. These 
apparatuses enable the observation, analysis, and understanding of motion that is too fast for the eye to perceive. Today's technology of ultra high-speed photography offers the possibilities to capture and visualise processes in the range of some billionth parts of a second. Several applications in the field of electric breakdown processes and high voltage engineering were realised in the past, for example, breakdown in compressed gases and liquids [7] [82] [97], as well as surface flashover on synthetic spacer surfaces [3] [86] [100] [101].

To the best of our knowledge, no applications of this experimental technique to study the very fast discharge initiation processes on ice surfaces have yet been reported. Therefore, this study aims to realise a technology transfer by adapting this existing technique and applying it for the first time to the field of electrical discharge processes on ice surfaces.

\subsection{Structure of the Thesis}

The literature review in the second chapter summarises some theoretical aspects and previous publications related to the present research work. This chapter is divided into three parts: First, a section on ice physics; second, a section on the theory of electrical discharges; third, a review of the literature in the field of surface discharge activity on synthetic surfaces, as well as on ice and water. 
The experimental set-up and test procedures are described in the third chapter. The physical model is presented and all experimental parameters are explained. Finally, error calculations are shown to evaluate the limits of interpretation of the results.

The experimental results are presented in Chapters four, five, and six. Each chapter concentrates on one of the three different experimental methodologies used, and the presentation of the results is followed by a discussion and analysis. Chapter four presents the results and discussion on the determination of the $50 \%$ breakdown voltages. Chapter five deals with the study of visible discharge initiation and development by means of ultra high-speed photography. Finally, Chapter six shows and discusses the waveform measurements.

In Chapter seven, general conclusions are deduced from the preceding discussions, and examples are given on how the knowledge may be applied. In addition, some recommendations are proposed for future research. 


\section{CHAPTER 2}

\section{LITERATURE REVIEW}




\section{CHAPTER 2}

\section{LITERATURE REVIEW}

\subsection{Introduction to Chapter 2}

The following chapter presents a brief overview of fundamental theories and preceding investigations related to the present study. This research project touches two different fields: Ice physics and electrical discharges. Therefore, data of both research fields is summarised in the two succeeding sections. Next, previous investigations on discharge processes along surface are summarised. In particular discharge processes on synthetic surfaces are focused, as numerous research work exists already in this field. Due to the fact that ice may be melted locally by discharge activity and water may be present simultaneously, investigations regarding discharges on ice surfaces as well as on water are reviewed. 


\subsection{Related Fundamentals on Ice Physics}

\subsubsection{General Characteristics of Ice under Considerations of the Conditions in the Present Study}

Water forms different solid phases in dependence of the environmental conditions. Under normal atmospheric conditions (temperature and pressure of natural life on earth), the water molecules are arranged in hexagonal, crystalline structure, the so-called "ice Ih" [48]. There exist at least eight other possible structures [75], but they are high-pressure polymorphs, and some of them are only metastable (see Appendix 1). As the present investigation deals with ice at normal atmospheric conditions, uniquely ice of the structure type "Ih" is studied.

The freezing point of a water-salt solution changes as a function of the salt concentration (Appendix 1). As the salt concentrations are extremely low in the present study (Appendix 10), the freezing temperature can be estimated to be constant for all cases. Although, the freezing point is influenced by pressure [80], but again, under the experimental conditions of the present study, this effect can be neglected.

As this study investigates temperatures near the melting point, not only the solid phase "ice", but also the liquid phase "water" has to be considered. Water is 
one of the most amazing substances in nature, which exhibits several unique physical properties. In particular, three of them may be interesting for the present study:

- Water has a high latent heat of fusion as well as a high specific heat, so it requires a large amount of energy to change the temperature. This also means that it releases heat energy slowly when it is cooled from the outside [89].

- The water molecule has an asymmetrical charge distribution. Oxygen atoms attract electrons more strongly than hydrogen atoms [98].

- Water and ice have high values for the relative permittivity. In the case of ice, the value is frequency dependent and the Debye theory has to be applied [90]. Different values for the relative permittivity can be found in the literature for the static case, for example $\varepsilon_{\mathrm{r}}=77$ [79] or $\varepsilon_{\mathrm{r}}=74.6$ [90]. For the present case, very short voltage impulses are used, which may be interpreted as a half-cycle of one oscillation. Therefore, the relative permittivity value is lower. For a corresponding frequency of $\mathrm{f}=20 \mathrm{kHz}$, an approximate value for the relative permittivity may be estimated as $\varepsilon_{\mathrm{r}}=10$ [48] (see also Appendix 1).

The water molecule has a quite simple atomic structure. It consists of two hydrogen $(\mathrm{H})$ atoms joined to one oxygen $(\mathrm{O})$ atom by sharing electrons. This relatively strong connection, forming the $\mathrm{H}_{2} \mathrm{O}$ molecule, is called "covalent bond". Due to its polarised structure, there exists also an attracting force between the 
negative part (O-atom) of one molecule to the positive part (H-atom) of another molecule. This kind of joint is called "hydrogen bond" [98]. During the phase change from liquid to solid, the arrangement pattern of the molecules changes causing volume expansion [89]. In water, the weak hydrogen bonds are constantly formed and broken up so that each molecule is bonded to approximately 3.4 other water molecules [98]. In ice (under ideal conditions without pollution), each molecule is bonded to 4 other molecules. Thereby, each molecule donates and accepts two hydrogen bonds. The orientation of the adjacent water molecules is such that one hydrogen atom lies between each pair of oxygen atoms [75]. Figure 2-1 shows the typical hexagonal structure of ice type "Ih".

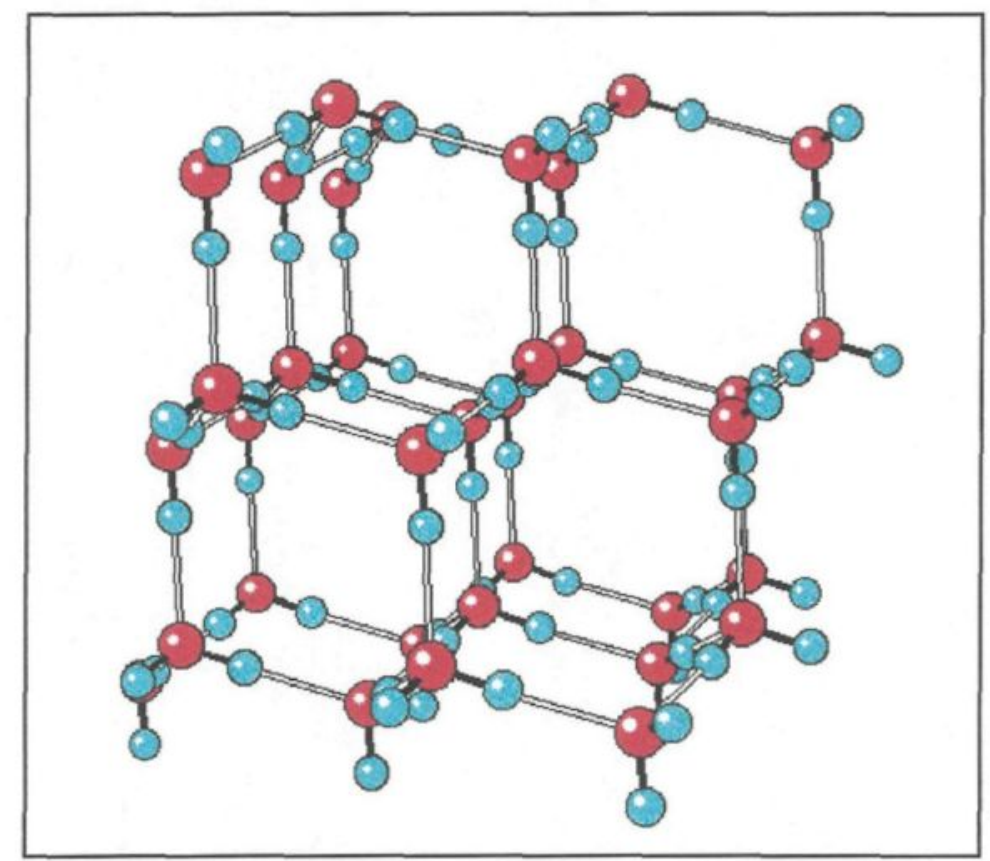

Fig. 2-1: Hexagonal structure of ice type "Ih" [75] 


\subsubsection{Electrical Conductivity of Ice}

For a perfect single ice crystal (homogenous crystalline structure without any pollution), the number of free electrons is negligible and the only mechanism of electrical conduction under a dc field is "proton jump" [47] [90]. The impurities play a major role for electrical conduction. Also, polarisation effects at external and internal surfaces (cracks, bubbles in the latter case) contribute to the true conductivity of ice. Furthermore, it was reported that the dc conductivity of ice samples depends very significantly on the time period between sample preparation and the experiment due to ageing effects. [94].

For an alternating field, additional phenomena can occur [90]. Whereas ice has no permanent electric dipole moment, it is readily polarised (shifts in the electron cloud distribution and by proton jumps). The same electric energy is dissipated in reversing of induced dipole moment. This dissipative effect, called dielectric absorption, gives rise to an effective electrical conductivity, $\sigma_{\theta}$, which is much larger than the dc conductivity of pure ice.

Conductivity measurements showed that pure ice may be classified as a semiconductor due to its specific conductivity of $\sigma=10^{-8} \ldots 10^{-9} \mathrm{~S} / \mathrm{cm}$ [90]. It was revealed that the conductivity of ice made from de-ionised water is roughly 
independent of temperature between $-20^{\circ} \mathrm{C}$ and $-0.1^{\circ} \mathrm{C}$, whereas the conductivity of tap water ice increases with temperature by a factor of ten within this range. Most of the increase appears between $-5^{\circ} \mathrm{C}$ and $-0.1^{\circ} \mathrm{C}$ [11]. Measurements on ice samples formed from ice with controlled conductivity $\left(\sigma=80 \times 10^{-4} \mathrm{~S} / \mathrm{m}\right.$ and $\sigma=160 \times 10^{-4} \mathrm{~S} / \mathrm{m}$ ) showed that the surface conductivity is about $1 \times 10^{-6} \mathrm{~S}$ for air temperatures below $0^{\circ} \mathrm{C}$ [24]. As the temperature rises above $0^{\circ} \mathrm{C}$, surface conductivity increases rapidly, which can be explained by the formation of a liquid water film on the ice surface. As the water covers the surface uniformly, conductivity value tends to saturation. A maximum value of about $5 \times 10^{-6} \mathrm{~S}$ was reached for ordinary frozen ice formed with freezing water of $160 \times 10^{-4} \mathrm{~S} / \mathrm{m}$. Regarding the atmospheric ice accretions on actual HV insulators, it was shown that the conductivity of the melted surface layer of the ice build-up exceeds the value of the freezing water clearly [34]. Particularly, the underside of the insulators and icicles exhibited values exceeding the freezing water conductivity by more than factor two. This was explained by the process of wet ice accretion on the insulators, where impurities diffuse to the surface before the water freezes (see Section 2.2.3).

In the case of polluted ice, the electric conduction in the water film on the ice surface is mainly based on proton diffusion, as protons are much smaller and lighter than any other atom or molecule [73]. In the case of water, different hypotheses exist at this moment on the proton diffusion process arguing either with 
the creation of "Eigen-cations" $\mathrm{H}_{9} \mathrm{O}_{4}^{+}$or "Zundel-cations" $\mathrm{H}_{5} \mathrm{O}_{2}^{+}$as the single water proton $\mathrm{H}^{+}$connects to surrounding water molecules or a combination of these different states. Hereby, a continuous creation and rupture of these cations take place transferring the structural defect from one proton to another, whereas the protons themselves barely move. Thus, proton diffusion can take place much faster as migration of any other ions (for example salt ions $\mathrm{Na}^{+}$and $\mathrm{Cl}^{-}$), which move randomly through the water solution towards the opposite electrode. Inside the ice, conduction is uniquely based on proton diffusion, as ions are fixed in the crystalline structure of the ice [99].

\subsubsection{Ice Surface Characteristics}

It was reported already several years ago that ice seems to be a member of the small family of solids, which may exhibit anomalous surface properties in the sense that a quasi-liquid transition layer exists on at least some crystal faces at temperatures somewhat below the melting point [40]. A phase change of the ice surface to quasi-liquid state is observed at a temperature a few degrees below the melting point. The temperature ranges from $-6^{\circ} \mathrm{C}$ to $-3^{\circ} \mathrm{C}$. This estimated temperature appears to agree with the critical temperature in the measurements of the surface conductivity of ice, where a large increase in surface conductivity is observed for temperatures above $T=-4^{\circ} \mathrm{C}$ [24]. Another study on the surface and volume conductivity of a single ice crystal [69] showed also that the value of 
surface conductivity increases rapidly as the temperature is raised. A threshold value was defined, where the surface conduction becomes more dominant than the volume conduction ranging between $-35^{\circ} \mathrm{C}<\mathrm{T}<-10^{\circ} \mathrm{C}$. An investigation on the surface conductivity of ice samples formed under various freezing conditions revealed that the ice bulk conductivity is very low compared to the surface conductivity in the range of ambient air temperatures between $-12^{\circ} \mathrm{C}$ and $-8^{\circ} \mathrm{C}$ [24]. Therefore, two different temperature characteristics are suggested for the regions below and above the threshold temperature [40].

Recent investigations show that a very thin quasi-liquid layer is present on the ice surface even for very low temperature [64] [74] [75] [112]. This layer is quite small at lower temperature, extending over just a few molecular layers for a temperature $\mathrm{T}=-10^{\circ} \mathrm{C}$, and it becomes thicker with increasing temperature [64]. Detailed molecular-scale pictures of the ice surface at temperatures as low as $90 \mathrm{~K}$, obtained by low-energy electron diffraction, showed that water molecules are bound in a lattice, but these are not frozen like those in the layers beneath them [112]. Thus, greater molecular mobility exists in the ice surface than in the crystalline bulk. The ice can be seen as composed of three parts, a core region of bulk ice, surrounded by a surface and a subsurface region, which can all be distinguished by their vibrational spectra [75]. The high degree of vibrational motion by the water molecules in the surface layer is attributed to the absence of other molecules above them resulting in unsatisfied bond. The existing bonds between 
the atoms are weakened, which gives rise to liquid-like vibrational motion and frees molecules to interact with other particles [112]. Above a certain temperature, this enhanced motion leads to a state of high energy ("high density phonon bath") and a separation of individual molecules from their original sites. This phonon-bath enables a high rate of accommodation of molecules and an easy energy transfer [74]. The unrelaxed surface bilayer can be characterised on an atomic level by both three co-ordinate molecules with either dangling hydrogens or dangling oxygens and four co-ordinate molecules distorted with respect to tetrahedral symmetry [75] (Fig. 2-2).

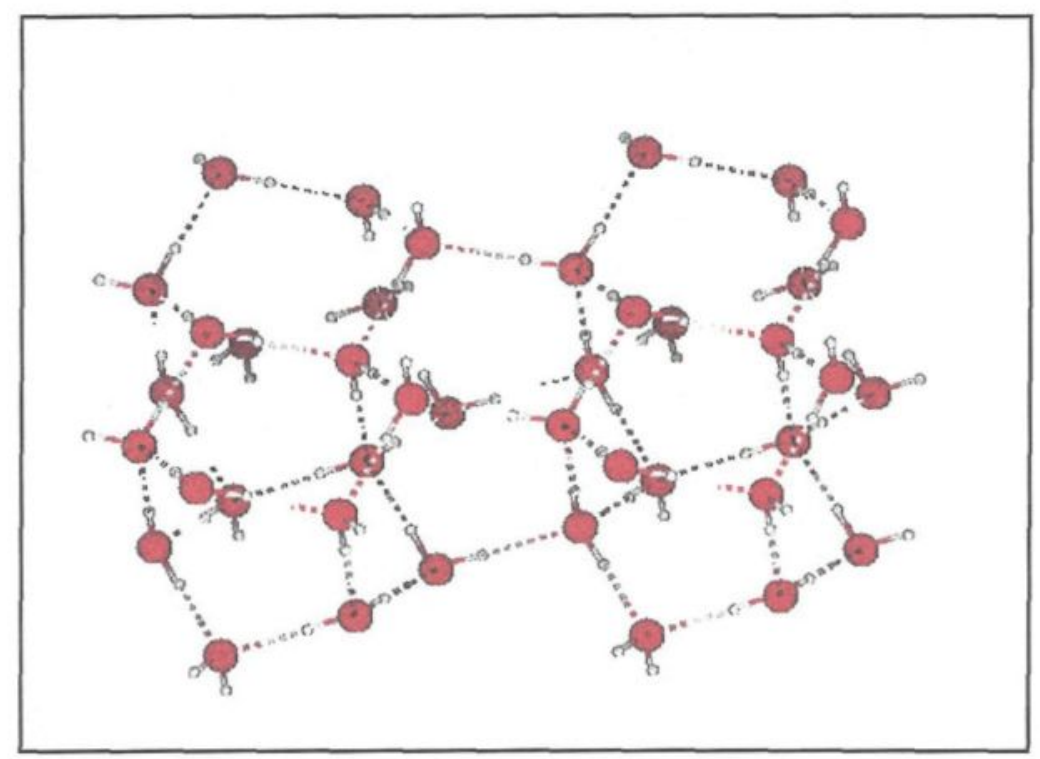

Fig. 2-2: Unrelaxed surface bilayer of ice [75]

In addition to the fact that a quasi-liquid layer is always present on the surface of the ice, another phenomenon contributes to an increased surface conductivity. 
Due to the fact that the potential energy of the crystal lattice varies inversely with the number of dislocations, foreign molecules are excluded at the liquid-solid interface during the ice formation [11]. When a water-salt solution is cooled down, first pure water freezes and forms an ice crystal, while salt ions diffuse into the liquid phase resulting in higher concentration of ions and thus higher electric conductivity of the surface layer [99]. Measurements on actual HV insulators confirmed that the conductivity of the melted surface layer exceeds significantly the conductivity of the freezing water that was used initially to form the ice [11] [34] [53].

\subsubsection{Charge Storage in lce}

Several investigations of charging and charge storage in ice have been reported in the literature. Three processes were identified, which may lead to charge storage in ice [48]:

- By cooling ice crystals in an electric field (ice electrets);

- Through phenomena that appear to be ferroelectric in nature;

- During the growth of ice from solutions (Workman-Reynolds-effect).

An ice electret exhibits a permanent electric dipole moment, which gives rise to an external electric field [48]. Under the influence of an electric field, negative surface charges can be observed on the surface, which were originally adjacent to 
the positive electrode (so-called "heterocharges"). These charges disappear within a few days. A spontaneously generated polarisation in the opposite direction occurs (so-called "homocharges"). The maximum value is reached in a few more days and remains unchanged for years. If the original electric field is less than a certain critical value, then no homocharges are observed for Carnuaba wax.

A gradient of ionic concentration is set up in ice subjected to a temperature gradient due to more rapid diffusion of positive hydrogen ions [78]. Hereby, the cold end becomes positively charged and the warm end negatively. If two grains with different temperatures are brought into temporary contact, the warmer one becomes negatively charged and the colder one positively charged. Maximum charge separation occurs for a contact time of $10^{-2} \mathrm{sec}$, and the charge declines with more prolonged contact.

As an ice crystal was cooled down to $-196^{\circ} \mathrm{C}$ and an electric field was applied at this temperature for several minutes, an electric current was released during the reheating [21]. In another experiment, ice discs were cooled down to $196^{\circ} \mathrm{C}$ while voltage was applied [44]. First heterocharges and, after three to eight days, homocharges were observed. While a voltage was applied to ice discs at $70^{\circ} \mathrm{C}$, the charging current decreased with time of voltage application and it reached a constant value within six minutes [17]. Also, the discharge current in reverse direction, which could be observed after the end of voltage application, 
decreased with time. Thereby, no difference could be observed between single crystals and polycrystalline ice samples.

The existence of an electric potential at the boundary between the ice and liquid water was demonstrated by measuring the electric surface potential with a vibrating surface electrometer, as the ice samples were heated [104]. The electric potential increased sharply to negative values when the temperature of the ice surface reached $0^{\circ} \mathrm{C}$. The negative electric potential of the liquid water occurred not only near $0^{\circ} \mathrm{C}$, but when the air temperature was $-13^{\circ} \mathrm{C}$ and $-20^{\circ} \mathrm{C}$. When the heating was stopped, the negative potentials returned to their original small magnitudes. A possible explanation for the charge separation at the boundary between the ice and water could be a higher concentration of $\mathrm{H}^{+}$and $\mathrm{OH}^{-}$ions in water than in ice and the relative high mobility of $\mathrm{H}^{+}$ions in ice.

Several experiments were carried out using the method of rubbing two ice rods against each in order to provoke a charge separation. When two pieces of ice of different temperature were rubbed together, the colder piece received positive charges [91] [114]. For asymmetrical rubbing of two ice rods, it could be observed that for temperatures below $-10^{\circ} \mathrm{C}$, the warmer ice rod was initially charged negatively, but it becomes positively charged for continued rubbing [70]. Above $-5^{\circ} \mathrm{C}$, the warmer ice rod was charged positively from the beginning of rubbing. Another investigation measured the surface electric potential of single crystals of 
ice from the Mendenhall glacier, which were rubbed with another single crystal or with a plane [105]. The electric potential of the ice surface became increasingly negative as the rubbing frequency was increased, but it reached a steady value of about $-200 \mathrm{mV}$ after several rubbings. When the rubbing was stopped, the electric potential of remained constant for a temperature $T=-16^{\circ} \mathrm{C}$, but it decreased exponentially for increasing temperatures between $-6^{\circ} \mathrm{C}$ and $-3^{\circ} \mathrm{C}$. In a second test, a negative electric potential of $-40 \mathrm{mV}$ appeared, when the ice surface was rubbed twenty times with ice cut from the same single crystal. After fifty more rubbings, it increased to $-75 \mathrm{mV}$, and then to $-105 \mathrm{mV}$ with an additional fifty rubbings. The surface electric potential decreased gradually after the rubbing was stopped and reached an equilibrium value. The negative potential of the surface returned to its original value when the ice surface as melted.

To the best knowledge of the author, no experimental data on charge accumulation and its measurement on the surface of ice are available. The studies discussed in this section report charge generation in the ice bulk. The experimental conditions of most of the investigations cited (for example very low temperatures [21] [44] [17] and the processes to create the charges (for example rubbing of two ice crystals [70] [91] [104] [114]) are very different from the conditions of the present study. Little quantitative data could be found, in most cases only a phenomenological description of the charging process was given. However, it may 
be supposed, under consideration of these previous investigations, that charges may be accumulated in the ice bulk as well as on the ice surface.

In contrast with the lack of knowledge on charge accumulation on ice surfaces, several studies were reported concerning similar processes on the surface of synthetic materials, which will be discussed in Section 2.4.1. Even though the data obtained on these investigations may be used for comparative analysis with the processes on ice surfaces, it has to be considered that processes of creation and accumulation of charges may be different in the case of ice, due to the particular characteristics of the ice surface. In particular, for higher conductivity and higher temperature values, no charge accumulation can be expected, as any charge on the quasi-liquid surface will be immediately conducted towards the electrodes.

\subsubsection{Influence of Electric Field on Ice Formation}

The visual appearance of an atmospheric ice accretion changes clearly if an electric field is present during ice formation [32]. Under the experimental conditions of this study, ice accretion showed only small protuberances in the absence of an electric field, whereas in the presence of electric fields higher than $10 \times 10^{5} \mathrm{~V} / \mathrm{m}$, ice surface protuberances grow once a uniform ice layer of a few millimetres has formed on the cylinder. For positive dc field of $+15 \times 10^{5} \mathrm{~V} / \mathrm{m}$, ice trees and side- 
branches look more numerous and thinner than those grown in an ac field. Under negative voltage polarity, the trunks of the ice feathers are even thinner than those observed in ac and dc+, but thickness of the accreted ice is limited to that of uniform ice preceding ice treeing for higher field strength $\left(-20 \times 10^{5} \mathrm{~V} / \mathrm{m}\right)$. The weight of the ice deposit for a given accumulation time first increases with field strength up to $10 \times 10^{5} \mathrm{~V} / \mathrm{m}$, whereas it decreases sharply with higher field strengths. It becomes almost negligible under negative fields above $-15 \times 10^{5} \mathrm{~V} / \mathrm{m}$. Mean ice density decreases from $0.77-0.85 \mathrm{~g} / \mathrm{cm}^{3}$ at $5 \times 10^{5} \mathrm{~V} / \mathrm{m}$ to about $0.2-0.3$ $\mathrm{g} / \mathrm{cm}^{3}$ at $10 \times 10^{5} \mathrm{~V} / \mathrm{m}[32]$.

The presence of an electric field influences also the growth of icicles as the water drop hanging from the tip of the icicle is deformed and elongated under enhanced field strength [31]. On the one hand, cooling effects are produced by decrease in drop diameter and increase in ionic wind, whereas, heating effects are created on the other hand by the conduction current. Evidence of the cooling effect is shown under dc+ and ac, where ionic wind is the strongest, but the effect is less important than the heat released by the conduction current.

The ice morphology exhibits different patterns as a function of the electric field applied during ice formation. Large air-bubbles appear in the presence of a negative voltage stress elongated in the direction of the field [59]. In another investigation, two distinct types of bubbles were identified [30]. The first type, 
observed only under dc- and ac, corresponds to large cavities, over $1 \mathrm{~mm}$ in size, which are located away from the insulator surface. The second type, observed in all samples, corresponds to spherical bubbles less than $200 \mu \mathrm{m}$ in diameter, arranged in layers parallel to the surface of the insulator. The spherical bubbles observed in all samples are found in greater number in dc- than in non-energised conditions. This could simply be attributed to the different locations of the ice cut. The crystalline texture of ice grown under ac and non-energised conditions is similar to that under dc- and dc+. In all these samples, ice grains are equiaxial with about the same mean diameter: $0.6 \mathrm{~mm}$ for $\mathrm{dc}-, 0.5 \mathrm{~mm}$ for $\mathrm{dc}+$ and without applied voltage and $0.4 \mathrm{~mm}$ for ac. These differences may be attributed to the stronger ionisation intensity and stronger deformation of water droplets under a negative electric field [87].

An application of neutron diffraction showed that the general hexagonal structure of ice molecules does not change under the presence of an electric field, but the distances in the crystalline structure (distance between two oxygen atoms) increases slightly in presence of an positive field, whereas it decreases in presence of an negative field [9]. Nevertheless, this change in the range of $10^{-3}$ under the chosen experimental conditions seems too small to explain the different phenomena observed. 
The influence of an electric field on the freezing process of water was also studied [93]. It was shown that under the influence of an electric field, the drops freeze at a temperature nearer $0^{\circ} \mathrm{C}$ than without the field and that the freezing process happens faster as the intensity of the electric field increases. Thereby, the formation of the ice crystals does not appear to depend on the polarity of the high voltage.

\subsection{Related Fundamentals on Electrical Discharges}

\subsubsection{Generation of Charges}

Protons, ions with either polarity or free electrons constitute charge carriers. In most cases, free electrons play a much more important role as sources of an electric current due to their weaker mass, thus higher mobility. Several processes exist for the generation of free electrons, which can be divided into two groups: Emission and ionisation. Emission is the liberation of electrons out of the surface of the solid electrodes. This can take place by different processes:

- Emission by electron impact

- Photoemission

- Thermal emission

- Electric field emission 
Ionisation is the phenomenon, in which free electrons are created inside the gaseous volume. Again, this can happen by different processes:

- Ionisation by impact

- Photoionisation

- Thermal ionisation

More details on these processes can be found in the literature (for example [8] [67] [76] [83]).

After their creation, free electrons may be captured by previously excited atoms inside the gaseous space, and thus, negatively charged ions will be created. As these ions are much less mobile than the previous electrons, they will create relatively static space charges. On the other hand, molecules that have lost an electron will form positive ionic charges.

\subsubsection{Different Types of Electrical Discharges}

Before the conditions for breakdown are established, stable partial discharges may appear. They are limited to a certain space where the electric field strength is high enough to sustain sufficient ionisation processes. The space charge created by recompensation of free electrons limits and may stop temporarily the propagation of the discharge processes. If the applied voltage is further increased to a sufficient value, a zone of ionisation is created, bridging the whole distance between the electrodes. Then, breakdown can take place. One of the visual 
aspects of the partial discharges before breakdown is a weak light emission, sometimes in the form of a bluish glow, which forms a circle around any asperity. Thus, the term "corona discharges" was created to describe the partial discharges.

It is important to distinguish the threshold voltage for initiation of partial discharges and the critical breakdown voltage. Normally, the latter is higher and is influenced by different parameters. Nevertheless, for very short distances breakdown may occur before the appearance of any partial discharge activity (see Section 2.3.3 [67] [100] [101]. In the general case of metallic electrodes in air, the threshold value for partial discharges is lower for negative voltage polarity, whereas the critical breakdown value is lower for positive polarity [4].

Discharges are basically of two types, Townsend, and streamer discharges. A short explanation of both types is given below.

\subsubsection{Townsend Process}

If the number of charged particles is lower than $10^{8}$, field distortion by space charges can still be neglected [8]. The discharge mechanism in this case is the Townsend process. 
The first Townsend coefficient, $\alpha$, is a local function of the electric field $E(x)$, which may be variable along distance $x$. It depends also on gas type and pressure, and can be determined by equation e2-1. The constants $A$ and $B$ depend themselves on pressure, type of gas, and ratio $E / p$.

$$
\frac{\alpha}{p}=A \cdot e^{\left[\frac{-B}{E / p}\right]}
$$

In the case of a uniform field, we have $\mathrm{N}$ free electrons after equation e2-2:

$$
N=e^{\alpha d}
$$

The spark criterion proposed by Townsend consists in the assumption that the discharge takes place when the current tends to infinity. For uniform field conditions, equation e2-3 can be established:

$$
\alpha d=k=\ln \frac{1}{\gamma}
$$

In uniform field conditions, Townsend discharge occurs for $k$ in a range of 7 to 9 [58]. Paschen-curves show the influence of pressure and electrode distance.

\subsubsection{Streamer Process}

If an electron avalanche consists of more than $10^{8}$ electrons, a space charge will be created by the positive ions left behind [8] provoking a distortion of the electric field in front and behind the avalanche (Fig. 2-3). The increased electric 
field leads to an increase in the first ionisation coefficient $\alpha$. A self-channelling space-charge-controlled ionisation will be created, known as "streamer". However, this streamer mechanism always needs a Townsend initial avalanche to start. For the transition from Townsend to streamer, a well-accepted criterion postulates that the space charge field becomes comparable with the external applied one. It has been observed that the streamer discharge needs for the product $\alpha^{\star} d$ values in the range of 18 to 20 [58]. For the non-uniform case, the streamer spark criterion may be written as shown in equation e2-3 [41]:

$$
\int_{0}^{d} \alpha d x \geq 18
$$

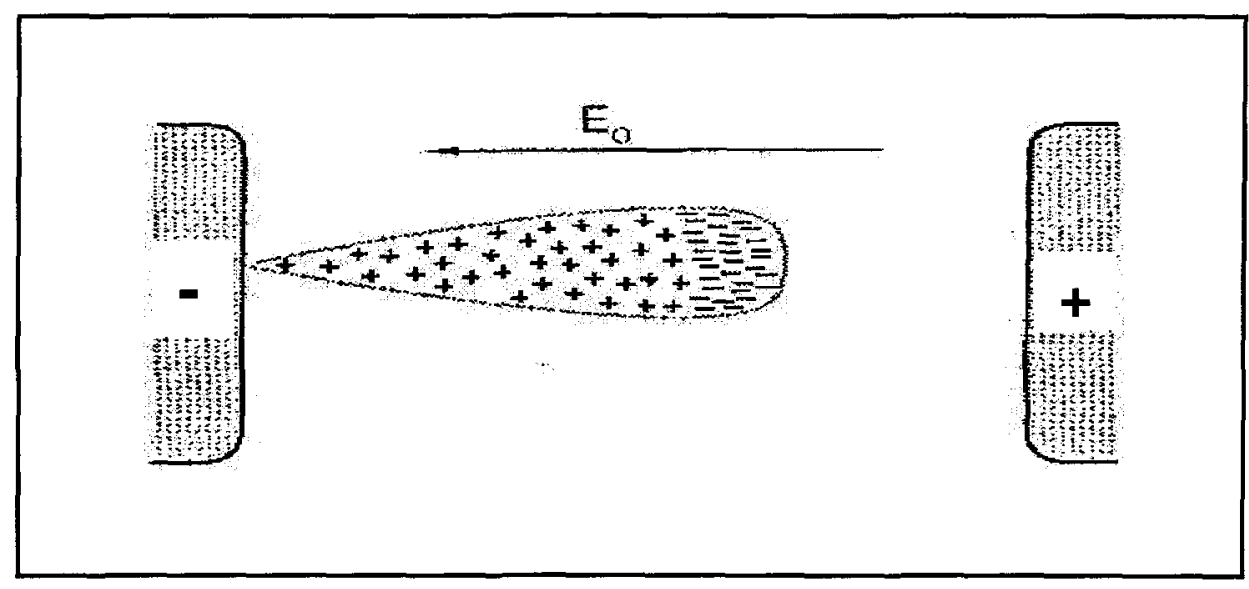

Fig. 2-3: Streamer discharge causing a field enhancement in front of and behind the electron avalanche [4]

Excited atoms returning to their normal condition emit photons. These photons can ionise other atoms or molecules and new free electrons will be 
created. Auxiliary electron avalanches appear behind and in front of the main streamer (Fig. 2-4). By this process, the streamer increases its speed of growth. The auxiliary avalanches behind the streamer approach more and more towards the cathode, which may give the impression that the streamer propagates towards the cathode. In fact, all avalanches propagate towards the anode as they consist of electrons, but by the creation of new secondary avalanches behind the prior ones, the total development shows an approach towards the cathode.

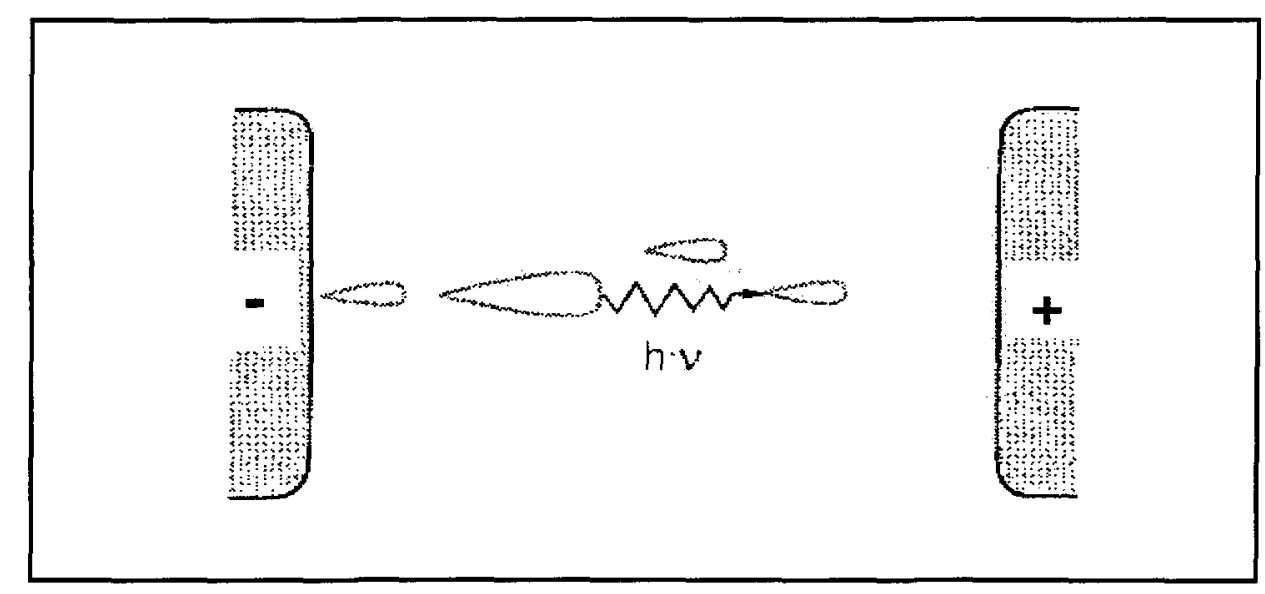

Fig. 2-4: Creation of secondary avalanches by emission of photons out of the primary streamer [4]

The appearance of a streamer in a homogeneous field configuration always leads to breakdown, whereas in the inhomogeneous case, the propagation of the streamer depends on the distortion of the electric field and it may stop at a certain distance from the point electrode, if the decreased field strength is too weak to maintain sufficient ionisation processes [60]. 
The electric field of the channel depends on the voltage polarity: It reaches to $5 \times 10^{5} \mathrm{~V} / \mathrm{m}$ for positive polarity, and $10 \times 10^{5} \mathrm{~V} / \mathrm{m}$ to $15 \times 10^{5} \mathrm{~V} / \mathrm{m}$ for negative [4].

\subsubsection{Discharge Characteristics for Short Distances}

For short distances, breakdown may occur without any preceding corona activity [67]. If corona does not set in for gaps with a distance ranging from millimetres to a few centimetres, spark breakdown happens immediately at the threshold voltage. If corona sets in, the spark may not appear until higher potential is reached. For longer gap lengths, pre-onset streamers appear, which lead to sparks.

Figure 2-5 [67] illustrates the breakdown characteristics for a sphere-plane configuration as a function of gap length, a (radius of spherical anode measures $r=1 \mathrm{~cm}$ ). Curve 1 for small gap spacing shows a breakdown without preceding discharge activity. As gap length reaches $\mathrm{a}=10 \mathrm{~cm}$, streamers do not always cross the gap. Pre-onset streamers are plotted in curve 2. Curve 4 then represents the streamer corona and curve 5 shows transition from streamer to glow corona without sparking. Finally, curve 3 represents the breakdown value with preceding corona glow. Between $13 \mathrm{~cm}$ and $16 \mathrm{~cm}$, two breakdown values exist. In one case, breakdown is achieved by a streamer (curve 2), in the other case it is preceded by a glow corona (curve 3). For a gap length shorter than $13 \mathrm{~cm}$, the dotted area 
cannot be achieved directly by increasing voltage, as breakdown occurs at the level of curve 1. However, if potential is raised at a larger gap spacing (for example from point ' $A$ ' to point $B$ at $a=18 \mathrm{~cm}$ ) and afterwards gap length is decreased with constant applied voltage (from point ' $\mathrm{B}$ ' to point ' $\mathrm{C}$ '), glow discharge activities can be created for distances shorter than $a=16 \mathrm{~cm}$ even above the breakdown level given by curve 1 .

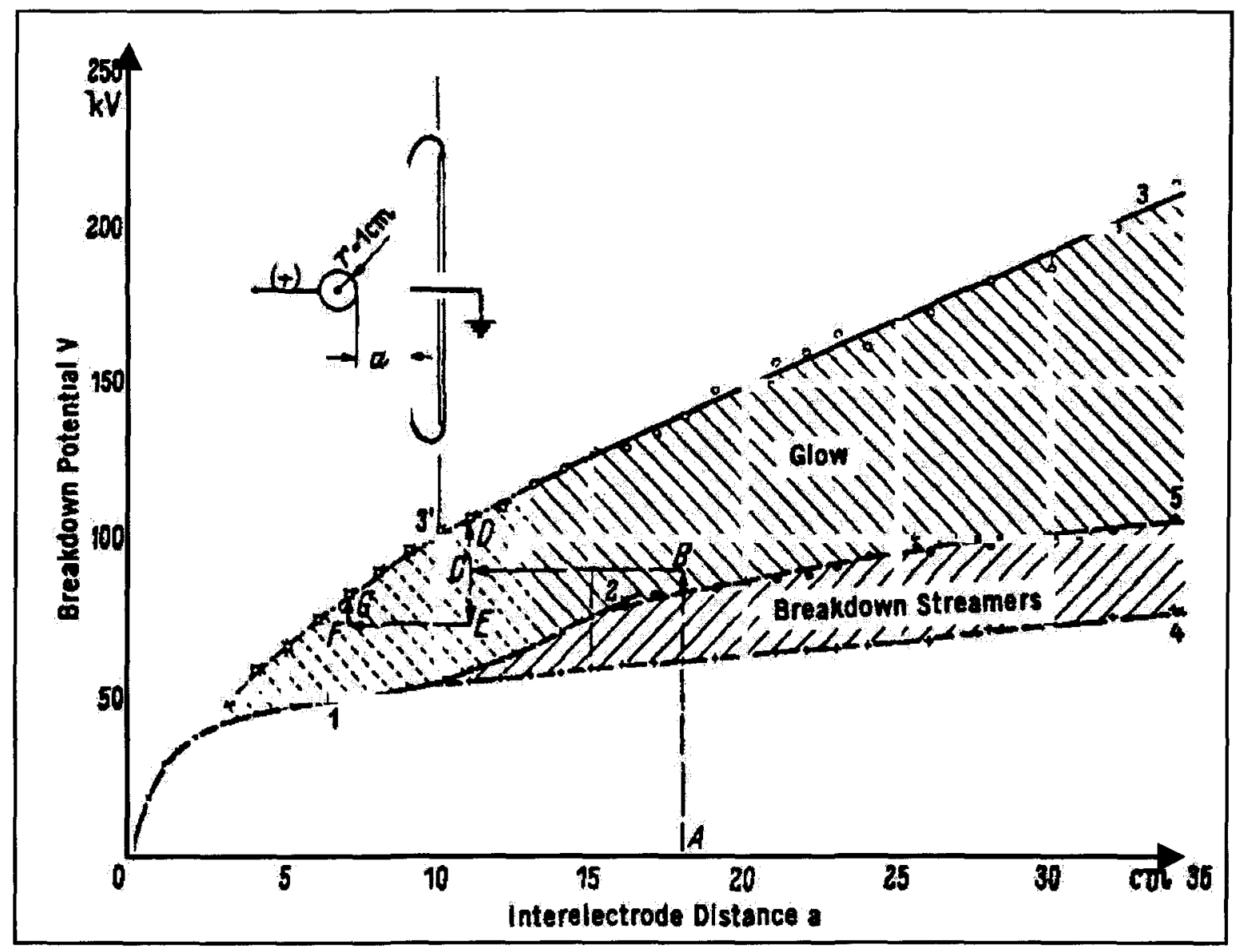

Fig. 2-5: Breakdown curves for sphere-plane configuration as a function of gap length [67] 


\subsection{Surface Discharges}

\subsubsection{Discharge Activity on Synthetic Surfaces}

Research on surface discharges was mainly motivated in the recent past by problems of surface discharges and breakdown in gas insulated substations and transmission lines (GIS and GITL). Whereas the materials used (for example, Teflon, ceramics etc.) have excellent insulation properties, partial discharge activity and breakdown happen at surprisingly low voltage levels inside the enclosed systems. Investigations are directed towards the surface of the insulators, as various tests in the past clearly indicated that dynamic interaction between the spacer surface and the surrounding gas volume determines the breakdown characteristics [103]. As these enclosed systems do work in vacuum [2] [18] [19] [81] [103] or with electronegative gases $\left(\mathrm{SF}_{6}, \mathrm{~N}_{2}\right)$ [86] [97] [107] [113], several aspects of the discharge phenomena may differ from the case of the present study. Also, very fast transient overvoltage (VFT) stress plays an important role for such systems, therefore, some studies work with such voltage types [86] [97] [107]. However, the scientific findings in this research field may help to identify and explain the processes in the domain of ice surface discharges. Therefore, it seems pertinent to review some results of this field. 


\subsubsection{Mechanism of Surface Charge Accumulation and Discharge Initiation}

Surface charge measurements in the past [14] [52] [117] showed that surfaces of synthetic insulators get charged when subjected to high voltage. First, it can be stated that an ideal surface does not exist in practice, especially when industrial production processes also have to satisfy economical considerations. There always exist microscopic scratches and voids due to machining processes. These non-uniformities may create local field enhancements leading to partial discharge initiation. The charges created are likely to be captured on the surface. Furthermore, contamination of the surface cannot be avoided totally (for example by absorption) [2], which may also play an important role for surface charging.

The first question to clarify for the elaboration of a theory on the surface charge accumulation may be on the origin of free charges. In the case of vacuum, different authors identified the metallic electrode - insulator - gas triple junction as source of free electrons [2] [63] [81]. For discharge processes along a gas-surface interface, relatively few significant studies exist on the early stages of discharge development [61]. Ionisation processes in the gaseous space next to the surface may provide the free electrons. Photoemission from the surface has also been mentioned previously [115]. 
Different processes have been proposed for the accumulation of surface charges in the case of vacuum [2]. Positive ions on the surface may be created when impinging free electrons dislodge other electrons from absorbed atoms or molecules (e2-5). If a free electron has sufficient energy it may even dissociate the molecule into smaller fractions (e2-6 and e2-7).

$$
\begin{array}{ll}
A B+e^{\cdot}==A^{+} B+2 e^{\cdot} & e 2-5 \\
A^{+} B==>A^{+}+B & e 2-6 \\
A^{+} B==>A+B^{+} & \text {e2-7 }
\end{array}
$$

Negative surface charges may be created when free electrons get trapped again at the surface. At low energy level, electrons may be trapped by positive ions (e2-8). As the accumulated energy of the electrons increases, they may also become trapped by neutral atoms or molecules (e2-9). At even higher voltages, already negatively charged particles may be charged further (e2-10).

$$
\begin{array}{ll}
A^{+}+e^{-}=>A & e^{2}-8 \\
A+e^{-}=>A^{-} & \text {e2-9 } \\
A^{-}+e^{-}=>A^{2-} & \text { e2-10 }
\end{array}
$$

The surface charge clusters of different polarities distort the electric field of the applied voltage. Strong electric fields may be created locally. If critical field strength is surpassed, trapped electrons in the negative charge regions may be liberated again and may be accelerated along the surface. These electrons then usually multiply as they travel along the insulator surface, either as a surface secondary electron emission avalanche, or as an electron cascade in a thin 
surface layer [81]. Thus, avalanches are created and are accelerated towards the anode, leading to breakdown.

\subsubsection{Main Characteristics of Discharges on Synthetic Surfaces}

Two reviews on the mechanisms of surface breakdown along solid dielectrics in vacuum summarise the research in this field [81] [103]. The first publication [103] discusses the different breakdown models existing at this moment, as well as some experimental results. It was stated that breakdown processes on insulator surfaces are affected predominantly by external factors like metallic particle contamination, surface defects, triple-junction interface, etc. Material properties such as permittivity are found to have less influence. However, at this stage of research, no investigations on other intrinsic material properties were reported. Various studies on practical design of GIS-systems were discussed in order to find insulator shapes and electrode configurations with uniform field distribution, and to eliminate high-stress regions. Surface charge measurements were limited, at that time, to electrostatic measurements without applied voltage. It was shown that charging is bipolar and that charge distribution strongly depends on triple-junction geometry, surface smoothness, surface field, and duration of applied voltage. Furthermore, the presence of a conducting particle increases the amount of surface charge. 
The effects of several parameters on the surface breakdown processes in vacuum were described in the second review [81]:

- Influence of applied voltage:

In general, short pulses in the range of nanoseconds have the highest breakdown voltage, pulses in the range of microseconds or dc voltage have intermediate breakdown voltages, while ac voltages give lowest results.

- Influence of insulator shape:

The exact shape of an insulator can have a strong effect upon its surface breakdown. The simplest shape, a cylinder, tends to have lower holdoff voltages than more complex shapes. In general, cones with an angle of $+45^{\circ}$ have the highest breakdown voltage. It appears that $-45^{\circ}$ cones perform about as well as $+45^{\circ}$ for insulators of organic materials, but are only slightly better than $0^{\circ}$ cones (cylinders) for glass. The poorest insulator performance seems to be for cones with slight negative angles. In many cases, the simplicity of cylindrical insulators outweighs the improved performance of insulators with more complex geometry. The use of metal inserts in insulators, or recessing the insulator ends into the electrodes, can significantly improve the insulator's performance.

- Influence of material:

The material of the insulator has a great effect on its performance. In general, homogenous materials are preferred to inhomogeneous, especially poor are 
materials of fibrous construction. There is an inverse relation between the relative permittivity, $\varepsilon$, of a material and its breakdown voltage.

- Influence of surface condition:

A surface breakdown can damage the surface of an insulator. This damage can be severe enough to lower subsequent breakdown voltages significantly. An insulator material strongly resistant to damage may be preferred to one with a higher surface breakdown voltage. It is generally desirable to clean the surface of an insulator to remove possible contaminants. Bakeouts of the assembled system are generally desirable if the insulator can tolerate the necessary temperatures. Both processes could remove contaminants from accumulating on the surface.

- Influence of temperature:

In general, surface breakdown voltage of insulators tends to decrease as the temperature increases.

A previous study on the surface breakdown processes of solid insulators [100] [101] used experimental conditions quite similar to the parameters chosen in the present study. Lightning impulse voltages of both polarities were used, experiments were carried out under atmospheric air pressure. The electrode configuration was different from the physical model of this study, but the range of electrode distances covers the values chosen in the present case. Determination of $50 \%$ breakdown voltage, as well as optical ultra high-speed observation were 
carried out, which may yield interesting data to compare with the results of this study. The surface discharges and breakdown phenomena were investigated on acrylic plates, 1 to $10 \mathrm{~mm}$ thick, under positive [100] and negative [101] impulse voltages. The $50 \%$ breakdown voltage, $\mathrm{U}_{50}$, and $50 \%$ corona inception voltage were measured, and observations of visible phenomena were carried out using an image converter camera, which was able to record streak as well as framing images. The following list summarises the results:

- The characteristics of the $50 \%$ breakdown voltage as a function of distance consists of three regions, i.e. $A, B$ and $C$. For regions $A$ and $C$, equations can be given to describe these characteristics.

- The discharge processes are different in the different regions, and they depend on the voltage polarity.

- Region A:

- Negative polarity: A highly conductive negative leader with a negative streamer at the tip of its channel appears, which plays an important role in the breakdown process.

- Positive polarity: A positive leader with intermittent leader coronas appears, which lead to breakdown, as seen in point-to-plane air gaps larger than $1.7 \mathrm{~cm}$.

- Region B: This region is a transition region between $\mathrm{A}$ and $\mathrm{C}$. Breakdown may occur through process $\mathrm{A}$ or $\mathrm{C}$, and the instantaneous value of voltage, at 
which the first primary streamer develops, plays an important part in determining the breakdown process.

- Region C:

- Negative polarity: A negative space charge formed by the negative streamer induces a positive discharge from the anode, then breakdown occurs.

- Positive polarity: An initial positive streamer leads to breakdown, without any following primary positive streamers, as in point-to-plane air gaps larger than $1,7 \mathrm{~cm}$, but no leaders are observed, in contrast to point-toplane air gaps.

- The equation for $U_{50}$ versus $d$ characteristics shows that the $50 \%$ breakdown voltage is independent of the thickness of the acrylic plate.

- Back discharges may occur with the drop in voltage in the wave tail of the applied voltage for both polarities.

The present study was carried out in co-operation with the University of British Colombia. Previous work in this institution used the technique of ultra highspeed streak photography for several studies on the discharge development on synthetic spacer surfaces in different gases [61] [62] [63]. These outcomes may also be interesting when compared to the present study; thus, some of the results are listed below: 
- It is very clearly shown that the spacer surface actively assists discharge development. In general, the discharge development accelerates in the presence of a synthetic spacer.

- Under impulse voltage, the spacer surface cannot be assumed to be dielectrically homogeneous. Therefore, discharge may be initiated at any location in a uniform or quasi-uniform field situation.

- It may be assumed that the spacer surface is not ideally homogenous and that micro-discharges may occur on the surface. These clusters of surface charges generate a continually changing surface electric field.

- The process of photoemission, already mentioned in a previous study [115], may also contribute to the creation of surface charging, thus lowering both formative time lag to breakdown and breakdown voltage.

Several authors agree that surface charge accumulation may be the main reason for the relatively poor surface breakdown characteristics. Thus, some investigations in the HV laboratory at UBC were carried out to measure surface charges and to study their contribution to surface breakdown [14] [117]. Some conclusions are listed below:

- The surface charging is found to be directly related to the corona phenomena. Surface charge density increases significantly when applied voltage reaches a critical value and increases thereafter with applied voltage. 
- Surface charging is strongly field dependent, related to the duration of voltage application, and it shows different patterns as a function of the gas (studies were carried out in air, $\mathrm{N}_{2}$ and $\mathrm{SF}_{6}$ ).

- A spacer reduces significantly the corona inception time of the spacer gap.

- In certain cases, both positive and negative charge accumulations are found on the spacer surfaces independently of polarity of applied voltage. Hereby, polarity of the accumulated surface charges depends on gas type and level of applied voltage.

\subsubsection{Propagation Velocity of Surface Discharges}

Regarding the speed of discharge propagation, several experimental studies for surface discharge in vacuum were reviewed by [81]. Surface roughness and surface composition present important factors influencing the speed of propagation For most cases, the results for propagation velocity are in the range of $10^{7} \mathrm{~m} / \mathrm{s}$. For surface discharge in air, values of $3 \times 10^{7} \mathrm{~m} / \mathrm{s}$ for the final stage and $9 \times 10^{6} \mathrm{~m} / \mathrm{s}$ as average velocity were determined [61]. Experiments in nitrogen revealed a velocity of propagation of $5 \times 10^{6} \mathrm{~m} / \mathrm{s}$ for the final breakdown [84]. A recent investigation presented experimental results on the streamer propagation along insulating surfaces at atmospheric air pressure [1]. It was concluded that stable streamer propagation is characterised by an intrinsic propagation field and velocity, which depend on the dielectric medium. They have higher values for propagation along 
insulating surfaces than for propagation in air. Depending on the different experimental conditions (distance of traverse, applied pulse amplitude, electric field, surface material) streamer propagation speeds between $v=2 \times 10^{5} \mathrm{~m} / \mathrm{s}$ and $v=13 \times 10^{5} \mathrm{~m} / \mathrm{s}$ were measured. If the applied electric field is higher than the minimum field required for stable streamer propagation, the discharge activity divides into two components: A surface and an air component. The propagation speed of the latter component is smaller than that of a streamer in air alone.

\subsubsection{Application of Ultra High-speed Photography}

Numerous investigations were reported using ultra high-speed optical observation techniques in order to study discharge initiation and development. Several examples of recent studies are listed here. [61] [71], [100] [101], and [111] reported applications of streak photography in air at atmospheric pressure. Research activities with streak cameras along synthetic spacer surfaces were carried out by [3], [18], [19] on vacuum discharges, other studies on discharges in compressed gases were reported by [62] [63] [97], [107] and [113]. Framing cameras were used in the past for investigations of discharge propagation in liquid dielectrics [5] [7] [65], [68], [82] and also for the breakdown processes along solid insulating surfaces in air [100] [101]. Furthermore, a single frame high-speed camera system was used to investigate of discharge initiation in $\mathrm{SF}_{6} / \mathrm{N}_{2}$ gas mixtures under very fast transient voltage stress [86], whereas [43] used an ICCD 
camera for studies on avalanches and streamer formation along Teflon spacers in dry air. The present study adopts the streak camera system that was used beforehand for studying discharge activity on various synthetic spacers in air and compressed gases [61] [62] [63].

\subsubsection{Discharge Activity on Ice Surfaces}

There exist only few investigations on the characteristics of electrical discharges along ice surfaces. Results of three previous studies are mentioned here.

A master project [12] at the University of Quebec in Chicoutimi studied the corona discharges and breakdown characteristics on a linear physical model, consisting of a metallic HV electrode and an ice plane placed on a grounded metal plate. The following points can be retained from this study:

- The resistance of ice decreases when passing from icing period to melting period. This is an important factor influencing the mobility of charge carriers on the conductive surface of the ice.

- For ice formed from water with low conductivity, the resistance decreases by $32 \%$ to $48 \%$ between icing and melting periods.

- If a thin water film covers the ice, total equivalent resistance is decreased to a higher degree than without water film. 
- For the icing period, a water film covering the ice surface decreases the resistance by approximately $97 \%$ in comparison with its initial value.

- If a liquid film covers the ice during the melting period, resistance decreases by $95 \%$ in addition to the decrease in resistivity due to melting. This is the most dangerous case, as ice resistance is decreased by two processes melting period and water film.

- For the icing period, a water film on the ice surface leads to a decrease in minimal breakdown voltage of about $12 \%$ to $20 \%$ in comparison with the value for dry ice surface condition.

- Minimal breakdown voltage is slightly lower for negative polarity for any temperature studied.

Another investigation aims to explain the characteristics of an established arc on ice surfaces [36] [116]. The present study deals with the discharge onset, thus, it studies processes before establishment of a stable arc. Nevertheless, some conclusions on the pervious work of arc propagation could be interesting to mention at this point. Experiments were carried out on a triangular model, $28 \mathrm{~cm}$ high. The velocity of the arc was determined using a high-speed video system. From the results, it may be concluded that:

- The arc propagation can be divided into two stages. In the first stage, covering about $40 \%$ to $50 \%$ of total leakage distance, the velocity of arc 
propagation is relatively small, varying between 0.04 and $0.3 \mathrm{~m} / \mathrm{s}$. In the second stage, velocity increases to a range of 3 to $50 \mathrm{~m} / \mathrm{s}$.

- In general, velocity is slightly lower under ac than under dc, except during the final moment just before breakdown. Hereby, velocity reaches its maximum value, which can be as high as $100 \mathrm{~m} / \mathrm{s}$ for $\mathrm{dc}$ and $440 \mathrm{~m} / \mathrm{s}$ for ac.

- In the case of dc-voltage, no obvious difference could be detected between propagation velocities of negative and positive arcs during the first stage. In the second stage, higher values were found for negative arc.

- In the case of ac, the partial arc extinguishes and reignites cyclically with the alternating voltage. Thereby, a time delay of about $1 \mathrm{~ms}$ exists between the variations of arc length and voltage.

The fundamental characteristics of ac breakdown under conditions of combined contamination and ice covering were also investigated [95]. Experiments were carried out on a rectangular physical model mounted at an angle of $30^{\circ}$. The ice-covered part had dimensions of $10 \mathrm{~cm}$ by $5 \mathrm{~cm}$. Optical high-speed observations in the range of milliseconds, as well as electrical measurements were carried out. The experimental conditions were very different to those normally used in the investigations at UQAC. Moreover, some terminology was defined in a different way, so comparison of results has to be done carefully. Nevertheless, some interesting points can be retained from this study: 
- The average value of salt deposit density (SDD) in the presence of icing is five to nine times higher than that for ice-free conditions. This may be explained by the fact that without ice the sprayed liquid contamination flows down on the inclined model.

- Thawed snow with a relatively low salt concentration can produce a sufficient SDD for flashover on an iced insulator surface.

- Under the experimental conditions of this study, soft rime conditions lead to lowest breakdown values. At the same SDD, soft rime takes on a sherbet state (mixture of water and ice) providing a $20 \%$ reduction of breakdown stress in comparison with icing-free conditions. This effect is explained by the fact that soft rime tends to increase the density of $\mathrm{Na}$ atoms in the discharge space at breakdown.

- The discharge behaviour depends on the type of ice:

- Soft rime shows discharge activity in front of both electrodes, growing gradually along the surface during several half-cycles.

- Hard rime and glaze show weak pre-discharge activity at different locations either near the electrodes or somewhere on the ice surface. The occurrence of final breakdown is very fast, the transition period from predischarge to breakdown lasting about one half-cycle.

- A common feature can be observed: In all three cases, the local discharges extinct and reignite at each half-cycle. 


\subsubsection{Discharge Propagation in Water and on its Surface}

Due to the fact that the ice surface exhibits a quasi-liquid characteristic and also the possible existence of a water film on the ice surface due to melting processes, some aspects of discharges in water and on its surface is reviewed. Several theories exist on the progression of electrical discharge activities in water. Papers are cited in this section in order to give an insight into two theories.

A study on the pre-breakdown phenomena in a uniform field in water [42] showed that pre-breakdown streamers exist for both polarities. They are either subsonic or supersonic in a non-uniform field. Formation and development of slow anodic and cathodic streamers are assumed to be induced by water cavitation in the band of injected space charge. Development of fast streamers is preceded by a kinetic phase transition, which causes a weak-conducting filament. Heating of this filament leads to appearance of an ionisation wave and the formation of a plasma channel.

A recent study focused on the propagation features of a streamer discharge in water [65]. The results reveal that the streamer propagates in a low-density vapour rather than in liquid. Due to the fact that electron avalanches do not occur in water, the concept of thermal processes plays a decisive role in the theory of water breakdown. It does not seem possible for electrons to gain the high energy 
necessary to initiate ionisation processes in water, while ionisation can take place in a low-density medium such as vapour. The calculated power required to evaporate the water inside a streamer channel during its propagation was found to be concurrent to the measurements. The streamer propagation velocity was found to be independent of the water conductivity, which indicates that the vaporisation at the tip of a streamer takes place due to charged particle flow from the discharge plasma in the streamer channel. Extrapolation of classical approaches give drift velocities of $10^{3} \mathrm{~m} / \mathrm{s}$ for heavy ions and $\leq 10^{5} \mathrm{~m} / \mathrm{s}$ for protons, which are the primary product of the water dissociation and ionisation.

Concerning the propagation of discharges on the water surface, a publication reports optical and field probe measurements using a water bath and a nonsymmetrical electrode configuration to identify the electrical conditions in the discharges as well as in the water layer [10]. The following details can be retained:

- A propagation arc establishes multiple contacts between the discharge channel and the conducting surface for both polarities.

- Shape and velocity of the discharge propagation are strongly voltage polarity dependent:

- The positive discharge is constricted and has many branches, whereas the negative appears broader and simpler. 
- In the case of positive voltage polarity, the velocity of discharge propagation is up to ten times faster than in the case of negative voltage polarity.

- The field intensity increases inside the discharge towards the advancing tip.

- The velocity of discharge propagation depends on the resistance of the electrolyte: The discharge propagates faster as the resistance decreases. 


\subsection{Conclusions of Chapter 2}

Despite the numerous investigations in ice physics and electrical surface discharges, little information is applicable to the present study. In general, the review of the available literature illustrates that electrical discharge phenomena on ice surfaces are very complex. The surface of ice is a sophisticated structure containing a greater number of impurities than the ice bulk due to the freezing process of water. In the range of normal atmospheric conditions, the surface can change from solid to liquid depending on the ambient air temperature. However, it is shown that even for low air temperatures it does not act as a solid material in some aspects, therefore it is described as quasi-liquid. From each of the concerned research fields, some points are summarised, which should be retained in respect to the following discussion and analysis of the experimental results of this study (Chapters 4 to 6 ).

From the literature review on electrical discharges along synthetic surfaces (Section 2.3), the following aspects can be retained:

- The homogeneity of the synthetic material influences the electrical performance of the insulating spacers.

- Different regimes govern the discharge process as a function of the distance between the electrodes. This is related to the fact that certain partial discharge modes require a minimum distance to develop. 
- The existence of surface charge accumulation has been shown and quantified for different synthetic insulating materials. These charge accumulations play an important role for the initiation of the discharges on the synthetic surfaces.

- Discharges between charge accumulation on the surface and one electrode (so-called "back-discharges") have been observed.

From the literature review on electrical discharges along water and ice surfaces (Section 2.4), the following aspects can be retained:

- The discharge process along the ice surface depends on the type and morphology of the ice.

- The propagation of an established arc can be divided into two different regimes: At the beginning, the propagation velocity of the arc is relatively small (in the range of $0.04 \mathrm{~m} / \mathrm{s}$ to $0.3 \mathrm{~m} / \mathrm{s}$ ). As the arc exceeds a certain length, about half the leakage distance, arc propagation velocity increases by a magnitude of approximately two.

- The presence of a liquid water film on the ice surface decreases significantly the surface resistance, which leads to lower critical breakdown voltages under applied ac and dc voltages.

- With dc voltage applied, lower breakdown voltages were obtained for negative voltage polarity. 
- The propagation velocity of an established arc along the surface of an electrolytic solution is a function of the resistance of the solution: A decrease of the resistance will lead to an increase of the arc propagation velocity.

- Higher propagation velocities could be found for positive polarity for a nonsymmetrical electrode configuration.

The studies on discharge processes on synthetic surfaces in vacuum and in diverse gases under high pressure showed that surface charge accumulation is of crucial importance for the initiation of surface discharges. Therefore, one may expect that they could also play a role for ice surface discharges. On the one hand, there is no doubt that charges cannot be accumulated on wet ice surfaces due to the increased surface conductivity. On the other hand, their role for discharge initiation on dry ice surfaces cannot be clarified in this review as no experimental data could be identified in the literature regarding the study and measurement of charge accumulation on ice surfaces. 


\section{CHAPTER 3}

\section{EXPERIMENTAL SET-UP AND PROCEDURES}




\section{CHAPTER 3}

\section{EXPERIMENTAL SET-UP AND PROCEDURES}

\subsection{Introduction to Chapter 3}

This chapter provides technical and practical information on the experimental set-up (Fig. 3-1), the physical model, and the test procedures.

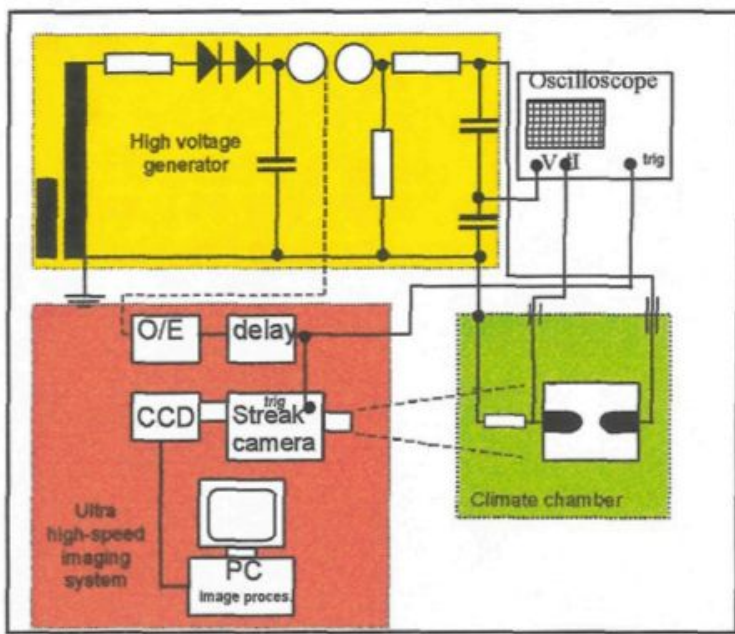

Fig. 3-1: Experimental set-up combining ultra high-speed imaging system, cold chamber, high voltage generator and measuring system 
At the beginning, the different components of the set-up are described. Next, design and preparation of the physical model consisting of two metal capped rod electrodes half submerged into the ice, are explained. All experimental parameters are listed and the chosen values are given. The following section presents the different test procedures. Finally, the limits of interpretation for the different experimental methodologies with the available equipment are discussed in the last section on error discussions.

\subsection{Test Equipment}

\subsubsection{Ultra High-speed Imaging System}

The main tools for this study are specialised ultra high-speed cameras, which can record and portray processes that are too rapid to be perceived by the human eye. Two different recording techniques exist: Framing recording and streak recording. Both techniques could be utilised within the framework of this study.

A framing camera provides two-dimensional photographs, where each of these images represents the integrated recording over the exposure time interval, $t_{\text {trame }}$. A series of framing recordings does not provide any information on the observed process during the time period between the frames, $t_{\text {interf. }}$. Even if this 
value is adjusted to zero so that at the end of one framing recording the next starts immediately, the process will not appear as a continuous phenomenon due to the integrating effect of the framing recording. On the other hand, a streak camera provides a continuous recording of one geometric dimension. The result - a twodimensional photograph, shows the development of any dynamic process along a line as a function of time (see Section 3.5.1). Thus, the advantage of continuous recording has to be won by the fact that one is limited to one geometric dimension. It may be concluded that both technologies - streak and framing camera - present complementary experimental methodologies, where each of them has certain advantages and disadvantages. The use of streak technology may be recommended for the study of the basic discharge processes, where a onedimensional discharge development can be contrived. However, for experiments on larger physical models or even real insulators with complex geometric structures, it can be expected that the electric arc will not follow a straight line any more. Thus, it seems to be necessary to use framing technologies with its possibility of two-dimensional representation of the dynamic processes. New framing cameras with shorter frame duration will be available in the near future, which may be very helpful for the study of the very fast surface processes.

A scheme of the different components of the imaging system used in the present study is given in Fig. 3-2. The streak camera model Hamamatsu C2830 was coupled to a CCD-camera model Hamamatsu C3640 allowing digital data 
processing and image storage with a desktop computer. Additional technical data are listed in Appendix 2.

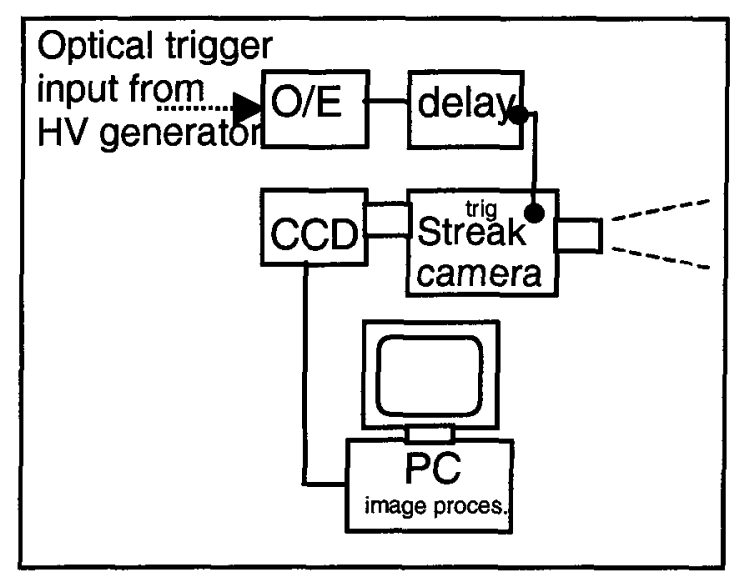

Fig. 3-2: Schematic diagram of the imaging system

The streak camera was triggered by the spark in the sphere gap of the HV impulse generator. The optical signal of the spark was transmitted by optical fibre to a device, which transformed it into an electrical signal. This circuit had a very short internal delay of only a few nanoseconds. The transformed trigger impulse passed through an electronic delay giving the possibility to offset the beginning of streak recording. Thus, the start of the streak recording could be adjusted continuously, and it is only limited by the delay time of imaging system (internal delay of streak camera, O/E-device, cables, etc.).

A framing camera system was available for a few measurements in order to test its performance and to compare the results with the streak recordings. This 
system was an IMACON 468 system, which provides framing recording with variable frame exposure, $\mathrm{t}_{\text {rame }}$, as well as variable time duration between each frame, $t_{\text {interrt. }}$. The minimum exposure is $t_{\text {trame }}=10 \mathrm{~ns}$. For framing recording, where one recorded photograph immediately follows the previous, the interframe duration can be adjusted to $t_{\text {intertr }}=0 \mathrm{~ns}$. The ultra-high speed camera was integrated into the existing trigger circuit, which was explained beforehand. Detailed information on this second system can be found in reference [20].

\subsubsection{Cold Chamber}

All experiments were carried out inside a cold chamber type "Envirotronics EH40-2-3". A microprocessor based temperature-humidity programmer controller is installed to provide an accuracy of $\delta \mathrm{T}= \pm 1.1 \mathrm{C}^{\circ}$. The technical data for the cold chamber are listed in Appendix 3. The front door of the cold chamber was equipped with a window, through which the experiments could be observed and recorded. Fig. 3-3 shows the experimental set-up with the streak camera in front of the cold chamber. 


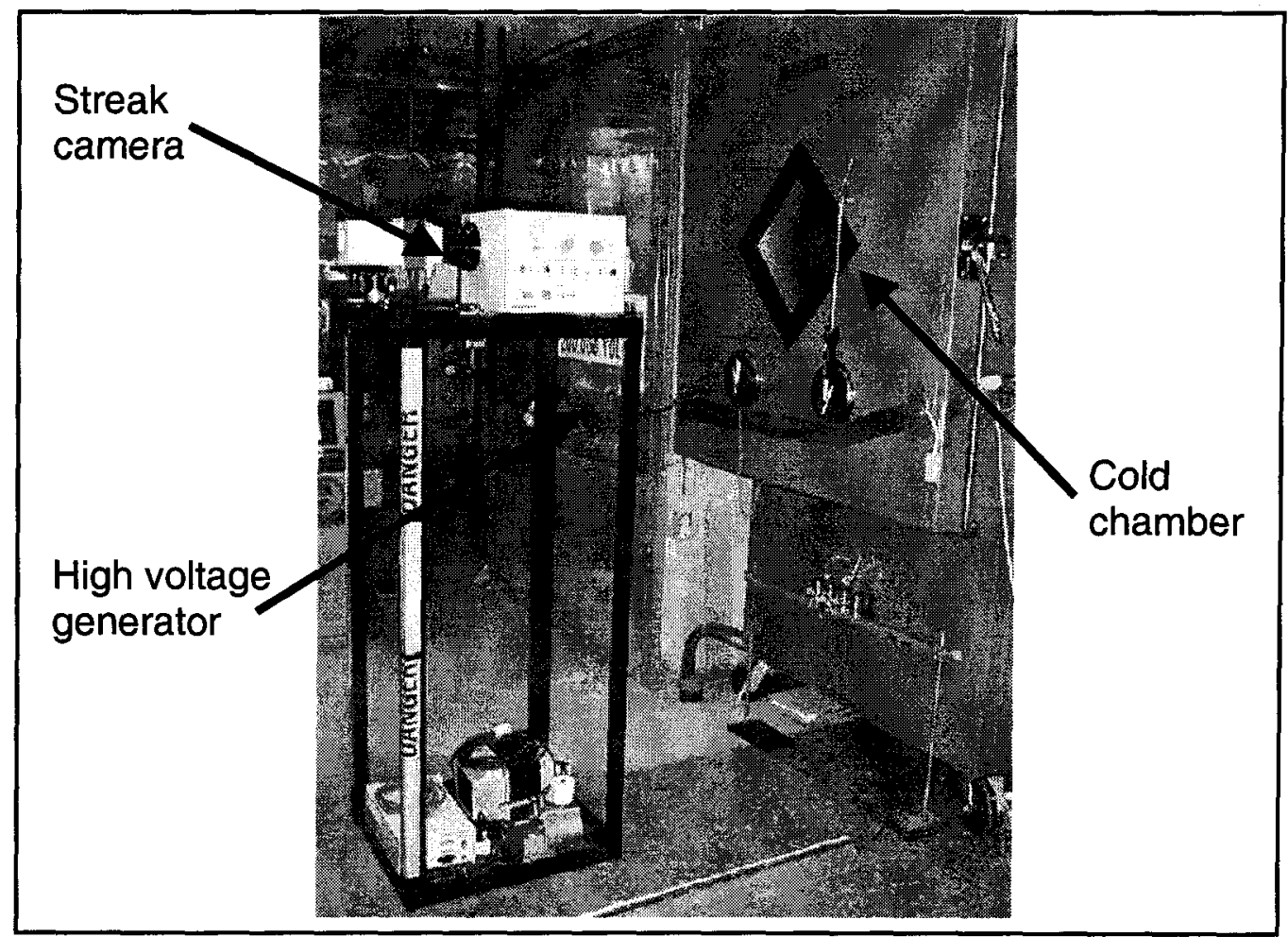

Fig. 3-3: Experimental set-up with the streak camera in front of the cold chamber

\subsubsection{High Voltage Generator}

Standard lightning impulse voltage was used for the experimental investigations. This voltage waveform provides a well-defined peak value, which is necessary for triggering the ultra high-speed camera. It can be described mathematically in form of a bi-exponential function, as shown in equation e3-1. Table 3-1 shows the specifications for the lightning impulse voltage as fixed in international standards [50], Fig. 3-4 shows the standard voltage waveform. 


$$
\begin{aligned}
& v(t)=V_{1}\left[e^{\frac{-t}{\tau_{2}}}-e^{\frac{-t}{\tau_{1}}}\right] \\
& \tau_{1}=\frac{t_{1}}{5}=0.2 \cdot t_{1} \\
& \tau_{2}=\frac{t_{2}}{\ln 2}=1.443 \cdot t_{2} \\
& V_{1}=V_{\max } \cdot e^{\frac{t \cdot \ln 2}{t 2}}
\end{aligned}
$$

Table 3-1: Specifications for a lightning impulse voltage (International Standard IEC 60-2 [50])

\begin{tabular}{|c|ll|}
\hline & Value & Accuracy \\
\hline$t_{1}$ & $1,2 \mu s$ & $+/-30 \%$ \\
front time & & \\
$t_{2}$ & $50 \mu s$ & $+/-20 \%$ \\
time to half-value & & \\
\hline
\end{tabular}

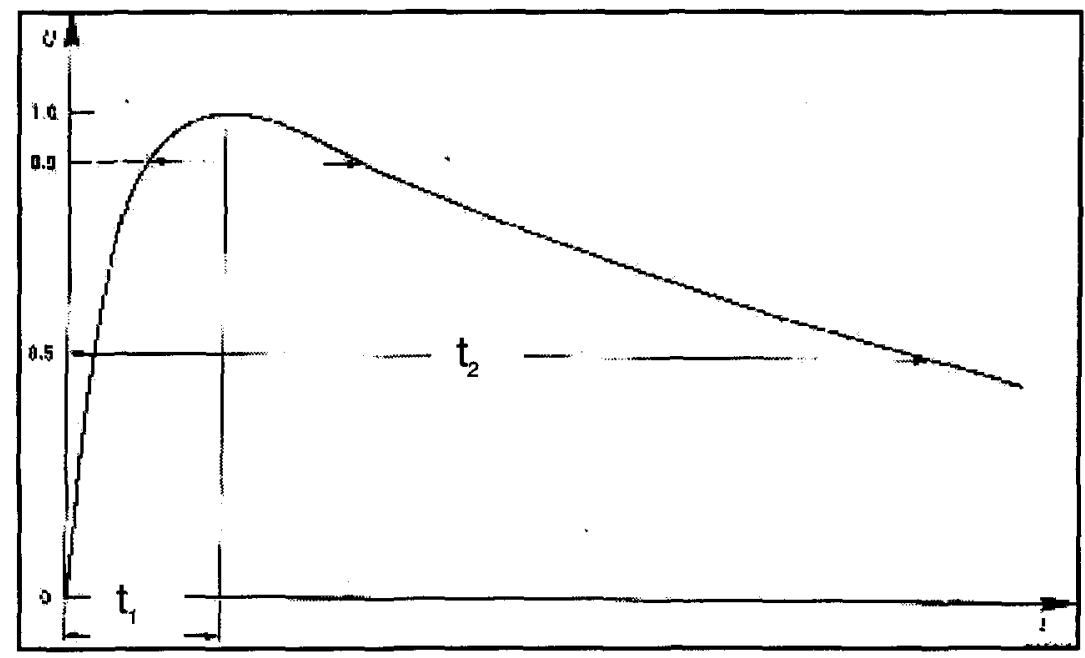

Fig. 3-4: Waveform of a lightning impulse voltage [50] 
As high voltage source, a single stage impulse generator based on the Marx multiplier principle, was assembled with elements of a "MessWandlerBau" - high voltage testing kit. The nominal rating of the generator is $U_{\text {peak, } \max }=130 \mathrm{kV}$ and $E_{\text {mpusse }}=50 \mathrm{~J}$. Figure 3-5 shows the equivalent electric circuit and Fig 3-6 shows a photograph of the actual set-up.

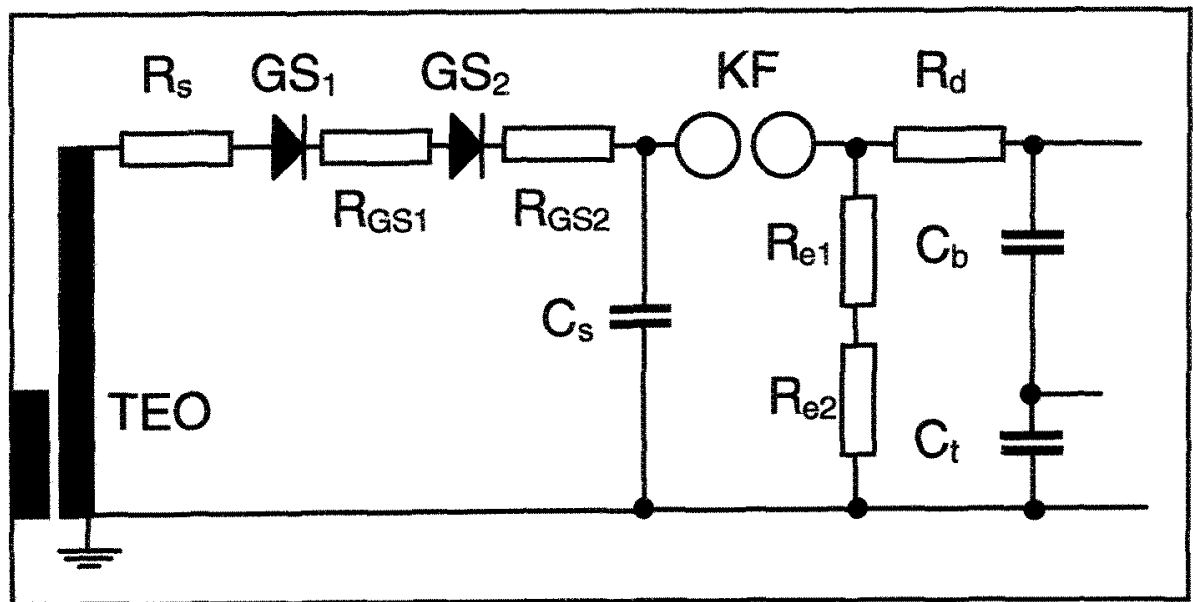

Fig. 3-5: Equivalent electric circuit of the high voltage impulse generator

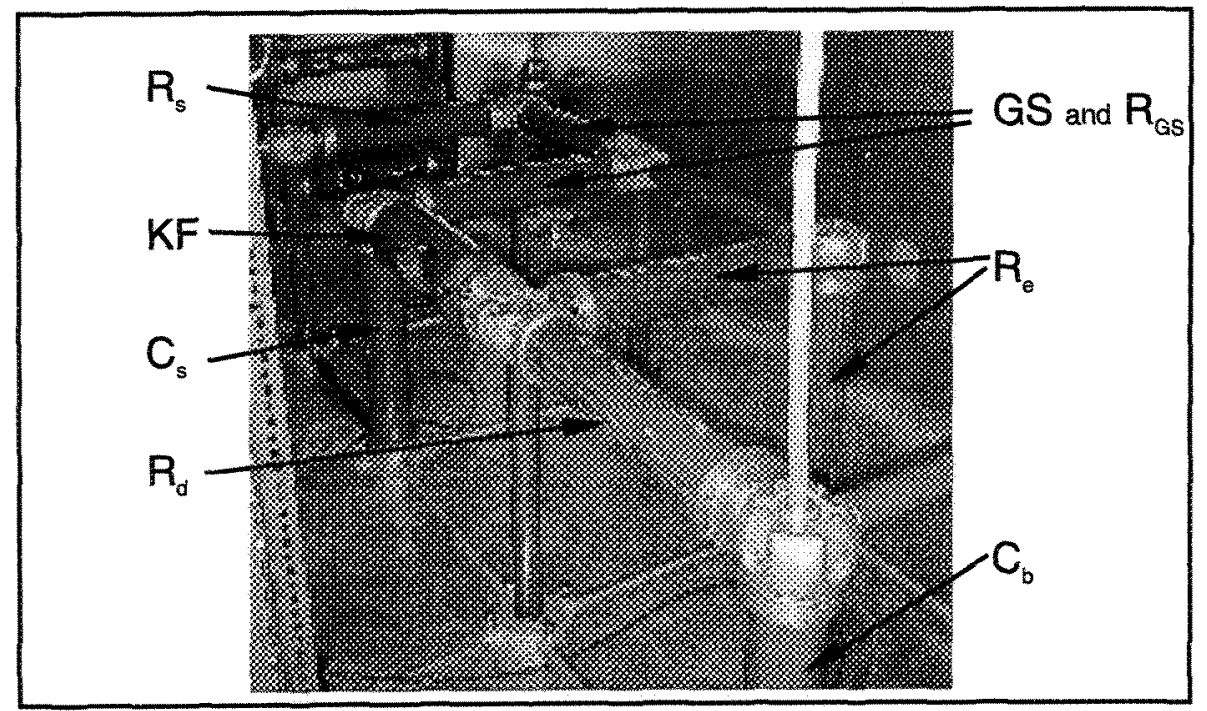

Fig. 3-6: Photograph of the real set-up of the high voltage impulse generator 
The values for the resistances and the capacitances can be calculated with equations e3-2 and e3-3. The specifications for the different elements can be found in Appendix 4.

$$
\begin{aligned}
& t_{1}=2.96 \cdot R_{d} \cdot \frac{C_{b} \cdot C_{s}}{C_{b}+C_{s}} \\
& t_{2}=0.73 \cdot R_{e} \cdot\left(C_{b}+C_{s}\right)
\end{aligned}
$$

With the available elements, the following values for $t_{1}$ and $t_{2}$ are obtained:

$$
\begin{aligned}
& t_{1}=1.11 \mu \mathrm{s} \\
& t_{2}=64.1 \mu \mathrm{s} \\
& \tau_{1}=222 \mathrm{~ns} \\
& \tau_{2}=92.3 \mu \mathrm{s}
\end{aligned}
$$

It can be seen that the value for $t_{2}$ exceeded the limit of the international standards [50] by $7 \%$, but it was judged to be still acceptable for this fundamental study.

\subsubsection{Measuring System}

A digitising oscilloscope type "Hewlett Packard 54111D" was used, which provides functions for measurement, storage, analysis, and printing of the experimental results for voltage and current waveforms. The technical specifications for this apparatus can be found in Appendix 5. Figure 3-7 shows the connections of the oscilloscope to the experimental set-up. As a safety measure, 
both inputs of the oscilloscope were protected by additional bi-directional overvoltage transient suppressors, which were connected in parallel to the measuring signal. The specifications of these devices are listed in Appendix 6.

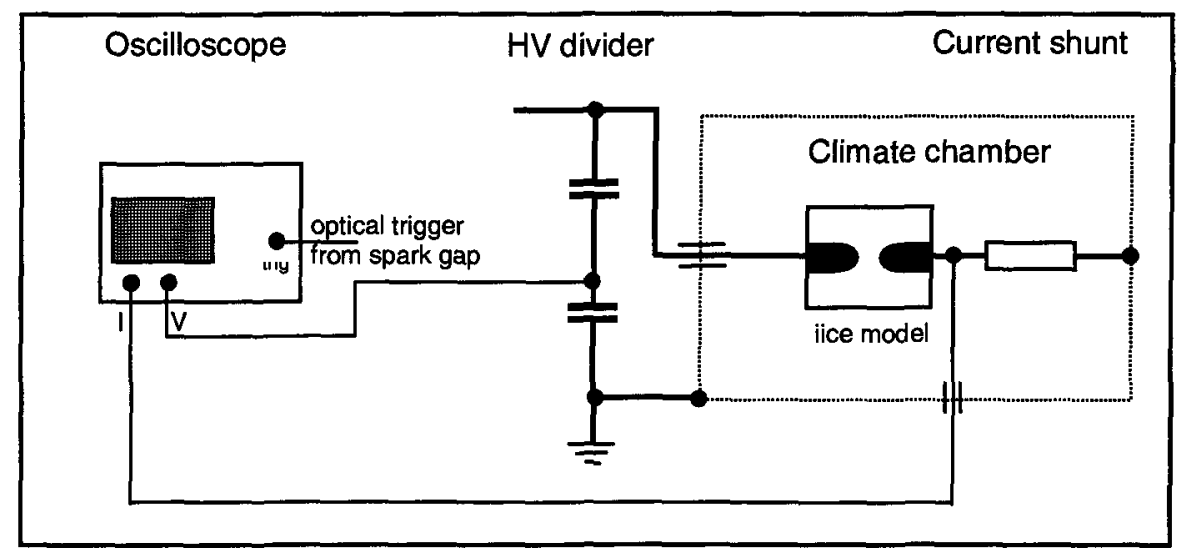

Fig. 3-7: Connections of the oscilloscope to the experimental set-up

The voltage was measured using a capacitive divider. The load capacitor $C_{b}$ of the MWB high voltage kit is designed to be used at the same time as the high voltage part of the capacitive divider. The low voltage part $\left(\mathrm{C}_{\mathrm{t}}\right)$ was modified to obtain an appropriate ratio for the measurements in this study. Its design parameters can be found in Appendix 7.

The current waveforms were measured by means of a resistance in series with the test model (at grounded side). The resistance had a coaxial design and measurements showed no evidence of any parasitic impedance or capacitance. Its specifications can be found in Appendix 8. 


\subsection{Physical Model}

\subsubsection{Geometric Configurations}

As an industrial HV insulator has a complex geometric structure and comprises different materials, a simplified physical model was used for the experiments. Regardless the geometric shape or the material of the insulator, electrical discharges will extend first over very short distances at locations of enhanced electric field. For a study on the discharge onset, observations may be limited on the region next to this process. Thus, the simplified geometric model may represent quite well the actual discharge initiation and the early stages of discharge development. Several different locations can be identified, where discharges may be initiated on an ice-covered HV insulator:

- Between one metal terminal (HV or ground contact) and the ice cover;

- From ice asperity to ice asperity bridging air gaps somewhere along the insulator;

- Along the ice surface between impurities imbedded in the ice.

The present study focuses on locations of second and third type.

The advantage of a simplified geometry is that the investigations can be concentrated on each single experimental parameter without having any effects 
caused by geometric form or material. The chosen model is derived from test specimens, which were already used for similar applications of ultra-high speed photography, for example for studies of surface discharge on synthetic spacers of Gas Insulated Sub-stations (GIS) [3] [49] [57] [61] [62] [63]. A similar model was also used in previous works at UQAC for AC and DC flashover tests on the ice surface [33]. Employing a model with similar geometric configuration allows comparison of results from this project with results from previous studies for different materials.

Due to the fact that a streak camera can only record one single geometric dimension, it is preferable that the discharge develops along a straight line. Otherwise, the application of streak photography becomes difficult and the interpretation of the results ambiguous. Therefore, the dimensions of the model were quite small. Furthermore, some special measures were applied to the ice to insure a straight discharge development (see Section 3.3.3). Two hemispherical stainless steel capped rods with an electrode curvature radius of $r=6 \mathrm{~mm}$ were half submerged into the ice bulk. The electrodes were screwed into a rectangular Plexiglas box with an internal dimension of $80 \mathrm{~mm} \times 75 \mathrm{~mm} \times 40 \mathrm{~mm}$, to keep them in the right position. The distance, $d$, between the electrodes could be adjusted continuously. This box was also used as a mould to hold the water to be transformed into ice. Figure 3-8 shows a schematic of a vertical section through the test specimen. Figure 3-9 shows two different views of a prepared ice sample. 


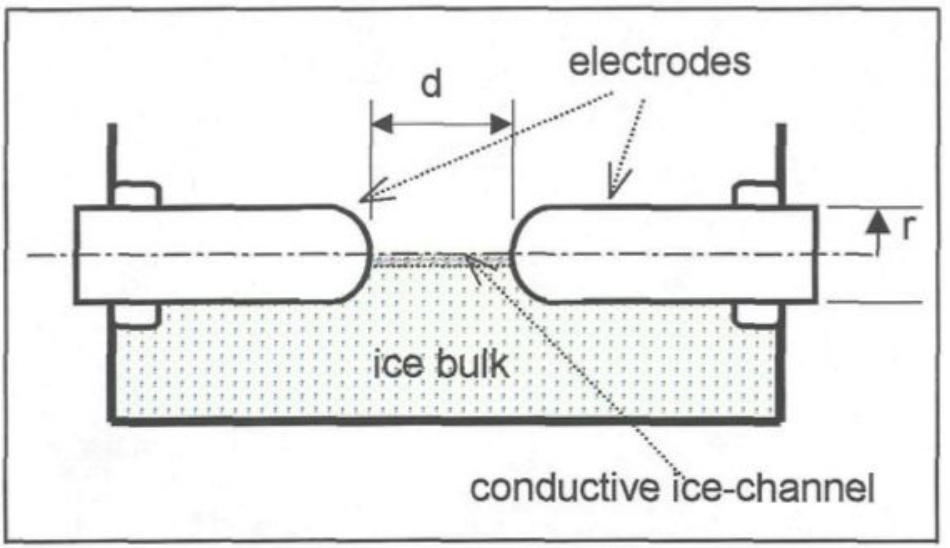

Fig. 3-8: Vertical section of the physical model

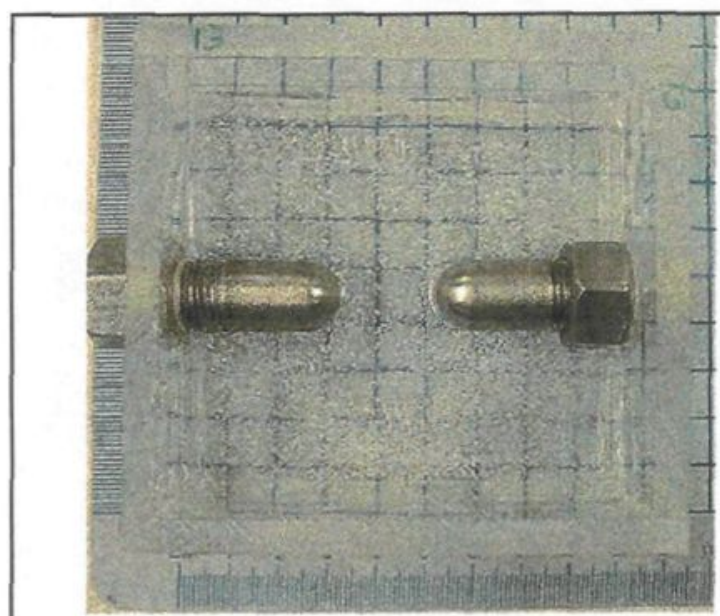

a) Horizontal view

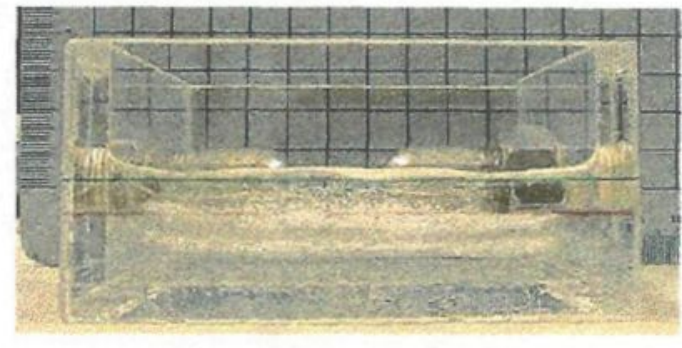

b) Vertical view

Fig. 3-9: Still photographs of ice sample

In order to record the light emitted by the discharges on the ice surface, the ice sample was placed in vertical position inside the cold chamber. The axis of the electrodes was oriented horizontally in parallel with the slit of the streak camera. This electrode axis orientation made it possible to record the optical phenomena without using reflective mirrors to change the optical orientation of the images. 


\subsubsection{Electric Field Conditions}

The electric field is quasi-uniform at the surface of the physical model along the axis of the electrodes. The results of a numerical simulation, using the software package "Cosmos" which is based on the finite element method, of the potential and field distributions are shown in Fig. 3-10 [108]. The maximum field at the tip of the electrodes was calculated to be $66 \mathrm{~V} / \mathrm{m}$ for $1 \mathrm{~V}$ applied between the electrodes (Fig. 3-11).

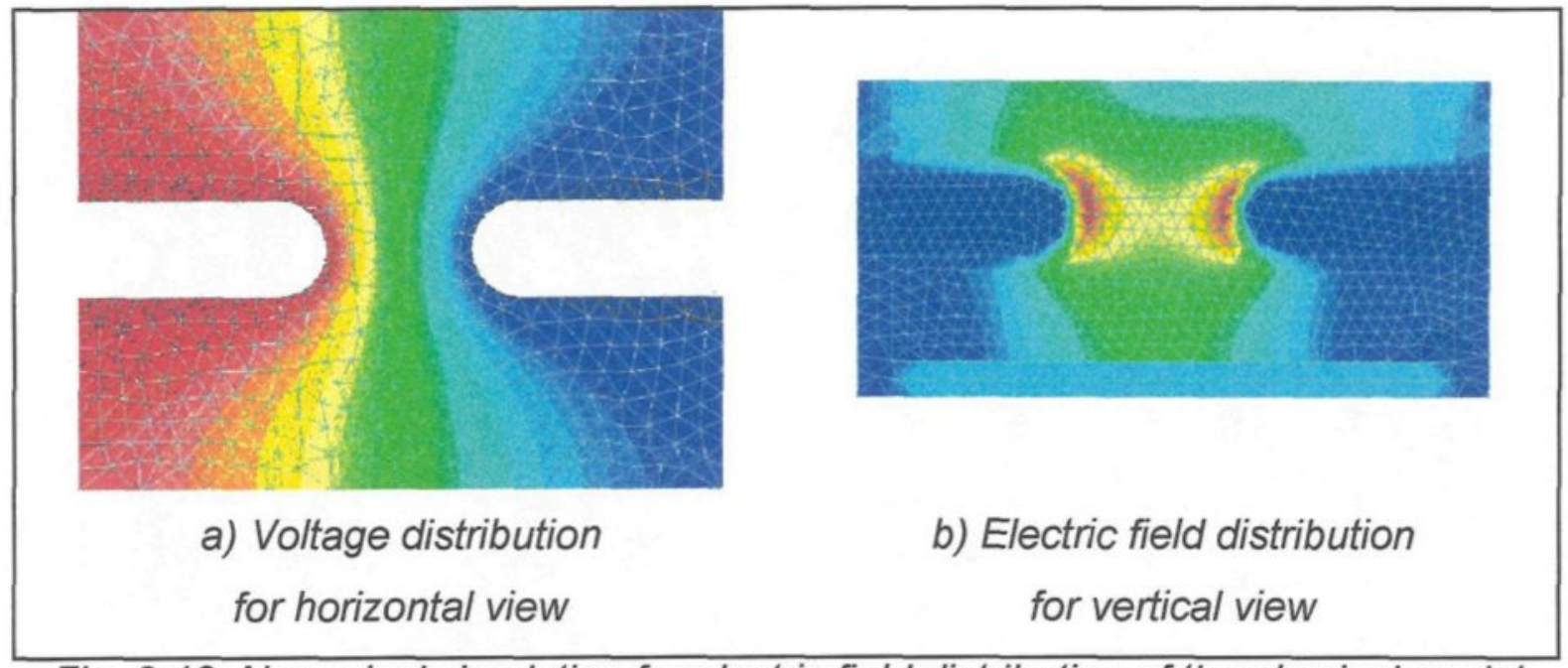

Fig. 3-10: Numerical simulation for electric field distribution of the physical model $(d=18 \mathrm{~mm} ; r=6 \mathrm{~mm})$ [108] 


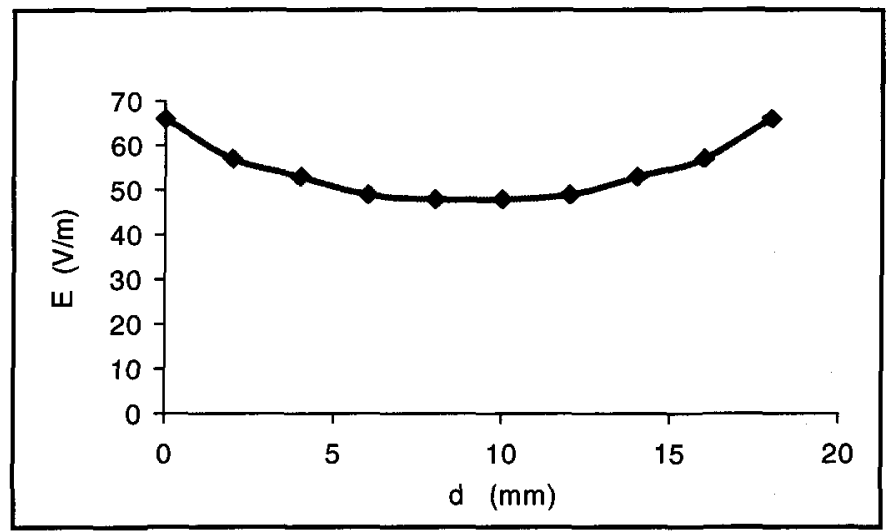

Fig. 3-11: Electric field values between the electrodes for an applied voltage of $1 \mathrm{~V}$

\subsubsection{Procedure of Ice Formation}

The ice bulk of the test specimen was built-up in 3 layers to get a flat surface. Figure 3-12 shows the different steps during the preparation of the ice specimen in a schematic diagram. At the beginning, the box was filled with a first layer of deionised water (1). The model was then placed in a conventional freezer with a temperature cycling around $-12^{\circ} \mathrm{C}(2)$. After a cooling period of about 2 hours, a second layer of de-ionised water was added (3), and the ice sample was again placed in the freezer (4). Once this ice-base was formed, the last water layer was added onto the ice (5). This last layer was either made with de-ionised water or with freezing water with an adjusted conductivity depending on the used method to keep the discharge on a straight path. The specimen was once more placed in the cold chamber. Ice samples were always prepared the day before the tests so that the last freezing-period in the cold chamber was overnight (6). The type of ice 
obtained by this method is semitransparent. It has a polycrystalline structure with numerous very small air-bubbles embedded homogeneously throughout the entire ice bulk. The surface of the ice is smooth so that the breakdown can develop along the surface of the ice. In the cases, where special ice accumulation processes where used for the preparation of the test samples (Section 3.4.8), the first two layers were produced by the conventional freezing method and only the uppermost layer was formed with the particular ice accumulation process.

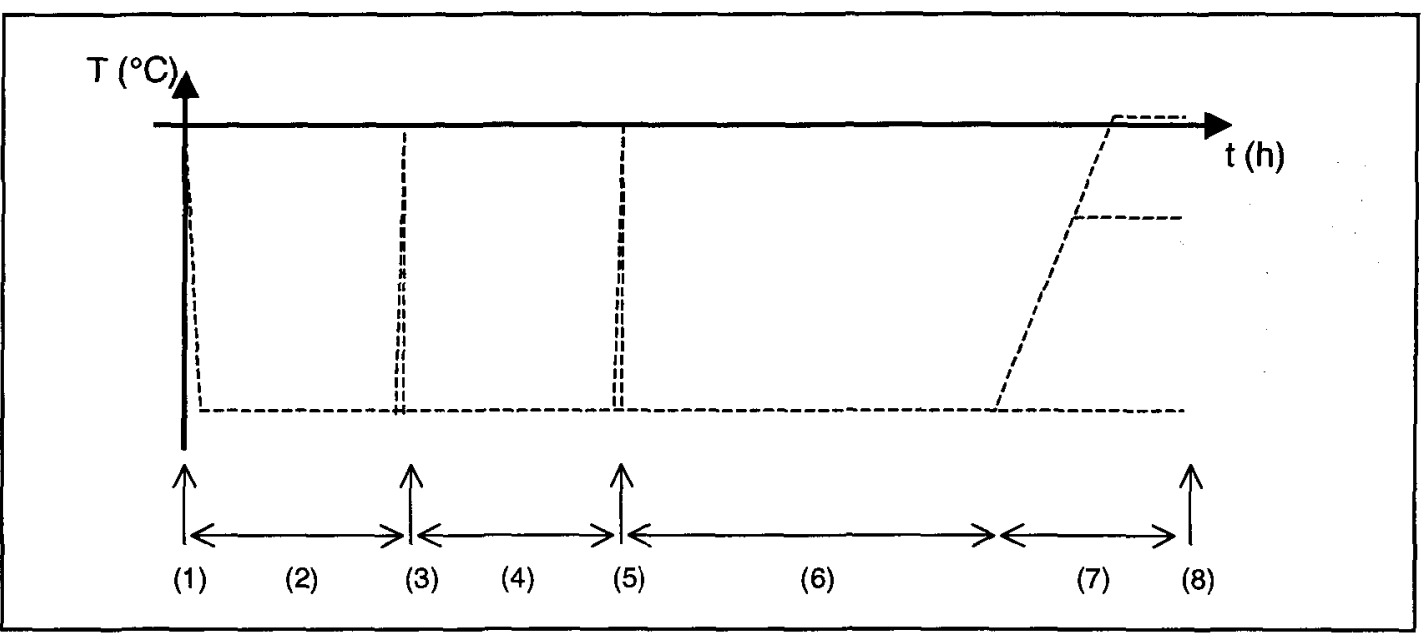

Fig. 3-12: Different steps for the preparation of the ice samples

As already mentioned beforehand, it is preferable to have a straight discharge development for an application of streak photography. Therefore, two methods were used in the experiments to force the arc to propagate along the axis of the electrodes:

1) For the first method, freezing water with an adjusted conductivity was used for the uppermost layer. A very shallow $(2 \mathrm{~mm})$ and narrow $(1 \mathrm{~mm})$ groove was 
milled into the ice surface along the axis of the electrodes. As this groove presents a non-uniformity of the surface, the discharge tends to stay inside the groove.

2) For the second method, the uppermost ice layer was also formed using deionised water. As in the first method, a narrow and shallow groove was milled into the ice along the axis between the electrodes. Then, the groove was filled with water having an adjusted conductivity creating an ice channel with a higher conductivity at the surface of the ice bulk formed with de-ionised water. The discharge was supposed to stay inside the ice channel due to the locally reduced ice resistance. For the case of the ice-sample formed from water with very low conductivity $\left(2.5 \times 10^{-4} \mathrm{~S} / \mathrm{m}\right)$, this method could not be applied and only the first method was used.

In this investigation, most of the experiments were carried out using the second method. The first method was used as a measure to verify the experiments and for experiments with different ice formation parameters.

At least 1 hour prior to the test, the ice samples were placed in the cold chamber "Envirotronics EH40-2-3" (7), in which the temperature was already adjusted to the test value $T_{\text {test }}$. As the volume of the ice bulk was small ( $80 \mathrm{~mm}$ by $75 \mathrm{~mm}$ by $20 \mathrm{~mm}$ ), this was judged as being sufficient to allow the temperature of the ice to equalise with the ambient air temperature of the test chamber. 


\subsection{Experimental Parameters}

Table 3-2 summarises the complete range of variable experimental parameters during the test series. When available, the parameter values were chosen to be consistent with those in previous studies in order to compare the various experimental or numerical results. Next, the ways to adjust the different experimental parameters are described and the method to measure the parameters is explained.

Table 3-2: Variable parameters during the test series

\begin{tabular}{|c|cc|}
\hline Parameter & Dimension & Chosen values \\
\hline Freezing water conductivity & {$\left[\times 10^{-4} \mathrm{~S} / \mathrm{m}\right]$} & $1.0 / 100 / 1000$ (UBC) \\
& & $2.5 / 30 / 80 / 160$ (UQAC) \\
Ice temperature & {$\left[{ }^{\circ} \mathrm{C}\right]$} & $-20 / 0$ (UBC) \\
& & $-12 /-4 / 0$ (UQAC) \\
Voltage polarity & & $+/-$ \\
Electrode distance & {$[\mathrm{mm}]$} & $7 / 18$ \\
Electrode curvature radius & {$[\mathrm{mm}]$} & $0.9 / 6 / 15.5$ \\
Electrodes axis orientation & & horizontal / vertical \\
Ice surface uniformity & & with / without artificial air gap \\
Cooling temperature & {$\left[{ }^{\circ} \mathrm{C}\right]$} & $-2 /-12 /-25$ \\
Ice accumulation process & & freezing / atmospheric \\
Electric field during cooling & & with / without \\
\hline
\end{tabular}




\subsubsection{Freezing Water Conductivity}

The range of conductivity was chosen in accordance with values observed on natural icing sites [15] [39]. These studies revealed that different compounds contribute to the conductivity of atmospheric precipitation. As the present investigation deals with the influence of the total electric conductivity of the ice samples, sodium chloride $(\mathrm{NaCl})$ was used only to adjust the conductivity of the freezing water. Previous investigations on the ac and dc flashover performance of the ice surface [33] and on flashover on ice-covered insulators [26] [27] used certain conductivity values. Therefore, it was judged useful to carry out the present studies with the same values. Due to the fact that the equipment for the conductivity measurements was different, other values were used for the first test series at UBC. All values for the freezing water conductivity are presented in Table 3-3.

Table 3-3: Chosen values of the freezing water conductivity

\begin{tabular}{|c|c|}
\hline Location of experimental set-up & $\begin{array}{c}\text { Freezing water } \\
\text { conductivity }\left[\times 10^{-4} \mathrm{~S} / \mathrm{m}\right]\end{array}$ \\
\hline UBC & $1.0 / 100 / 1000$ \\
UQAC & $2.5 / 30 / 80 / 160$ \\
\hline
\end{tabular}


As it is quite difficult to determine precisely the electric conductivity of ice, especially to differentiate between surface and bulk conduction, a common procedure in the laboratories of CIGELE/UQAC [24] [26] [27] [34] as well as in other research institutions [6] [53] [77] [96] [110] is to measure the freezing water conductivity before forming the ice samples. To obtain water with a certain conductivity, sodium chloride $(\mathrm{NaCl})$ is added to de-ionised water while its conductivity is constantly measured with a conductivity-meter type "Yokogawa SC82", until the desired value of conductivity was reached. With this method, it is ensured that the chosen value is obtained exactly, even if the conductivity of the de-ionised water changes or the salt used is of inconsistent quality.

As the electric conductivity of water changes with temperature, all the conductivity data are corrected for a temperature of $20^{\circ} \mathrm{C}$. Details on the correction procedure can be found in Appendix 10.

\subsubsection{Ice Temperature}

It was judged to be interesting to study the electrical phenomena for an ice temperature well below the melting point, and for a temperature of $0^{\circ} \mathrm{C}$, when the surface of the ice starts to melt. These two temperatures would simulate the two opposite conditions of dry and wet ice surfaces. They were already used in a preceding study on ac and dc flashover performance of the ice surface [33]. 
Furthermore, a third value was chosen as an intermediate temperature. Previous investigations in the field of ice physics reported that the ice surface changes its solid condition already at temperatures clearly below the melting point (see Section 2.2.3). Different values are given in the literature depending on the author (for example [40] [69] within the interval $-6^{\circ} \mathrm{C}<\mathrm{T}<-3^{\circ} \mathrm{C}$. For the present study, an temperature value $\mathrm{T}=-4^{\circ} \mathrm{C}$ was chosen.

The first test series, carried out at UBC, was done only under dry or wet ice surface conditions. The temperature value for dry ice surface differed from that used in the later test series at UQAC. Nevertheless, as both temperatures were located well below the melting point the difference was estimated to be nonsignificant for the discharge behaviour. Table 3-4 shows the values of the temperatures chosen for the tests.

Table 3-4: Chosen values for the ice temperature

\begin{tabular}{|c|c|c|}
\hline \multirow{2}{*}{ Surface Condition } & \multicolumn{2}{|c|}{ Ice Temperature $\left.{ }^{\circ} \mathrm{C}\right]$} \\
\cline { 2 - 3 } & UBC & UQAC \\
\hline dry surface & -20 & -12 \\
transitive surface & - & -4 \\
wet surface & 0 & 0 \\
\hline
\end{tabular}


Even for the highest value of freezing water conductivity, the percentage of $\mathrm{NaCl}$ in the water solution was very low so that the freezing temperature did not change observably (see Appendix 10 and phase diagram in Appendix 1). Therefore, it can be assumed that no water film exists on the ice surface at the chosen temperatures for the surface condition "dry ice surface". However, the particular characteristics of the uppermost molecular layers along the ice surface have to be kept in mind (see Section 2.2.3) [64] [74] [75] [112].

The temperature was measured with two different thermometers. The first thermometer is part of the "Envirotronics"- cold chamber. It is a digital meter with a resolution of $+/-0.1^{\circ} \mathrm{C}$. It measures the ambient air temperature in the upper section of the chamber. As the air was constantly circulated inside the chamber, the air temperature was considered to be constant throughout the whole volume of the cold chamber. A second digital thermometer was glued to the metal table, on which the ice samples where placed for the tests.

The models were placed in their final test position on the table inside the cold chamber about one hour before each test, to allow the temperature of the ice sample and surrounding air volume to reach a stable value. It was estimated that the heat exchange between the ice sample, the Plexiglas mould, and the metal table would be sufficient to equalise any temperature differences. Using this 
consideration, all temperature values given in this report may be regarded as "ice temperature".

\subsubsection{Voltage Waveform}

All experiments in the framework of this study were carried out using lightning impulse (LI) voltages (see Section 3.2.3). To reasons may justify this choice:

- The main reason for the decision to use $\mathrm{LI}$ voltage is the fact that the welldefined voltage peak value of the impulse is needed to trigger the ultra highspeed camera. Otherwise, ultra-high speed recordings become very difficult with today's available camera technologies, as very long optical delays (several hundreds of nanoseconds) would be necessary [56].

- As the duration of voltage application is very short for such a type of voltage impulse, no important melting processes are expected, which would alter the ice surface condition and influence the discharge processes.

As the transmission of electric energy in actual power networks is done using ac voltage and also dc voltage for very long distances, the question may be raised what value the experiments with $L I$ voltages would have. The interpretation of the experimental outcome has to be done carefully. However, the results may be useful under several viewpoints: 
- The breakdown behaviour under lightning impulse is an important parameter for insulation co-ordination. In some cases, power networks can work well under stationary conditions, whereas transient events and overcharges set off breakdown processes on insulators. In theses cases, impulses voltages are superposed to the stationary ac or dc voltage and the knowledge of their characteristics becomes very important.

- Until now, most flashover tests on ice-covered insulators were carried out using ac and dc voltages. If more tests on actual ice-covered insulators will be realised applying impulse voltage, then, results of fundamental studies such as this one can be compared to the data obtained on industrial insulators. The necessary HV infrastructure is now available at UQAC [23]; thus, this kind of comparison will be possible in the near future.

- Some data is available on the breakdown characteristics of ice surfaces under ac and dc voltages [33]. The comparison of these results and the measurements from the present study may enable some general conclusions for any voltage type.

\subsubsection{Voltage Polarity}

Due to the symmetrical electrode configuration of the test specimen, no polarity effect may be expected for voltage or current measurements. On the other hand, optical investigations may reveal distinct processes in the vicinity of the two 
electrodes as a function of the voltage polarity applied to the electrodes. Therefore, positive and negative lightning impulse voltages were used for the experiments.

\subsubsection{Electrode Distance}

The distances between the two electrodes were selected in accordance with preceding studies about surface discharges on synthetic surfaces [61] and in accordance with the study on ac and dc flashover performance of the ice surface [33]. Table 3-5 shows the different distances used.

Table 3-5: Chosen distances between the electrodes

\begin{tabular}{|c|c|}
\hline UBC & Electrode distance [mm] \\
\hline Optical ultra high-speed observations & 7 \\
\hline UQAC & \\
\hline Optical ultra high-speed observations & $7 / 18$ \\
Determination of 50\% breakdown voltage & 18 \\
Current waveform measurements & 18 \\
\hline
\end{tabular}




\subsubsection{Electrodes Curvature Radius}

For most of the tests, the electrodes curvature radius was also similar to previous studies on surface discharges [33] [61], which used electrodes with a curvature radius of $\mathrm{r}=6 \mathrm{~mm}$. The hemispherical electrodes were made from stainless steel. In the case that the electrode distance increases from $\mathrm{d}=7 \mathrm{~mm}$ to $\mathrm{d}=18 \mathrm{~mm}$, the ratio between distance and radius of the electrodes is changed. To keep this ratio constant, the electrode radius was increased in accordance to the increase in distance. Table 3-6 shows the values for the different cases.

Table 3-6: Electrode curvature radii

\begin{tabular}{|c|c|}
\hline Normal case & $\begin{array}{c}\text { Curvature radius } \\
{[\mathrm{mm}]}\end{array}$ \\
\hline $\begin{array}{c}18 \mathrm{~mm} \text { model with same electric } \\
\text { field as 7 mm model }\end{array}$ & 6 \\
\hline
\end{tabular}

\subsubsection{Electrode Axis Orientation}

The ice samples were placed inside the cold chamber with the ice surface in vertical position. For most of the experiments, the axis of the electrodes was aligned horizontally in parallel to the slit of the streak camera. As actual high 
voltage insulators are not only mounted horizontally, but also vertically, some tests were also carried out with vertically orientated electrode axis.

\subsubsection{Ice Surface Uniformity}

In order to simulate the non-uniform ice surface with a void of known dimensions at a defined location, a small air gap with a length of $\mathrm{g}=1.6 \mathrm{~mm}$ was introduced in the ice. This void was placed at different locations (Table 3-7) to investigate a possible influence of this parameter on the discharge development.

Table 3-7: Different locations of the artificial air gap

\begin{tabular}{|c|c|}
\hline Location of air gap & Distance from HV electrode $[\mathrm{mm}]$ \\
\hline at HV electrode & 0 \\
$1 / 3$ from HV electrode & 6 \\
in the middle of the electrodes & 9 \\
$2 / 3$ from HV electrode & 12 \\
at ground-electrode & 18 \\
\hline
\end{tabular}

\subsubsection{Cooling Rate}

In normal cases, the ice samples were formed by the conventional freezing method and no voltage was applied during cooling period. In one test series, the 
cooling rate was adjusted by changing the temperature during cooling period, which led to different cooling durations. The values for the three different cooling rates investigated can be found in Table 3-8. Once the ice was formed, the air temperature in the cold chamber was adjusted to $-12^{\circ} \mathrm{C}$ for overnight storage.

Table 3-8: Experimental parameters for different cooling rates

\begin{tabular}{|c|cc|}
\hline $\begin{array}{c}\text { Cooling } \\
\text { rate }\end{array}$ & $\begin{array}{c}\text { Temperature during cooling } \\
{[\mathrm{C} C]}\end{array}$ & $\begin{array}{c}\text { Duration of cooling } \\
{[\mathrm{h}]}\end{array}$ \\
\hline slow & -2 & 30 \\
normal & -12 & 6 \\
fast & -25 & 1 \\
\hline
\end{tabular}

\subsubsection{Ice Accumulation Process}

The parameters of the different ice accumulation processes are shown in Table 3-9. As the natural ice accretions on high voltage insulators are created by precipitation of either already iced particles or supercooled water droplets and not by the freezing of water, a test series was carried out with ice samples produced by artificial atmospheric ice, formed from supercooled water droplets. The description of the laboratory installations and procedures may be found in a paper on laboratory investigations on the flashover performance of ice-covered insulators [26]. 
Another difference of the ice accretion on actual high voltage insulators in comparison with the conventional ice formation of the physical models is the presence of an electric field during the ice accumulation (case of ice-covered insulators on an energised power line). Therefore, a few tests were carried out with high voltage applied to the ice samples during the cooling period. The voltage to be applied to the ice samples was chosen to be equivalent to the voltage stress on actual post insulators in the $735 \mathrm{kV}$ network of Hydro Québec, which ranges between $100 \times 10^{3} \mathrm{~V} / \mathrm{m}$ and $110 \times 10^{3} \mathrm{~V} / \mathrm{m}$ depending on the type of insulator [27] [29]. Thus, a voltage of $U_{\text {colling }}=2 \mathrm{kV}$ was applied to the $18-\mathrm{mm}$ model during cooling rate in the present case.

Table 3-9: Chosen ice accumulation processes

\begin{tabular}{|c|c|}
\hline Applied voltage & \multicolumn{1}{|c|}{ Ice formation process } \\
\hline without & - freezing method with different cooling rates \\
& - atmospheric ice accretion \\
with & - freezing method with normal cooling rate \\
\hline
\end{tabular}




\subsection{Test Procedures}

\subsubsection{Basic Principle of Streak Photography}

A streak photograph shows a continuous projection of one geometric dimension over an extremely short time interval. The objective of such an ultra high-speed camera has the form of a streak, therefore the name "streak camera". Figure 3-13 shows the orientation of the two dimensions for all streak images in this study.

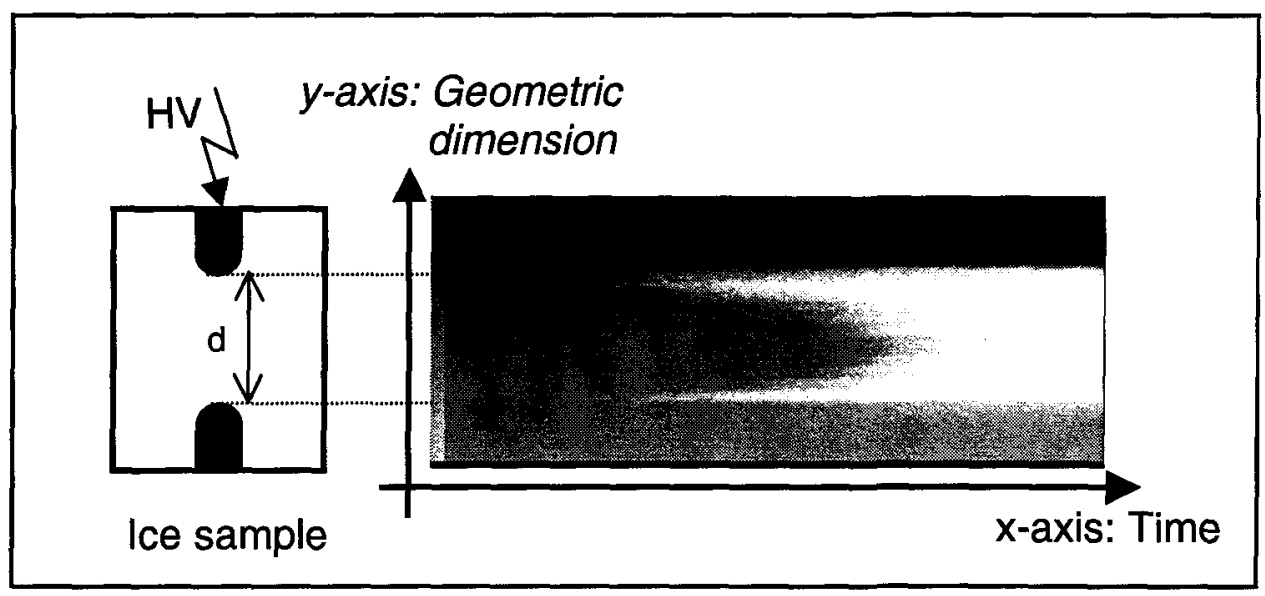

Fig. 3-13: Orientation of the streak photographs in this study

The advantage of a continuous observation of the physical processes has to be balanced with the disadvantage of only one geometric dimension. Thus, for unambiguous interpretation, the discharge has to follow a straight line. Some 
measures were mentioned earlier to ensure such a discharge behaviour without influencing the discharge process (Section 3.3.3).

\subsubsection{Interpretation of Streak Recordings}

Modern streak camera systems represent powerful tools to study the very fast processes of early surface discharge development. Recording, storage, and processing of the streak images are done by digital image processing in recent generations of these systems. This has several advantages, for example, immediate review of the image, no loss of material, and money in the case of insignificant photographs, and powerful image post-processing. However, the interpretation of the results has to be carried out very carefully, as the digital image processing can easily lead to misinterpretations. With the system used in this study, the analysis of the light intensities is limited as this data got lost during the digital image processing.

The streak camera produces an artificially coloured image, which is stored on the control computer in a camera-specific format. To export the image, it is transformed into a "tif-type" file, in which the information on colour is lost. This black-and-white image is then transferred to another computer, where it was processed with different software packages. For the present study, MS-Photoeditor (version 3.0) and Adobe PhotoShop (version 5.0) were used in most cases. The 
example in Fig. 3-14 shows very clearly that the appearance of the image may change totally by the use of image processing. In the case of decreased brightness (Fig. 3-14c), the colours of the streak photograph representing relative intensities change totally in comparison with an image with increased brightness (Fig. 3-14b) and the first weak light emissions get lost. In conclusion, all following discussions and analyses will be limited to relative comparisons of light intensities inside one captured image. By studying in particular the front of the emitted light, initiation and development of the visible discharge phenomena can be analysed.

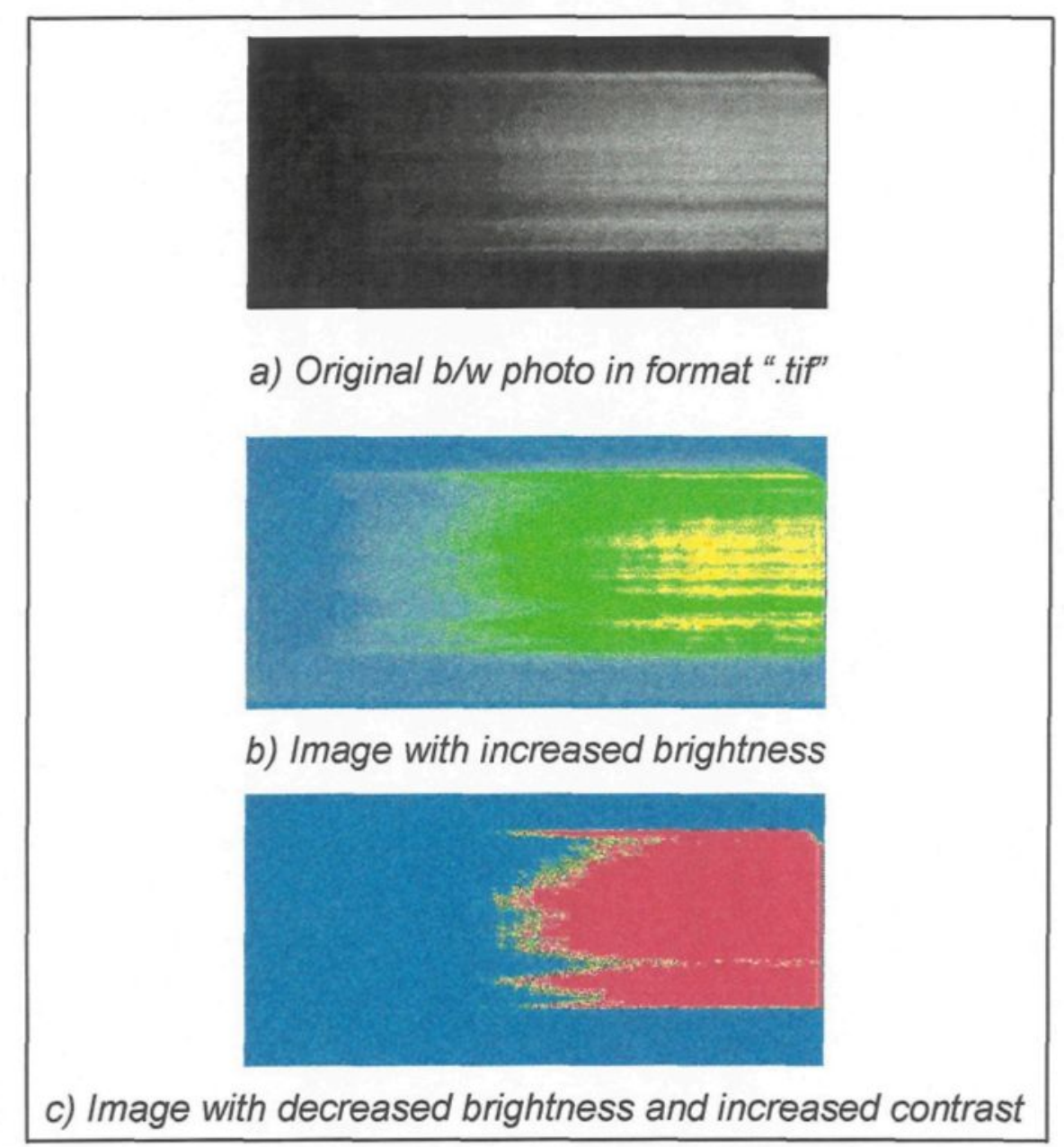

Fig. 3-14: Processed versions of a streak recording 
The velocity of discharge propagation along the ice surface can be calculated with the knowledge of the values for time to breakdown and the geometric distances. The distances on the streak recordings are determined by the means of corresponding focus-recordings, which show a still photograph of the electrode configuration at the beginning of each experiment. In order to calculate the propagation velocity, the distance that the discharge newly covers during each $3 \mathrm{~ns}$ interval is measured. The value for the time interval is chosen by considering the accuracy of the streak camera for a sweep period $t_{\text {sweep }}=50 \mathrm{~ns}$ (see Table 3-11).

\subsubsection{Definition of the Instant of Breakdown on the Streak Recordings}

In general, it was intended to obtain a streak recording showing total darkness at the left border (blue in the coloured images) and total illumination of the space between the electrodes at the right border (yellow or red in the coloured images). Neglecting the oscillations, which could sometimes be observed in the streak recordings (see Section 3.6.5), the instant of breakdown was identified as the moment, when the total space between the electrodes was filled with light for the first time. Figure 3-15 illustrates this definition for streak recording using the 7-mm model. 


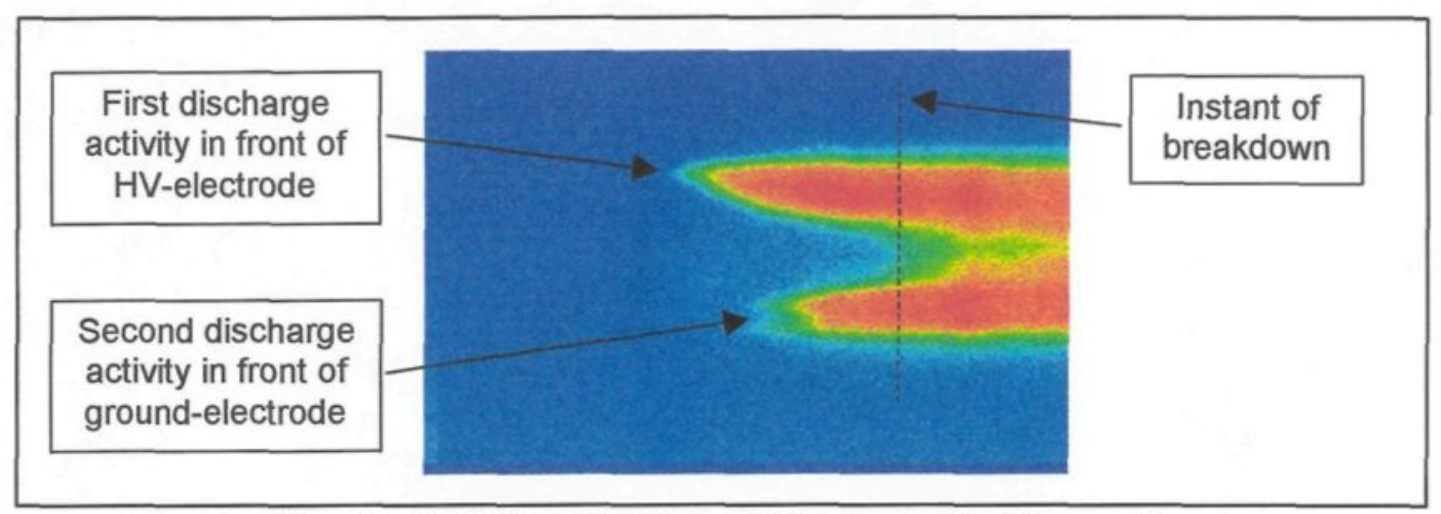

Fig. 3-15: Determination of the instant of breakdown

During the streak recordings, the sensitivity of the camera was adjusted so that the light emitted would not damage the camera at the moment of breakdown. This adjustment produced, on the other hand, the effect that pre-discharge phenomena with very weak light emissions might not be seen on the recordings. This disadvantage had to be accepted to prevent any damage or destruction of the fragile ultra high-speed camera. At this point, it is reminded that all results and discussions in the following chapters deal with the "visible" discharge phenomena under the experimental conditions explained.

\subsubsection{Determination of $\mathbf{5 0} \%$ Lightning Impulse Breakdown Voltage}

The $50 \%$ lightning impulse breakdown voltage was determined according to IEC-507 [51] and IEC-60-2 [50]. The up-and-down method was used to perform the experiments with steps of about $10 \%$ of the supposed critical breakdown voltage. 
For each test series, at least 10 useful tests were carried out. If the experiment resulted in breakdown, the test voltage was reduced one step. After a withstand test, the voltage was increased one step. After each voltage application, regardless of the result, breakdown or withstand, the ice specimen was replaced to ensure that only one voltage impulse was applied to each ice sample. The calculation of the $50 \%$ breakdown voltage was based on 10 experimental results. The first "useful" result was encountered when the outcome of the experiment did change (from withstand to breakdown or vice versa). This result and the nine following were considered for the calculation. The $50 \%$ lightning impulse breakdown voltage was determined by calculating the mean value with equation e3-4.

$$
U_{50 \%}=\sum \frac{n_{i} \cdot U_{i}}{N}
$$

$$
\begin{array}{ll}
U_{i} \quad \text { peak value of applied impulse voltage } \\
n_{i} \quad \text { Number of tests with the same voltage value } \\
\mathrm{N} \quad \text { Number of useful tests }
\end{array}
$$

\subsubsection{Interpretation of Current Waveforms}

The measurement of the leakage currents and current peaks in the case of breakdown under high voltage and for the very fast events like lightning impulses presents a complex technical task. The main aspect of the present study is the ultra high-speed observation of the first visible discharge phenomenon. In addition, electrical measurements were made to provide more data in addition to the 
photographic investigations. Figure 3-16 shows a typical example for such a waveform recording. A vertical dotted line marks the moment of breakdown. Voltage was recorded on channel 1, and current on channel 2. The scales for both channels are given below the graph (adjustment of channel 1: 3V/div, channel 2: $100 \mathrm{mV} / \mathrm{div})$. In most of the following figures, the axes are labelled in correspondence to these adjustments (Fig. 3-17).

Several impulses could be detected on the current waveform as shown in Fig. 3-17. The first impulse, so-called "dielectric displacement current", $I_{d d c}$, is observed in all cases. The electrode configuration has a certain parasitic capacitance. It may be seen as a small capacitor, which is charged when voltage is applied. The current impulse represents this charging current. It is related to the electrode configuration and not to the ice surface, therefore, it will not be considered in the following discussion and analysis of the results. However, this decision is no conclusion that partial discharge activity may not happen at this moment on the ice surface, but any weak current impulse will be covered by the dielectric displacement current. For further studies, it would be necessary to work with a differential measuring circuit (see Section 7.2).

The second event, which is called "pre-discharge current impulse", $I_{\text {pdi }}$, in this report, was observed in a few current recordings. It took place clearly before the beginning of the breakdown process, while no voltage decline could be detected. 
Therefore, it is associated with a partial discharge activity, which may produce free charges and may lead to a surface charge accumulation on dry ice surfaces, without initiating the final breakdown.

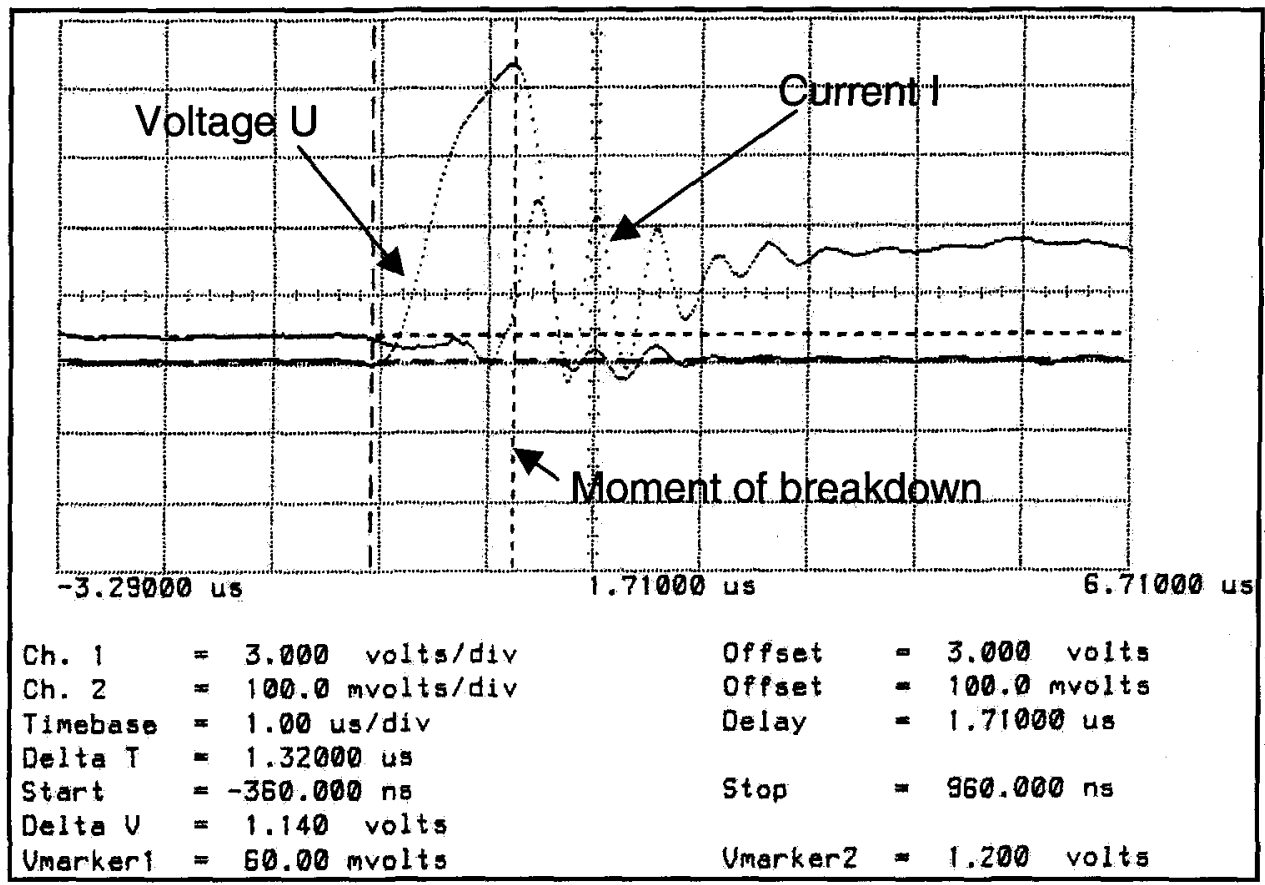

Fig. 3-16: Typical waveform recording for voltage and current

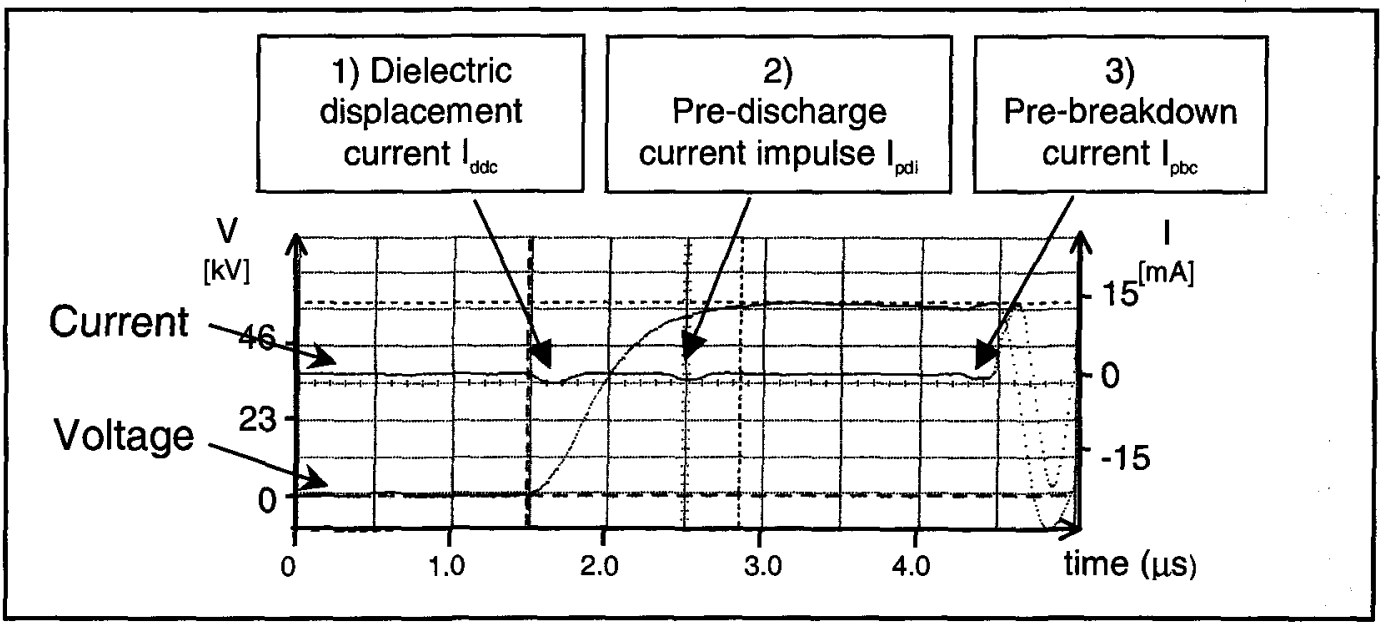

Fig. 3-17: Observed impulses on the current waveform recordings 
Finally, a third current event could be observed in all waveform measurements, which happened immediately before breakdown. Thus, it is called "pre-breakdown current", $I_{p b c}$. This current changed slightly as a function of certain experimental parameters and will be object of the discussion in Section 6.

The experiments showed that the experimental set-up for current measurements was not free of reflections and the HV circuit had some parasitic impedances and capacitances. In addition, the measured values for the current were not very high due to the means of protection for the oscilloscope. Thus, the analysis of the results has to be made carefully. As already mentioned in relation to light intensities of the discharge phenomena in the streak recordings, the interpretation of the current measurements will be limited to the study of waveform shapes and to relative comparisons of the current values.

\subsection{Error Discussions}

\subsubsection{Accuracy in the Determination of $50 \%$ Breakdown Voltage}

As no international standard exists yet prescribing the determination of any critical breakdown voltage on ice surfaces, the international standard IEC 507 for 
artificial pollution tests on high voltage insulators [51] was applied to obtain the $50 \%$ lightning impulse breakdown voltages. The choice of the voltage step was affected by the control of the available high voltage generator. Each step of $5 \mathrm{~V}$ of the regulated voltage corresponds to a step of $2.5 \mathrm{kV}$ of the peak value of the high voltage impulse. IEC 507 stipulates a step of about $10 \%$ of the estimated $50 \%$ breakdown voltage. Under certain experimental conditions, the results dropped below $25 \mathrm{kV}$, though the voltage step exceeds $10 \%$ for these cases. Standard deviation, $\mathrm{s}$, is given for all results in order to estimate the exactitude of the statistical mean value.

\subsubsection{Temperature Characteristics of Current Shunt}

The value of the current shunt was measured at ambient temperature, whereas during the experiments, the shunt was placed in the cold chamber near to the test sample. Therefore, the change of resistance value with temperature has to be considered. As an average value derived from data of different manufacturers, a temperature dependence of $1000 \mathrm{ppm} /{ }^{\circ} \mathrm{C}$ can be assumed for a carbon resistance. For a difference between temperature at measurement $\left(25^{\circ} \mathrm{C}\right)$ and test temperature (varying between $-12^{\circ} \mathrm{C}$ and $0^{\circ} \mathrm{C}$ ), a worst-case estimation can be done for a value of $37 \mathrm{~K}$. In this case, the reduction of the resistance amounts to $-3.7 \%$, thus, the value of current shunt no. 1 (small shunt with $R_{25}{ }^{\circ}=1.45 \Omega$ ) at $T=-12^{\circ} \mathrm{C}$ changes to $R_{-12}{ }^{\circ}=1,4 \Omega$. 


\subsubsection{Time Resolution of Digitising Oscilloscope}

The used digitising oscilloscope automatically adjusts its sampling rate. The maximum value is $1 \mathrm{GSa} / \mathrm{s}$, but for measurements with a deflection rate higher than $50 \mathrm{~ns} / \mathrm{div}$, the digitising rate decreases proportionally with an increase in deflection rate. Also, the time resolution accuracy decreases with an increasing deflection rate, as the time interval between two sample points gets longer. Table 3-10 shows these time intervals for different deflections rates, which were chosen for most of the experiments. It can be observed that they correspond to $2 \%$ of the deflection factor.

Table 3-10: Accuracy of time resolution of digitising oscilloscope

\begin{tabular}{|c|cc|}
\hline $\begin{array}{c}\text { Adjusted } \\
\text { deflection factor } \\
\text { [time/div.] }\end{array}$ & $\begin{array}{c}\text { Digitising rate } \\
{[\mathrm{MSa} / \mathrm{s}]}\end{array}$ & $\begin{array}{c}\text { Time interval between } \\
\text { two sample points } \\
\text { [ns] }\end{array}$ \\
\hline $200 \mathrm{~ns}$ & 250 & 4 \\
$500 \mathrm{~ns}$ & 100 & 10 \\
$1 \mu \mathrm{s}$ & 50 & 20 \\
\hline
\end{tabular}

\subsubsection{Time Resolution of the Streak Camera}

The time resolution of the streak camera is limited as the slit of the streak camera has a certain width. The phosphor screen size is $15 \mathrm{~mm}$. In most of the 
experiments, a slit width of 0.5 to $1 \mathrm{~mm}$ was chosen. For a slit width of $0.5 \mathrm{~mm}$, the time resolution is limited to $3.3 \%$ of the chosen sweep period, for example, for a sweep period of $50 \mathrm{~ns}$, the time resolution is limited to $1.7 \mathrm{~ns}$. With increasing slit width, the limit of time resolution is increasing. Thus, only results above this limit can be treated and an uncertainty in all derived time values and propagation velocities of $3.3 \%$ of the chosen total sweep period has to be considered. Table 311 shows the percentages of uncertainty as a function of the slit width.

Table 3-11: Accuracy of time resolution of streak recordings as a function of slit width

\begin{tabular}{|c|cc|}
\hline $\begin{array}{c}\text { Slit width } \\
{[\mathrm{mm}]}\end{array}$ & $\begin{array}{c}\text { Sweep period } \\
{[\mathrm{ns}]}\end{array}$ & $\begin{array}{c}\text { Time resolution accuracy } \\
{[\mathrm{ns}]}\end{array}$ \\
\hline 0.5 & 50 & $+/-1.7$ \\
& 200 & $+/-6.6$ \\
1 & 50 & $+/-3.3$ \\
& 200 & $+/-13.2$ \\
\hline
\end{tabular}

\subsubsection{Oscillations in the Streak Recordings}

On a number of streak recordings, oscillations of the light intensity could be observed (for example Fig. 5-14c, Fig. 5-31b, and others). They occurred only in the time-axis dimension, and not in spatial-axis dimension. In most cases, this phenomenon became visible when the space between the two electrodes is totally 
filled with light (after breakdown occurred). It was also recorded for surface discharges along various synthetic insulators (Fig. 5-3) and for air gap discharges (Fig. 5-1). In the last case, time to breakdown is much longer and the oscillations can already be seen before final breakdown. At several moments during the experimental phases, questions about the origins and meaning of these oscillations were raised. In the following paragraphs, this phenomenon is discussed and different hypotheses for its explication are proposed.

The oscillations were observed for all kinds of different surface materials: Synthetic spacer, ice samples, and also for experiments with air gaps. The oscillations were observed at two different laboratory locations (UBC and UQAC) on two different experimental set-ups. They appeared to be the same for both setups. No influence by any of the experimental parameters (freezing water conductivity, temperature, electrode distance etc.) could be identified. The only parameter, which apparently influenced the oscillations, was the adjusted sweep period of the streak camera. For a sweep period of $200 \mathrm{~ns}$, about 40 cycles could be counted in a recording, whereas, a recording with a sweep period of $50 \mathrm{~ns}$ showed about 10 cycles. Thus, it may be concluded that the oscillation has a period of $5 \mathrm{~ns}$. Considering the fact that the oscillations are independent of any experimental parameters, it may be concluded that they are related to the process of image acquisition and processing in the camera. As the camera was placed near the high voltage generator and the test object, electromagnetic influences cannot 
be excluded. The housing of the camera does not present an ideal screen, neither do the Faraday-cage of the high-voltage area (see Fig. 3-3). The inside and outside walls of the climate chamber, where the test object is placed, are metallic, and may give a relatively good screening effect. Nevertheless, the window in the front door and the rubber sealing around the door may restrict the screening effect of the door.

In order to get more information on the theory that the camera could be the possible source of these oscillations, the company was consulted for further information. Two points can be retained from this contact [16]:

- The oscillations may results from electromagnetic noise applied to the streak sweep electrode.

- On the other hand, the company estimates that streak sweep circuitry should be immune to such high frequency electromagnetic noise (about $200 \mathrm{MHz}$ ).

Thus, no definite answer could be found on whether the camera would be the source of the oscillation or not. Therefore, several theories were developed in order to explain the oscillations, but in the most cases, reasons contradicting these theories came up immediately. Nevertheless, these various theories will be presented in what follows. 
Light needs a time period of $3 \mathrm{~ns}$ to cover one meter. Thus, during a period of $5 \mathrm{~ns}$, light could pass a distance of somewhat less than $2 \mathrm{~m}$. Regarding the second experimental set-up at UQAC, it can be stated that the distance between test specimen and camera is somewhat less than 1 meter. The inside wall is a transparent aluminium plate. It is located at a distance of about $50 \mathrm{~cm}$ from the model. Thus, light may be emitted from a discharge activity towards the back of the chamber and then reflected. It has to cover about twice the distance between the model and the back wall. This could create a second light event, leading to a positive interference with an increase in light intensity on the streak recordings. Nevertheless, this theory would explain a single oscillation, but not a repetitive phenomenon, as observed. Furthermore, the experiments at UBC showed the same oscillations, but the climate chamber at that laboratory was significantly smaller. Finally, similar oscillations were also observed for experiments with an air gap in another experimental chamber where reflection could not happen. Thus, it was concluded that the theory of reflections on the back wall could not be the reason for this phenomenon.

Another theory is based on a remark concerning observations of increase in light intensity during the processes of pre-breakdown discharges at the moment when a streamer reaches the opposite electrode [60]. The theory to explain these oscillations would be based on the assumption that a shockwave travels forward and backward between the two electrodes. However, the frequency of the 
oscillations should change for a change of the electrode distance, d, but no indications of any influence of electrode distance on the oscillations were found on the streak recordings. Furthermore, a longitudinal shockwave in the discharge path should result in changing light intensity in the spatial dimension (vertical axis of the streak images), but the oscillations were actually found on the time dimension along the horizontal axis of the photographs. Therefore, this theory was also discarded.

At one occasion during a test series with the streak camera, the switch for the gate mode was accidentally adjusted to a wrong position. Instead of choosing the adjustment "streak trigger" creating the sweeping movement on the streak recording, the switch was put into "focus position", which meant that no movement was created and the same vertical line was focused during the whole recording. Thereby, a still photograph of the discharge phenomenon would be recorded (Fig. 3-18). This function is used before each new experimental series to focus the camera on the test object. Theoretically, the images obtained by accident in the experiment with the incorrect gate adjustment should only show a narrow light in the middle with a width depending on the adjusted width of the slit of the streak camera objective. Actually, the recordings do not correspond to this expectation, which can be seen in Fig. 3-19. They clearly show some light phenomena at the right side of the streak. As in the focus mode, only light in the centre of the image 
(see Fig. 3-18) can be recorded, it is concluded that these phenomena do not represent a real light emission, but are created artificially by the camera.

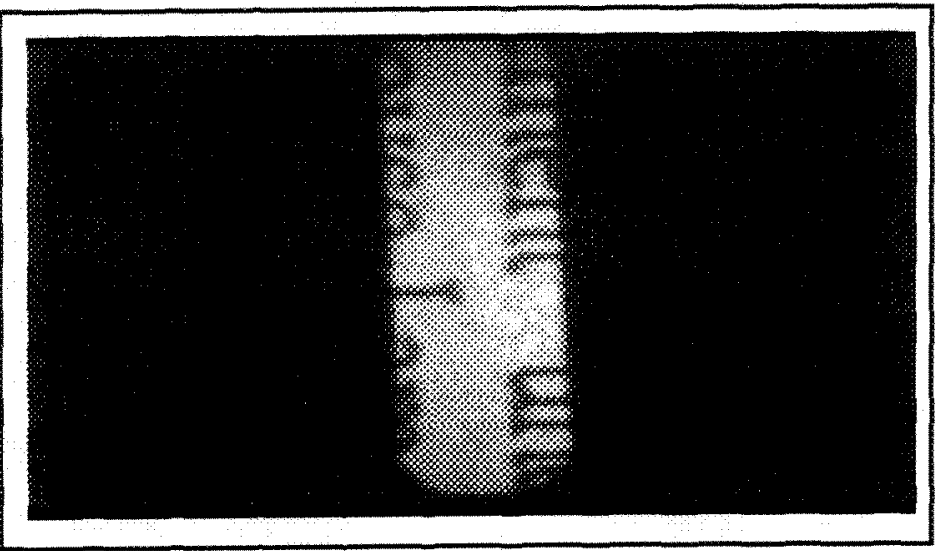

Fig. 3-18: Focus image recorded with the streak camera (showing two lines of a newspaper in this example)

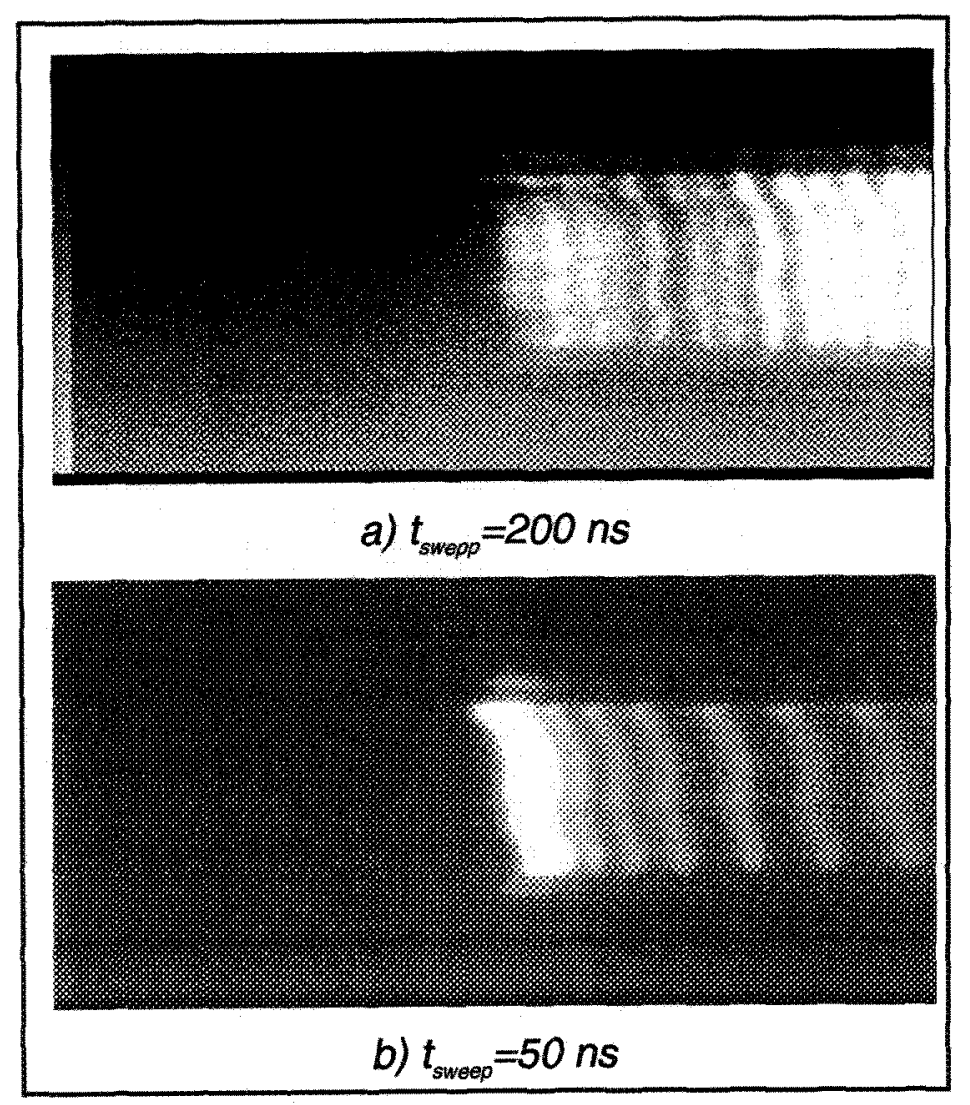

Fig. 3-19: Recordings with streak camera accidentally adjusted to focus mode 
In another research institution, oscillations in ultra high-speed recordings have been detected in a different context [18]. After several tests, it was found that these oscillations were created by electromagnetic interference of the high voltage generator to the high-speed camera [19]. As already mentioned earlier, strong electric fields and important gradients of voltage and current exist, especially for applications with high voltage impulse generators. They may cause interference, which are able to bypass protective devices like grounding screens, if these are not totally ideal. Such severe conditions were identified in the actual experimental setup. Considering the previous discussions, it is concluded at the present moment that the oscillations observed may be related to the processes of image acquisition and processing inside the camera. 


\section{CHAPTER 4}

\section{STUDY OF CRITICAL BREAKDOWN VOLTAGES}




\section{CHAPTER 4}

\section{STUDY OF CRITICAL BREAKDOWN VOLTAGES}

\subsection{Introduction to Chapter 4}

The determination of the critical breakdown voltages of ice surfaces under different conditions was the initial object of the experimental work, in order to determine applied voltage values for optical investigations with the ultra high-speed cameras. Furthermore, several parameters influencing the breakdown voltages could be analysed. Measurements were carried out using the up-and-down method according to IEC 507 [51]. The electrode distance was $\mathrm{d}=18 \mathrm{~mm}$ in these experiments, and the electrode axis was placed horizontally (with exception of results presented in Tables 4-5 and 4-6).

In Section 4.2, the results are presented in Tables 4-1 to 4-10, showing the $50 \%$ lightning impulse breakdown voltage, $\mathrm{U}_{50 \%}$, and the standard deviation, $\mathrm{s}$. In 
addition, several still photographs of ice surfaces are shown to provide information on ice morphology under different experimental parameters.

Afterwards, the effects of various experimental parameters on the ice surface breakdown are analysed in Section 4.3. The following parameters were investigated:

- Surface material

- Freezing water conductivity

- Ice temperature

- Voltage polarity

- Voltage waveform

- Electrode curvature radius

- Electrode axis orientation

- Ice surface uniformity

- Cooling rate

- Ice accumulation process 


\subsection{Experimental Results}

\subsection{1 $U_{50 \%}$ Values}

First, the experimental results for the $U_{50 \%}$ values are presented as a function of the freezing water conductivity, $\sigma$, in Tables 4-1 to 4-3. Each table represents an experimental series for a given temperature, T. All tables show the results for both voltage polarities.

Table 4-1: $50 \%$ lightning impulse breakdown voltage as a function of freezing water conductivity, $\sigma$, for ice surfaces without artificial air gap ( $T=-12^{\circ} \mathrm{C} ; d=18 \mathrm{~mm} ; \mathrm{r}=6 \mathrm{~mm}$; orient.=hor.)

\begin{tabular}{|c|rrrr|}
\hline$\sigma\left[\times 10^{4} \mathrm{~S} / \mathrm{m}\right]$ & 2.5 & 30 & 80 & 160 \\
\hline$+U_{5003}[\mathrm{kV}]$ & 43.7 & 41.9 & 32.6 & 25.8 \\
$s[\mathrm{kV}]$ & 2.2 & 2.8 & 1.5 & 2.4 \\
& & & & \\
$-U_{5035}[\mathrm{kV}]$ & 46.7 & 39.6 & 28.3 & 22.8 \\
$s[\mathrm{kV}]$ & 2.2 & 4.7 & 1.7 & 2.5 \\
\hline
\end{tabular}


Table 4-2: 50 \% lightning impulse breakdown voltage as a function of freezing water conductivity, $\sigma$, for ice surfaces without artificial air gap

( $T=-4^{\circ} \mathrm{C} ; d=18 \mathrm{~mm} ; \mathrm{r}=6 \mathrm{~mm}$; orient.=hor.)

\begin{tabular}{|c|rrrr|}
\hline$\sigma\left[\times 10^{4} \mathrm{~S} / \mathrm{m}\right]$ & 2.5 & 30 & 80 & 160 \\
\hline$+U_{50 \%}[\mathrm{kV}]$ & 37.7 & 24.8 & 20.8 & 16.5 \\
$s[\mathrm{kV}]$ & 2.8 & 2.4 & 1.8 & 3.1 \\
& & & & \\
$-U_{50 \%}[\mathrm{kV}]$ & 44.3 & 29.8 & 19.8 & 19.7 \\
$s[\mathrm{kV}]$ & 2.2 & 1.8 & 1.8 & 3.1 \\
\hline
\end{tabular}

Table 4-3: 50 \% lightning impulse breakdown voltage as a function of freezing water conductivity, $\sigma$, for ice surfaces without artificial air gap

( $T=0^{\circ} \mathrm{C} ; \mathrm{d}=18 \mathrm{~mm} ; \mathrm{r}=6 \mathrm{~mm}$; orient.=hor.)

\begin{tabular}{|c|rrrr|}
\hline$\sigma\left[\times 10^{4} \mathrm{~S} / \mathrm{m}\right]$ & 2.5 & 30 & 80 & 160 \\
\hline$+U_{50 \%}[\mathrm{kV}]$ & 41.9 & 24.3 & 22.3 & 17.1 \\
$s[\mathrm{kV}]$ & 2.8 & 2.4 & 1.8 & 2.1 \\
& & & & \\
$-U_{50 \%}[\mathrm{kV}]$ & 43.1 & 27.3 & 21.8 & 19.2 \\
$s[\mathrm{kV}]$ & 2.8 & 1.8 & 2.4 & 2.5 \\
\hline
\end{tabular}

Next, the $U_{50 \%}$ results for the breakdown voltages as a function of the electrode curvature radius, $r$, are presented in Table 4-4. Table 4-5 shows the $U_{50 \%}$ results for variation of the electrode axis orientation. While the axis was oriented either horizontally or vertically, the surface of the ice was always kept on a vertical 
plane. The results for temperature variation, while keeping the electrode axis with vertical orientation, are presented in Table 4-6.

Table 4-4: $50 \%$ lightning impulse breakdown voltages as a function of electrode curvature radius, $r$, for different temperatures, $T$, and for ice surfaces without artificial air gap $\left(\sigma=30 \times 10^{4} \mathrm{~S} / \mathrm{m} ; d=18 \mathrm{~mm}\right.$; orient.=hor.)

\begin{tabular}{|c|rrrrrr|}
\hline$\left.T l^{\circ} \mathrm{C}\right]$ & \multicolumn{2}{|c}{-12} & \multicolumn{2}{c}{-4} & \multicolumn{2}{c|}{0} \\
\hline$r(\mathrm{~mm})$ & 6 & 15.5 & 6 & 15.5 & 6 & 15.5 \\
\hline$+U_{50 \%}[\mathrm{kV}]$ & 41.9 & 54.4 & 24.8 & 48.3 & 24.3 & 49.4 \\
$s[\mathrm{kV}]$ & 2.8 & 2.6 & 2.4 & 3.1 & 2.4 & 2.7 \\
& & & & & & \\
$-U_{50 \%}[\mathrm{kV}]$ & 39.6 & 52.1 & 29.8 & 45.9 & 27.3 & 45.8 \\
$s[\mathrm{kV}]$ & 4.7 & 2.7 & 1.8 & 2.8 & 1.8 & 4.2 \\
\hline
\end{tabular}

Table 4-5: 50 \% lightning impulse breakdown voltage as a function of electrode axis orientation $\left(\sigma=80 \times 10^{4} \mathrm{~S} / \mathrm{m} ; T=0^{\circ} \mathrm{C} ;\right.$ pol.=pos.; $\left.d=18 \mathrm{~mm}, r=6 \mathrm{~mm}\right)$

\begin{tabular}{|c|cc|}
\hline $\begin{array}{l}\text { Electrode axis } \\
\text { orientation }\end{array}$ & horizontal & vertical \\
\hline$+U_{50 \%}[\mathrm{kV}]$ & 22.3 & 22.3 \\
$s[\mathrm{kV}]$ & 1.8 & 2.5 \\
\hline
\end{tabular}


Table 4-6: $50 \%$ lightning impulse breakdown voltage as a function of temperature, $T$, for vertical electrode axis orientation $\left(\sigma=80 \times 10^{4} \mathrm{~S} / \mathrm{m} ;\right.$ pol.=pos.; $d=18 \mathrm{~mm} ; r=6 \mathrm{~mm}$; orient.=ver. $)$

\begin{tabular}{|c|rc|}
\hline$\left.T l^{\circ} \mathrm{C}\right]$ & -4 & 0 \\
\hline$+U_{50 \%}[\mathrm{kV}]$ & 24.3 & 22.3 \\
$s[\mathrm{kV}]$ & 3.3 & 2.5 \\
\hline
\end{tabular}

The critical breakdown voltage values, $\mathrm{U}_{50 \%}$, were also determined as a function of ice uniformity. A small air gap with a length of $\mathrm{g}=1.6 \mathrm{~mm}$ was introduced into the ice to simulate non-uniformity. Tables 4-7 and 4-8 show these results.

Table 4-7: 50 \% lightning impulse breakdown voltage as a function of ice surface condition ( $\sigma=30 \times 10^{4} \mathrm{~S} / \mathrm{m} ; \mathrm{T}=-12^{\circ} \mathrm{C}$; $d=18 \mathrm{~mm} ; \mathrm{r}=6 \mathrm{~mm}$; orient.=hor.)

\begin{tabular}{|c|ccc|}
\hline $\begin{array}{c}\text { Ice surface } \\
\text { condition }\end{array}$ & $\begin{array}{c}\text { no gap } \\
\text { gap in middle } \\
\text { of electrodes }\end{array}$ & $\begin{array}{c}\text { gap at } \\
\text { HV electrode }\end{array}$ \\
\hline$+U_{50 \%}[\mathrm{kV}]$ & 41.9 & 38.9 & 30.1 \\
$s[\mathrm{kV}]$ & 2.8 & 2.2 & 2.2 \\
& & & \\
$-U_{50 \%}[\mathrm{kV}]$ & 39.6 & 39.8 & 38.0 \\
$s[\mathrm{kV}]$ & 4.7 & 2.0 & 2.5 \\
\hline
\end{tabular}


Table 4-8: $50 \%$ lightning impulse breakdown voltage as a function of ice surface condition ( $\sigma=30 \times 10^{-4} \mathrm{~S} / \mathrm{m} ; T=0^{\circ} \mathrm{C} ; d=18 \mathrm{~mm} ; \mathrm{r}=6 \mathrm{~mm}$; orient.=hor.)

\begin{tabular}{|c|ccc|}
\hline $\begin{array}{c}\text { Ice surface } \\
\text { condition }\end{array}$ & $\begin{array}{c}\text { no gap } \\
\text { gap in middle } \\
\text { of electrodes }\end{array}$ & $\begin{array}{c}\text { gap at } \\
\text { HV electrode }\end{array}$ \\
\hline$+U_{50 \% \%}[\mathrm{kV}]$ & 24.3 & 33.6 & 30.7 \\
$s[\mathrm{kV}]$ & 2.4 & 2.6 & 2.6 \\
& & & \\
$-U_{50 \%}[\mathrm{kV}]$ & 27.3 & 37.0 & 37.6 \\
$s[\mathrm{kV}]$ & 1.8 & 2.0 & 1.9 \\
\hline
\end{tabular}

The ice formation method was changed in another experimental series. Table 4-9 shows the results for the critical breakdown voltage, $U_{50 \%}$, as a function of the cooling rate, whereas, in Table 4-10, atmospheric ice formation and freezing ice formation with applied voltage are compared to the normal freezing process.

Table 4-9: $50 \%$ lightning impulse breakdown voltage as a function of cooling rate $\left(\sigma=30 \times 10^{-4} \mathrm{~S} / \mathrm{m} ; \mathrm{T}=-12^{\circ} \mathrm{C} ;\right.$ pol. $=$ pos.; $d=18 \mathrm{~mm} ; \mathrm{r}=6 \mathrm{~mm}$; orient.=hor.)

\begin{tabular}{|c|ccc|}
\hline Cooling rate & slow & normal & fast \\
\hline Cooling period $[\mathrm{h}]$ & \multicolumn{1}{|c}{30} & \multicolumn{1}{c|}{6} & 1 \\
\hline$+U_{50 \%}[\mathrm{kV}]$ & 31.3 & 41.9 & 47.3 \\
$s[\mathrm{kV}]$ & 2.7 & 2.8 & 2.2 \\
\hline
\end{tabular}


Table 4-10: $50 \%$ lightning impulse breakdown voltage as a function of ice accumulation process

$$
\left(\sigma=30 \times 10^{-4} \mathrm{~S} / \mathrm{m} ; \mathrm{T}=-12^{\circ} \mathrm{C} ; \text { pol.=pos.; } d=18 \mathrm{~mm} ; \mathrm{r}=6 \mathrm{~mm}\right. \text {; orient.=hor.) }
$$

\begin{tabular}{|c|c|c|c|}
\hline \multirow{2}{*}{$\begin{array}{c}\text { Ice accumulation } \\
\text { process }\end{array}$} & \multicolumn{2}{|c|}{ Normal freezing } & \multirow{2}{*}{$\begin{array}{l}\text { Atmospheric ice } \\
\text { accumulation }\end{array}$} \\
\hline & without electric field & with electric field & \\
\hline$+U_{50 \% \%}[k V]$ & 41.9 & 32.8 & 38 \\
\hline$s[\mathrm{kV}]$ & 2.8 & 3.0 & - \\
\hline
\end{tabular}

\subsubsection{Surface Photographs}

Changes in ice accumulation parameters resulted in changes of the ice morphology. Still photographs of the ice surface were taken to analyse the ice structure. An enlarged horizontal view on the region between the two electrodes is shown with the HV electrode on the top and the ground electrode on the bottom of the images (The still photograph of the whole ice sample for slow cooling rate was already presented in Fig. 3-9. In this case, the HV electrode was placed on the left side). Figure 4-1 presents the surface still photographs as a function of the cooling rate. Figure 4-2 shows the appearance of the ice samples for two different ice accumulation processes (atmospheric ice accretion and normal freezing with applied electric field). 


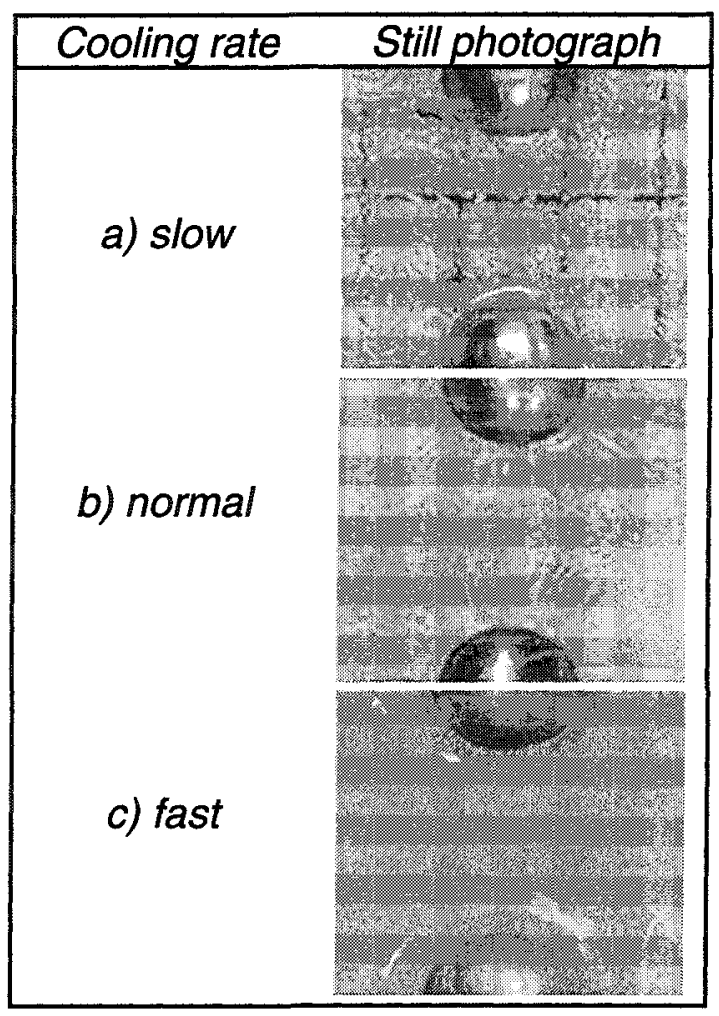

Fig. 4-1: Surface still photographs as a function of cooling rate $\left(\sigma=30 \times 10^{4} \mathrm{~S} / \mathrm{m} ; T=-12^{\circ} \mathrm{C}\right.$; pol.=pos.; $d=18 \mathrm{~mm} ; r=6 \mathrm{~mm}$; orient.=hor.)

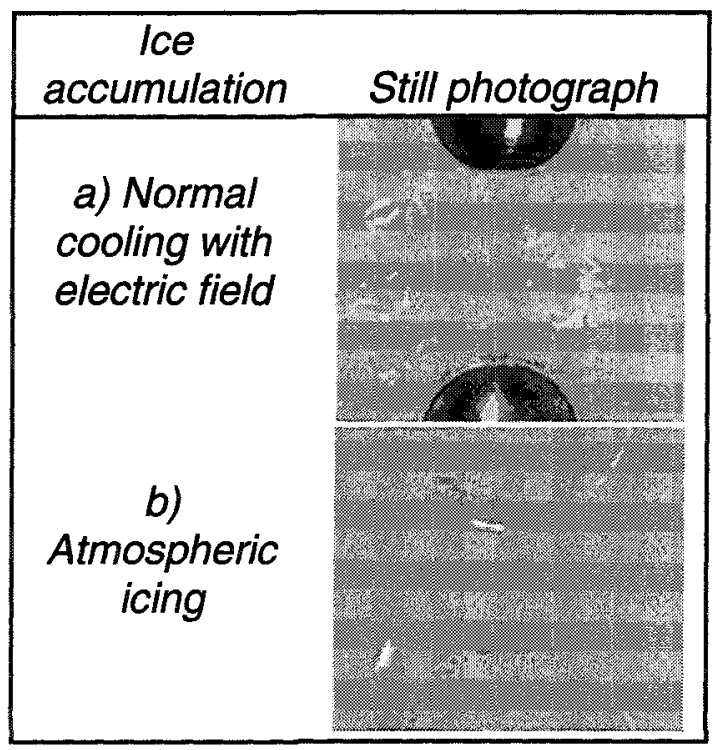

Fig. 4-2: Surface still photographs as a function the ice accumulation process $\left(\sigma=30 \times 10^{4} \mathrm{~S} / \mathrm{m} ; \mathrm{T}=-12^{\circ} \mathrm{C} ;\right.$ pol. $=$ neg.; $d=18 \mathrm{~mm} ; \mathrm{r}=6 \mathrm{~mm}$; orient.=hor. $)$ 


\subsection{Discussion and Analysis}

\subsubsection{Comparison of Different Materials}

The critical voltage values for synthetic surfaces (Teflon in this case), an air gap, and ice samples with various surface conditions were obtained during a preliminary test series at UBC. An electrode distance of $d=7 \mathrm{~mm}$ was used in this case for all configurations. The results are compared in Fig. 4-3.

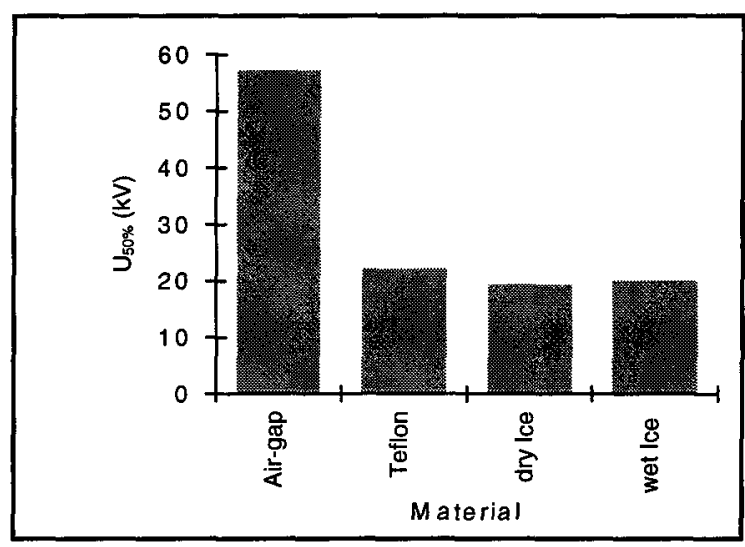

Fig. 4-3: $50 \%$ lightning impulse breakdown voltage for different materials (dry ice: $\sigma=1000 \times 10^{4} \mathrm{~S} / \mathrm{m} ; \mathrm{T}=-20^{\circ} \mathrm{C}$; wet ice: $\sigma=1 \times 10^{4} \mathrm{~S} / \mathrm{m} ; \mathrm{T}=0^{\circ} \mathrm{C}$; all: pol.=pos.; $d=7 \mathrm{~mm} ; r=6 \mathrm{~mm}$ )

In general, the ice surface shows a similar behaviour as other solid materials investigated beforehand (for example [61] [62], see also Section 2.4.1). The presence of such a solid surface leads to a significant decrease in breakdown voltage. 


\subsubsection{Effect of Freezing Water Conductivity}

Figure 4-4 presents a graph of the critical breakdown voltage measurements as a function of freezing water conductivity, $\sigma$, and ice temperature, $T$, (derived from Tables 4-1 to 4-3). Ice temperature is assigned to the $x$-axis (to the left), freezing water conductivity to the y-axis (to the right). The values for the $50 \%$ lightning impulse breakdown voltage, $\mathrm{U}_{50 \%}$, assigned to the z-axis, are expressed as percentages related to the highest result obtained. This value is $U_{50 \%}=46.7 \mathrm{kV}$, found for a test model with a dry ice surface, formed from de-ionised freezing water under negative applied voltage $\left(T=-12^{\circ} \mathrm{C}, \sigma=2.5 \times 10^{-4} \mathrm{~S} / \mathrm{m}\right.$, pol.=neg.). On the other hand, the lowest value, $U_{50 \%}=17,1 \mathrm{kV}$, is obtained for the case of wet ice surface with ice formed from very conductive water with positive voltage applied $\left(T=0^{\circ} \mathrm{C}, \sigma=160 \times 10^{-4} \mathrm{~S} / \mathrm{m}\right.$, pol. $=$ pos. $)$.

It can be observed that the breakdown voltage decreases as the freezing water conductivity increases for any of the chosen temperatures. The rate of decrease is greatest for low freezing water conductivity and tends to saturation at higher values. A similar behaviour was already revealed under applied ac and dc voltages [33]. It may seem surprising at first sight to observe this voltage decrease under dry ice surface conditions (at temperature $T=-12^{\circ} \mathrm{C}$ ), but the special characteristics of the ice surface can explain this phenomenon (see Section 2.2.3). 


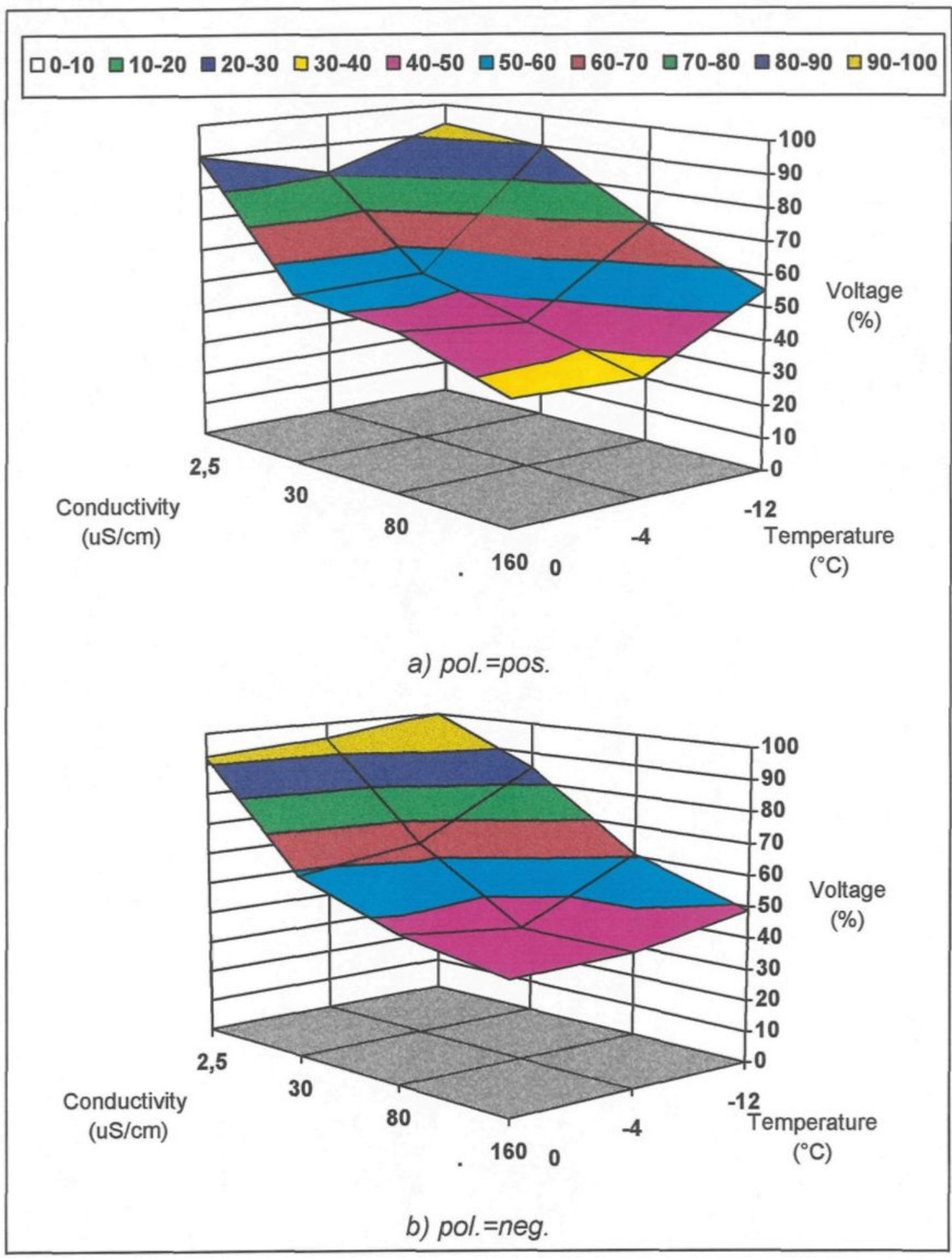

Fig. 4-4: 50 \% lightning impulse voltages for ice surfaces without artificial air gap as a function of freezing water conductivity, $\sigma$, and ice temperature, $T$

$$
\text { ( } d=18 \mathrm{~mm} ; \mathrm{r}=6 \mathrm{~mm} \text {; orient. }=\text { hor.) }
$$


First, pollution particles are carried to the surface during the freezing process [11] [99]. Thus, the surface contains a higher degree of pollution than the ice bulk. Second, studies on the structure of ice showed that even for temperatures below the melting point, a quasi-liquid layer is present on the surface of the ice [64] [74] [75] [112]. The appearance of a dry ice surface obscures the fact that the uppermost molecular layers of the ice surface are still much more reactive than the solid crystalline ice structure of the inner ice bulk. Therefore, ice surface conductivity is assumed to be influenced by freezing water conductivity, even for lower temperatures without any initial water film at the ice surface.

Once pre-discharge activity is initiated, local arc may provoke melting, thus creating a water film, which further increases ice surface conductivity. Then, conditions become favourable - high conductivity due to pollution particles at the ice surface and the presence of a liquid film in a locally limited area - to provoke a breakdown at relatively low voltage levels even for temperatures well below the melting point (as in this case $\mathrm{T}=-12^{\circ} \mathrm{C}$ ). It is believed that increasing freezing water conductivity will lead to higher leakage currents, so that a critical current can already be reached at lower voltage levels provoking electrical breakdown [24]. This will be studied in another experiment (Chapter 6). 


\subsubsection{Effect of Ice Temperature}

The same characteristic as for freezing water conductivity can be observed for changing ice temperature: Breakdown voltage decreases as the temperature is increased from $-12^{\circ} \mathrm{C}$ to the melting point. A significant decrease in ice surface breakdown voltage with increasing temperature was already observed in studies on the ac and dc flashover characteristics [12] [33]. In contrast to the behaviour for changing freezing water conductivity, the decrease in breakdown voltage for changing ice temperature is not gradual for the parameter values chosen in the present study. The measurements exhibit approximately the same order of magnitude for the two temperatures, $T=-4^{\circ} \mathrm{C}$ and $\mathrm{T}=0^{\circ} \mathrm{C}$, for any conductivity (with exception of the value for de-ionised water under positive voltage polarity). The appearance of a water film on the ice surface for temperature values near, but below the melting point can explain these observations [40] [69]. This process will lead to a significant increase in the surface conductivity [24].

By comparing the effects of the two parameters, temperature and conductivity, it can be said that the breakdown voltage has about the same value for a test specimen formed with highly conductive water under dry surface conditions $\left(\sigma=160 \times 10^{-4} \mathrm{~S} / \mathrm{m} ; \mathrm{T}=-12^{\circ} \mathrm{C}\right)$ as for an ice model formed with less conductive freezing water, but with a liquid film on its surface $\left(\sigma=30 \times 10^{-4} \mathrm{~S} / \mathrm{m} ; \mathrm{T}=0^{\circ}\right.$ 
C): $U_{50 \%}=25.8 \mathrm{kV}$ in the first case, and $U_{50 \%}=24.3 \mathrm{kV}$ in the second case under positive voltage. If both freezing water conductivity and ice temperature are increased simultaneously, the decrease in critical breakdown voltage is enhanced for both polarities. Lowest breakdown voltages were obtained for a freezing water conductivity of $\sigma=160 \times 10^{-4} \mathrm{~S} / \mathrm{m}$ and ice temperatures near the melting point.

A regression analysis was carried out in order to determine the relation between the critical breakdown voltage and the freezing water conductivity in the form of a mathematical equation (Appendix 11). As the critical breakdown voltage does not seem to change gradually with increasing ice temperature, it is proposed to model the breakdown characteristic with two different regimes, depending on the ice surface condition. Due to the non-linear characteristic of the results for varying freezing water conductivity, a regression type "power" was used. In the case of dry ice surface conditions $\left(T=-12^{\circ} \mathrm{C}\right)$, the first regression result for a range of freezing water conductivity of $2.5 \times 10^{-4} \mathrm{~S} / \mathrm{m}<\sigma<160 \times 10^{-4} \mathrm{~S} / \mathrm{m}$ showed significant deviations from the measurements. An improved result was obtained when the lowest value of freezing water conductivity was excluded. In the case of wet ice surface conditions $\left(T_{\text {ice }} \geq-4^{\circ} \mathrm{C}\right)$, the resulting equation shows good agreement to the measurements for the whole range of freezing water conductivity values used. Table 4-11 presents the two retained equations. 
Table 4-11: Equations describing the effect of the freezing water conductivity on the critical breakdown voltage for the two ice surface conditions $(d=18 \mathrm{~mm} ; r=6 \mathrm{~mm})$

\begin{tabular}{|c|c|}
\hline Ice surface condition & Regression result \\
\hline $\begin{array}{c}\text { Dry ice surface }\left(\pi_{\mathrm{ce}}=-12^{\circ} \mathrm{C}\right) \\
\left(30 \times 10^{4} \mathrm{~S} / \mathrm{m} \leq \sigma \leq 160 \times 10^{4} \mathrm{~S} / \mathrm{m}\right)\end{array}$ & $U_{50 \%}=116.55 \cdot \sigma^{-0.31}$ \\
$\begin{array}{c}\text { Wet ice surface }\left(\pi_{\mathrm{ie}} \geq-4^{\circ} \mathrm{C}\right) \\
\left(2.5 \times 10^{4} \mathrm{~S} / \mathrm{m} \leq \sigma \leq 160 \times 10^{4} \mathrm{~S} / \mathrm{m}\right)\end{array}$ & $U_{50 \%}=50.73 \cdot \sigma^{-0.20}$ \\
\hline
\end{tabular}

\subsubsection{Effect of Voltage Polarity}

Due to the symmetrical configuration and the simplified geometry of the ice samples used in the framework of the present study, no polarity effect on the critical breakdown may be expected. Comparison of the results for the two voltage polarities reveals some minor differences, which are presented in Fig. 4-5. For a dry ice surface $\left(T=-12^{\circ} \mathrm{C}\right)$ a slightly lower value was obtained for negative voltage polarity, whereas the $U_{50 \%}$ value was somewhat lower for positive voltage in the case of ice with a water film on its surface $\left(T=0^{\circ} \mathrm{C}\right)$.

These differences observed can be attributed to two effects: First, the ice samples were placed inside a climate chamber with metallic walls. The ground connection of the climate chamber connects the metallic walls to the grounded electrode, which may disturb the symmetry of the electric field distribution to a 
certain degree despite the fact that the ice samples are placed in the geometric centre of the climate chamber. Furthermore, any discussion of the $U_{50 \%}$ results has to consider that these values presented (Tables $4-1$ to $4-3$ and Fig. 4-5) are the outcome of a statistical analysis. If the actual measurements are considered, it can be stated that, for instance, for dry ice surface conditions $\left(T=-12^{\circ} \mathrm{C}\right)$, the same maximum value was obtained for both voltage polarities $\left(+38 \mathrm{kV}<\mathrm{U}_{50 \% \text { pos. }}<+47 \mathrm{kV}\right.$ and $-32,5 \mathrm{kV}<\mathrm{U}_{50 \% \text { neg. }}<-47 \mathrm{kV}$ ).

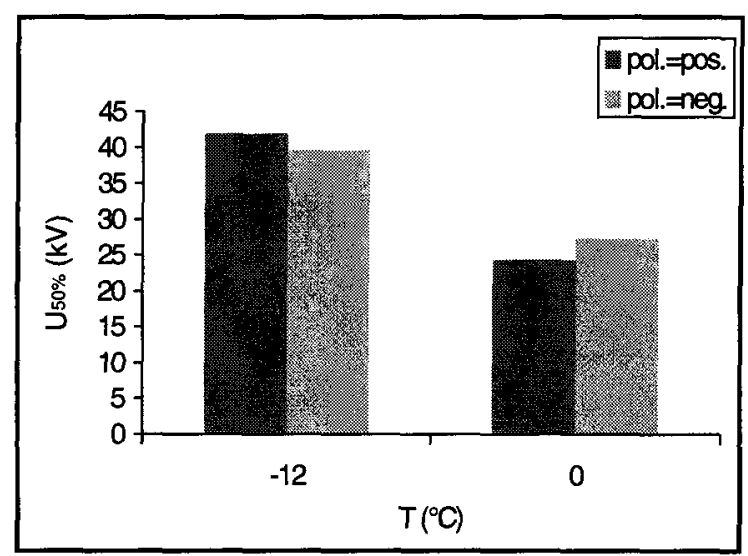

Fig. 4-5: $50 \%$ lightning impulse breakdown voltage as a function of voltage polarity for different temperatures $\left(\sigma=30 \times 10^{4} \mathrm{~S} / \mathrm{m} ; d=18 \mathrm{~mm} ; r=6 \mathrm{~mm}\right.$; orient.=hor.)

A strong polarity effect on the withstand performance could be observed on industrial insulators [26] [37]. To the best of our knowledge, no consistent theory yet exists, but the effect is related to the complex shape of the insulators. The location of discharge initiation, most often the air gap between the HV terminal and the first insulator unit, presents a non-symmetrical configuration of a metallic plane 
electrode and a point electrode formed by an icicle with or without a water drop at its tip. Such non-symmetrical configurations exhibit a strong polarity effect [6] [22] [42] [74] [88] [106]. As in the present case, the discharge does not develop in front of ice or water, but between two metallic electrodes along an ice-air interface, it can be assumed that the breakdown process is governed by the ionisation processes in air. Therefore, the phenomena identified in the literature on discharges in front of icicles and water drops are not applicable to explain a possible polarity effect for flashover appearance along an ice-air interface.

\subsubsection{Effect of Voltage Waveform}

A former study [33] did determine the critical breakdown values for applied ac and dc voltages using the same physical models. Thus, the $50 \%$ lightning impulse breakdown voltages can be compared to the breakdown performance for other voltage types, as shown in Fig. 4-6. As may be expected, the $50 \%$ breakdown voltage is much higher for lightning impulse voltage applied under the same experimental conditions, due to the steeper rate of voltage rise and the shorter duration of voltage application. 


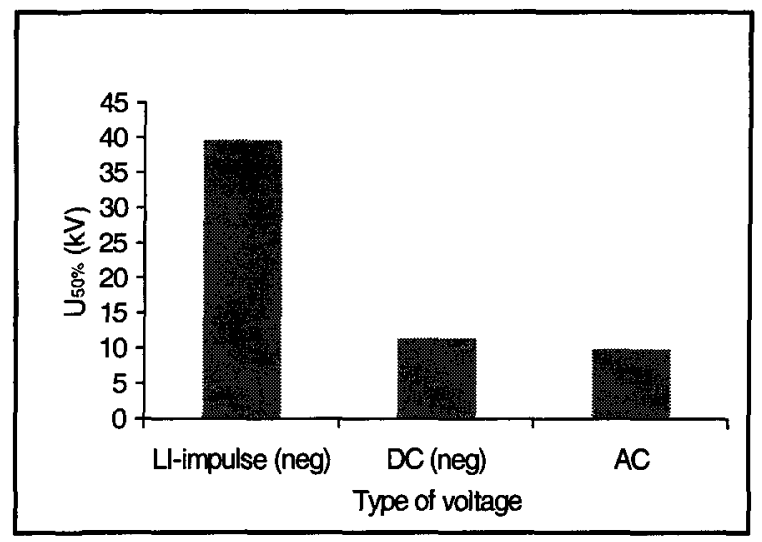

Fig. 4-6: $50 \%$ breakdown voltages as a function of the voltage waveform $\left(\sigma=30 \times 10^{4} \mathrm{~S} / \mathrm{m} ; T=-12^{\circ} \mathrm{C}\right.$; pol.=neg.; $d=18 \mathrm{~mm} ; \mathrm{r}=6 \mathrm{~mm}$; orient.=hor.)

\subsubsection{Effect of Electrode Curvature Radius}

Figure 4-7 illustrates the influence of the electrode curvature radius on the critical breakdown voltages, $\mathrm{U}_{50 \%}$, for both polarities, derived from Tables 4-4 to 4-6. The $50 \%$ lightning impulse breakdown voltage is higher for a radius of $r=15.5 \mathrm{~mm}$ than for $r=6 \mathrm{~mm}$, for any temperature. As the electric field strength in front of a tip is indirectly proportional to its curvature radius, higher voltage has to be applied to create partial discharge activity initiating ionisation processes in the case of increased electrode radius [67]. 


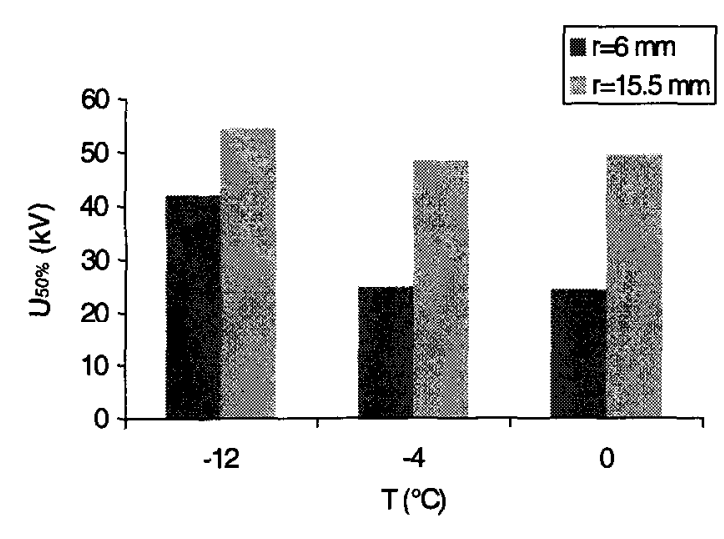

a) $p o l .=p o s$.

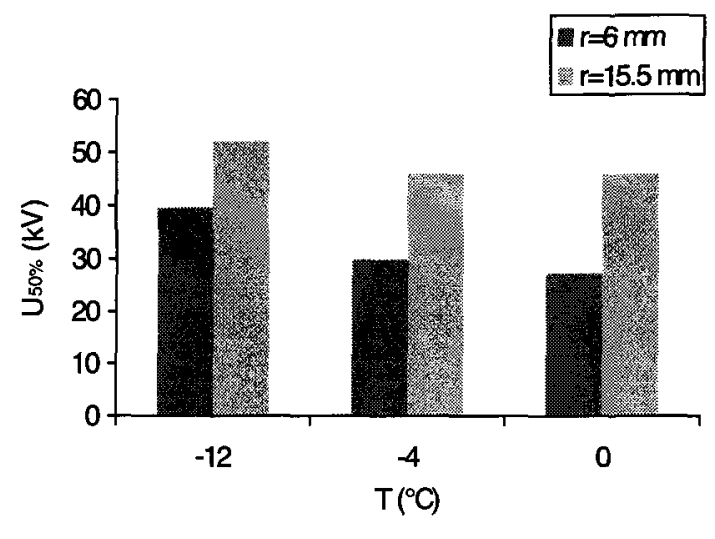

b) pol.=neg.

Fig. 4-7: $50 \%$ breakdown voltages as a function of electrode curvature radius for different ice temperatures $\left(\sigma=30 \times 1 \sigma^{4} \mathrm{~S} / \mathrm{m} ; d=18 \mathrm{~mm}\right.$; orient.=hor.)

\subsubsection{Effect of Electrode Axis Orientation}

The results of Table 4-8 show that orientation of the electrode axis has no significant influence on the critical breakdown voltage of the ice surface, whereas former studies reported that it plays an important role for actual HV insulator strings [53] [96]. Insulators installed horizontally or in V-configuration (at angle $\beta=45^{\circ}$ ) showed a better withstand performance under icing conditions than those fixed vertically. This behaviour can be explained by the fact that the ice built-up cannot bridge the gaps between the insulator sheds and the arcing distance is not shortened. Orientation also plays a role when melting occurs. Experiments on ac and dc ice surface breakdown using the same simplified model showed that the critical breakdown value is considerably lower for vertical orientation [33]. Melt- 
water flows downward due to gravity in parallel to the electrode axis. This water flow provides a low resistive path for an electric current flow. In the case of horizontal orientation, any water melted through partial discharge activity does not flow towards one of the electrodes, but leaves the space between the electrodes in a direction perpendicular to the axis of the electrodes.

In the framework of the present study, the physical model used has a simplified geometry without any protruding parts. Voltage was only applied for a very short period (about $100 \mu$ s for standard 1.2 / 50 lightning impulse), therefore, it is not surprising that the electrode axis orientation did not have any effect. It can be concluded that the differences in flashover performance of actual insulators related to orientation do not originate from the discharge process along the ice surface, but are an effect of insulator shape and flow direction of melt-water.

\subsubsection{Effect of Ice Surface Uniformity}

The $U_{50 \%}$ results for ice models with and without an artificial air gap (Tables 4-7 and 4-8) are presented graphically in Fig. 4-8. In the case of dry ice surface conditions (Fig. 4-8a), it can be observed that the $U_{50 \%}$ values are in the same order of magnitude as for test specimens without artificial air gap and those with a centrally located air gap. The results for the ice sample with an air gap located in front of the HV electrode are almost the same as for the ice sample 
without artificial air gap for negative voltage polarity, but for positive voltage applied, $U_{50 \%}$ is about $28 \%$ lower. This decrease in critical breakdown voltage in the case of positive voltage is higher than the proportional decrease in ice surface distance, as the ice surface is shortened by about $10 \%$ due to the presence of the air gap. Therefore, it may be concluded that the air gap acts as a partial discharge initiator, leading to breakdown at lower voltages than for a corresponding ice surface without artificial void.

A similar experiment with air gaps artificially introduced into the surface of a Teflon spacer was already performed during the preliminary experimental phase at UBC. In that case, two small holes, $1 \mathrm{~mm}$ in diameter and $2 \mathrm{~mm}$ deep, were drilled into the empty groove. Figure 4-9 compares the results for the Teflon and the ice models. Despite the different dimensions of the artificial introduced air gaps, it can be observed that the critical breakdown voltage decreases in the presence of voids for both materials under dry surface conditions, which may be explained by the field enhancement due to inhomogeneous dielectric constant. Other evidence can be found in previous investigations on surface discharges along synthetic insulators reporting that the breakdown characteristic is strongly dependent on surface defects [103] and homogeneity of the surface [81]. 


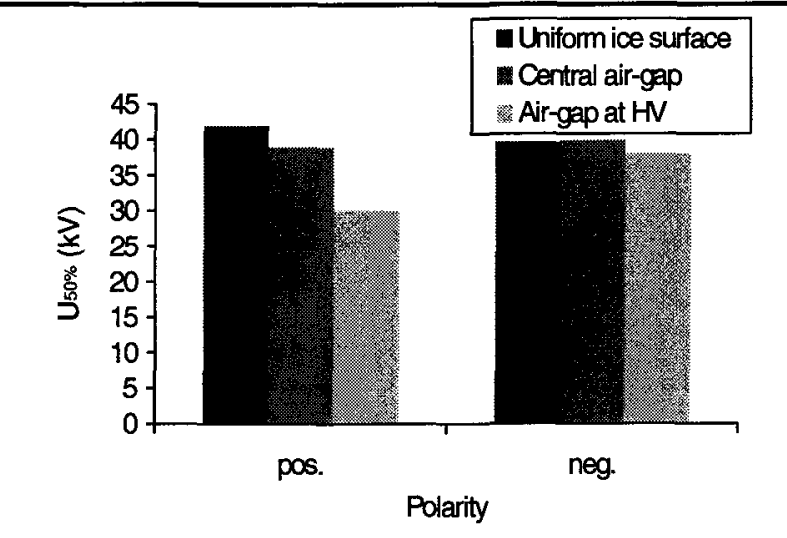

a) $T=-12^{\circ} \mathrm{C}$

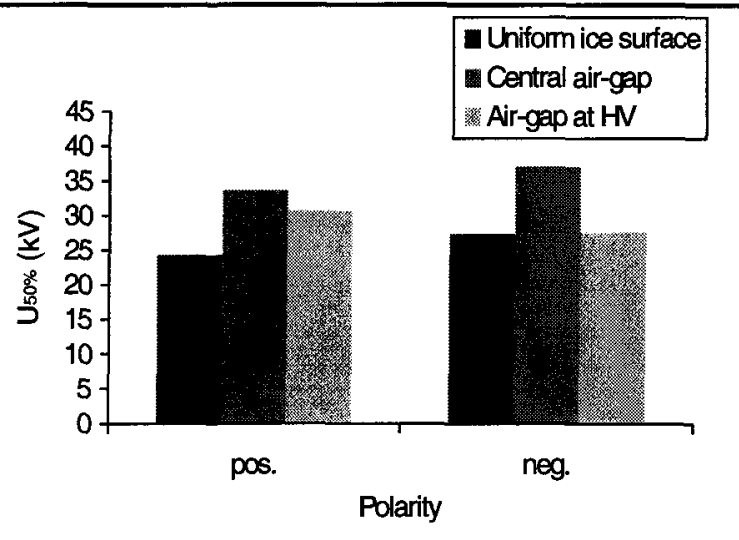

b) $T=0^{\circ} \mathrm{C}$

Fig. 4-8: $50 \%$ breakdown voltages as a function of ice surface uniformity $\left(\sigma=30 \times 10^{4} \mathrm{~S} / \mathrm{m} ; d=18 \mathrm{~mm} ; \mathrm{r}=6 \mathrm{~mm}\right.$; orient.=hor. $)$

For a comparison of the critical breakdown voltages for the two temperatures (different ice surface conditions: Fig. 4-8a shows results for dry ice surface conditions, Fig. 4-8b shows results for wet ice surface conditions), it can be seen that the decrease in critical breakdown voltage due to the presence of a water film is not as significant when there is an air gap in the ice surface (for example, under negative voltage polarity: $7 \%$ for a central air gap, $27 \%$ for an air gap in front of the HV electrode, and $31 \%$ for ice surface without artificial air gap). Therefore, it can be deduced that the withstand capacity of an ice model with an air gap may be less dependent on the presence or absence of a water film, thus less temperature dependent. This behaviour may be explained by the fact that the ice surface has become more conductive at temperature $\mathrm{T}=0^{\circ} \mathrm{C}$, due to the water film at the surface, but essentially the situation in the air gap has not changed. The withstand characteristic of a combination ice surface and air gap deteriorates less. 


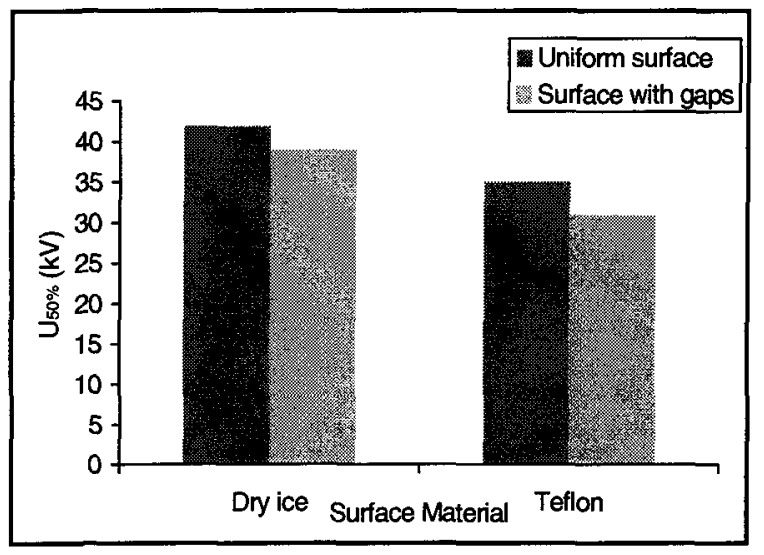

Fig. 4-9: $50 \%$ breakdown voltages as a function of surface material and for different surface conditions (with and without gaps)

$$
\left(\sigma_{i c e}=30 \times 10^{4} \mathrm{~S} / \mathrm{m} ; T=-12^{\circ} \mathrm{C} \text {; pol.=pos.; } d=18 \mathrm{~mm} ; \mathrm{r}=6 \mathrm{~mm}\right)
$$

The difference in the performance of a centrally located air gap in comparison with a gap in front of the HV electrode may be explained by the fact that the electric field is somewhat lower in the centre between the electrodes for the physical model used (Fig. 3-11) [108]. Thus, a higher voltage has to be applied to attain critical field values in the centrally located air gap to initiate partial discharge activity and create visible discharges, which lead to breakdown. However, it is difficult to arrive at a conclusive explanation, as the configuration of the air gap has to be considered also. The gap is limited on one side by Plexiglas with a certain relative permittivity constant,$\varepsilon_{\text {pexiglas }}$, on two sides by ice, $\varepsilon_{\text {ice, }}$, and on the top by air. Furthermore, thin water layers may also be present at the intersection between ice and air. The different materials may influence these processes of discharge initiation and development. It is a quite complex arrangement and the electric field 
distribution is difficult to ascertain. A recent study on discharge phenomena in systems with dielectric-covered electrodes [102] showed that charge depositions on the dielectric coatings on the electrodes reduce the electric field in the air gap. If, in the present case for very low temperature and low conductivity, the ice is be seen as a dielectric cover of the metallic electrodes, it may be argued that charge deposition on the ice decreases the electric field inside the air gap. Therefore, higher voltage is needed to breakdown the air gap and, consequently, the total distance between the electrodes compared to surfaces without any gap.

Another parameter is also assumed to influence breakdown characteristics the length of the air gap in relation to the electrode distance. In the present study, an air gap length of $\mathrm{g}=1.6 \mathrm{~mm}$ was chosen, whereas the electrode distance was $\mathrm{d}=18 \mathrm{~mm}$. Thus, the gap represents almost $10 \%$ of the discharge path. If the gap in the conductive layer becomes too large, the field enhancement at its edges might not be sufficient to maintain the discharge activity and cause breakdown. Thus, the gap may improve the withstand performance if it is large enough (as observed in the case of wet ice surface conditions). During investigations on the flashover performance of actual industrial insulators, it could be observed that a growing air gap was created due to melting by local arcs quenching the partial discharges after a certain period [54] [96]. 
In summary, it can be concluded that an ice surface containing a very small air gap acts like any synthetic surface containing a roughness: The small void presents a non-uniformity in the ice surface, which causes a field enhancement [63] [103], partial discharge initiation [62] [81] [103] and perhaps charge accumulation along the surface [14] [52] [117], resulting in breakdown at lower voltages than for ice surfaces without gaps. If, on the other hand, the dimension of the gap exceeds certain limits, it will lead to an increase in withstand strength, if the field inside the void is not strong enough to initiate ionisation processes and partial discharge activity [96]. Thus, the dimension of the air gap in relation to the dimension of the total electrode configuration may be a decisive parameter, if the air gap acts as an initiator or preventer of discharge activity. The dimension of the air gap was not changed in this study, but it seems to be an important experimental parameter that should be considered in future investigations, for a better understanding of the combined air gap and ice surface breakdown processes. Furthermore, it was already pointed out in Chapter 2 that no experimental evidence yet exists about surface charge accumulation on ice.

\subsubsection{Effect of Cooling Rate}

The results of the $50 \%$ lightning impulse breakdown voltage, $U_{50 \%}$, as a function of the cooling rate (Table 4-9), are presented in Fig. 4-10. It can be seen very clearly that the critical breakdown voltage increases with increasing cooling 
rate. This phenomenon is thought to be related to the surface structure of the ice samples, as it was already observed in a previous observation that the surface flashover characteristic under combined icing and contamination conditions depends on the type and morphology of the ice [95].

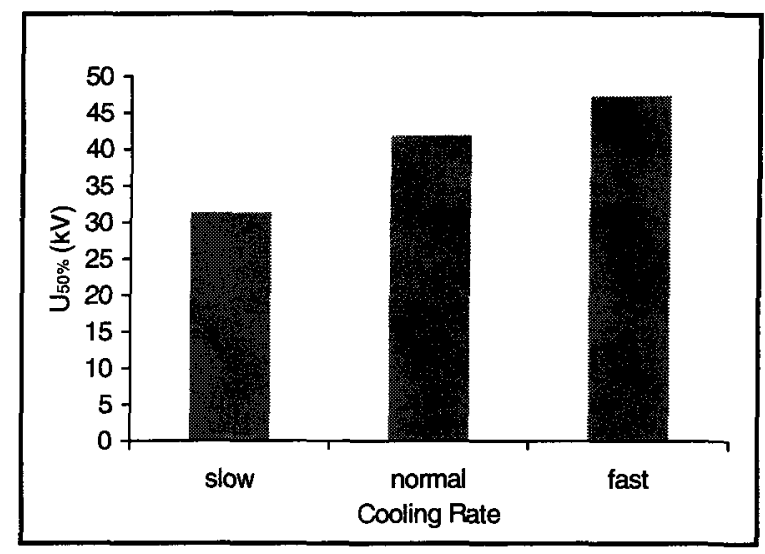

Fig. 4-10: $50 \%$ breakdown voltages as a function of cooling rate $\left(\sigma=30 \times 10^{-4} \mathrm{~S} / \mathrm{m} ; \mathrm{T}=-12^{\circ} \mathrm{C}\right.$; pol.=pos.; $d=18 \mathrm{~mm} ; \mathrm{r}=6 \mathrm{~mm}$; orient.=hor.)

Still photographs of the different ice samples are presented in Section 4.2.2. They show that the number and dimension of enclosed air bubbles varies depending on the cooling rate. For a slow cooling rate (cooling period of 30 hours; Fig. 4-1a), only a small number of relatively large air-bubbles were visible, fewer than for a normal cooling rate (cooling period of 6 hours; Fig. 4-1b), whereas the rest of the ice was very homogeneous with a transparent appearance. In the case of fast cooling (cooling period of 1 hour; Fig. 4-1c), the number of air bubbles was very high, whereas the dimension of the bubbles was much smaller than in both 
former cases, leading to a white-coloured appearance of the ice. As the bubbles are distributed uniformly over the whole ice bulk, their number on or near the surface is proportional to the number in the whole sample. Assuming that predischarge activity causes local melting, air bubbles enclosed near the ice surface are uncovered and transformed into small gaps resulting in a non-uniform surface.

The low critical breakdown voltage in the case of a slow cooling rate can be attributed to the considerable size of the cavities at the ice surface. The dielectric constant is discontinuous leading to an electric field enhancement. With a faster cooling rate, the gaps become more numerous but much smaller and they are uniformly distributed in the ice, therefore the ice sample can be seen as a kind of homogeneous mixture of two materials. This may allow higher critical breakdown voltages. To improve the understanding of the mechanisms of discharge progression in mixed configurations, including air gaps and ice surfaces, a study of the visible processes is proposed in order to gather more data (see Chapter 5).

\subsubsection{Electric Field during Cooling Period}

Table 4-10 illustrates that a $22 \%$ decrease in the critical breakdown voltage was found if an electric field was applied the cooling period, compared to normal freezing. As in the previous section on cooling rate, it is supposed that the phenomena observed may be partially related to the ice surface structure. During 
the cooling period, some weak motion could be observed near the electrodes at the beginning of cooling. Once the water was frozen, the surface of the ice remained uneven and the ice bulk contained a lot of microscopic encapsulations created by water movement, which is also reported in other studies [30] [59] (Fig. 4-2a). No difference could be observed for this process regarding the two electrodes, which is in accordance to previous observations, where no polarity effect was detected [93].

Besides the uneven ice surface, the ice formed under an electric field at a normal cooling rate appeared to be quite similar to the specimen produced with no electric field and at a fast cooling rate (Fig. 4-1c). Whereas the breakdown voltage increased in the case of for fast cooling rate, the presence of an electric field led to a decrease in breakdown voltage. Therefore, it is supposed that the presence of an electric field causes processes like polarisation or charge accumulation in the ice, changing the electric field distribution along the ice surface. Previous investigations provide indications that the ice is able to accumulate charges [48] [78] [104], but the experimental methods of this study were not adapted to quantify such phenomena in the present case. As this point seems to be important for any further interpretation, it is proposed that in future experiments, surface charge measurements will be carried out as previously done for synthetic surfaces [14] [103] [117] in order to gain more knowledge on the possible processes of charge accumulation on dry ice surfaces. 


\subsection{Conclusions of Chapter 4}

In this chapter, the experimental results on the determination of the $50 \%$ lightning impulse breakdown voltages for ice surfaces under different conditions were presented and analysed. Several typical characteristics of ice surface breakdown can be identified:

1) The $50 \%$ lightning impulse breakdown voltage decreases drastically when an ice surface is present between the electrodes (reduction of up to $60 \%$ compared to an air gap for an electrode distance $\mathrm{d}=7 \mathrm{~mm}$ ).

2) Increasing freezing water conductivity leads to a gradual reduction of the $50 \%$ lightning impulse breakdown voltage, $\mathrm{U}_{50 \%}$, for both voltage polarities (for example, reduction from $\mathrm{U}_{50 \%}\left(\sigma=2.5 \quad \times 10^{-4} \quad \mathrm{~S} / \mathrm{m}\right)=43.7 \mathrm{kV}$ to $\mathrm{U}_{50 \%}\left(\sigma=160 \times 10^{-4} \mathrm{~S} / \mathrm{m}\right)=25.8 \mathrm{kV}$ for $18-\mathrm{mm}$ model and positive voltage polarity). The effect tends to saturation for higher values of freezing water conductivity.

3) An increase in ice temperature from low temperatures to the melting point causes a loss of withstand performance for any voltage polarity, but the $U_{50 \%}$ decrease is not gradual with increasing temperature. For a critical temperature value, which is situated in the range $-12^{\circ} \mathrm{C}<\mathrm{T}<-4^{\circ} \mathrm{C}$, 
breakdown voltage decreases significantly (reduction from $U_{50 \%}\left(T=-12^{\circ} \quad C\right)=41.9 \mathrm{kV}$ to $U_{50 \%}\left(T=-4^{\circ} \quad \mathrm{C}\right)=24.8 \mathrm{kV}$ for $\sigma=30 \times 10^{-4} \mathrm{~S} / \mathrm{m}$; pol.=pos.; $d=18 \mathrm{~mm}$ ), due to the fact that a water film exists on the ice surface for ice temperatures slightly below the melting point.

4) No explanation of the polarity effect observed on ice-covered HV insulators can be provided by the present study with the physical model used. The differences measured as a function of voltage polarity are assumed to be a result of the experimental methodologies.

5) The $50 \%$ lightning impulse breakdown voltage of a flat ice surface without artificial gaps is not influenced by the electrode axis orientation. Therefore, the effect of the orientation on the withstand performance of actual HV insulators can be attributed exclusively to their complex shape, preventing total ice bridges between the sheds for horizontal and angled installations.

6) The uniformity of the ice surface (number and size of air gaps) has a significant influence on the $50 \%$ lightning impulse breakdown voltage. Depending on the dimension of an air gap, it can act as a discharge initiator for very small gaps or it can increase the critical breakdown voltage if the gap $(\mathrm{g}=1.6 \mathrm{~mm}$ in the present case) occupies a significant portion of the space between the electrodes $(\mathrm{d}=18 \mathrm{~mm})$. 


\section{CHAPTER 5}

STUDY OF VISIBLE DISCHARGE DEVELOPMENT 


\section{CHAPTER 5}

\section{STUDY OF VISIBLE DISCHARGE DEVELOPMENT}

\subsection{Introduction to Chapter 5}

With the knowledge obtained on the critical breakdown voltages (Chapter 4), the experiments using ultra high-speed photography could be carried out. A voltage level $5 \%$ to $10 \%$ higher than the critical voltage was applied to the ice sample, to ensure that breakdown takes place. For each case, several similar images were obtained, and the most significant recording was retained for further analysis. Further information on the interpretation of streak recordings can be found in Section 3.5.2.

The first section of this chapter shows recordings of two typical discharge processes, one in an air gap and the second along a synthetic surface (in the present case Teflon) in order to provide data for comparison and classification of ice surface recordings under different conditions. Next, some test recordings are 
presented to verify if the ultra high-speed recordings correspond to the actual discharge developments, and if the experimental methodology influences or falsifies the physical discharge processes.

The ultra high-speed streak recordings are presented in several groups to point out the specific characteristics of the different experimental parameters. Not only do they allow capturing the general visual appearance of the discharge activity, but also the derivation of various physical parameters is enabled:

- Time to breakdown, $\mathrm{t}_{\text {breakdown }}$

- Discharge propagation velocity

- Point of origin of first visual discharge activity

- Light emission pattern (for example linear discharge growth, stepped development, continuous growth of final jump, etc.)

The experiments on the determination of the breakdown voltages (Chapter 4) revealed that the uniformity of the ice surface plays and important role on the ice surface discharge process. Therefore, the succeeding presentation and discussion of the experimental results is divided into two parts, one for ice surfaces without artificial air gap and the other for ice surfaces with artificial and natural air gaps. 


\subsection{Discharge Development in an Air Gap and along Synthetic}

\section{Surfaces}

In order to get a reference recording, the discharge developments in an air gap and along different synthetic surfaces were recorded in a preliminary test series at the HV laboratory at UBC. Previous experiments at UBC have also yielded useful data [61] [62] [63]. The electrode configuration in these experiments was similar to the test specimen of the present study (see Section 3.3.1).

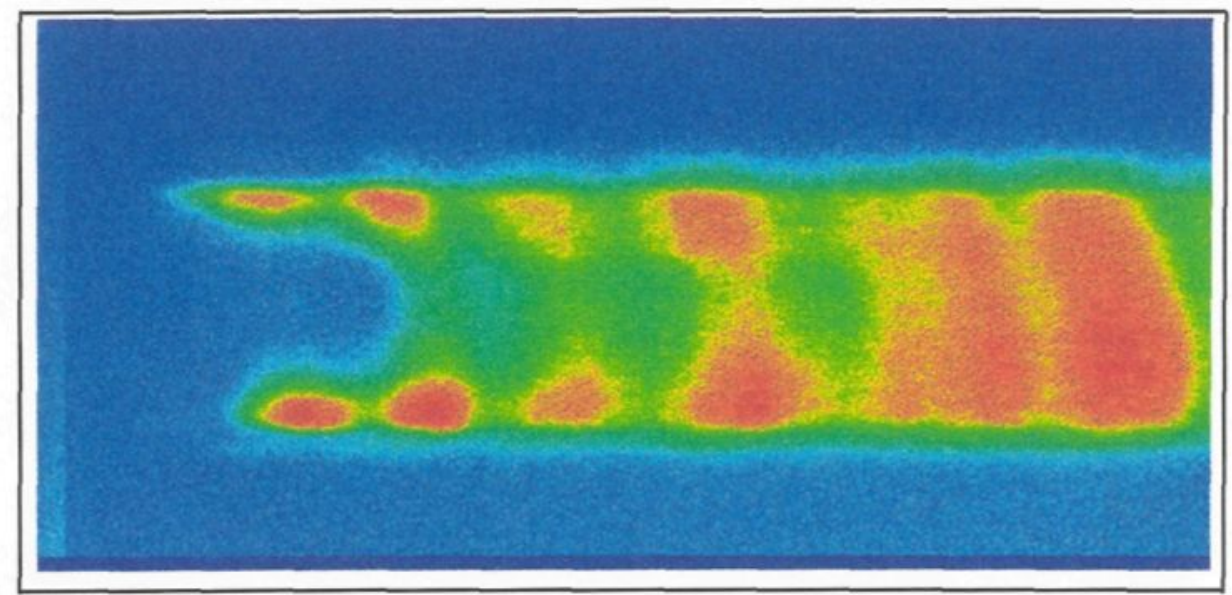

Fig. 5-1: Discharge development in an air gap

( $T=20^{\circ} \mathrm{C}$; pol. $=$ pos.; $d=7 \mathrm{~mm} ; r=6 \mathrm{~mm}$; orient. $=v e r$.; $\left.t_{\text {sweep }}=100 \mathrm{~ns}\right)$

Figure 5-1 shows a typical streak photograph of discharge development in an air gap. The first visible discharge activity can be seen in front of the HV electrode (at the top). Shortly afterwards, a second visible discharge appears in front of the ground electrode. Both discharges grow into the space between the electrodes and, after a considerable period (in the present case $t_{\text {breakdown }}=31 \mathrm{~ns}$ ), they 
amalgamate and lead to breakdown. This period is called "time to breakdown", $t_{\text {breakdown. }}$. The same air gap was also recorded by a framing camera (Fig. 5-2) and the outcome confirms very well the discharge development process observed in the streak recording.

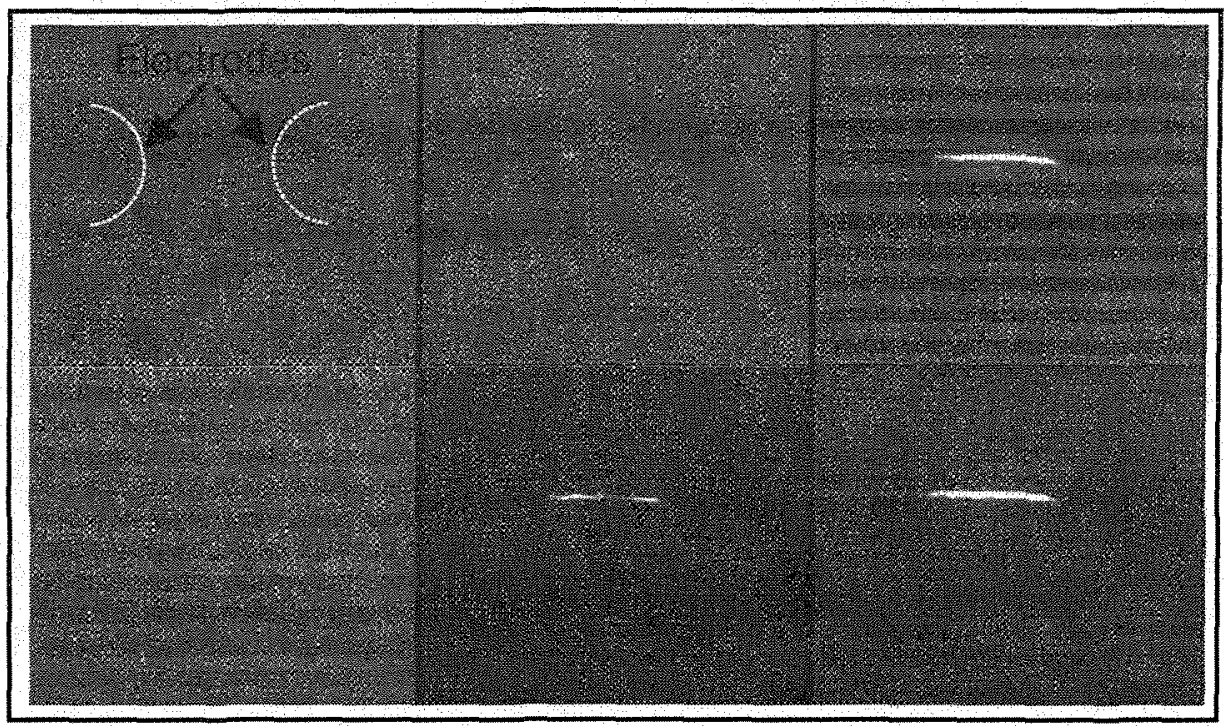

Fig. 5-2: Series of framing recordings showing the temporal discharge development in an air gap

$\left(T=-12^{\circ} \mathrm{C} ;\right.$ pol. $=$ pos.; $d=7 \mathrm{~mm} ; \mathrm{r}=6 \mathrm{~mm}$; orient.=hor.; $\left.t_{\text {trame }}=10 \mathrm{~ns} ; t_{\text {intert. }}=0 \mathrm{~ns}\right)$

The preliminary tests showed that the pattern of discharge development on synthetic surfaces was not influenced in a significant manner by the surface material (see also [61] [62]). As an example, the streak recording of a test sample made from Teflon (PTFE) is shown in Fig. 5-3. 


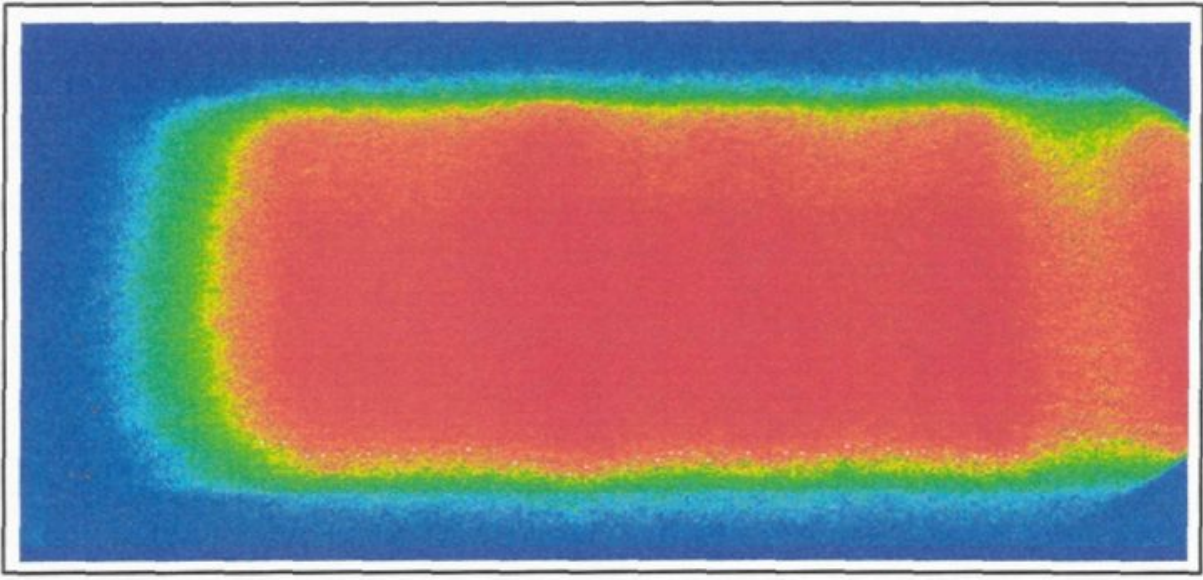

Fig. 5-3: Discharge development along the surface of a Teflon spacer ( $T=20^{\circ} \mathrm{C}$; pol. $=$ pos.; $d=7 \mathrm{~mm} ; r=6 \mathrm{~mm}$; orient. $=$ ver.; $t_{\text {sweep }}=50 \mathrm{~ns}$ )

In this case, the discharge develops extremely fast so that the discharge front appears still as a vertical line in a $50 \mathrm{~ns}$ streak recording. The appearance of a first visible discharge activity is immediately followed by breakdown. Visible discharge initiation can take place at any location on the synthetic surface. This phenomenon is commonly attributed to surface charge accumulation [14] [52] [103] [117].

\subsection{Verification of Experimental Methodology}

As there is no possibility to verify the correctness of the ultra high-speed recordings with the human eye, as much caution as possible was used during the experiments. To avoid misinterpretations, several experiments were carried out to verify if the discharge processes really develop along a straight path on the surface 
of the ice, and if the phenomena observed on the ultra high-speed recordings correspond to the actual discharge processes.

\subsubsection{Discharge Path}

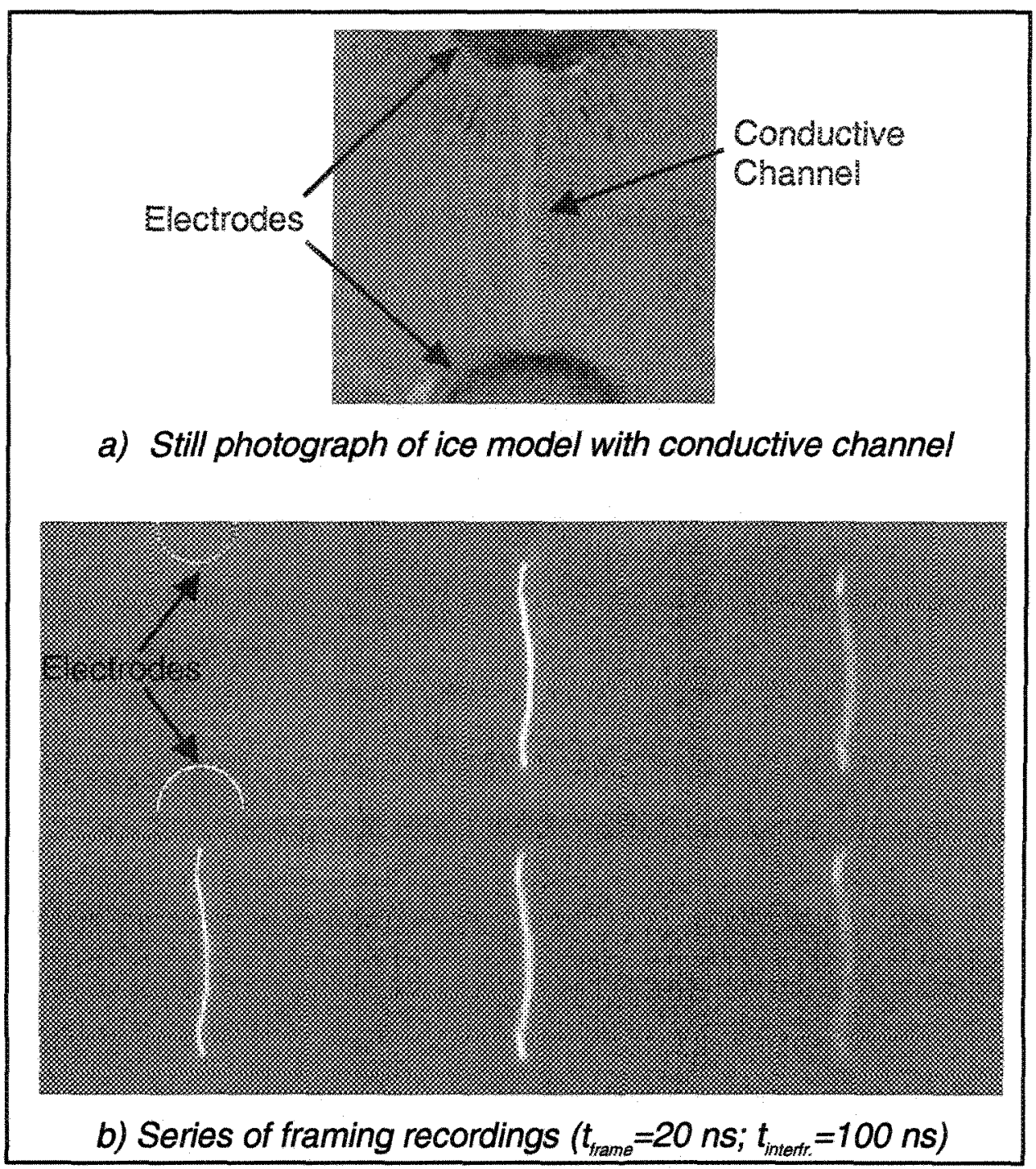

Fig. 5-4: Photographs of discharge staying inside the conductive channel $\left(\sigma=30 \times 10^{4} \mathrm{~S} / \mathrm{m} ; T=0^{\circ} \mathrm{C} ;\right.$ pol.=pos.; $d=18 \mathrm{~mm} ; r=6 \mathrm{~mm}$; orient.=hor.; path=cha.) 
As mentioned in Section 3.4.3, some measures had to be applied to ensure a straight discharge development. Figure 5-4 shows the effects of the first method ("conductive channel") on the growth of the discharge activity. It can be observed that the discharge stays inside the channel.

Figure 5-5 shows the streak recordings for the two measures proposed under similar experimental conditions. The two streak recordings yielded coincident results, therefore, it was concluded that these experimental procedures do not influence the actual discharge process.

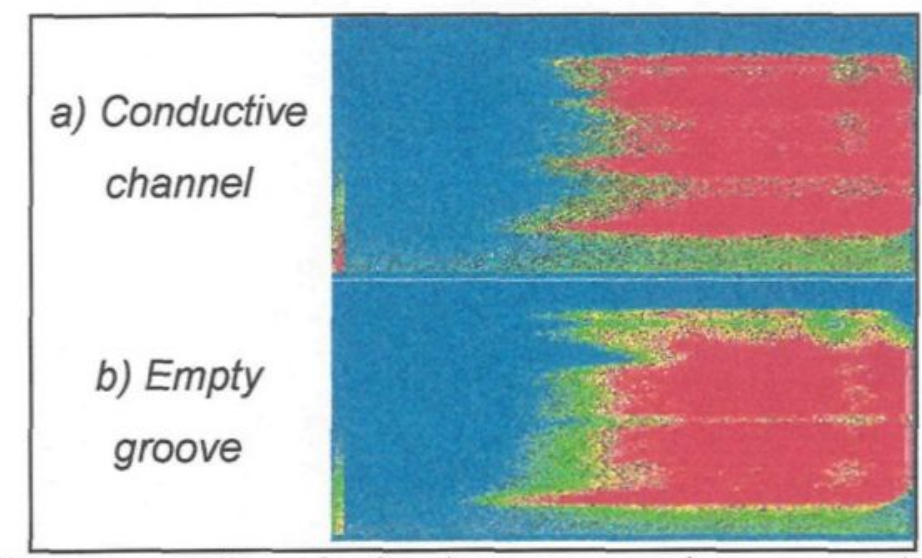

Fig. 5-5: Streak recordings for the two proposed measures to keep the discharge on a straight line $\left(\sigma=30 \times 10^{-4} \mathrm{~S} / \mathrm{m} ; T=-12^{\circ} \mathrm{C}\right.$; pol. =pos.; $d=18 \mathrm{~mm} ; r=6 \mathrm{~mm}$;

$$
\text { orient. }=\text { hor.; } t_{\text {sweep }}=50 \mathrm{~ns} \text { ) }
$$

Figure 5-6 presents a view of the ice model, placed vertically, in order to observe the discharge path in that dimension. It demonstrates that the discharge in fact propagates along the surface of the ice and not in the air above the ice. 
discharge in fact propagates along the surface of the ice and not in the air above the ice.

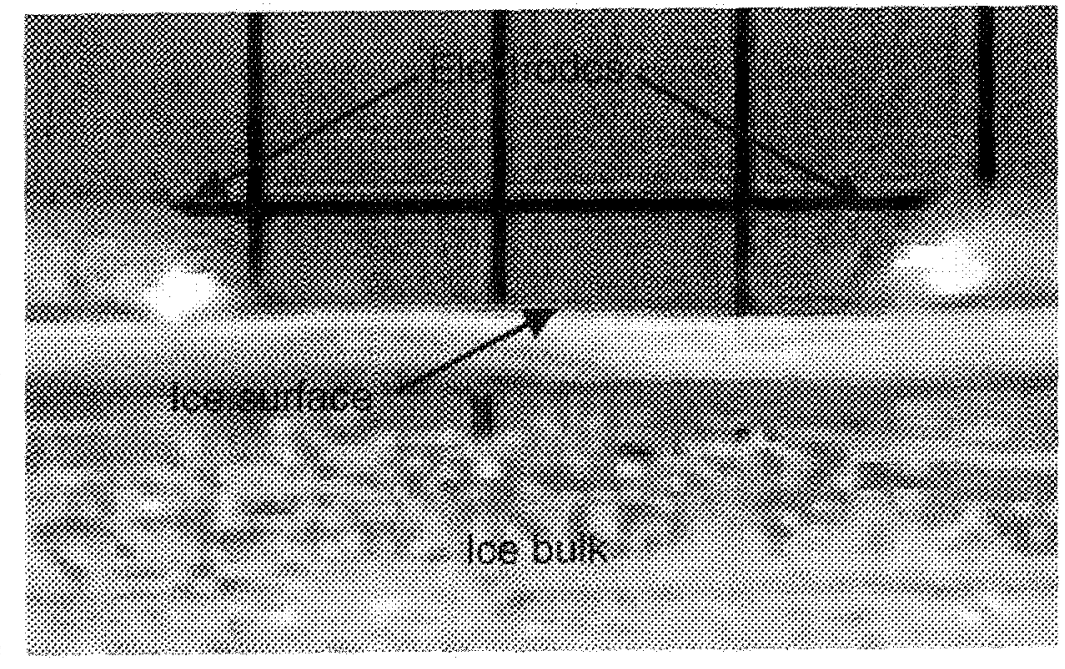

a) Still photograph with a horizontal view of the ice model

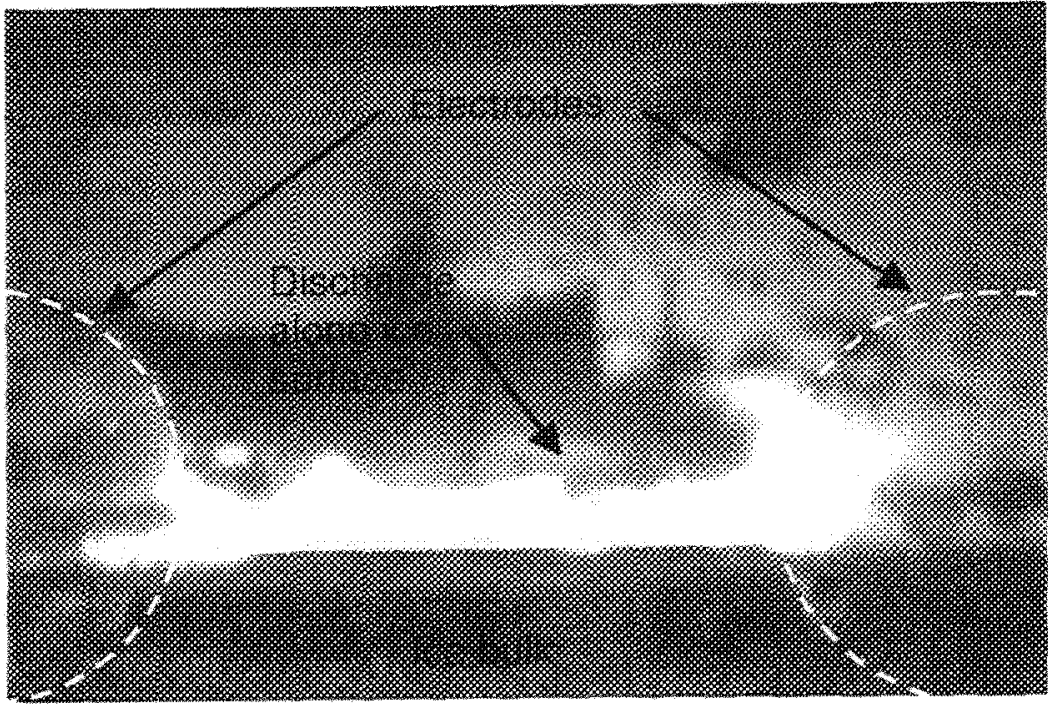

b) Single Framing recording ( $t_{\text {tang }}=50 \mathrm{~ns}$ )

Fig. 5-6: Photographs of a discharge propagating along the surface of the ice $\left(\sigma=30 \times 10^{4} \mathrm{~S} / \mathrm{m} ; \mathrm{T}=-12^{\circ} \mathrm{C}\right.$; pol.=pos.; $d=18 \mathrm{~mm} ; \mathrm{r}=6 \mathrm{~mm}$; orient.=hor.; path=cha.) 
After these verifications, it was concluded that the experimental technique of ultra high-speed streak photography represents the actual discharge process on ice surfaces. Therefore, this apparatus is an adequate tool to observe the first nanoseconds of visible ice surface discharges.

\subsubsection{Repeatability of the Experiments}

As complex experimental methodologies are used for the optical ultra highspeed investigations, the question may be raised whether these experiments would be repeatable, or if the phenomena are unique observations. Experiments with comparable test conditions (similar set of experimental parameters) were carried out in different laboratories (Fig. 5-7) and with different camera systems (Fig. 5-8).

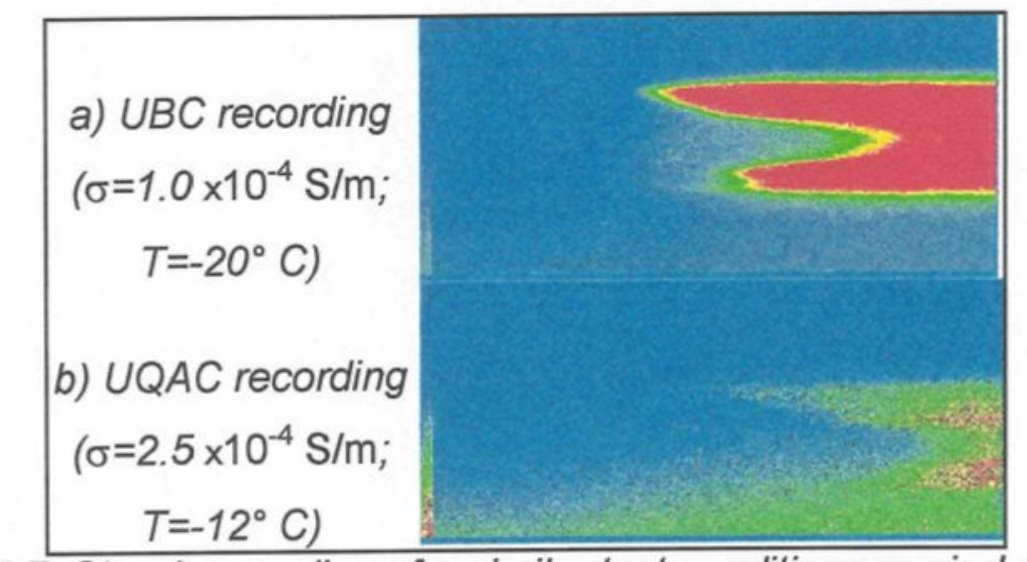

Fig. 5-7: Streak recordings for similar test conditions carried out in different laboratories (pol. $=$ pos.; $d=7 \mathrm{~mm} ; r=6 \mathrm{~mm}$; orient. $=$ hor.; $t_{\text {sweep }}=50 \mathrm{~ns}$ ) 
To compare the two camera systems, the recording of the streak camera and the series of photographs obtained with a framing camera were used in Fig. 5-8. Only the central part of each frame recording was used and placed at the right time in relation to the streak recording.

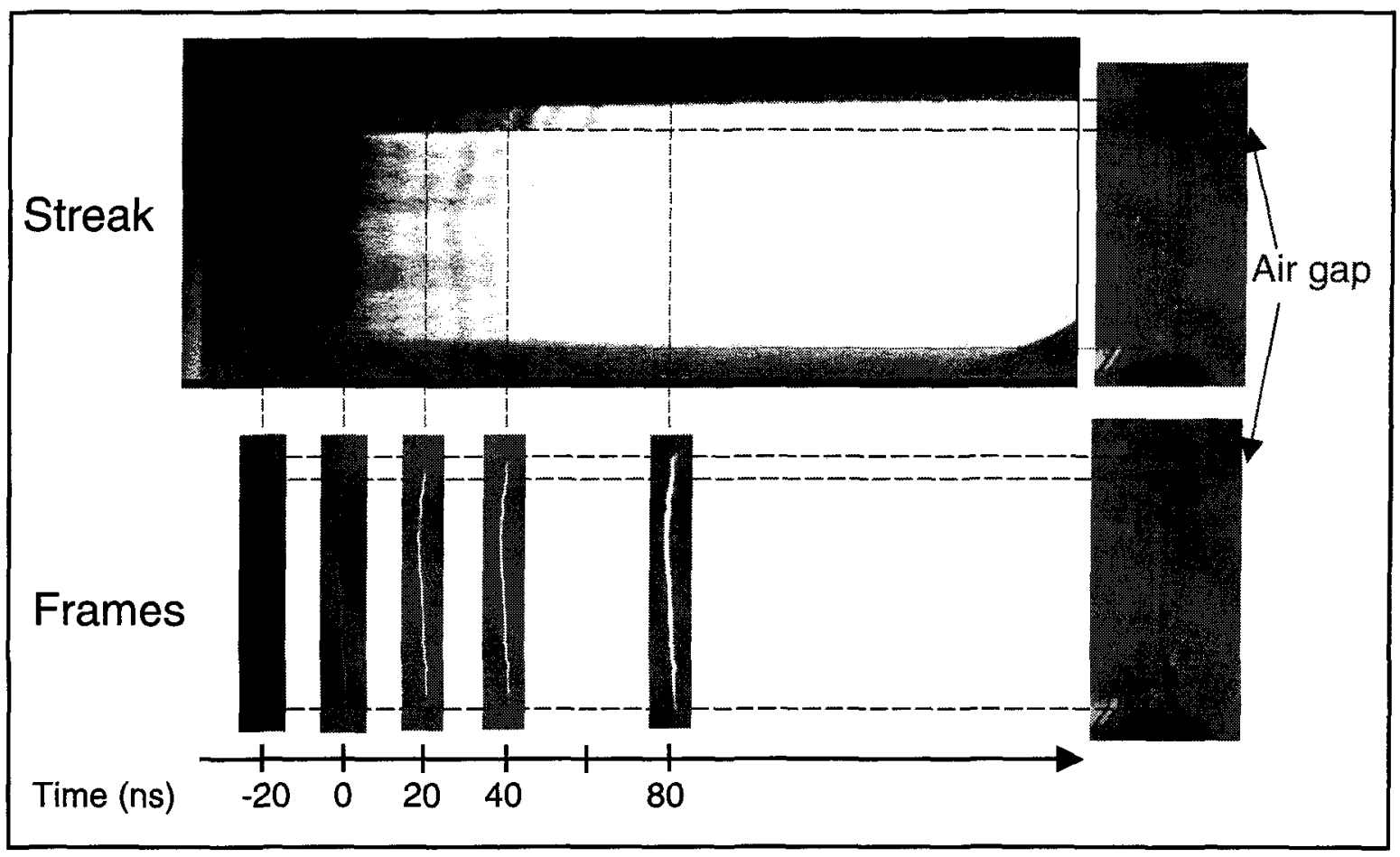

Fig. 5-8: Comparison of a streak recording with a framing recording for similar experimental conditions $\left(\sigma=30 \times 10^{4} \mathrm{~S} / \mathrm{m} ; T=0^{\circ} \mathrm{C}\right.$; pol.=pos.; $d=18 \mathrm{~mm} ; \mathrm{r}=6 \mathrm{~mm}$; orient.=hor.; path=cha.; $a=0 \mathrm{~mm}$ )

The repetitive recordings with the same camera system at different laboratories (Fig. 5-7), as well as the recordings with different camera systems (Fig. 5-8), yield identical results. Thus, it can be stated that the results obtained with the experimental methods of the present study (see Chapter 3) are not only reliable, but also repeatable. Furthermore, it may be interesting to observe in 
Fig. 5-8 that breakdown occurred $45 \mathrm{~ns}$ after the first appearance of a visible ionisation process. This moment is located in-between two frames and can not be determined with the framing camera only. Therefore, it may be said that both photographic techniques - framing and streak recording - have their advantages and are complementary.

At this point, it should be kept in mind that no interpretation of the intensity of the light emissions in the streak recordings is done in this study, as the appearance of the recorded image strongly depends on image processing (see Section 3.5.2). Attention is directed towards the shape of the light emissions before the arrival of total breakdown.

\subsection{Ultra High-speed Photographic Observations for Ice Surfaces without Artificial Air Gap}

\subsubsection{Experimental Results}

\subsubsection{7-mm Model}

First, the streak recordings are presented for distance, $d=7 \mathrm{~mm}$, between the electrodes. Figure 5-9 shows the streak recordings as a function of freezing water conductivity, and Fig. 5-10 illustrates the influence of ice temperature. 


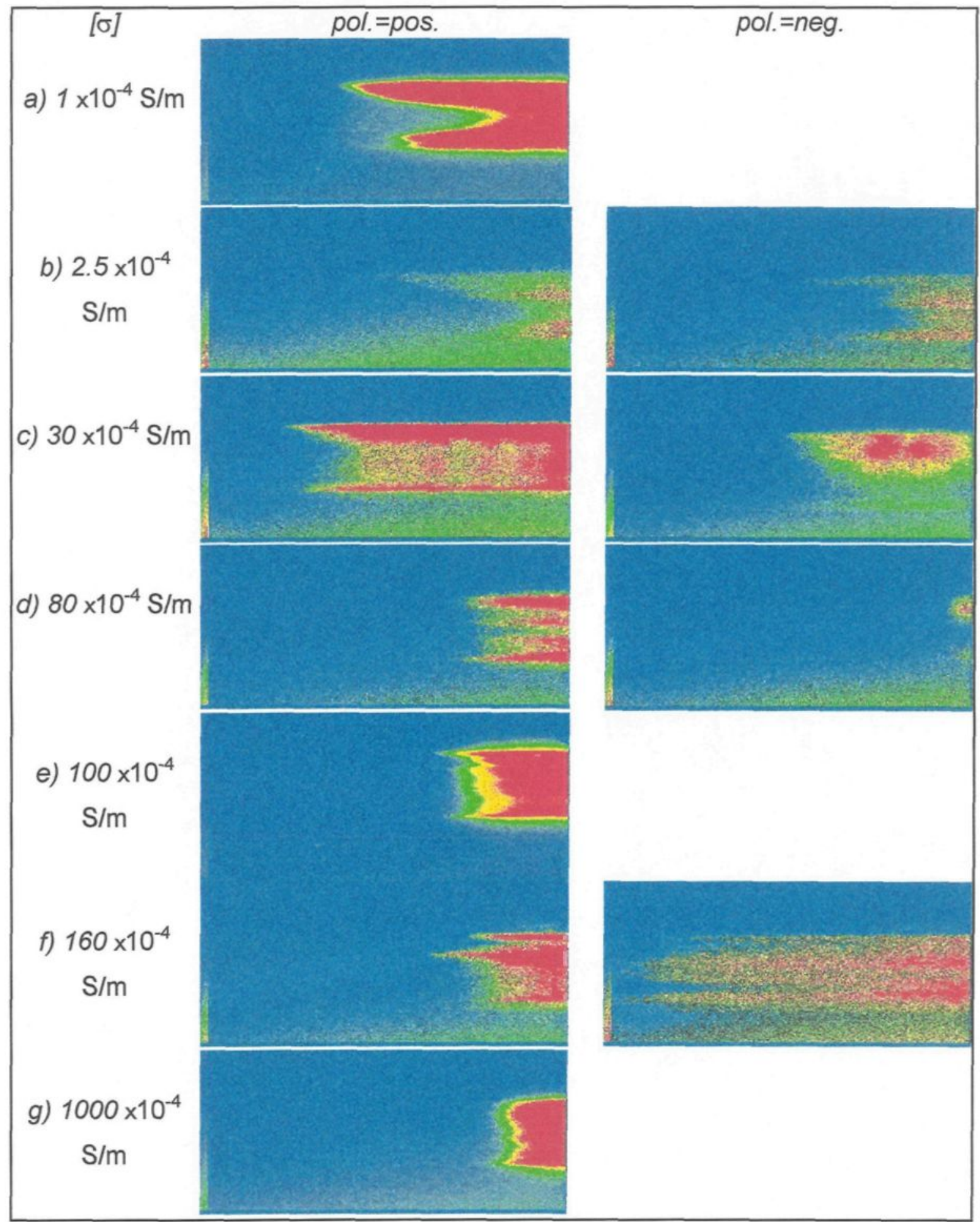

Fig. 5-9: Streak recordings as a function of freezing water conductivity, $\sigma$ ( $T=-12^{\circ} \mathrm{C}$ or $T_{u b c}=-20^{\circ} \mathrm{C} ; d=7 \mathrm{~mm} ; r=6 \mathrm{~mm}$; orient. $=$ hor.; $t_{\text {sweep }}=50 \mathrm{~ns}$ ) 


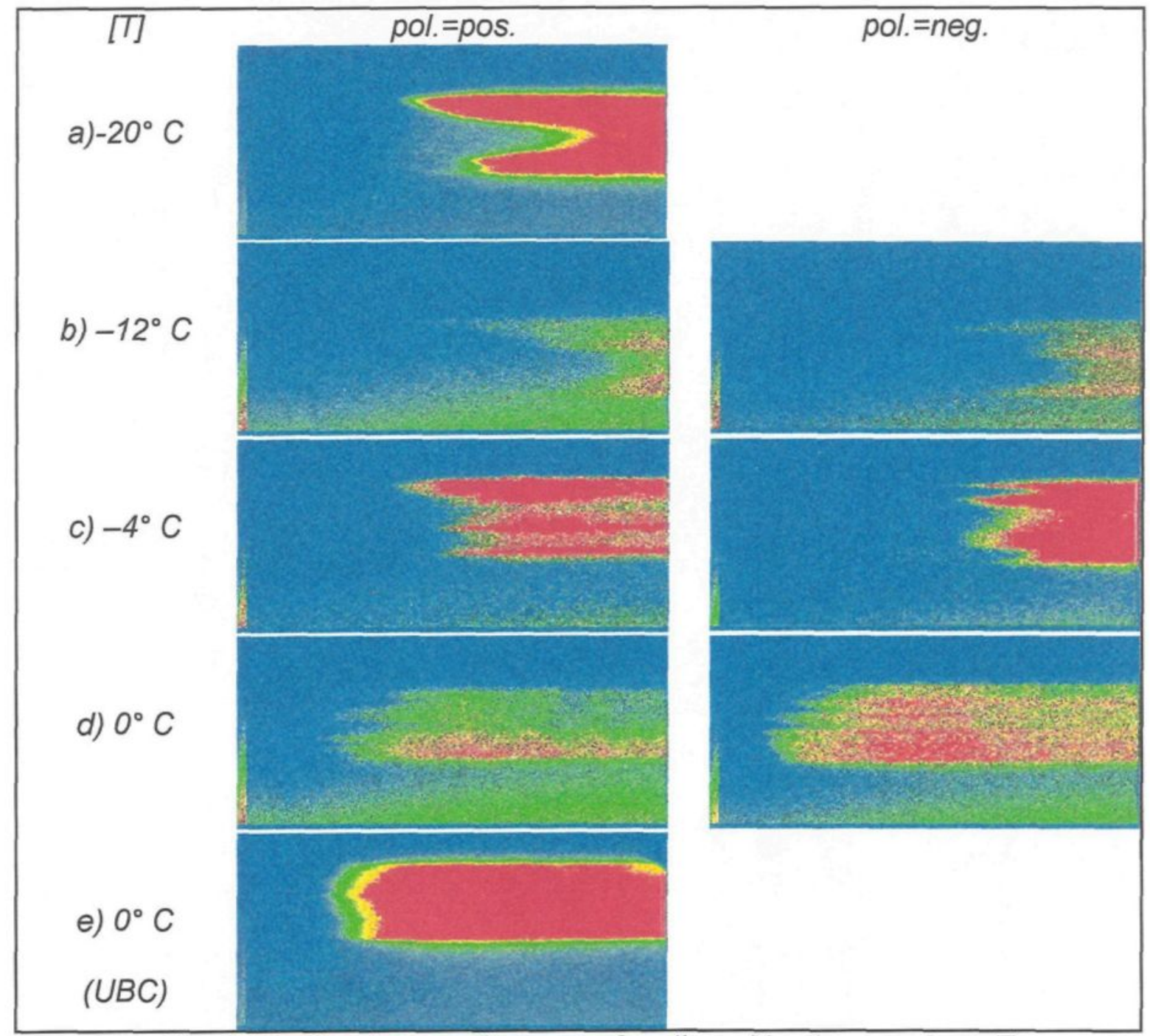

Fig. 5-10: Streak recordings as a function of ice temperature, $T$ $\left(\sigma=2.5 \times 10^{-4} \mathrm{~S} / \mathrm{m}\right.$ or $\sigma_{u b c}=1 \times 10^{-4} \mathrm{~S} / \mathrm{m} ; d=7 \mathrm{~mm} ; r=6 \mathrm{~mm}$; orient. $=$ hor.; $t_{\text {sweep }}=50 \mathrm{~ns}$ ) 


\subsubsection{18-mm Model}

The streak recordings for the $18-\mathrm{mm}$ model are presented next. Figure 5-11 shows the results as a function of freezing water conductivity, and Fig. 5-12 illustrates the influence of ice temperature on the discharge development. A series of framing recordings in Fig. 5-13 illustrates the very fast discharge development along the ice surface. A comparison of streak recordings for the two electrode distances $(d=7 \mathrm{~mm}$ and $d=18 \mathrm{~mm})$ is shown in Fig. 5-14. Afterwards, results are presented for experimental parameters, which were only investigated with the 18-mm model. Figures 5-15 and 5-16 show results for different values of electrode curvature radius. The influence of the electrode axis orientation is illustrated in Fig. 5-17. 


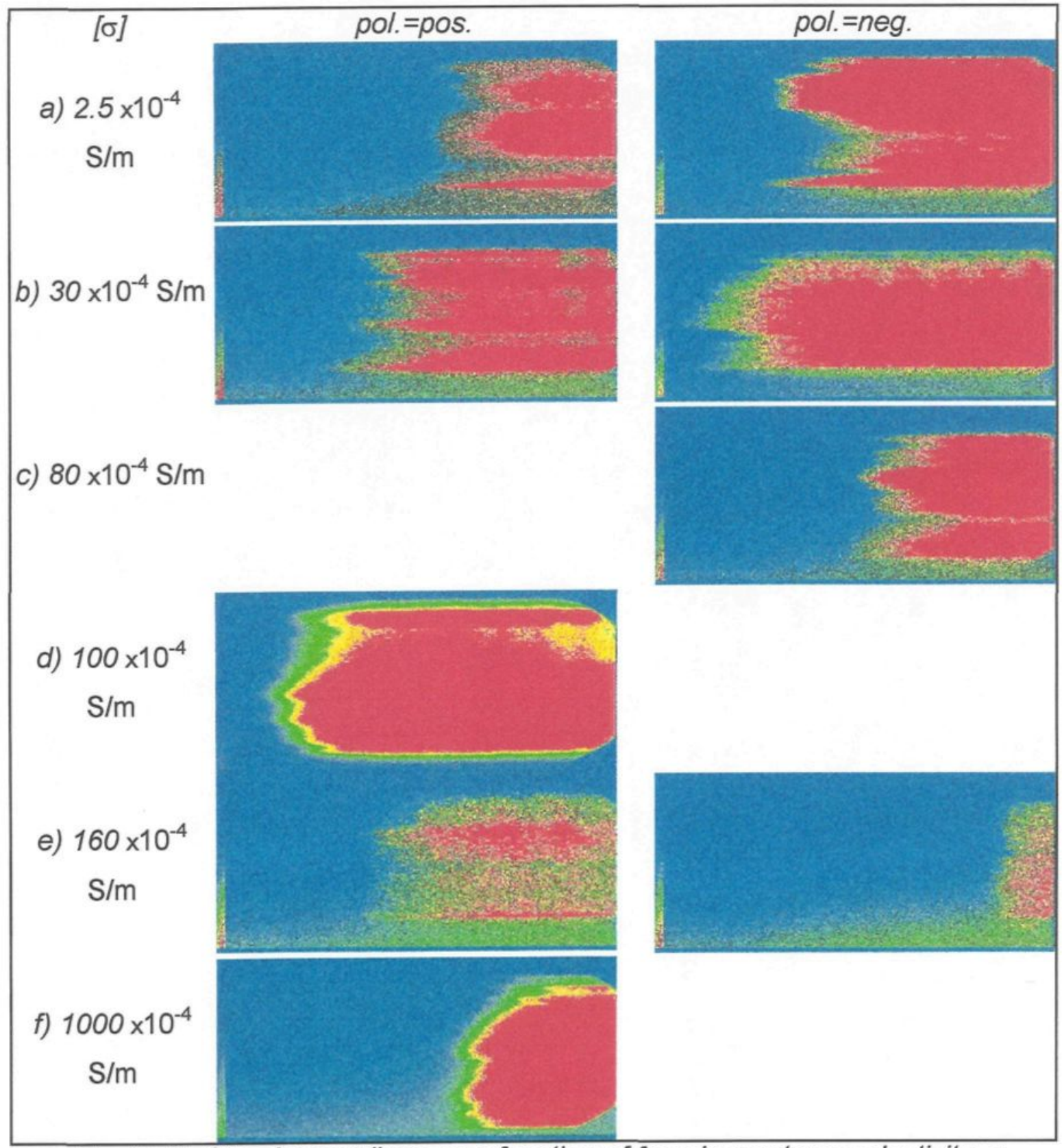

Fig. 5-11: Streak recordings as a function of freezing water conductivity, $\sigma$ ( $T=-12^{\circ} \mathrm{C}$ or $T_{u b c}=-20^{\circ} \mathrm{C} ; d=18 \mathrm{~mm} ; r=6 \mathrm{~mm}$; orient. $=$ hor.; $\left.t_{\text {sweep }}=50 \mathrm{~ns}\right)$ 


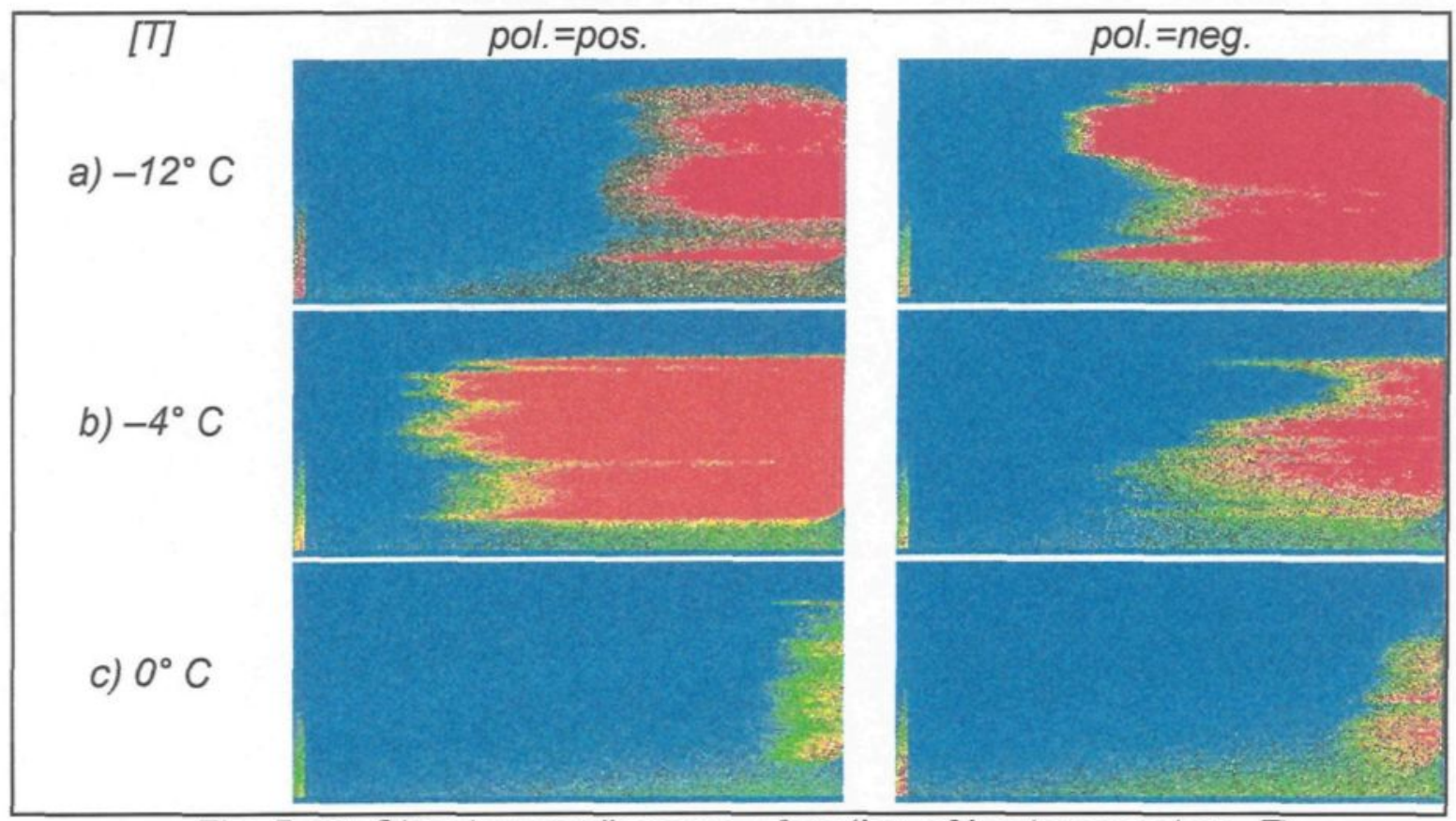

Fig. 5-12: Streak recordings as a function of ice temperature, $T$ $\left(\sigma=2.5 \times 10^{-4} \mathrm{~S} / \mathrm{m} ; d=18 \mathrm{~mm} ; r=6 \mathrm{~mm}\right.$; orient. $=$ hor.; $t_{\text {sweep }}=50 \mathrm{~ns}$ )

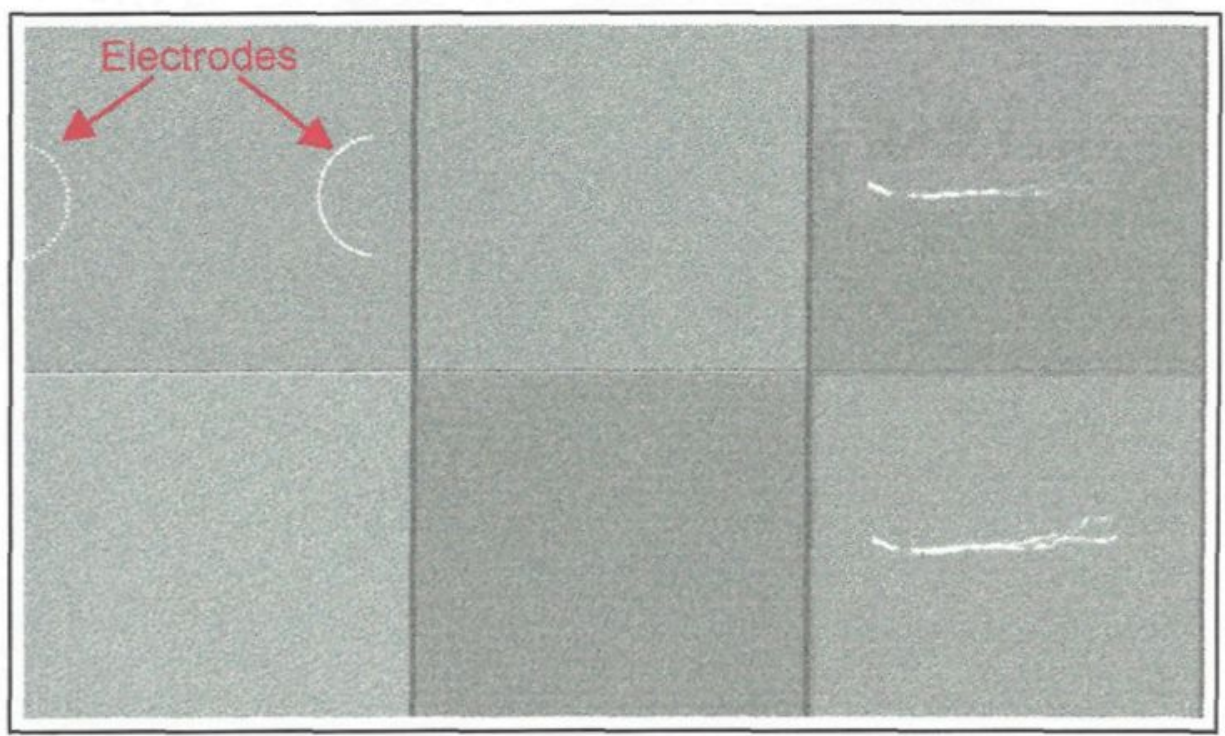

Fig. 5-13: Series of framing recordings showing the very fast temporal discharge development along the surface of the ice $\left(\sigma=30 \times 10^{-4} \mathrm{~S} / \mathrm{m} ; \mathrm{T}=-12^{\circ} \mathrm{C}\right.$; pol. =pos.; $d=18 \mathrm{~mm} ; r=6 \mathrm{~mm}$; orient. $=$ hor.; $t_{\text {frame }}=10 \mathrm{~ns} ; t_{\text {intert. }}=0 \mathrm{~ns}$ ) 


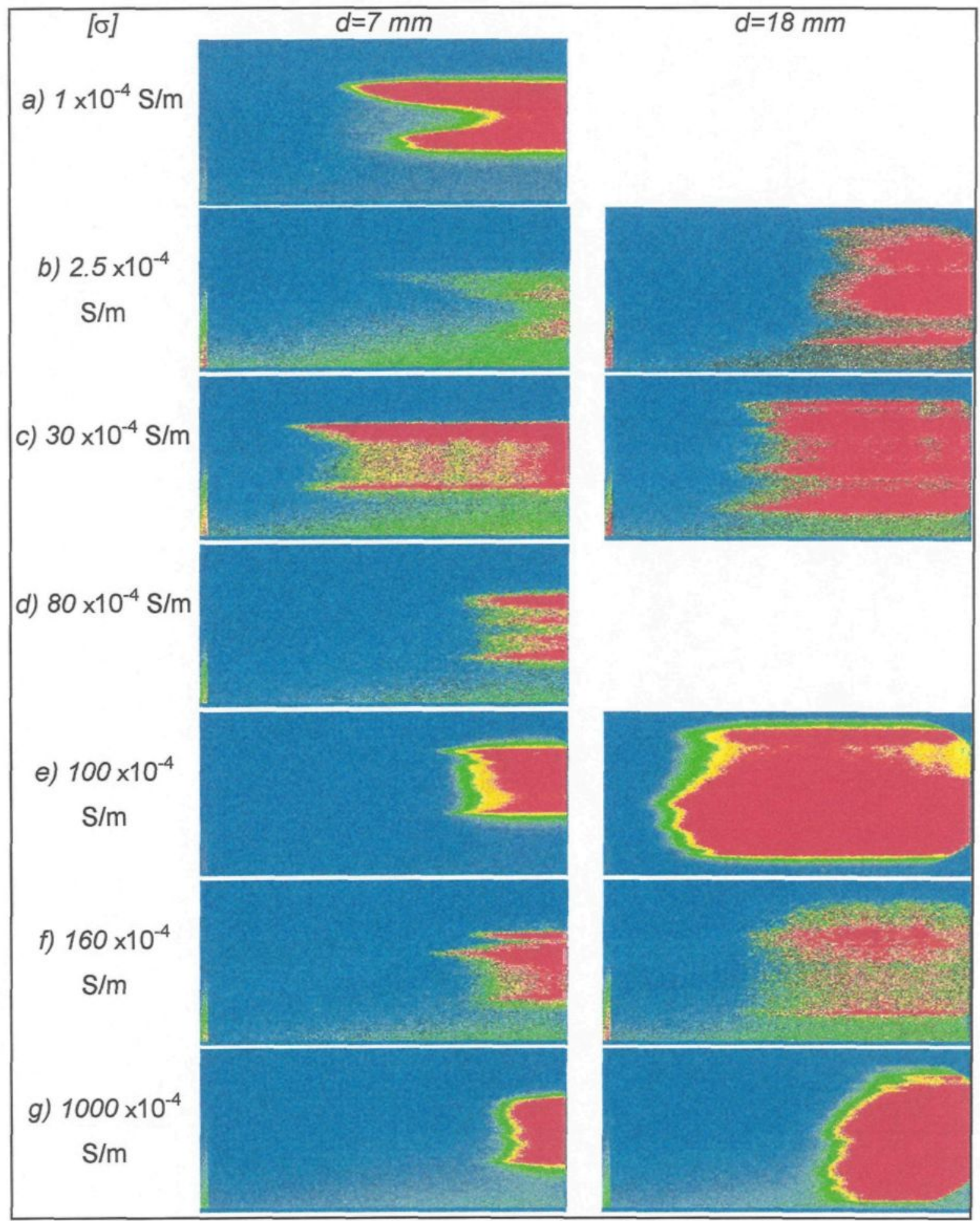

Fig. 5-14: Streak recordings as a function of electrode distance, $d$ ( $T=-12^{\circ} \mathrm{C}$ or $T_{u b c}=-20^{\circ} \mathrm{C}$; pol. =pos.; $r=6 \mathrm{~mm}$; orient. $=$ hor.; $t_{\text {sweep }}=50 \mathrm{~ns}$ ) 


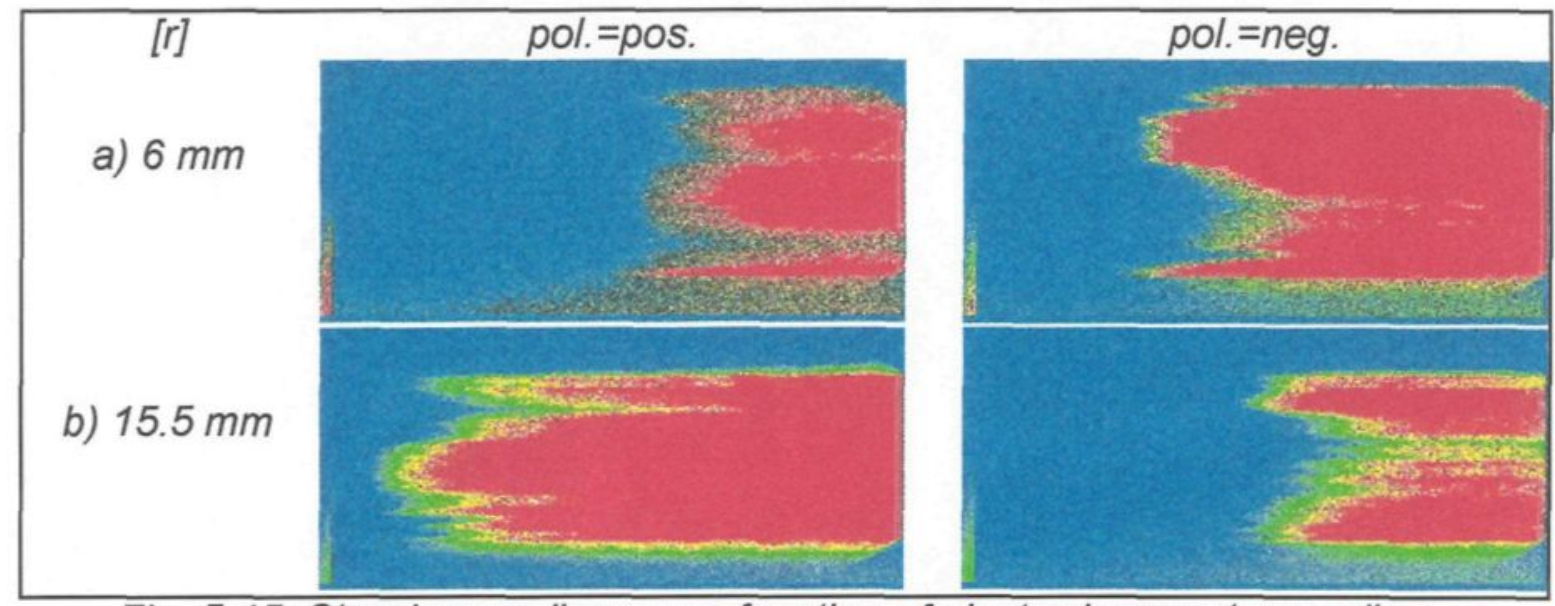

Fig. 5-15: Streak recordings as a function of electrode curvature radius, $r$ $\left(\sigma=2.5 \times 10^{-4} \mathrm{~S} / \mathrm{m} ; T=-12^{\circ} \mathrm{C} ; d=18 \mathrm{~mm}\right.$; orient. $=$ hor.; $\left.t_{\text {sweep }}=50 \mathrm{~ns}\right)$

Fig. 5-16: Streak recordings for increased electrode curvature radius as a function of freezing water conductivity and ice temperature (pol.=pos.; $d=18 \mathrm{~mm} ; r=15.5$ $\mathrm{mm}$; orient. $=$ hor.; $t_{\text {sweep }}=50 \mathrm{~ns}$ ) 


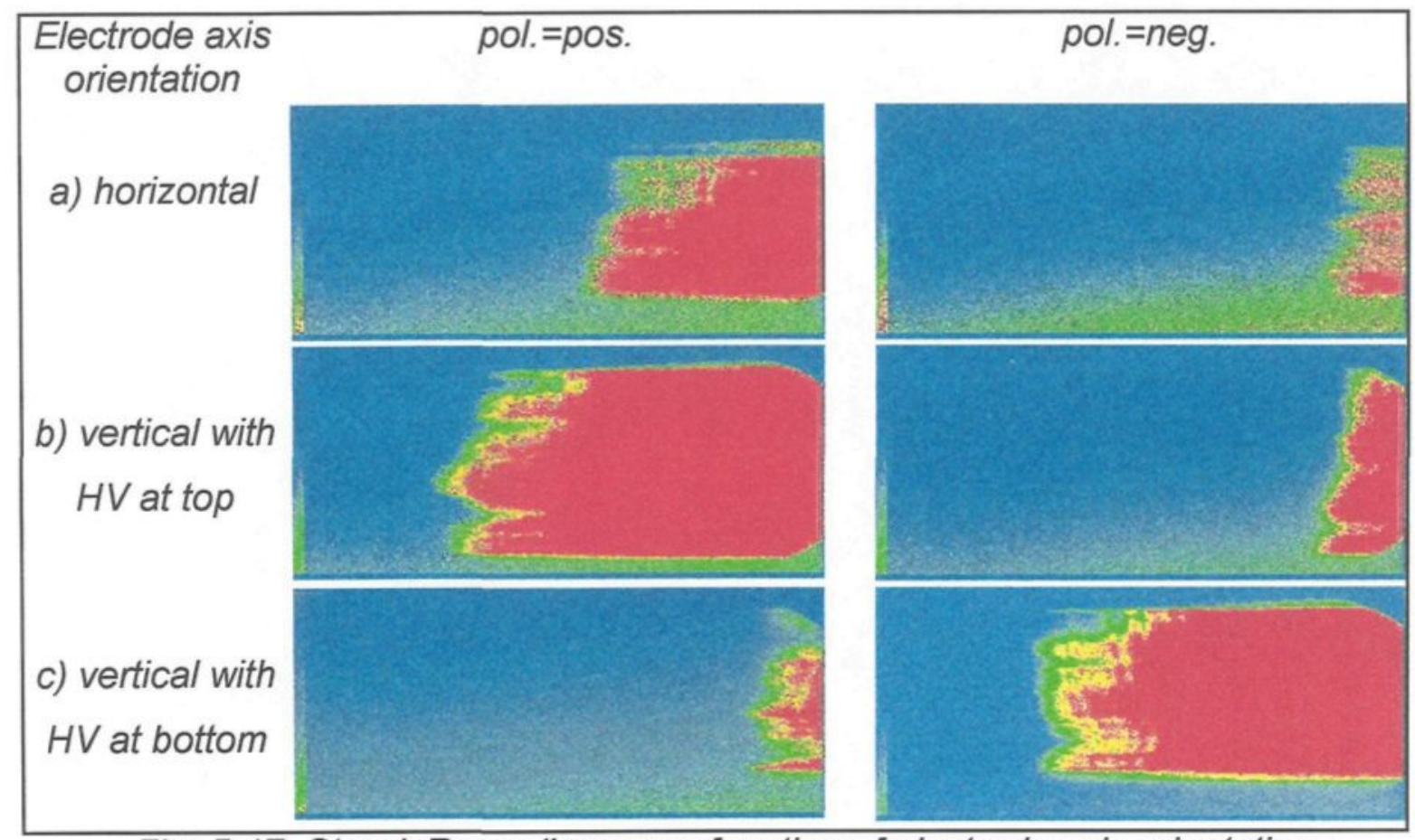

Fig. 5-17: Streak Recordings as a function of electrode axis orientation $\left(\sigma=30 \times 10^{-4} \mathrm{~S} / \mathrm{m} ; T=0^{\circ} \mathrm{C} ; d=18 \mathrm{~mm} ; \mathrm{r}=6 \mathrm{~mm} ; t_{\text {sweep }}=200 \mathrm{~ns}\right)$

\subsubsection{Discussion and Analysis}

\subsubsection{Comparison of Different Materials}

Figure 5-18 presents a comparison of the discharge development for different materials. In general, the discharges propagate much faster along ice surfaces than in an air gap for the same electrode configuration (Fig. 5-1). For higher values of freezing water conductivity or ice temperature, the discharge processes on an ice surface are quite similar to those found on synthetic insulating surfaces: The discharge develops very fast along the surface, and streak recordings with sweep 
periods $t_{\text {sweep }}=50$ ns show an almost vertical discharge front (Fig. 5-3). Several studies analysed this phenomenon for synthetic surfaces (see Sections 2.4.1 and 5.2) and it may be concluded that the deterioration of the withstand performance is founded in the charge accumulation along the surface. As ice shows similar effects on the discharge process, it may be assumed that it can also accumulate surface charges for dry ice surface conditions.

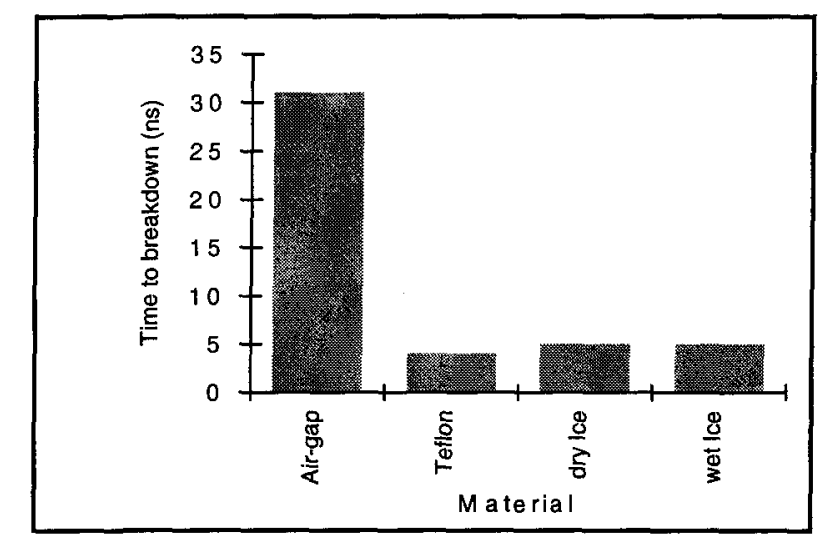

Fig. 5-18: Discharge development for different materials (dry ice: $\sigma=1000 \times 10^{-4} \mathrm{~S} / \mathrm{m} ; \mathrm{T}=-20^{\circ} \mathrm{C}$; wet ice: $\sigma=1 \times 10^{-4} \mathrm{~S} / \mathrm{m} ; \mathrm{T}=0^{\circ} \mathrm{C}$; all: pol.=pos.; $d=7 \mathrm{~mm} ; r=6 \mathrm{~mm}$ )

A closer look to the discharge front of the streak recordings of the surface of Teflon and those of ice under various conditions still reveals a difference. Whereas the discharge front of the streak recording for the Teflon surface is very smooth (Fig. 5-19a), it appears a little bit rough on the streak recordings for ice surfaces (Fig. 5-19b). The slightly discontinuous discharge development along an ice surface can be attributed to the ice's polycrystalline structure and numerous very small air gaps on the surface (see Section 3.3.3), while the surface of the Teflon 
spacer is very uniform. The influence of ice structure and uniformity on the discharge development is further discussed in Section 5.5 .

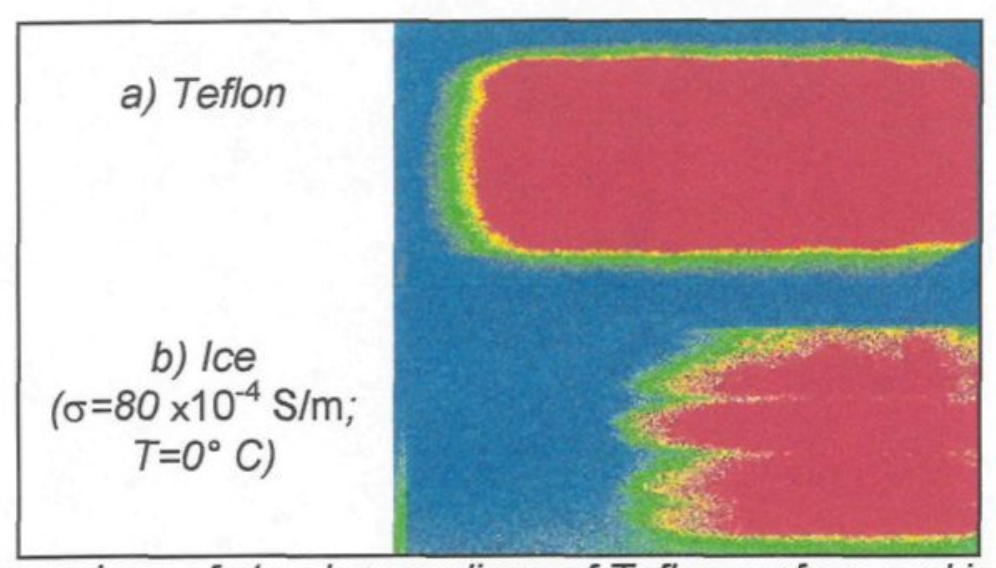

Fig. 5-19: Comparison of streak recordings of Teflon surface and ice surface for similar electrode configurations (pol. $=$ pos.; $d=18 \mathrm{~mm} ; r=6 \mathrm{~mm}$; $t_{\text {sweep }}=50 \mathrm{~ns}$ )

\subsubsection{Effect of Freezing Water Conductivity}

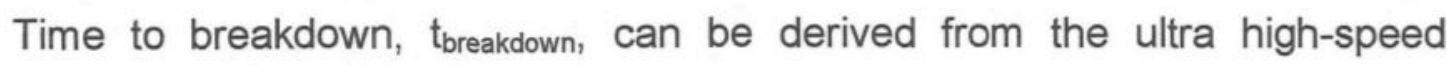
recordings. The results for the 7-mm model are derived from Fig. 5-9 and are presented in Fig. 5-20. Figure 5-21 illustrates the values obtained for the 18-mm model, derived from the streak recordings in Fig. 5-11.

The analysis reveals that the development of the discharge accelerates as freezing water conductivity increases. This behaviour appears for both voltage polarities and electrode distances. Previous research on ice physics has shown that ice surface conductivity depends on freezing water conductivity [24]. Furthermore, the conductivity of the water frozen in the surface layer exceeds that 
of the freezing water with which the ice was formed, due to the specific freezing process of ice where impurities migrate to the surface [11] [99]. Therefore, it can be stated that the faster discharge propagation is caused by an increase in ice surface conductivity.

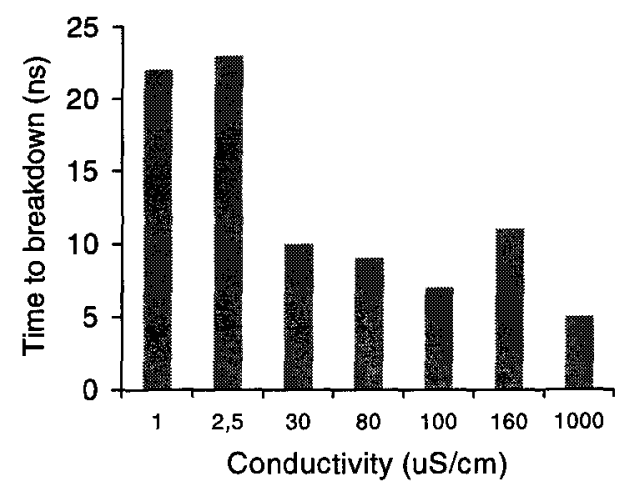

a) $p o l .=p o s$.

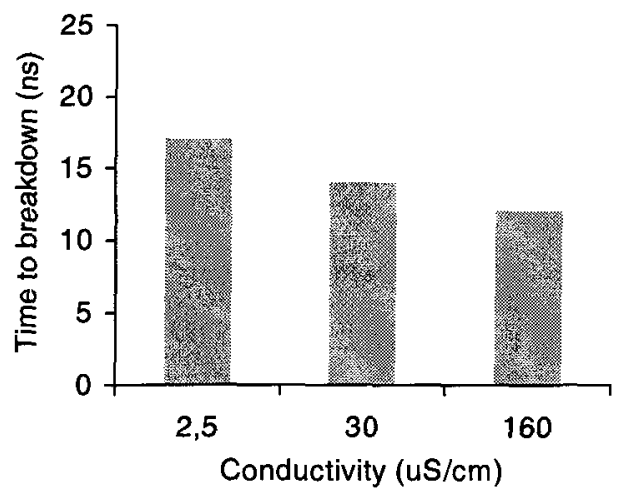

b) $p o l .=n e g$.

Fig. 5-20: Time to breakdown as a function of freezing water conductivity, $\sigma$ $\left(T=-12^{\circ} \mathrm{C}\right.$ or $T_{u b c}=-20^{\circ} \mathrm{C} ; d=7 \mathrm{~mm} ; r=6 \mathrm{~mm}$; orient.=hor.)

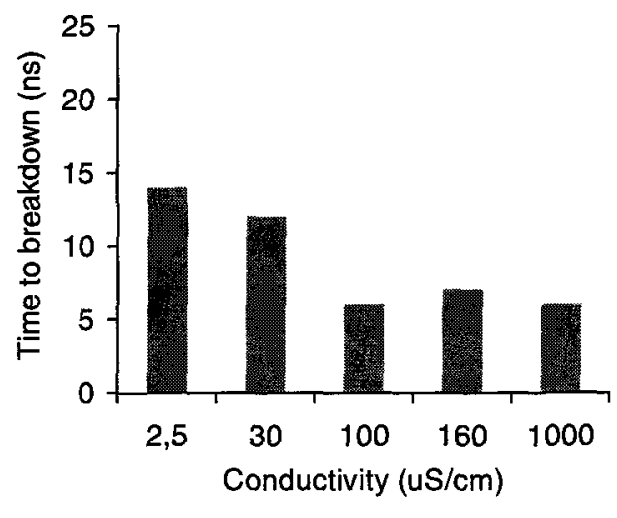

a) $p o l .=p o s$.

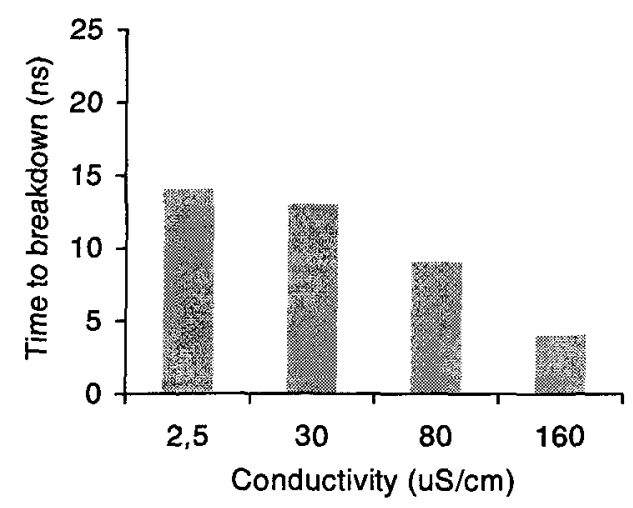

b) $p o l .=n e g$.

Fig. 5-21: Time to breakdown as a function of freezing water conductivity, $\sigma$ $\left(T=-12^{\circ} \mathrm{C}\right.$ or $T_{u b c}=-20^{\circ} \mathrm{C} ; d=18 \mathrm{~mm} ; r=6 \mathrm{~mm}$; orient.=hor.) 
The patterns of discharge development are discussed for the series of streak recordings with the 7-mm model (Fig. 5-9). For ice with high surface resistivity (low temperature, $T=-20^{\circ} \mathrm{C}$, and low freezing water conductivity, $\sigma=1 \times 10^{-4} \mathrm{~S} / \mathrm{m}$, Figs. 5-9a and b), it can be observed that the first visible discharge activity starts in front of the HV electrode. About 10 ns later, a second light emission appears in front of the ground electrode. Both partial discharges proceed into the middle of the space between the electrodes until breakdown occurs after about 22 ns. For ice samples produced with freezing water of higher conductivity, visible discharge activity starts again at the electrodes, but then bridges the whole interval between the electrodes after a shorter period, and total breakdown occurs faster (for example in Fig. 5-9d, for a freezing water conductivity of $\sigma=80 \times 10^{-4} \mathrm{~S} / \mathrm{m}$, the time to breakdown is $\mathrm{t}=9 \mathrm{~ns})$. For ice produced with highly conductive freezing water $\left(\sigma=160 \times 10^{-4} \mathrm{~S} / \mathrm{m}\right.$ or $\left.\sigma=1000 \times 10^{-4} \mathrm{~S} / \mathrm{m}\right)$, the discharge development is not only accelerated, but the discharge process obeys another pattern. The discharge seems to start somewhere on the surface of the ice (for example Fig. 5-9f), or at several places at the same time (for example Fig. 5-9g). The duration, from the start of the first visible discharge activity to total breakdown, was even shorter for the highest conductivity, $\sigma=1000 \times 10^{-4} \mathrm{~S} / \mathrm{m}$, compared to lower conductivity of $\sigma=100 \times 10^{-4} \mathrm{~S} / \mathrm{m}$ and less. 
In comparison with the results of the determination of the critical breakdown voltages, it can be seen that the decrease in $50 \%$ lightning impulse breakdown voltage is concurrent with a faster discharge development for ice surfaces without artificial air gap.

Furthermore, it can be seen very clearly that the time to breakdown is significantly shorter for the $18-\mathrm{mm}$ model, in comparison with the $7-\mathrm{mm}$ model, even if the distance between the electrodes is two and half times greater. This point will be discussed in Section 5.4.2.5.

\subsubsection{Effect of Ice Temperature}

Figure 5-22 shows the time to breakdown, $t_{\text {breakcown }}$, as a function of ice temperature for the 7-mm model, as derived from Fig. 5-10. The corresponding results for the 18-mm model, derived from Fig. 5-12, are presented in Fig. 5-23.

In general, the time to breakdown decreases for increasing temperatures towards the melting point. Furthermore, this behaviour is observed for both polarities. The characteristics of accelerated discharge development found for increasing ice temperature is quite similar to the results for increasing freezing water conductivity. Thus, the observations for both cases are attributed to the same physical phenomenon: Increasing ice surface conductivity. 


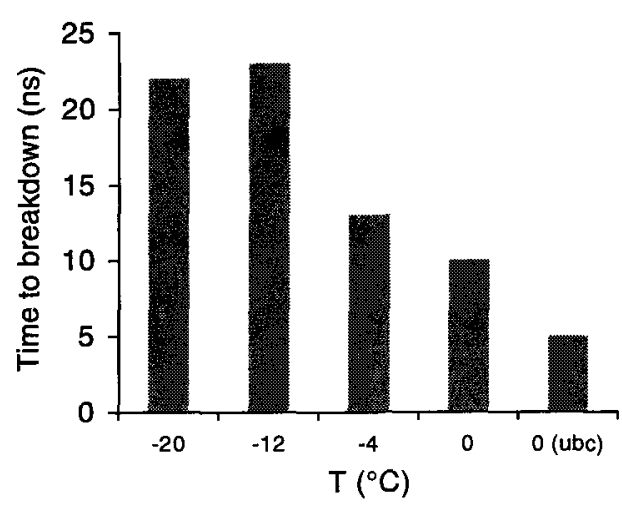

a) $p o l .=p o s$.

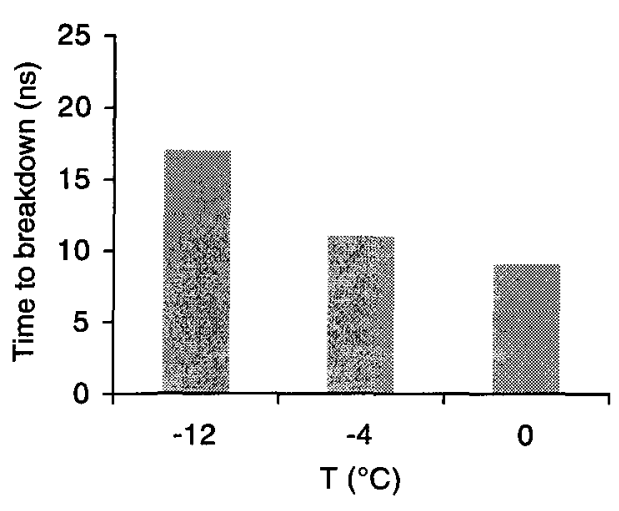

b) pol.=neg.

Fig. 5-22: Time to breakdown as a function of ice temperature, $T$ $\left(\sigma=2.5 \times 10^{4} \mathrm{~S} / \mathrm{m}\right.$ or $\sigma_{u b c}=1 \times 10^{4} \mathrm{~S} / \mathrm{m} ; d=7 \mathrm{~mm} ; r=6 \mathrm{~mm}$; orient.=hor.)

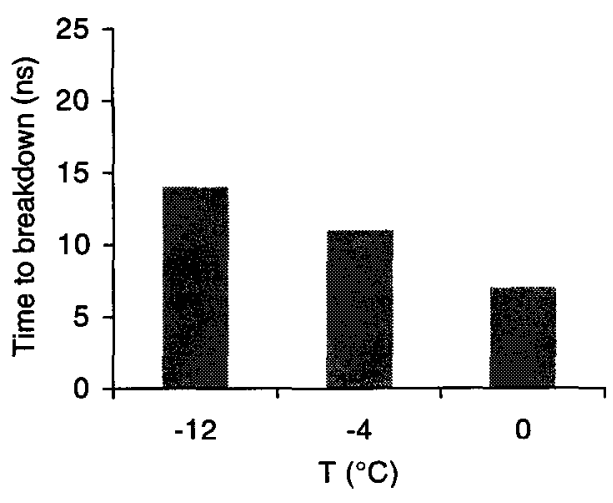

a) $p o l .=p o s$.

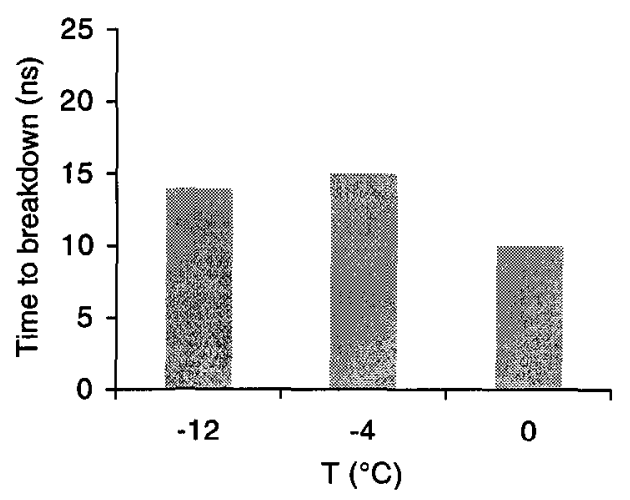

b) pol.=neg.

Fig. 5-23: Time to breakdown as a function of ice temperature, $T$ $\left(\sigma=2.5 \times 10^{4} \mathrm{~S} / \mathrm{m} ; d=18 \mathrm{~mm} ; r=6 \mathrm{~mm}\right.$; orient.=hor.)

It was already shown that ice surface conductivity increases with increasing ice temperature [11]. At lower temperatures (in the present case $T=-12^{\circ} \mathrm{C}$ ), the few uppermost layers of water molecules play an important role, as they exhibit a 
quasi-liquid characteristic [64] [74] [75] [112] (Section 2.2.3). The thickness of this bilayer increases with temperature [64], increasing in turn ice surface conductivity to a certain extent. At temperatures still somewhat below the melting point, a water film builds up at the solid-gas interface. This phenomenon causes an important increase in ice surface conductivity [40] [69], which can explain the significant difference in time to breakdown, $t_{\text {breakdown }}$, between temperatures $T=-12^{\circ} \mathrm{C}$ and $\mathrm{T}=-4^{\circ} \mathrm{C}$ (with exception of Fig. 5-23b).

A quantitative comparison of the influence of the two parameters "freezing water conductivity" and "ice temperature" reveals that the time to breakdown was about as long for a wet ice surface produced from de-ionised freezing water (Fig. 5-10e) as for a dry ice surface formed with highly conductive water (Fig. 5-9g): $\mathrm{t}_{\text {breakdown }}=5 \mathrm{~ns}$ in both cases.

Considering the results for the determination of the critical breakdown voltage (Section 4.3.3) and the visible discharge development, it can be concluded that lower breakdown voltage is concurrent to a faster discharge development along ice surfaces without artificial air gap, represented by a shorter time to breakdown. 


\subsubsection{Effect of Voltage Polarity}

To analyse the effect of voltage polarity on the visible discharge development, the patterns of light emission in the streak recordings in front of the two electrodes can be compared. In the case of the $18-\mathrm{mm}$ model, a pronounced discharge development was recorded for temperature $T=-4^{\circ} \mathrm{C}$ (Fig. 5-12b). Therefore, these images are discussed in more detail. A schematic representation of the streak recordings is presented in Fig. 5-24.

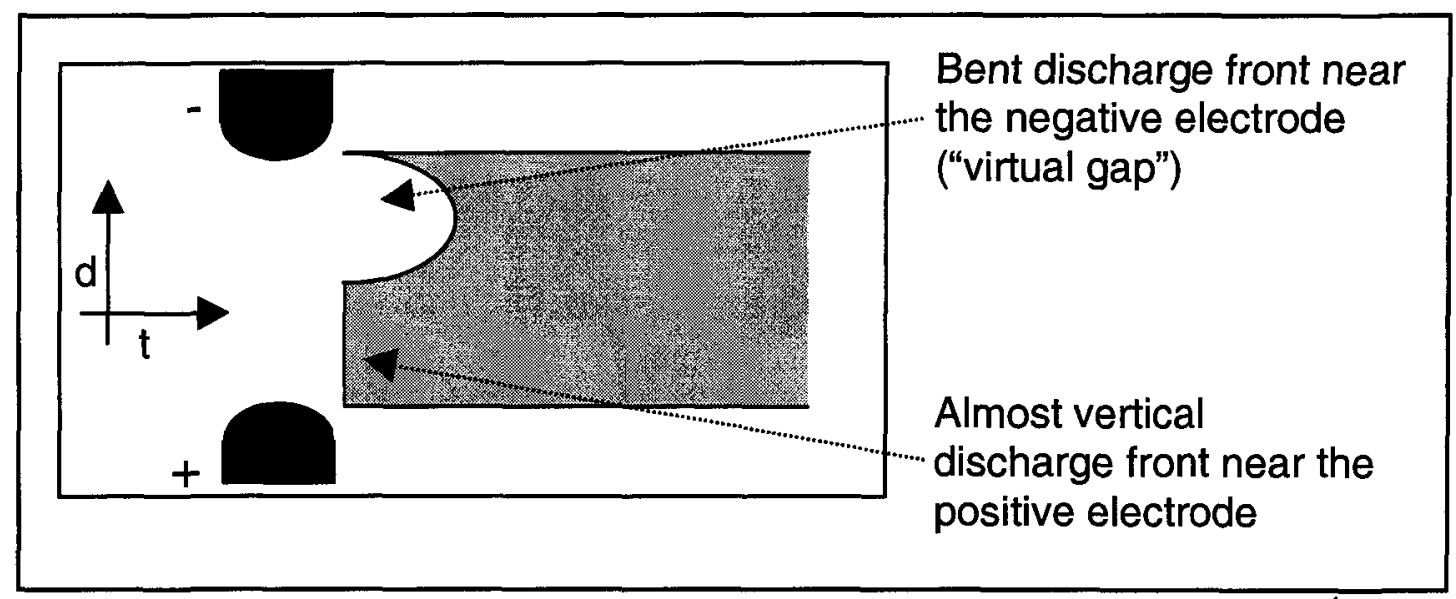

Fig. 5-24: Schematic representation of the streak recordings $\left(\sigma=2.5 \times 10^{4} \mathrm{~S} / \mathrm{m}\right.$;

$T=-12^{\circ} \mathrm{C} ;$ pol. $=n e g . ; d=18 \mathrm{~mm} ; r=6 \mathrm{~mm}$; orient.=hor.; $t_{\text {sweep }}=50 \mathrm{~ns}$ )

For negative voltage polarity applied to the HV electrode (HV electrode at the top in Fig. 5-12b and Fig. 5-24), the first discharge appeared at a location on the ice surface, not far from the grounded electrode (electrode at bottom in Fig. 5-12b). A short period later, a second discharge started in front of the negative HV electrode. Both activities grew together to finish in breakdown at a time $t=15 \mathrm{~ns}$. 
Thus, a pronounced discharge development can be observed starting near the grounded electrode (in this case positive pole as shown in Fig. 5-24) towards the negative $\mathrm{HV}$ electrode. If the recording for positive voltage polarity is regarded under the same aspect (Fig. 5-12b, left column), this arc-like discharge front can also be found, this time in front of the grounded electrode at the bottom of the photograph, which plays the role of negative pole for positive impulse voltage applied to the HV electrode. More cases of discharge development towards negative electrode (HV electrode for negative voltage or grounded electrode for positive voltage) can also be found in several other streak recordings for the 7-mm model, for example Fig. 5-9f or Fig. 5-10c. Furthermore, discharge activity is initiated first in front of the positive electrode for the $7-\mathrm{mm}$ model, at very low freezing water conductivity $\left(\sigma \leq 2.5 \times 10^{-4} \mathrm{~S} / \mathrm{m}\right)$ and low temperatures $\left(\mathrm{T} \leq-12^{\circ} \mathrm{C}\right)$ (Fig. 5-9a and b). Some nanoseconds later, a second visible discharge activity appears in front of the negative electrode.

Generally, the first visible discharge activity is somewhat more likely to appear in front or near the positive electrode and the succeeding growing process develops towards the negative electrode. However, this is not always the case. For example, a different discharge initiation near the negative HV electrode can be seen in Fig. 5-12a. In the case that discharge activity appears in front of both electrodes simultaneously, the discharge in front of the positive HV electrode propagates faster in most cases (see Section 5.4.2.8). A similar polarity effect of 
faster moving positive discharge was already observed in a study on propagation of electrical discharges along the surface of a water bath (see Section 2.4.2) [10].

For dry ice surfaces, this observation may be related to the fact that the electric conduction of ice is mainly of protonic nature [47] [73]. First, free charges may be created in regions of increased electric field in the gaseous space. These free charges may lead to surface charge accumulations similar to those proposed for discharges on synthetic surfaces (see Section 2.4.1) [2]. Near the anode, positive charges in the form of protons and positive ions are accumulated, whereas, in front of the cathode, an excess of negative ions is present. A study on streamer propagation along insulating surfaces showed that a streamer system consisting of two components appears in the presence of a solid-gas interface [1]. The surface component travels much faster than a streamer in air alone. If we assume that in the present case of an ice surface, the same phenomenon of a combined streamer system exists, we can expect that it will propagate much faster in front of the positive electrode, due to the protonic conduction characteristic of ice.

\subsubsection{Effect of Electrode Distance}

Figure 5-14 presents a comparison of the streak recordings for the two different electrode distances under the same experimental conditions. It can be 
seen very clearly that the discharge development is in general faster for the $18-\mathrm{mm}$ model, even if the distance is more than twice that of the 7- $\mathrm{mm}$ model. Not only the streak photographs, but also the framing recordings show the very fast discharge development along the ice surface (Fig. 5-13). Even with the fastest framing rate $\left(t_{\text {rame }}=10 \mathrm{~ns} ; t_{\text {intertr }}=0 \mathrm{~ns}\right)$, no gradual discharge development could be recorded. Whereas the fourth frame does not show any visible light emission, the fifth frame shows a local arc bridging almost the whole distance (in this case $d=18 \mathrm{~mm}$ ) between the electrodes. In comparison with this fast ice surface discharge, the discharge of a 7-mm air gap develops gradually over 4 frames for the same camera adjustments (Fig. 5-2).

Previous research showed that breakdown may occur immediately without the appearance of preceding corona discharges for very short distances between the electrodes (see Section 2.3.3) [67]. Therefore, it is assumed that no charge accumulation takes place in the case of the $7-\mathrm{mm}$ model, as no pre-discharge activity is encountered. The ionisation processes start in front of the electrodes from where they proceed along dry ice surfaces until they meet to initiate ice surface breakdown.

For the 18-mm model, the streak recordings show that the visible discharge may start at a location on the ice surface (Fig. 5-11b, c, d, e, and f) or in front of the electrodes (Fig. 5-11a, b, c, e, and f). Sometimes, it appears at several locations at 
the same time (Fig. 5-11b, c and f). A previous investigation on surface flashover under combined icing and contamination conditions reported also the possibility of discharge initiation on the ice surface [95]. Therefore, it is assumed that some nonvisible processes take place and lead to charge accumulation along the ice surface before the appearance of visible discharges. The electric field becomes distorted locally due to the surface charges, and ionisation processes may start at the locations where the critical field value is exceeded.

This hypothesis is supported by a recent publication on pre-breakdown phenomena at a solid-gas interface in the case of $\mathrm{SF}_{6} / \mathrm{N}_{2}$ mixtures [85], which reports a comparison of experimental investigations and numerical simulations of the pre-breakdown process. The experimental investigations revealed that due to surface charge accumulation, first appearance of visible discharges were found on the surface, at a certain distance from the electrodes. A calculation based on a numerical model without considering any surface charge accumulation did indicate that the first visible discharge activity would appear in front of the electrode. A reason for this discrepancy could be the fact that the numerical model did not take into account surface charge accumulation. These findings, despite the different materials investigated, may confirm the explanation for the different discharge development processes as a function of electrode distance as found in the present study. 
Another factor may enhance the acceleration of discharge development. The greater distance between the electrodes, $d=18 \mathrm{~mm}$, for constant electrode radius $r=6 \mathrm{~mm}$, leads to a less uniform electric field. This may initiate non-visible predischarge phenomena ("pre-cursor") leading again to charge accumulation on the dry ice surface, which changes locally the electric field distribution along the ice surface.

Depending on the distance between the electrodes, different regimes for the discharge development along the ice surface may be identified. Such a theory was already proposed in the field of flashover processes on solid insulator surfaces [100] [101], where three different regions for flashover characteristics as a function of distance were identified. The results of the present study provide data on two distances, $d=7 \mathrm{~mm}$ and $\mathrm{d}=18 \mathrm{~mm}$. The observations allow describing the different processes for the two distances, but no upper or lower limits of the different regions of the discharge regimes may be determined.

\subsubsection{Effect of Electrode Curvature Radius}

The values for the time to breakdown as a function of electrode curvature radius, derived from the streak recordings in Fig. 5-15, are shown in Fig. 5-25. 


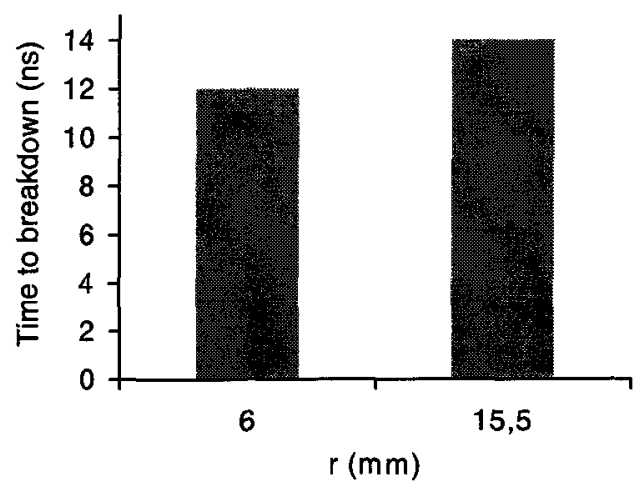

a) $p o l .=p o s$.

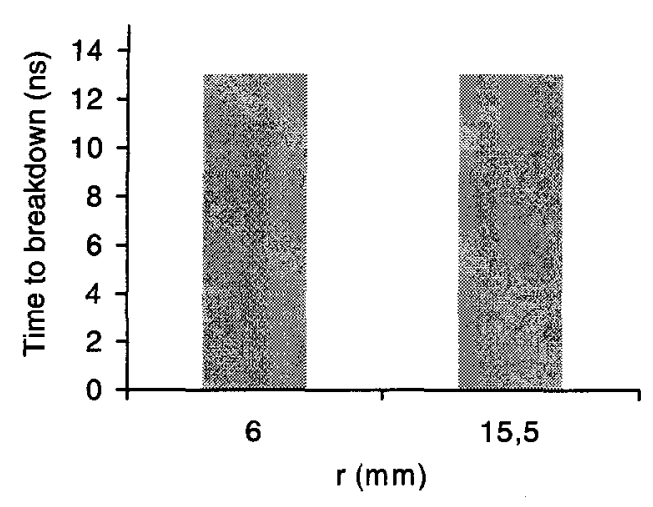

b) pol.=neg.

Fig. 5-25: Time to breakdown as a function of electrode curvature radius, $r$ $\left(\sigma=2.5 \times 10^{4} \mathrm{~S} / \mathrm{m} ; \mathrm{T}=-12^{\circ} \mathrm{C} ; d=18 \mathrm{~mm}\right.$; orient.=hor.)

Under consideration of the accuracy of the streak recordings with sweep time $t_{\text {sweep }}=50 \mathrm{~ns}$, no significant difference can be found for the two different electrode radii, whereas, some differences can be identified regarding the pattern of the light emissions in the streak recordings: In case of electrode radius $r=6 \mathrm{~mm}$, the discharge starts at several points at the same time, in the middle of the ice surface as well as in front of the two electrodes. The streak recording for increased electrode radius (Fig. 5-15b) and positive voltage shows a similar discharge development. For negative voltage however, the visible discharge initiation takes place in front of the two electrodes. This difference in the charge deposit and discharge initiation disappears for higher freezing water conductivity and ice temperatures (Fig. 5-16). In these cases, surface charges cannot be accumulated due to the increased ice surface conductivity. The discharge front becomes almost 
vertical and the time to breakdown decreases as observed beforehand for ice models with standard electrode radii (Figs. 5-11 and 5-12).

As discussed earlier, discharge initiation on dry ice surfaces is assumed to be influenced by surface charge accumulation (Section 5.4.2.5). In this respect, it can be concluded that an increased electrode radius for a constant distance between the electrodes leads to a more uniform field distribution and reduces the deposit of surface charges. The fact that a larger electrode radius leads to higher critical breakdown voltage levels for any value of ice temperature (Section 4.3.6) confirms the proposed theory on reduced surface charge accumulation.

\subsubsection{Effect of Electrode Axis Orientation}

The pattern of light emissions (Fig. 5-17), as well as the derived values for the time to breakdown (Fig. 5-26), revealed that the electrode axis orientation does not seem to influence the visible discharge development significantly for the physical model of this study. As already mentioned in Chapter 4, concerning the critical breakdown voltages (Section 4.3.7), the absence of any influence of electrode axis orientation is attributed to the simplified geometric shape of the model. 


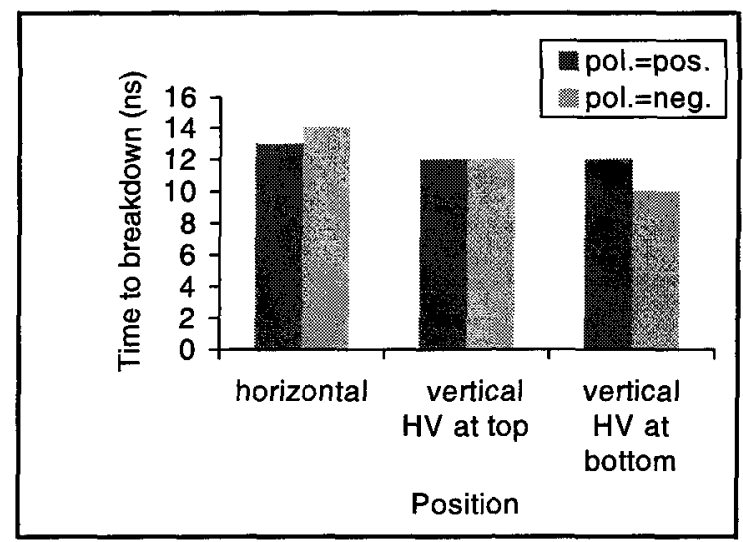

Fig. 5-26: Time to breakdown as a function of electrode axis orientation $\left(\sigma=30 \times 10^{4} \mathrm{~S} / \mathrm{m} ; T=0^{\circ} \mathrm{C} ; d=18 \mathrm{~mm} ; \mathrm{r}=6 \mathrm{~mm}\right)$

\subsubsection{Discharge Propagation Velocity}

The velocity of discharge propagation can be obtained from the streak images (see Section 3.5.2 for further information on speed calculation). However, the results do not represent the actual propagation speed of particles like electrons or molecules. The calculated values represent the velocity with which the zone of ionisation is advancing along the ice surface. No distinction is made between the time that it takes first to initiate the ionisation processes, and the duration of propagation of the charge carriers along the surface. Nevertheless, the results may give a good idea about the order of magnitude of the speed of discharge development along ice surfaces under the experimental conditions used. 


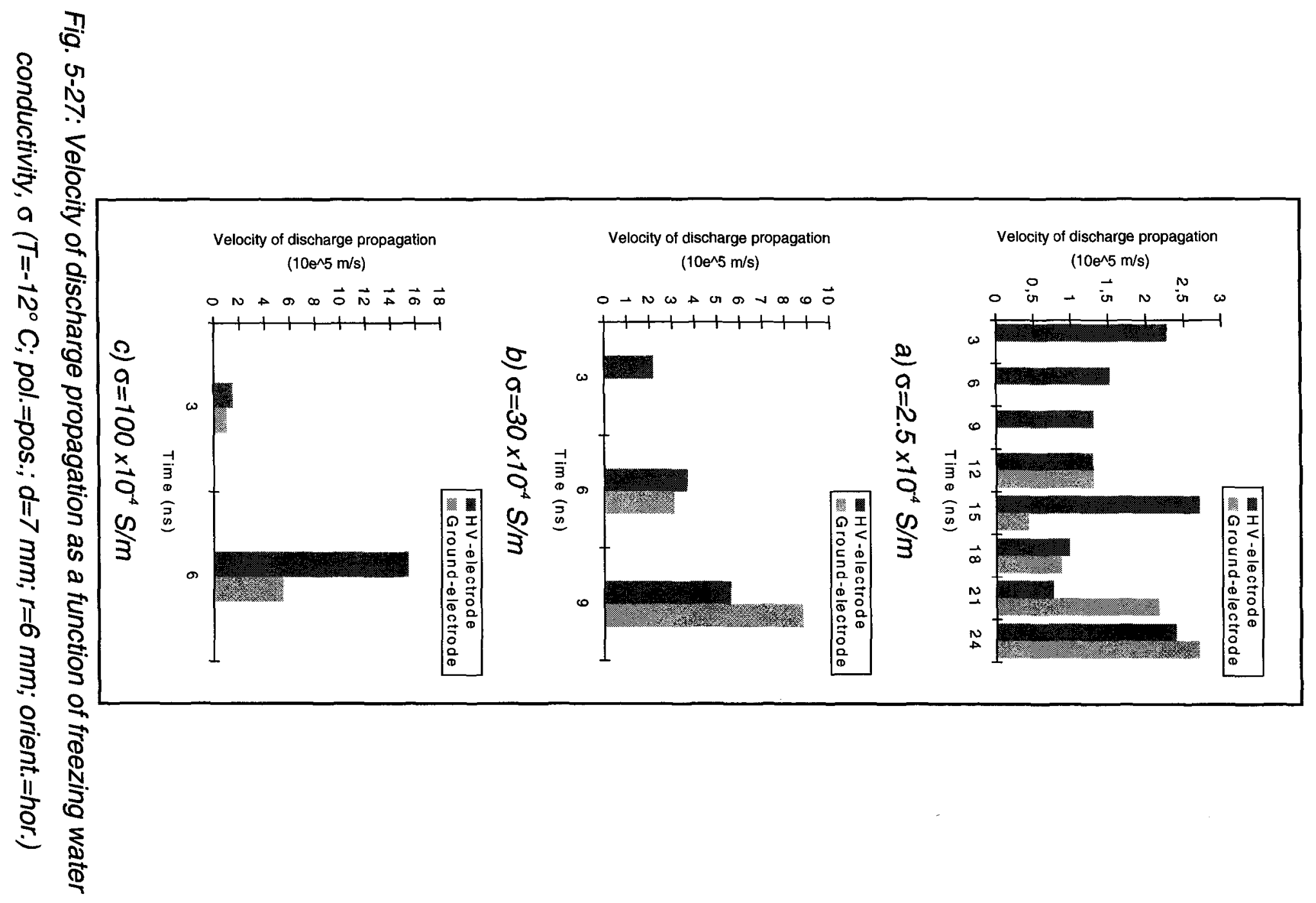


As the discharge development lasts longer for the 7-mm model, calculations of the discharge propagation velocity are carried out for the 7-mm model representatively. Three levels of freezing water conductivity are studied and the results are presented in Fig. 5-27. The corresponding streak recordings can be found in Figs. 5-9b, c and e.

It can be seen that the velocity of discharge propagation is not constant. After the discharge has started at a certain velocity, it continues to propagate somewhat slower. This behaviour can be attributed to the distribution of the electric field in the space between the electrodes, which is not totally uniform (see Section 3.3.2). Then, the velocity increases again as the discharge proceeds from the electrodes along the surface and approaches the second discharge activity, which has started in front of the other electrode. From time to time, the velocity seems to increase in steps, in particular in the final stage. A very fast development (like a final jump) can be found when both partial discharges meet, leading to final breakdown along the ice surface. The values for discharge propagation velocity range from about $1.5 \times 10^{5} \mathrm{~m} / \mathrm{s}$ to $2.5 \times 10^{5} \mathrm{~m} / \mathrm{s}$ in the first $3 \mathrm{~ns}$-interval up to more than $10 \times 10^{5} \mathrm{~m} / \mathrm{s}$ for the final jump in the last 3 ns-interval immediately before total breakdown. Furthermore, the calculated velocity values illustrate very clearly the acceleration effect of increasing ice surface conductivity revealed beforehand (Sections 5.4.2.2 and 5.4.2.3). 
It can be said that the discharge growth from the positive HV electrode is faster in most cases, in comparison with the discharge activity in front of the negative electrode (with exception of the final stages for $\sigma=2.5 \times 10^{-4} \mathrm{~S} / \mathrm{m}$ and $\sigma=30 \times 10^{-4} \mathrm{~S} / \mathrm{m}$, Fig. 5-9a and b). A similar polarity effect of faster moving positive discharge was already observed in a study on discharge propagation of electrical discharges along the surface of an electrolyte [10].

In the case of the 18-mm model, propagation velocities of the visible discharge processes are much higher than for the 7-mm model (Section 5.4.2.5). The gradual development observed for the $7-\mathrm{mm}$ model is not found for increased electrode distance, therefore it can be concluded that another type of discharge process takes place (see Section 5.4.2.5). For low freezing water conductivity and low temperature, discharge propagation velocities of about $15 \times 10^{5} \mathrm{~m} / \mathrm{s}$ can be observed in the case of increased electrode distance, whereas for freezing water conductivity exceeding $\sigma=100 \times 10^{-4} \mathrm{~S} / \mathrm{m}$ and temperatures near the melting point, $\mathrm{T}=0^{\circ} \mathrm{C}$, the discharge development becomes so fast that it cannot be resolved with the experimental set-up used. The front of the visible discharge phenomenon appears as a vertical line on the streak photograph.

In summary, it can be said that the values obtained for the discharge development velocity along the ice surfaces are in the same range as results of a study on streamer propagation on different synthetic insulating surfaces [1]. 


\subsubsection{Effect of Steepness of Voltage Rise}

Another experimental parameter should be mentioned: The steepness of the applied impulse voltage. During the preliminary test series at UBC, some experiments were carried out using a 7-mm Teflon spacer. The streak recordings did change if the steepness of the applied voltage was increased. The assumption was established that there may be a dependence of the waveform of the applied impulse voltage on the discharge development process. However, no other results or discussions on this point were found in the literature, in spite of the numerous studies in the field of discharges on synthetic insulator surfaces.

Some tests were carried out with ice models in the first experimental phase at UBC. The images obtained are shown in Fig. 5-28, related to the $U_{50 \%}-t$ characteristic. The streak recordings show a change in the light emissions: The discharge propagation velocity seems to decrease for decreasing steepness of voltage rise. It is assumed that longer voltage application time allows the nonvisible pre-discharge phenomena to accumulate more surface charges on dry ice surfaces, which leads in turn to faster visible discharge development leading to breakdown. However, no general tendency can be concluded at this moment, as experiments on the parameter "voltage rise time" did not always reveal the same results for constant experimental conditions. Furthermore, the experimental set-up at UQAC did not allow continuing the recordings of very early breakdown. 
Therefore, no conclusion can be drawn at this moment, but it is proposed that the gradient of increase of applied voltage may be considered as one of the experimental parameters in further investigations. A new control unit of the HV system at UQAC will render the observation of very early discharge phenomena possible in the future.

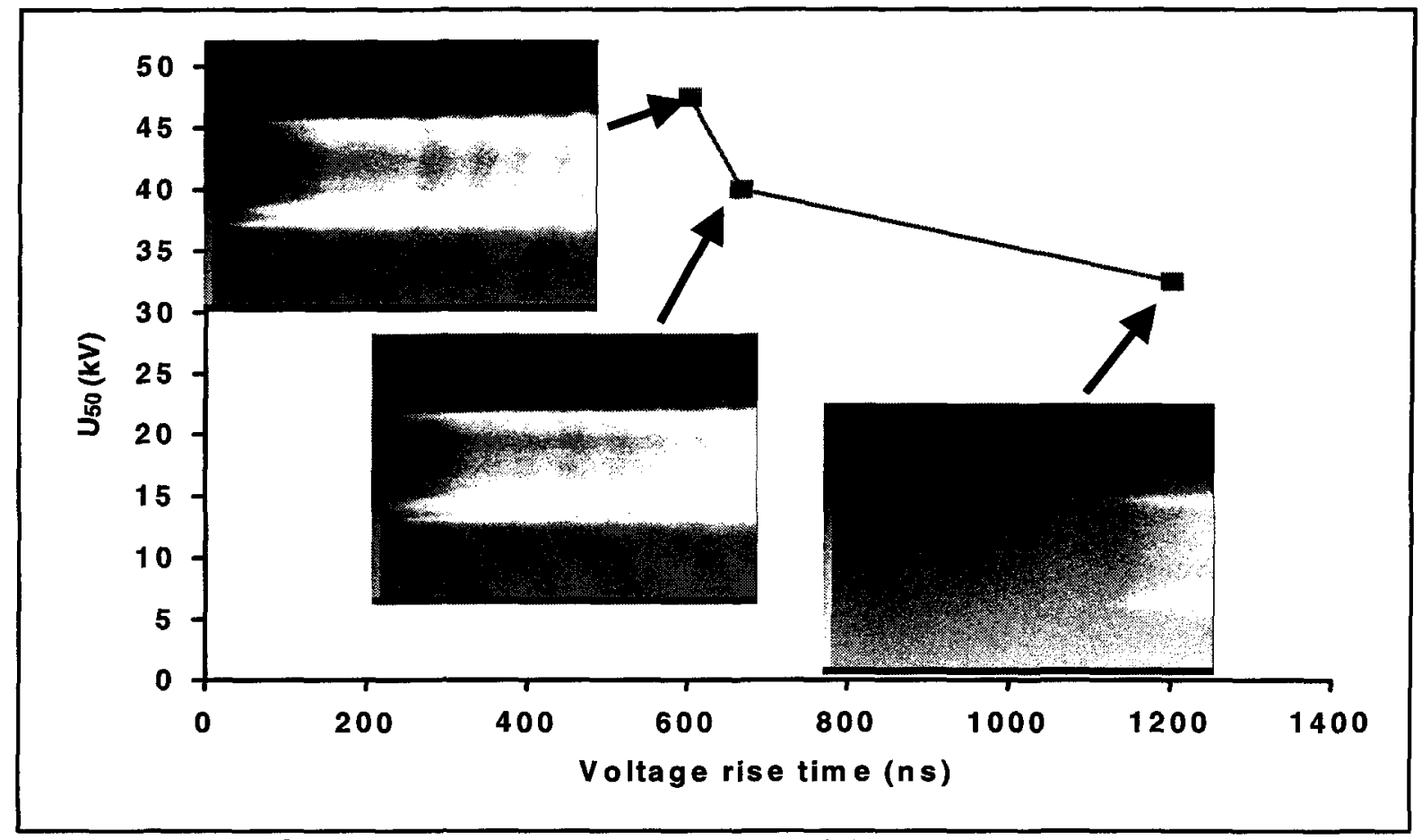

Fig. 5-28: Streak recordings as a function of the steepness of voltage rise $\left(\sigma=30 \times 10^{-4} \mathrm{~S} / \mathrm{m} ; \mathrm{T}=-12^{\circ} \mathrm{C}\right.$; pol.=pos.; $d=7 \mathrm{~mm} ; \mathrm{r}=6 \mathrm{~mm}$; orient.=hor.) 


\subsection{Ultra High-speed Photographic Observations for Ice Surfaces with Air Gaps}

\subsubsection{Experimental Results}

\subsubsection{Ice Samples with Artificial Air Gap}

Several experiments were carried out using the $18-\mathrm{mm}$ ice model with an artificially introduced air gap in order to create a non-uniform ice surface, and study the combined air gap and ice surface breakdown. Figure 5-29 shows some still photographs and streak recordings for different air gap locations. A series of framing recordings for an artificial air gap in front of the HV electrode is presented in Fig. 5-30. Figure 5-31 shows the influence of ice temperature on the combined air gap and ice surface breakdown. As the determination of the $50 \%$ lightning impulse breakdown voltage already revealed that air gap location influences the ice surface breakdown process (Tables 4-7 and 4-8 and Section 4.3.8), an experiment was carried out to study visible discharge development as a function of air gap location. Results for this parameter $(a=$ distance from $\mathrm{HV}$ electrode $)$ are presented in Fig. 5-32. Finally, Fig. 5-33 shows some streak recordings, which may provide indications of pre-discharge activity inside the air gap, and of discharge initiation at the border of the artificial air gap. 


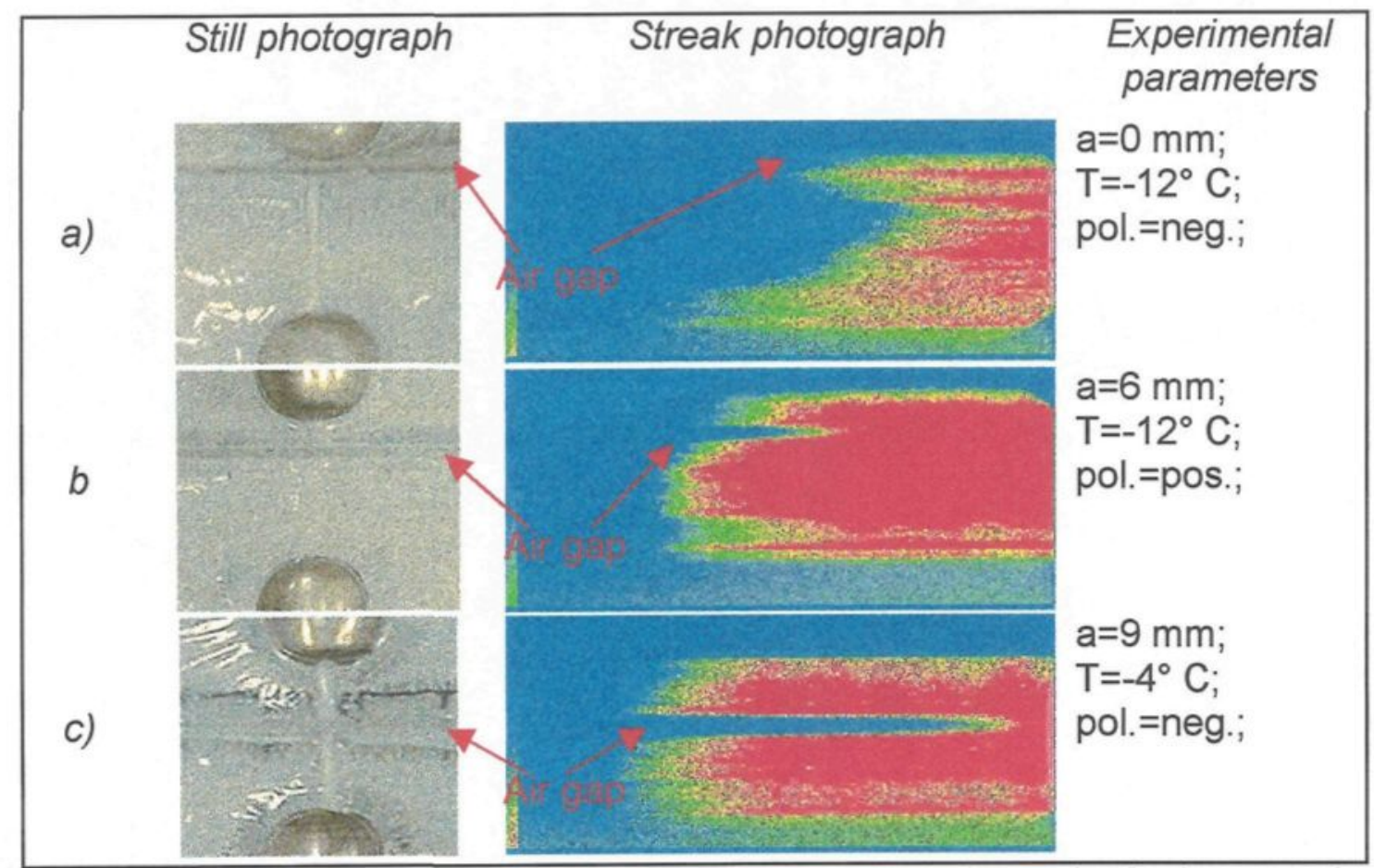

Fig. 5-29: Parallel streak recordings and surface still photographs for ice samples with an artificially introduced air gap

$$
\left(\sigma=30 \times 10^{-4} \mathrm{~S} / \mathrm{m} ; d=18 \mathrm{~mm} ; r=6 \mathrm{~mm} \text {; orient. }=h o r \text {.; } t_{\text {sweep }}=50 \mathrm{~ns}\right. \text { ) }
$$




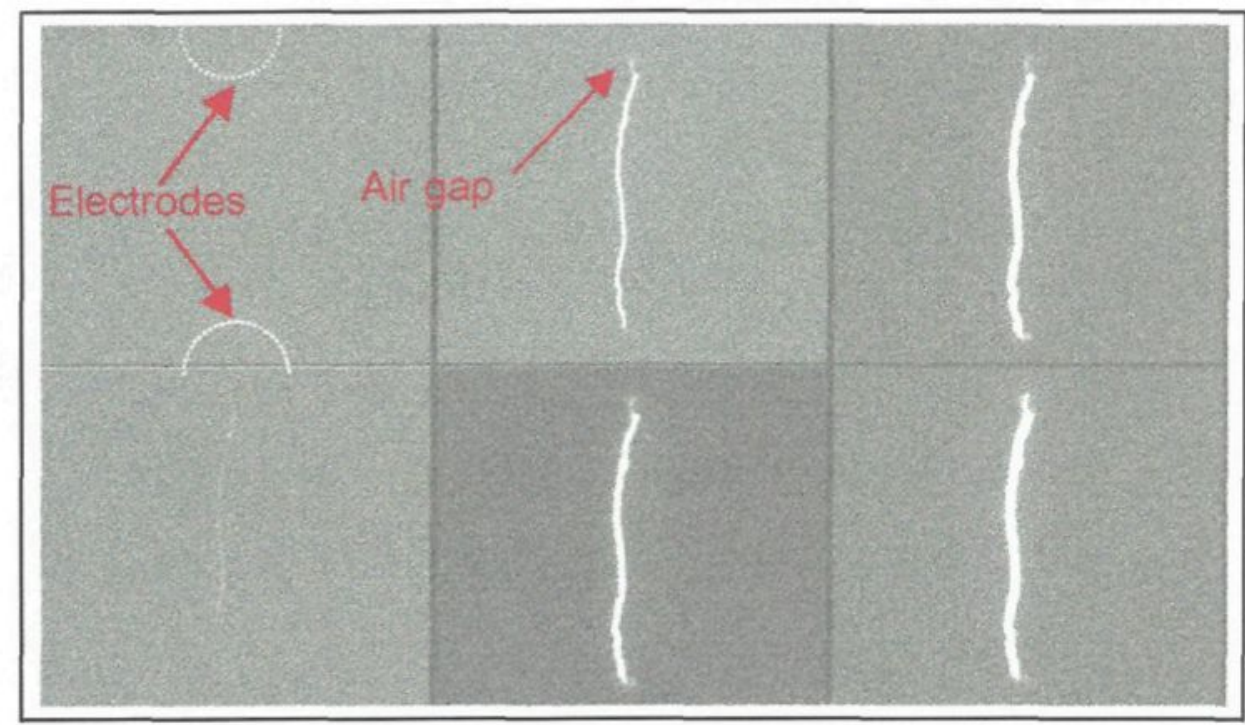

Fig. 5-30: Series of framing recordings of the discharge development for an air gap located in front of the $\mathrm{HV}$ electrode $\left(\sigma=30 \times 10^{-4} \mathrm{~S} / \mathrm{m} ; \mathrm{T}=0^{\circ} \mathrm{C} ; \mathrm{pol}\right.$. $=p o s$.; $d=18 \mathrm{~mm}$; $r=6 \mathrm{~mm}$; orient. =hor.; $a=0 \mathrm{~mm}$; no channel or groove; $\left.t_{\text {frame }}=10 \mathrm{~ns} ; t_{\text {interf. }}=50 \mathrm{~ns}\right)$

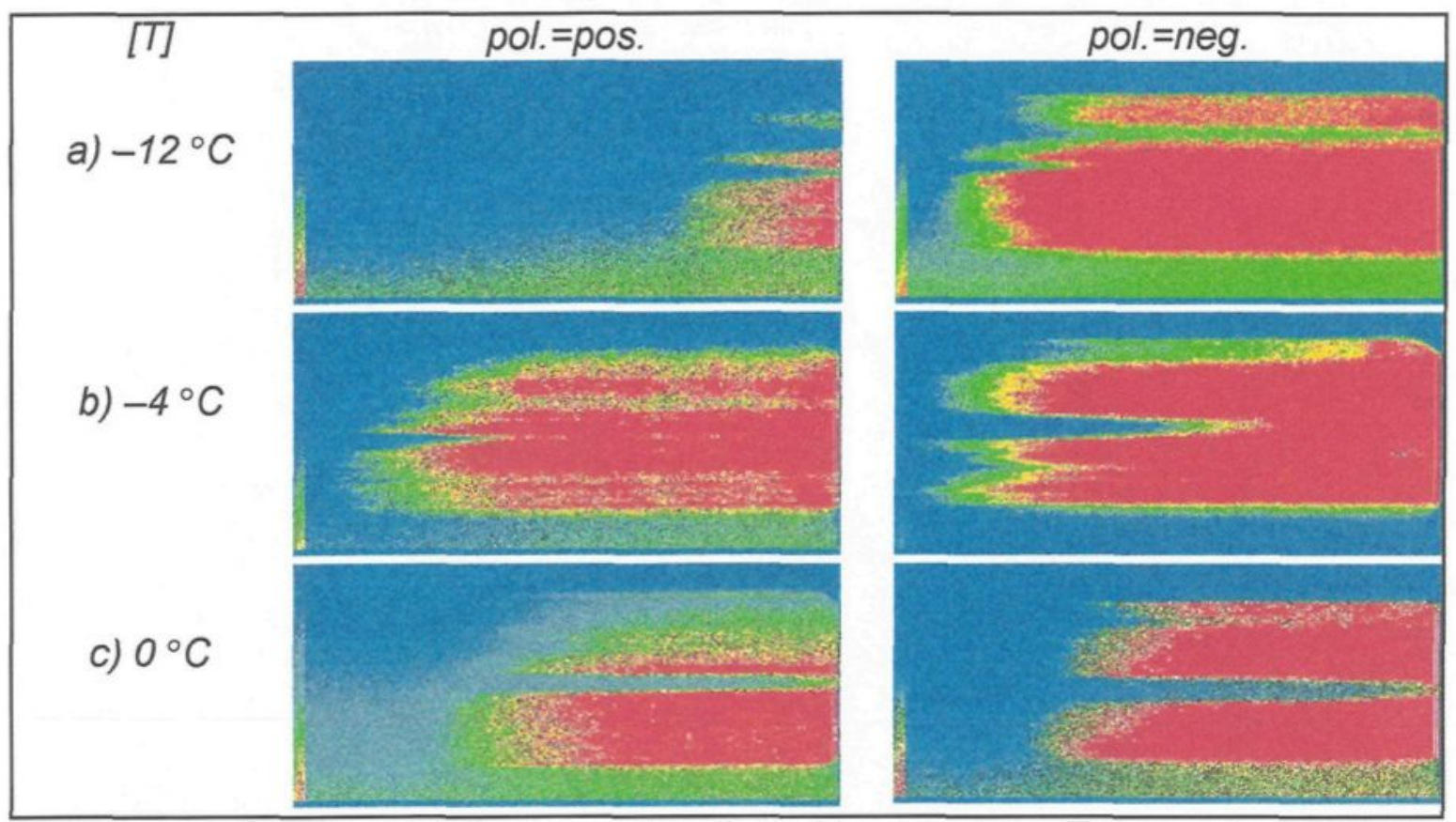

Fig. 5-31: Streak recordings as a function of temperature, T, for central air gap $\left(\sigma=30 \times 10^{-4} \mathrm{~S} / \mathrm{m} ; d=18 \mathrm{~mm} ; \mathrm{r}=6 \mathrm{~mm}\right.$; orient.=hor.; path=cha.; $\left.a=9 \mathrm{~mm} ; t_{\text {sweep }}=50 \mathrm{~ns}\right)$ 


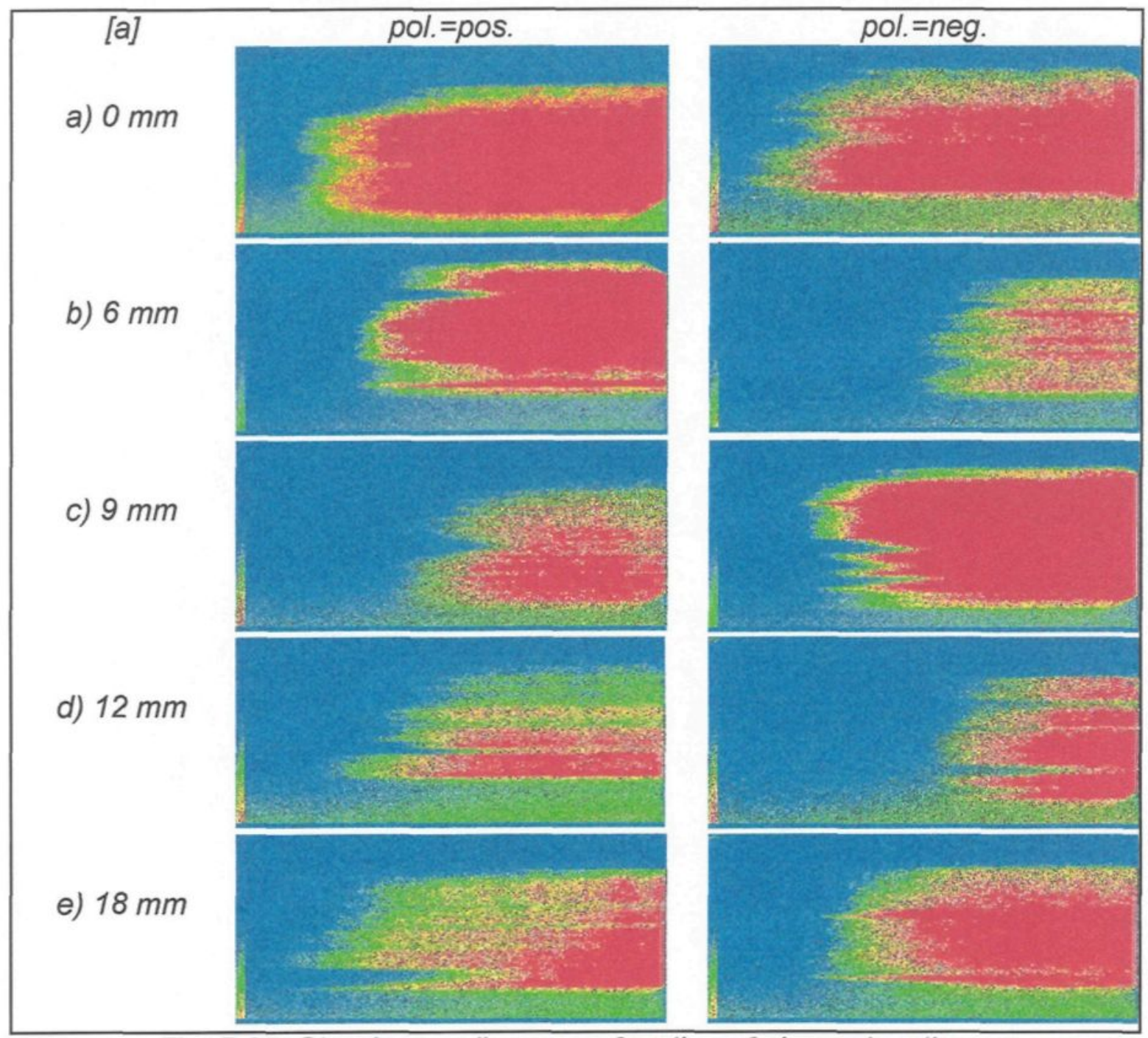

Fig. 5-32: Streak recordings as a function of air gap location, a $\left(\sigma=30 \times 10^{-4} \mathrm{~S} / \mathrm{m} ; T=-12^{\circ} \mathrm{C} ; d=18 \mathrm{~mm} ; r=6 \mathrm{~mm}\right.$; orient.=hor.; path=gro.; $t_{\text {sweep }}=50$ ns) 


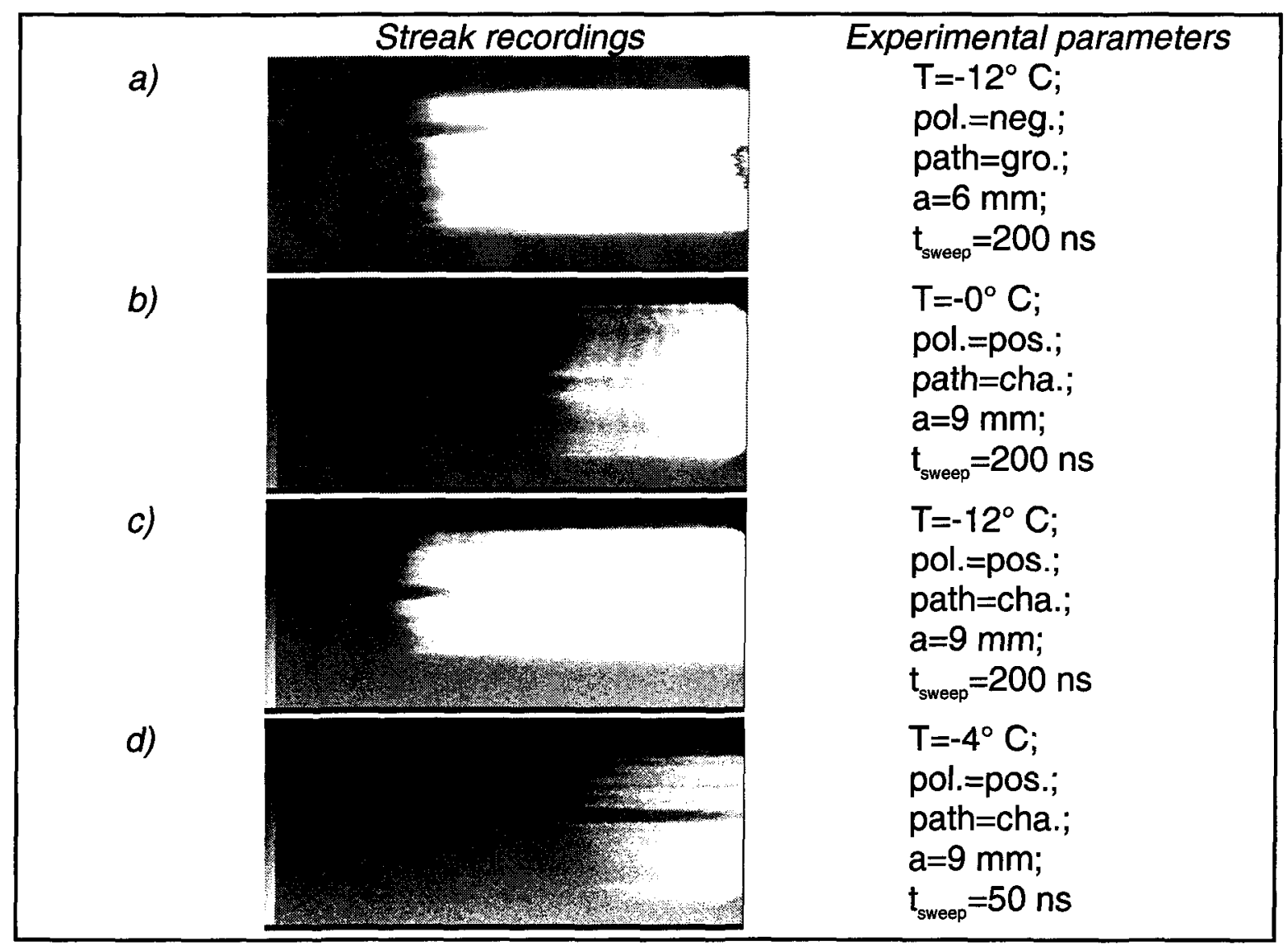

Fig. 5-33: Streak recordings for ice models with artificial air gap showing visible pre-discharge phenomena $\left(\sigma=30 \times 10^{4} \mathrm{~S} / \mathrm{m} ; d=18 \mathrm{~mm} ; \mathrm{r}=6 \mathrm{~mm}\right.$; orient.=hor.)

\subsubsection{Ice Samples with Natural Air Gaps}

Figure 5-34 presents the results of the investigations with the streak camera for different cooling rates; Fig. 5-35 shows the streak recordings for different ice accumulation processes. Still photographs of the ice surfaces were already presented in Section 4.2.2, to analyse ice surface morphology. 


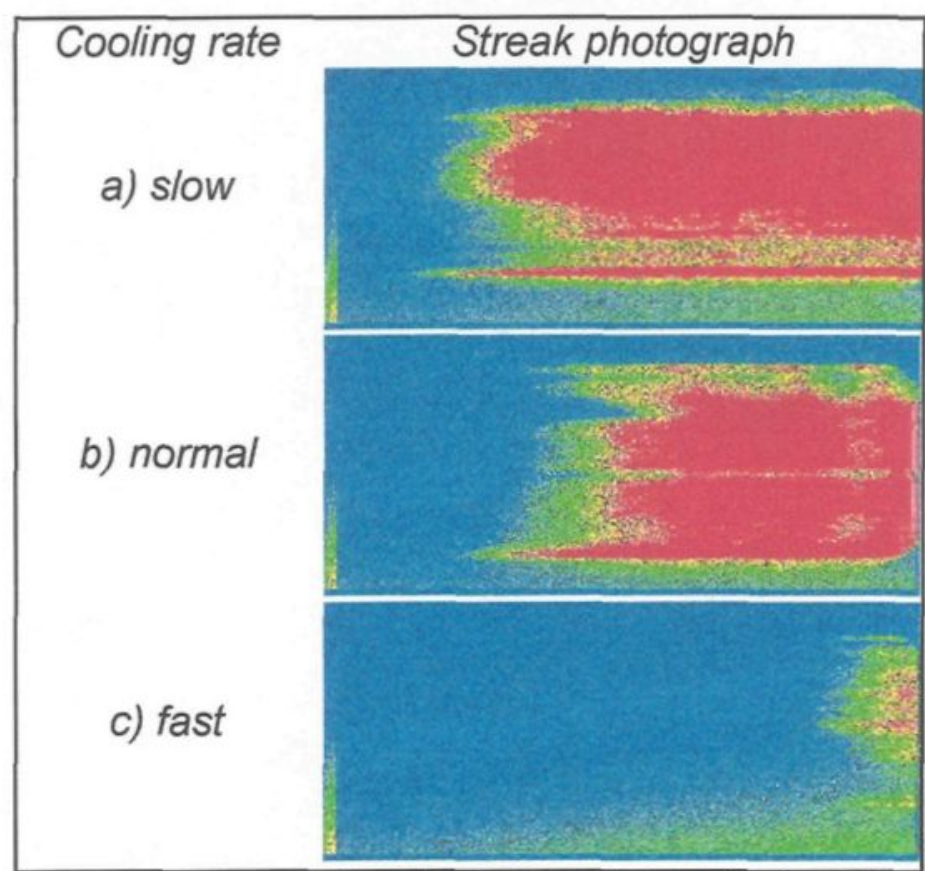

Fig. 5-34: Streak recordings as a function of cooling rate $\left(\sigma=30 \times 10^{-4} \mathrm{~S} / \mathrm{m} ; \mathrm{T}=-12^{\circ}\right.$ C; pol.=pos.; $d=18 \mathrm{~mm} ; r=6 \mathrm{~mm}$; orient. =hor.; path=gro.; $t_{\text {sweep }}=50 \mathrm{~ns}$ )

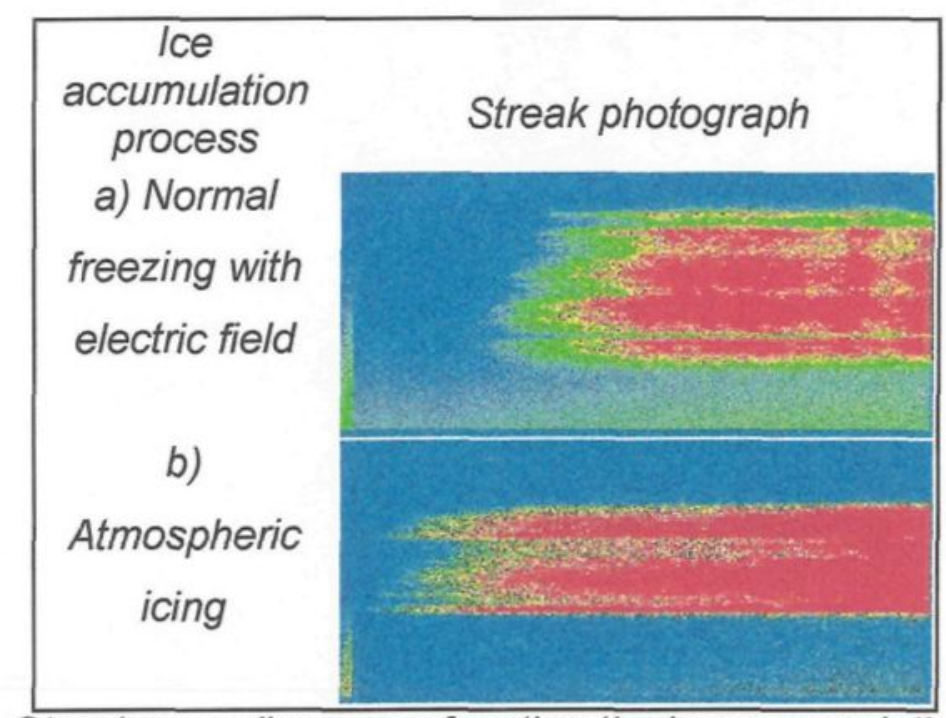

Fig. 5-35: Streak recordings as a function the ice accumulation process $\left(\sigma=30 \times 10^{-4} \mathrm{~S} / \mathrm{m} ; \mathrm{T}=-12^{\circ} \mathrm{C} ; \mathrm{pol} .=n e g . ; d=18 \mathrm{~mm} ; \mathrm{r}=6 \mathrm{~mm}\right.$; orient. =hor.; path=gro.; $t_{\text {sweep }}=50$ ns) 


\subsubsection{Discussion and Analysis}

The streak recordings (Fig. 5-29) as well as the series of framing recordings

(Fig. 5-30) show that the discharge propagates very fast along the ice surface, whereas breakdown inside the artificial air gap occurs somewhat later. Two different time values can be derived for the combined air gap and ice surface breakdown:

- Time to breakdown inside the air gap alone;

- Overall time to breakdown, $t_{\text {breakdown }}$.

\subsubsection{Effect of Ice Temperature}

The streak photographs reveal that the time to breakdown for combined air gap and ice surface breakdown is dependent on ice temperature. The two possible time to breakdown values are presented in Fig. 5-36 as a function of the ice temperature (derived from Fig. 5-31). An interesting difference can be observed in comparison to the results for ice surfaces without artificial air gap. Figure 5-37 compares the times to breakdown for ice surfaces without artificial air gap and for an ice model with a centrally located air gap. 
It was shown in Section 5.4.2.3 that the time to breakdown for the latter case decreases for an increase in ice temperature from $T=-12^{\circ} \mathrm{C}$ to $\mathrm{T}=0^{\circ} \mathrm{C}$ (Fig. 5-10 and Fig 5-12). In the presence of a centrally located air gap and temperature increasing towards the melting point, the time to breakdown inside the air gap increases. Thus, the overall time to breakdown increases. This observation may be related to the fact that more energy is consumed by the partial discharge process along the ice surface for increased ice temperature due to increased ice surface conductivity. Therefore, it takes more time to establish favourable breakdown conditions inside the air gap for increased ice temperature, leading to an increase in overall time to breakdown.

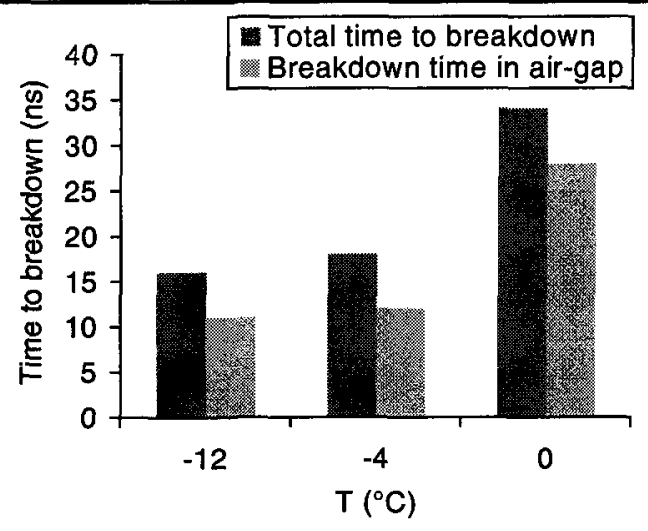

a) $p o l .=p o s$.

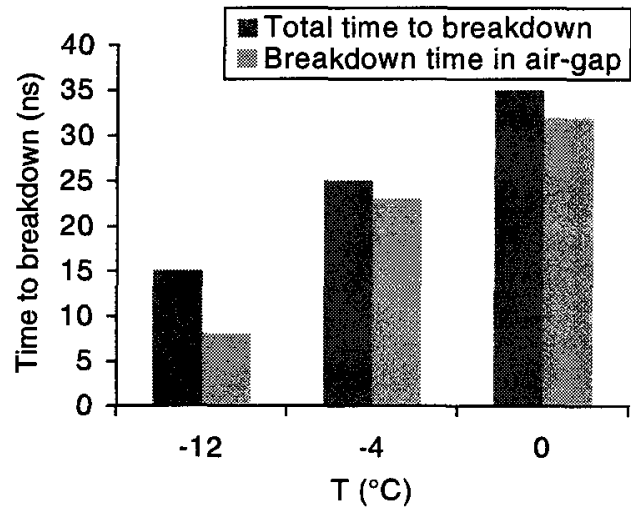

b) $p o l .=n e g$.

Fig. 5-36: Time to breakdown values as a function of ice temperature, T, for a centrally located air gap $\left(\sigma=30 \times 10^{4} \mathrm{~S} / \mathrm{m} ; \mathrm{T}=-12^{\circ} \mathrm{C}\right.$;

$$
d=18 \mathrm{~mm} ; r=6 \mathrm{~mm} \text {; orient. }=\text { hor.) }
$$




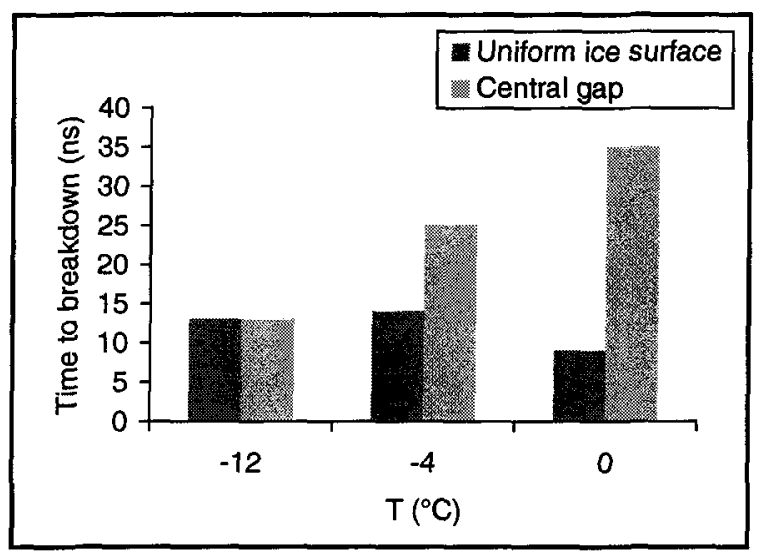

Fig. 5-37: Time to breakdown as a function of ice temperature, $T$, for different ice surface conditions $\left(\sigma=30 \times 10^{4} \mathrm{~S} / \mathrm{m}\right.$; pol.=neg.; $d=18 \mathrm{~mm} ; r=6 \mathrm{~mm}$; orient.=hor.)

\subsubsection{Effect of Air Gap Location}

The values for the overall times to breakdown and the time to breakdown inside the artificial air gap, as a function of air gap location, are presented in Fig. 5-38 (derived from Fig. 5-32). These results show that the breakdown occurs fastest for an air gap located within the space between the electrodes. When the air gap is located nearer to the electrodes, the time to breakdown increases. For positive voltage, the lowest value, $t_{\text {breakoown }}=13 \mathrm{~ns}$, was found for the centrally located air gap $(a=9 \mathrm{~mm})$, whereas, for negative voltage, the lowest value, $\mathrm{t}_{\text {breakdown }}=13 \mathrm{~ns}$, was measured for an air gap at distance $a=6 \mathrm{~mm}$ from the HV electrode. However, the difference in the latter case between the air gap at $a=6 \mathrm{~mm}$ and $\mathrm{a}=9 \mathrm{~mm}$ may be neglected if the accuracy of time resolution of the streak camera is considered. 


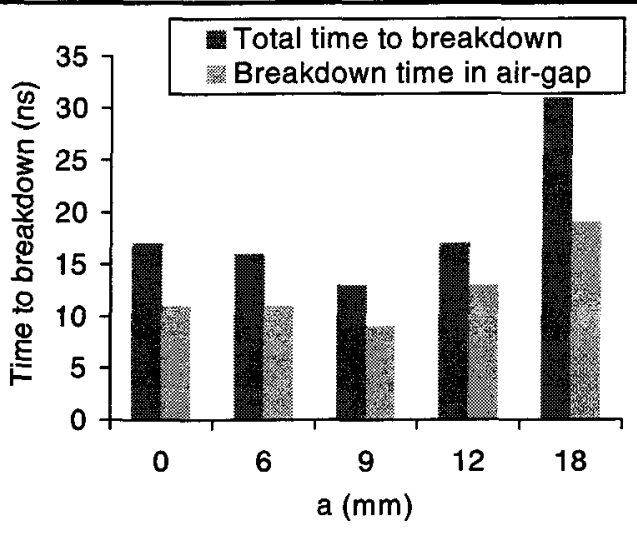

a) $p o l .=$ pos.

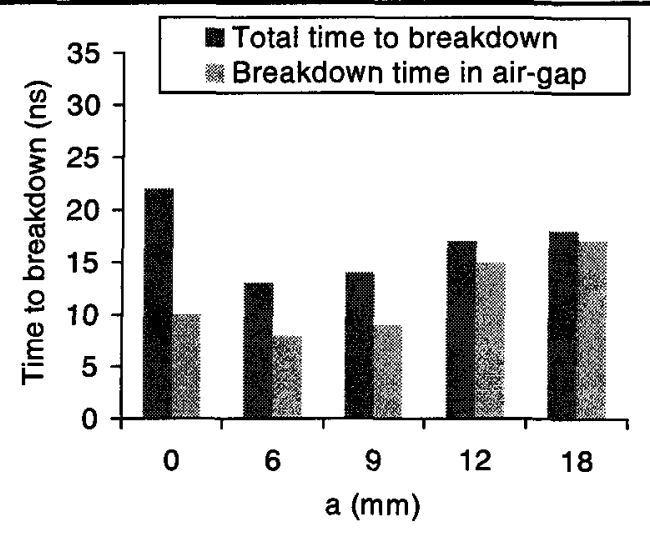

b) pol.=neg.

Fig. 5-38: Time to breakdown values as a function of air gap location, a $\left(\sigma=30 \times 10^{4} \mathrm{~S} / \mathrm{m} ; T=-12^{\circ} \mathrm{C} ; d=18 \mathrm{~mm} ; r=6 \mathrm{~mm}\right.$; orient.=hor.)

The reason for such behaviour may be found in the way the discharge develops. In fact, the streak images show that the discharge normally starts on the ice surface for this series of experiments. The discharge propagates so fast that the streak camera cannot resolve its actual development even with a sweep speed of $50 \mathrm{~ns}$. The discharge front appears almost as a vertical line much like a stepped phenomenon. After bridging the surface of the ice, the discharges stop at the edges of the air gap until the ionisation processes allow the breakdown in the gaseous space. If the air gap is located in the middle of the space between the electrodes, the electric discharges can proceed simultaneously from both sides into the air gap. For an air gap in front of either the HV or ground electrodes, the discharge approaches only from one side. Thus, it takes more time to for the breakdown inside the air gap to develop. For an air gap located nearer to one of 
the electrodes (Fig. 5-32b and d), the time to breakdown is intermediate for the extreme cases (Fig. 5-32a, $c$ and e).

It is very interesting to observe that for positive voltage polarity, Fig. $5-38 \mathrm{a}$ presents almost the mirrored image of Fig. 5-38b, for negative polarity. In the case of positive voltage, longest time to breakdown, $t_{\text {breakoown }}=31 \mathrm{~ns}$, was found for an air gap in front of the grounded electrode (Fig. $5-38 a, a=18 \mathrm{~mm}$ ). On the other hand, for negative voltage, the longest time to breakdown, $\mathrm{t}_{\text {breakdown }}=22 \mathrm{~ns}$, was measured for an air gap in front of the negative HV electrode (Fig. 5-38b, $a=0 \mathrm{~mm}$ ). A previous investigation [13] on the effects of an air gap in front of either the HV or ground electrodes showed that there exists a quite strong effect of air gap location on the flashover voltage of an ice-covered cylinder. Although the physical models and the type of high voltage were different in that study compared to the present investigation, those results suggest a possible explanation for the phenomena observed: It was found that the voltage drop is lower along the air gap if it is located in front of the ground electrode. The results of the present study show a similar behaviour despite symmetrical electrode configuration. As the surrounding climate chamber is connected to ground potential, the electric field distribution is slightly non-symmetrical (see also Section 4.3.4). For positive voltage applied to the HV electrode, longer time to breakdown is observed for an air gap in front of the ground electrode (Fig. 5-38a), which may be explained by the findings of the cited study [13], showing a lower voltage drop along an air gap in front of the 
ground electrode, as opposed to the HV electrode. When negative voltage was applied, the grounded electrode became positively charged. As may be expected, observations revealed a shorter time to breakdown for an air gap in front of the positive electrode, rather than in front of the negative $\mathrm{HV}$ electrode, which explains the mirrored appearance of the two graphs for both voltage polarities.

\subsubsection{Discharge Initiation for Ice Surfaces with Artificial Air Gap}

The behaviour of the discharge observed in the case of a combined air gap and ice surface breakdown may seem surprising at first. The experiments with an artificially introduced air gap were carried out with the idea that the discharge would be initiated at the location of non-uniformity, and bridge first the air gap before progressing along the ice surface. Under consideration of the fact that the air gap covers almost $10 \%$ of the space between the electrodes (as already discussed in Section 4.3.8), the results can be explained. Therefore, the applied voltage may not be high enough to create immediate breakdown inside the gap before any discharge development occurs on the surface. It seems that first visible ionisation processes start at the border of the air gap for the geometric configuration used. From there, the discharge grows towards the electrodes due to the favourable conditions on the ice surface, which leads to very fast discharge development along the surface. Once discharge activity has bridged the ice surface, it stops at the borders of the air gap. At the same time, ionisation 
processes take place inside the air gap, but they proceed more slowly than the discharge development along the ice surface. After a certain period, the breakdown conditions are fulfilled inside the small void and total breakdown of the distance between the electrodes can take place.

Several streak recordings (Figure 5-33) can help to strengthen this theory of discharge initiation at the borders of the air gap, first development along the ice surfaces, and final breakdown inside the air gap. The photographs in Figs. 5-33a and 5-33b show first light emissions at the border of the artificial air gap. The discharge development from these locations towards the metallic electrodes can be clearly observed in Figs. 5-33c and 5-33d. The whole light emission phenomenon has the form of a tip of a left-wing oriented arrow with a crack in the middle (at the location of the void).

\subsubsection{Effect of Cooling Rate}

The still photographs of the ice samples formed with different cooling rates (see Section 4.2.2) show that the number and size of the voids vary depending on the cooling rate (Section 4.3.9). The streak photographs for these cases show some interesting details in the discharge front, which seem to be related to the ice structure. For normal and fast cooling rates (cooling period of six hours and one hour, respectively), the streak recordings show a slightly rugged front of the 
discharge (Fig. 5-34b and Fig. 5-34c). Fewer, but larger virtual gaps are present in the streak recording (Fig. 5-34a) in the case of slow cooling (cooling period of 30 hours).

These results can be explained with the findings of the experiment with an artificially introduced air gap (Section 5.5.2.1), where it was shown that a nonuniformity of larger size delays discharge development. The appearance of virtual gaps in the discharge front of the streak recordings seems to be dependent on the concentration, distribution, and dimension of the natural air gaps on the ice surface. If the number of voids is low, but they are relatively large (the case of slow cooling rate), the streak recording of the discharge exhibits a rough front with several significant virtual gaps. With an increase in the number of voids under a faster cooling rate, the number of virtual gaps in the light phenomenon increases. As the gaps in the ice surface become smaller, the front of the discharge gets smoother. This behaviour is also demonstrated by the derivation of the time to breakdown values from the streak images in Fig. 5-34. It can be seen in Fig. 5-39 that the time to breakdown becomes shorter for an accelerated cooling rate. 


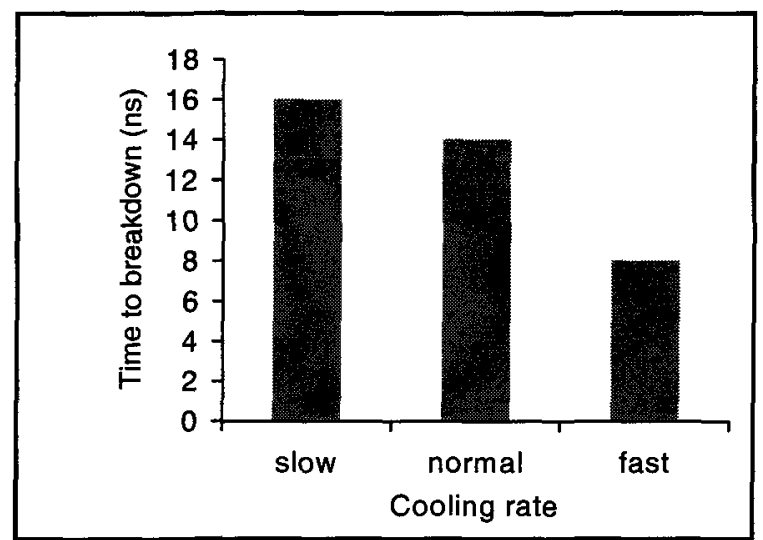

Fig. 5-39: Time to breakdown as a function of cooling rate $\left(\sigma=30 \times 10^{4} \mathrm{~S} / \mathrm{m} ; T=-12^{\circ} \mathrm{C}\right.$; pol.=pos.; $d=18 \mathrm{~mm} ; r=6 \mathrm{~mm}$; orient.=hor. $)$

An interesting phenomenon can be observed in comparing the derived time to breakdown values and critical breakdown voltages (Section 4.3.9), as a function of cooling rate. For all experimental parameters studied up to now for ice surfaces without artificial air gap, decrease in time to breakdown was always concurrent with decrease in critical breakdown voltage. Now, the results for the different cooling rates show a different characteristic: Time to breakdown , $t_{\text {breakown }}$, was shortest for fast cooling rate, whereas the greatest value for the critical breakdown voltage, $U_{50 \%}$, was obtained in this case. In order to understand the contrary characteristics of the parameter "cooling rate", it has to be considered that the ice surface structure did not change for any of the preceding experimental parameters (such as freezing water conductivity and ice temperature). Thus, the established relation between decreasing breakdown voltage and decreasing speed of discharge development is valid only for ice surfaces without artificial air gap. In the last case, 
ice morphology was altered by changing the cooling rate, which can explain that an accelerated discharge development does not cause a decrease in critical breakdown voltage at the same time.

\subsubsection{Effect of Electric Field during Cooling}

It was already mentioned in the analysis of the critical breakdown voltages that the still photograph of the ice sample formed with an electric field applied during cooling period at a normal cooling rate (Fig. 4-2a) shows a comparable appearance as that of an ice sample formed at a fast cooling rate (Fig. 4-1c) (Section 4.3.10). The discharge development recorded with the streak camera coincides with the observations of the surface photographs for the two cases: Both times, a fast development of the light emission and a smooth discharge front was found. This observation indicates that the growing discharge could bridge the small irregularities almost immediately, and the overall breakdown was not delayed.

It can be concluded from previous research that the electric field does not seem to have any significant influence on the crystalline microstructure of the ice [9], whereas an influence on the morphology can be noticed [30] [59], which in turn alters the ice surface uniformity. Considering these findings, it can be concluded that the acceleration of the discharge development observed in the present study, with an electric field applied during the cooling period, is caused by the alteration of 
the ice surface uniformity. However, it is impossible to come to any final conclusion, as no measurements were made on the effect of polarisation or accumulation of charges on the surface or in the bulk of the ice. Any further unambiguous interpretation will need more data on surface charge accumulation on the ice surface as a function of the electric field during ice formation. Therefore, it is recommended to carry out some experiments on this aspect in the future.

\subsubsection{Effect of Type of Ice Accumulation Process}

In the case of atmospheric ice accretion, the surface still photograph (Fig. 4-2b) clearly shows that the ice is not as semi-transparent as that obtained with the normal freezing method. This appearance is caused by the porous structure of atmospheric ice accretion and a rough ice surface due to successive impinging of supercooled water droplets that froze immediately upon impact. Furthermore, it can be seen that the electrodes are totally covered with an ice layer due to the accumulation process. The streak photograph (Fig. 5-35b) shows a very rugged front of discharge phenomenon, which can be related to the rough and porous structure of the ice surface. Light emissions appear at several locations somewhere on the ice surface, between the electrodes, at the beginning of the visual discharge development. These light spots grow over a short period until they join the neighbouring discharge activity. 
Besides this effect of "virtual gaps" in the discharge front, the behaviour of the discharge development does not seem to be very different from all preceding experiments with ice formed by normal freezing method. Therefore, it can be concluded that all experimental results of the present study, obtained with ordinary frozen ice, are also valid to deduce general conclusions on initiation and development of ice surface discharges. However, as atmospheric ice formation is the type of ice found on actual insulators, it may be recommended that further studies with larger models also include this type of ice in the experimental parameters, to provide conditions as close as possible to real conditions.

\subsection{Conclusions of Chapter 5}

From the results of the presented experiments on the visible discharge development along ice surface using ultra high-speed photography, several conclusions can be made:

1) The experimental methodology of streak photography is an adequate technique for the observation and analysis of very fast discharge initiation and propagation processes in small intervals along ice surfaces, under various experimental conditions. Several verification recordings provided data that allow to assume that the preparations of the ice model, which are necessary 
to keep the discharge on a straight path, do not influence the general characteristics of ice surface discharges.

2) Increasing freezing water conductivity (in the range from $\sigma=2.5 \times 10^{-4} \mathrm{~S} / \mathrm{m}$ to $\sigma=160 \times 10^{-4} \mathrm{~S} / \mathrm{m}$ ) leads to faster discharge development along the ice surface, as more dissolved faults migrate to the surface increasing the ice surface conductivity: $\mathrm{t}_{\text {breakcown }}\left(\sigma=2.5 \quad \times 10^{-4} \quad \mathrm{~S} / \mathrm{m}\right)=23 \quad \mathrm{~ns}$ decreases to $\mathrm{t}_{\text {breakdown }}\left(\sigma=160 \times 10^{-4} \mathrm{~S} / \mathrm{m}\right)=11 \mathrm{~ns}$ for the $7-\mathrm{mm}$ model and positive voltage polarity. Thus, ionisation processes in the air next to the ice surface may be enhanced, and streamer propagation along the solid-gas interface may be accelerated. In extreme cases, the discharge appears immediately over the whole space between the electrodes.

3) An increase in ice temperature, from the value $T=-12^{\circ} \mathrm{C}$ to $\mathrm{T}=0^{\circ} \mathrm{C}$, also causes a significant acceleration of the discharge development: $t_{\text {breakdown }}\left(T=-12^{\circ} \mathrm{C}\right)=23 \mathrm{~ns}$ decreases to $t_{\text {breakdown }}\left(T=0^{\circ} \mathrm{C}\right)=10 \mathrm{~ns}$ for the $7-\mathrm{mm}$ model and positive voltage polarity. As the temperature increases towards the melting point, a phase transition from solid to liquid enables faster discharge propagation due to the higher mobility of the ionic charges in the water film on the ice surface. 
4) Several observations indicate that local distortion of the electric field leads to discharge initiation on the ice surface in the space between the electrodes. The study carried out within the framework of this thesis did not allow to distinguish if this field distortion is created by space charge accumulation on the surface or by charge injection from the electrodes. With no quantitative data available, the present study proposes that charge deposit on the ice surface under conditions of low temperature and low conductivity seems to exist, as already shown for various other dielectric solid materials. These surface charge accumulations distort the electric field. Visible discharge activity may start at any location on the ice between the electrodes, where the local electric field exceeds the critical value for discharge initiation. However, from the experimental data obtained, it seems more probable that visible discharge processes start nearer to the positive HV electrode, in the presence of an ice surface in the space between the electrodes.

5) Two different patterns of visible discharge development could be observed for the two electrode distances chosen $(\mathrm{d}=7 \mathrm{~mm}$ and $\mathrm{d}=18 \mathrm{~mm}$ ). Therefore, it is assumed that due to the lack of pre-discharge activity, no charge accumulation prior to breakdown can take place on the ice surface for very short distances. Visible discharges start at the tip of the electrodes. Both processes progress into the space between the electrodes and meet somewhere in the middle. The transition from one development pattern to the 
other is thought to happen for a distance between the two chosen distance values.

6) An air gap in the ice surface presents a non-uniformity leading to a field enhancement and to the initiation of partial discharge activity at its borders. If the voids are microscopic, they may be bridged immediately by the discharge; therefore, they will have no influence on the discharge development. On the other hand, larger gaps (in the present case $\mathrm{g}=1.6 \mathrm{~mm}$ ) may cause an increase in time to breakdown, as they interrupt a continuous, fast discharge development along the surface. Due to the rapid discharge development along the ice surface, which proceeds faster than the ionisation of the air in the gap, visible light emissions appear first along the ice surface. Later, the air gap gets ionised as well, and combined air gap and ice surface breakdown occurs. The time to breakdown inside the air gap is increased for ice temperatures near the melting point: $t_{\text {breakdown }}\left(T=-12^{\circ} C\right)=11$ ns increases to $t_{\text {breakdown }}\left(T=0^{\circ} \mathrm{C}\right)=28 \mathrm{~ns}$ for the $18-\mathrm{mm}$ model and positive voltage polarity. 


\section{CHAPTER 6}

\section{STUDY OF THE VOLTAGE AND CURRENT WAVEFORMS}




\section{CHAPTER 6}

\section{STUDY OF THE VOLTAGE AND CURRENT WAVEFORMS}

\subsection{Introduction to Chapter 6}

The preceding studies on critical breakdown voltages (Chapter 4 ) and visible discharge development (Chapter 5) revealed numerous aspects of discharge initiation and development on ice surfaces. Nevertheless, these experiments turned out to be insufficient to prove the existence of pre-discharge activity before the occurrence of visible ionisation processes leading to final breakdown. It may be assumed that the first discharges are very weak, so they might not necessarily be visible to the streak camera. Therefore, waveform measurements of current and voltage were carried out to obtain more data on possible early pre-discharge activity. The distance between the electrodes was fixed at $d=18 \mathrm{~mm}$, and the electrode axis was always kept in horizontal orientation for these measurements. 


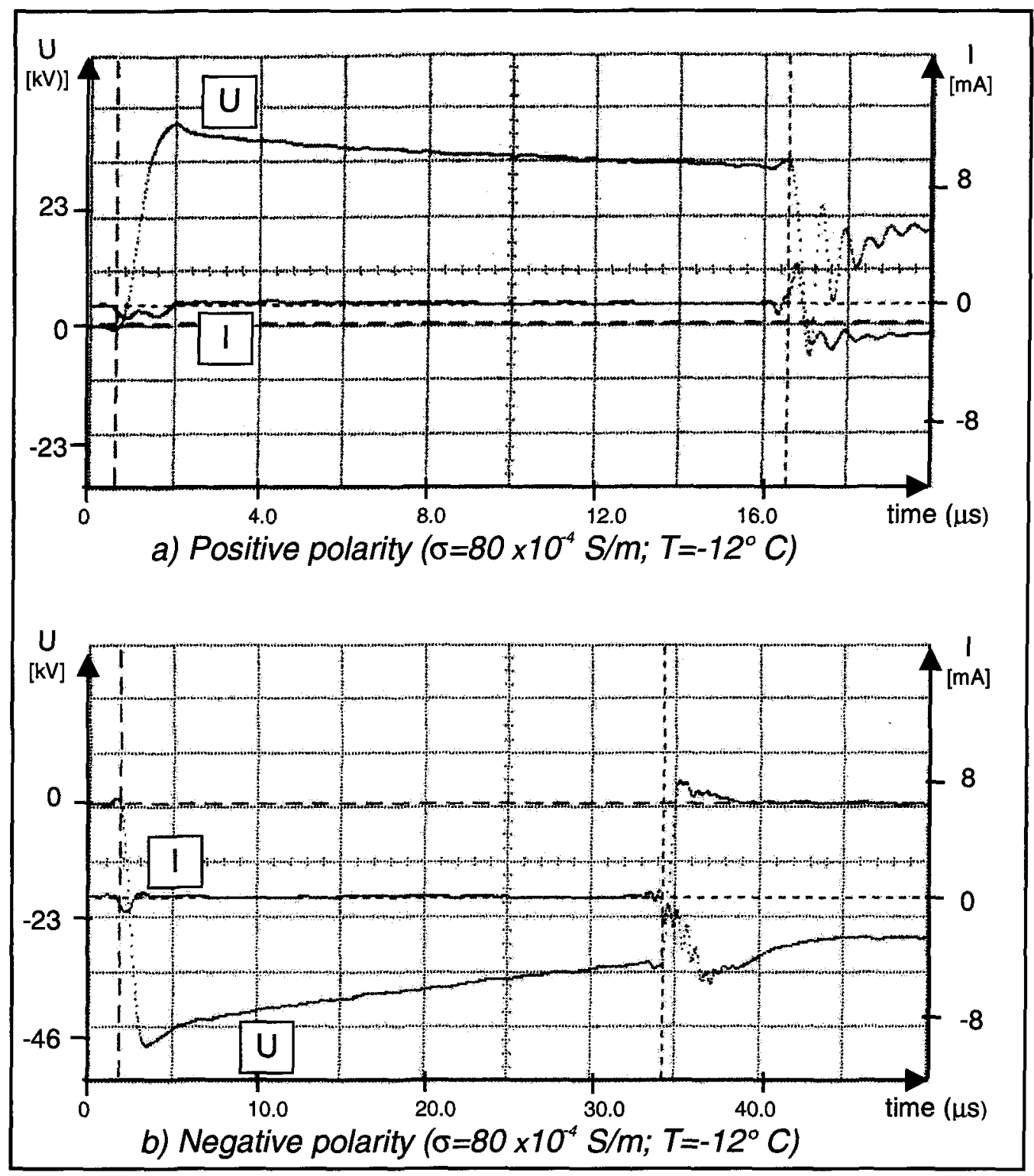

Fig. 6-1: Waveform recordings for very late breakdown ( $d=18 \mathrm{~mm} ; \mathrm{r}=6 \mathrm{~mm}$; orient=hor.)

Already, at the beginning of the waveform measurements, it could be observed that the statistical time lag of the moment of breakdown is quite large for the ice surface discharges. In some rare cases, the ice surface breakdown 
happened very late. Examples for each polarity are shown in Fig. 6-1. In particular, case $b$ shows a delay of 32.5 microseconds between application of voltage and moment of breakdown. At the moment of breakdown, voltage had already dropped to less than $2 / 3$ of the peak value. This may strengthen the assumption that some phenomena occur, preparing the surface for later breakdown. Particularly, charge accumulation is supposed to take place in the case of dry ice surfaces.

In the following sections, the presentation of the experimental results and their discussion are divided into two parts. First, the breakdown process itself is analysed (Section 6.2), and the next part focuses on measurements to give evidence of pre-discharge phenomena (Section 6.3).

\subsection{Voltage and Current Waveform Recordings}

\subsubsection{Experimental Results for Ice Surfaces without Artificial Air Gap}

The following Figs. 6-2 and 6-3 show the waveform recordings as a function of freezing water conductivity for both voltage polarities in the case of ice surfaces without an artificial air-gap. 


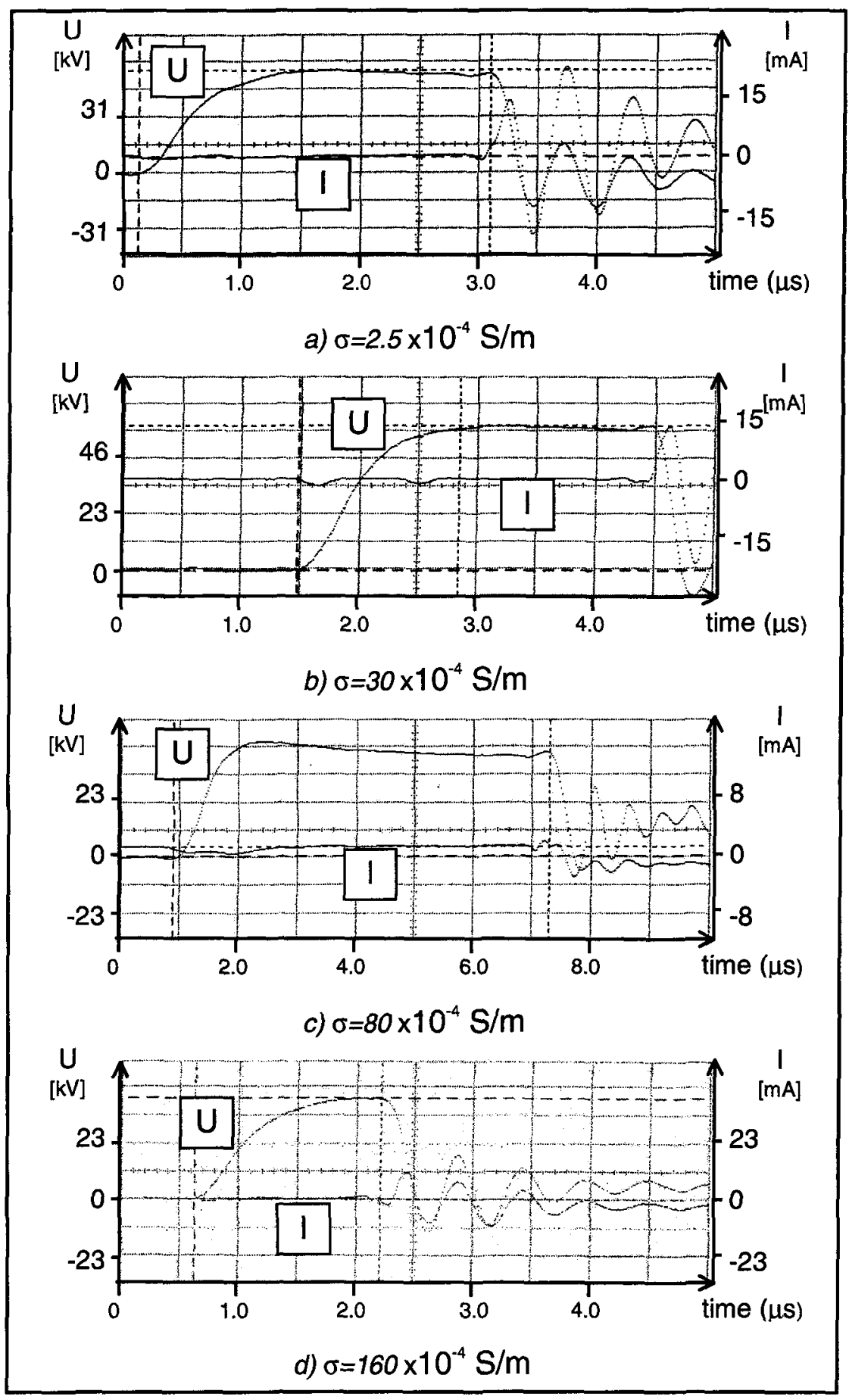

Fig. 6-2: Waveform recordings as a function of freezing water conductivity, $\sigma$ ( $T=-12^{\circ} \mathrm{C}$; pol.=pos.; $d=18 \mathrm{~mm} ; \mathrm{r}=6 \mathrm{~mm}$; orient=hor.) 


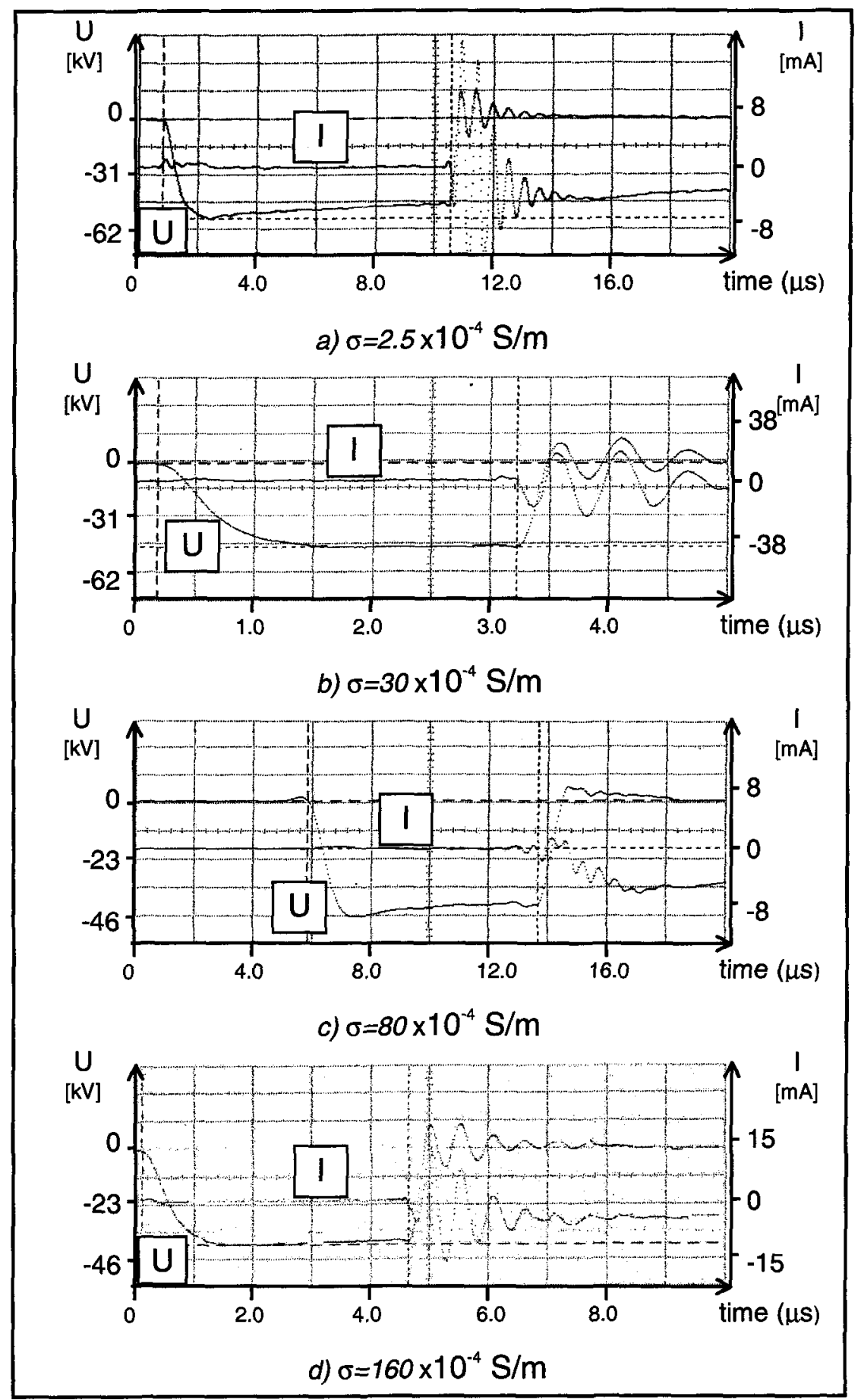

Fig. 6-3: Waveform recordings as a function of freezing water conductivity, $\sigma$ ( $T=-12^{\circ} \mathrm{C}$; pol.=neg.; $d=18 \mathrm{~mm} ; \mathrm{r}=6 \mathrm{~mm}$; orient.=hor.) 


\subsubsection{Experimental Results for Ice Surfaces with Artificial Air Gap}

Figure 6-4 shows the results from the investigations on the pre-breakdown current, $l_{p b c}$, for different ice surface conditions, respectively ice surface without artificial air gap (a), and artificially introduced air gap either centrally located (b), or in front of the HV electrode (c).

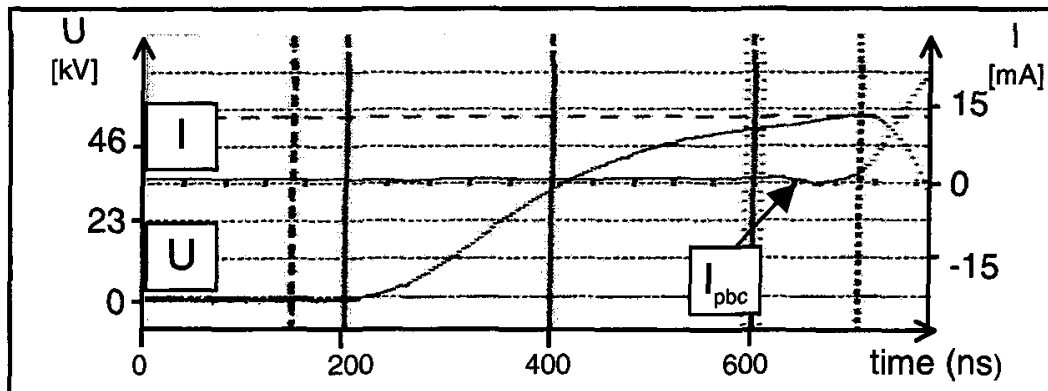

a) Ice surface without artificial air gap

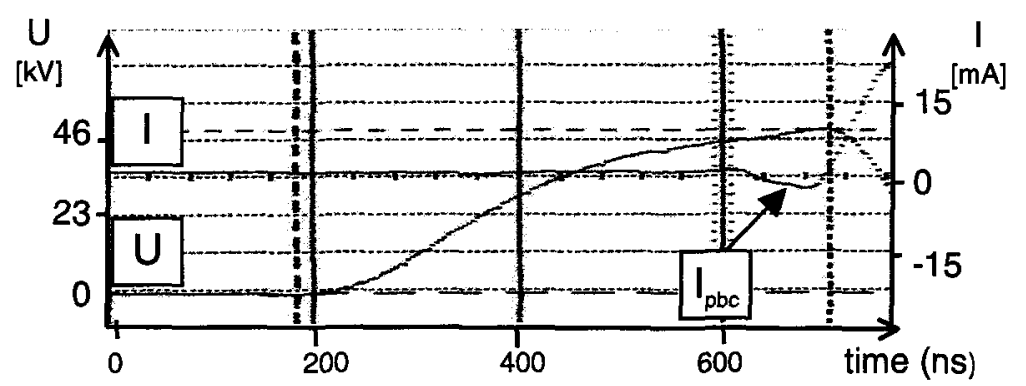

b) Centrally located air gap $(a=9 \mathrm{~mm})$

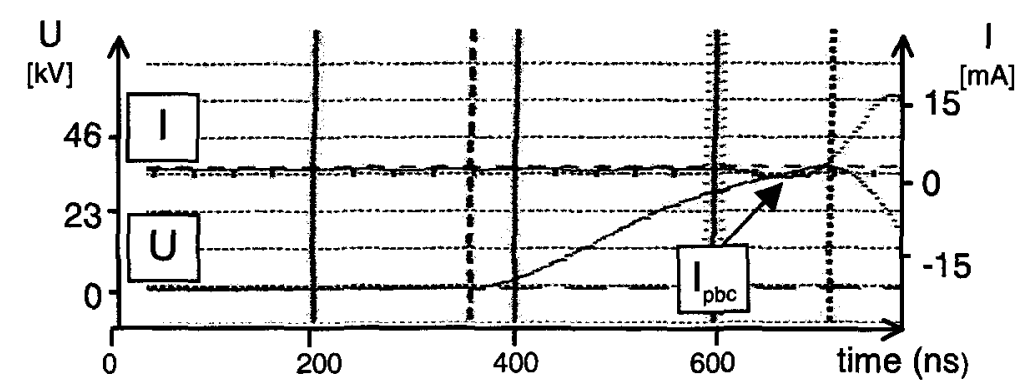

c) Air gap in front of the HV electrode $(a=0 \mathrm{~mm})$

Fig. 6-4: Waveform recordings as a function of ice surface conditions $\left(\sigma=30 \times 10^{4} \mathrm{~S} / \mathrm{m} ; T=-12^{\circ} \mathrm{C}\right.$; pol.=pos.; $d=18 \mathrm{~mm} ; \mathrm{r}=6 \mathrm{~mm}$; orient.=hor.) 


\subsubsection{Discussion and Analysis}

The waveform measurements for ice surfaces without artificial air gap (Figs. 6-2 and 6-3) do not show any significant influence of freezing water conductivity or voltage polarity on the general shape of the current. The peak values of the voltage curves decreases with increasing conductivity, which was already shown in the experiments on the determination of the critical breakdown voltages (Chapter 4).

The current signal showed strong oscillations after the occurrence of breakdown, which are attributed to the magnitude and nature of parasitic impedances in the HV circuit (Section 3.5.5). This may obstruct the determination of the exact peak value of the breakdown current. Nevertheless, it may be seen that the current oscillations vary around comparable values in most cases. Thus, it can be concluded that ice surface conductivity decreases with increasing freezing water conductivity, due to the fact that the current at the moment of breakdown stays roughly stable, whereas the voltage peak value decreases. This result matches with measurements on the surface conductivity of ice [11] [24] [34] and confirms the assumption that critical leakage currents leading to breakdown may be reached at lower voltage levels for increasing surface conductivity (Section 4.3.2), thus decreasing the critical breakdown voltage. 
Changes of the "pre-breakdown current", $I_{p b c}$, could be detected as a function of the ice surface uniformity. The waveform recordings for the three cases (Fig. 6-4) show that the current impulse lasts somewhat longer when there is an air gap on the ice surface (Fig. 6-4b and Fig.6-4c). The photographic ultra high-speed observations (Figs. 5-29 to 5-33) have already revealed a longer time to breakdown for ice samples with an air gap (Section 5.5), which is in good agreement with the detection of extended pre-breakdown currents for ice surfaces of substantial non-uniformity. Furthermore, the results give indications that the rise in pre-breakdown current is less steep in the presence of an air gap. The waveforms recorded do not have enough resolution to determine the exact values in order to prove this assumption, but the attenuated onset of the discharge current may be attributed to the initiation of the first visible discharges along the ice surfaces adjacent to the void, whereas the space inside the gap still remains free of visible discharges (Section 5.5.2.3). 


\subsection{Waveform Recordings of Pre-discharge Activity}

\subsubsection{Experimental Results}

Occasionally, during the first series of current recordings for ice surfaces without artificial air gap, a "pre-discharge current impulse", $I_{\text {pbil }}$ could be observed, which appeared detached from the final breakdown process (Fig. 6-5). A second test series was carried out to get more data on this phenomenon, this time using ice samples with and without air gaps. On that occasion, pre-discharge current impulses of positive and negative polarities could be detected for applied voltages of both polarities. Figure 6-6 illustrates these measurements.

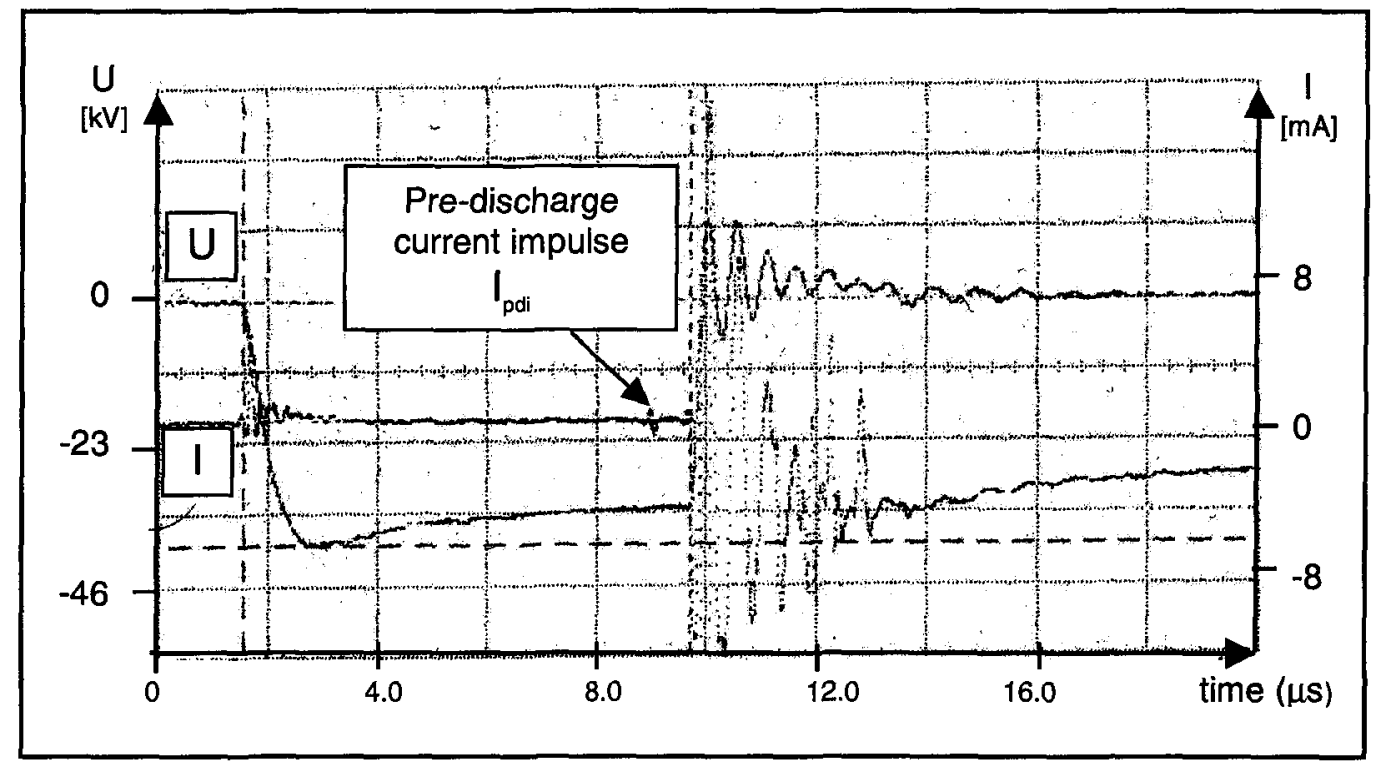

Fig. 6-5: Recording of a pre-discharge current impulse $\left(\sigma=30 \times 10^{4} \mathrm{~S} / \mathrm{m} ; \mathrm{T}=-4^{\circ} \mathrm{C} ;\right.$ pol.=neg.; $d=18 \mathrm{~mm} ; \mathrm{r}=6 \mathrm{~mm}$; orient.=hor.) 


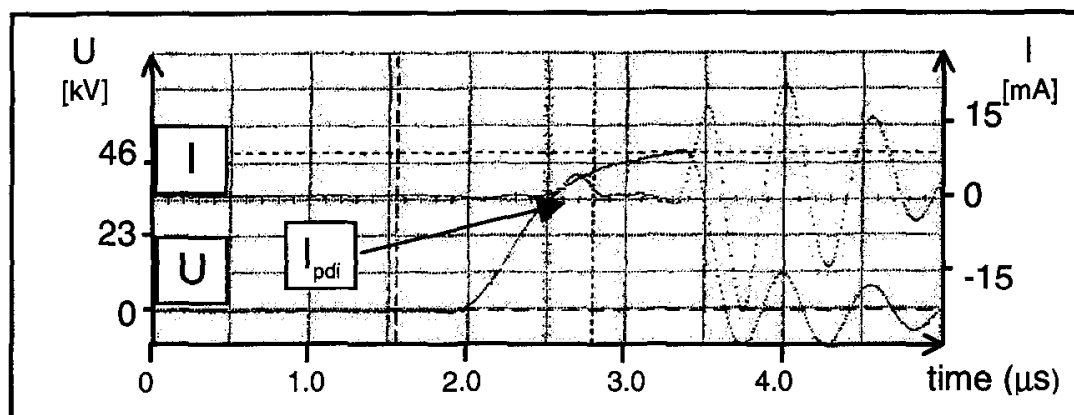

a) Positive impulse under positive applied voltage

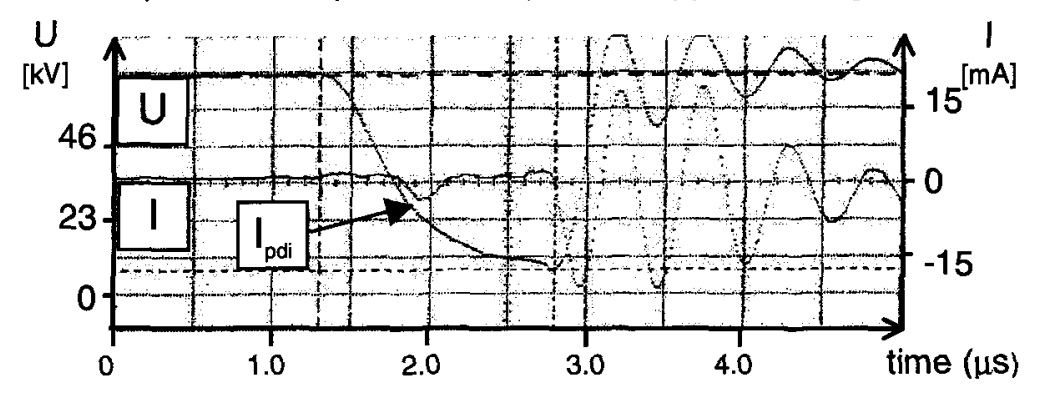

b) Negative impulse under negative applied

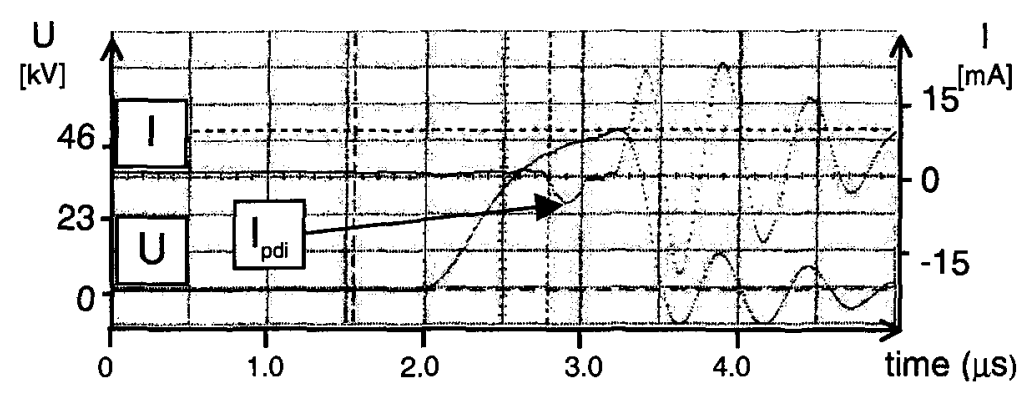

c) Negative impulse under positive applied voltage

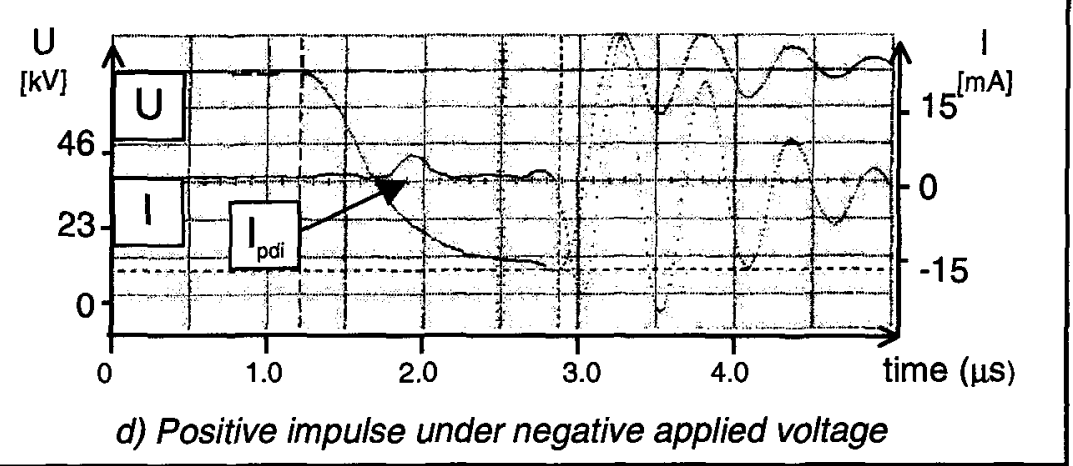

Fig. 6-6: Waveform recordings with pre-discharge current impulses as a function of voltage polarity $\left(\sigma=30 \times 1 \sigma^{4} \mathrm{~S} / \mathrm{m} ; T=-12^{\circ} \mathrm{C} ; d=18 \mathrm{~mm} ; r=6 \mathrm{~mm}\right.$; orient.=hor.) 


\subsubsection{Discussion and Analysis}

These "pre-discharge current impulses" are attributed to partial discharge activity, which do not directly lead to breakdown, as the voltage waveform does not show any significant voltage decrease at the moment when the current impulse appears. Thus, these measurements of current impulses can be interpreted as being a conclusive confirmation of the existence of pre-discharge activity on the ice surface, preceding the final breakdown process. On some occasions, these impulses were detected relatively late, when the voltage value was already decreasing (for example Fig. 6-5). It does not seem logical that a charging process happens at this moment, but on the assumption that electric charges are accumulated on the ice surface during voltage rise (which may not be visible in the current recording due to the displacement current, $I_{\mathrm{ddc}}$, see Section 3.5.5), this impulse could indicate partial discharge activity leading to a neutralisation of the accumulated charges without initiating immediate breakdown.

Table 6-1 shows the number of detected current impulses as a function of ice surface conditions for different polarities of applied voltage and pre-discharge current. With the exception that no negative current impulses could be observed for test models with an air gap under positive voltage, all possible combinations of applied voltage polarity with current impulse polarity were observed for all three surface conditions, but they did not appear with the same frequency. 
The appearance of positive pre-discharge current impulses for positive applied voltage and negative pre-discharge current for negative applied voltage can be associated with discontinuous partial discharge events appearing first in front of the electrodes. As they fail to ionise sufficient free charges to create breakdown along the entire distance between the electrodes, discharge activity is quenched and current goes back to zero.

Table 6-1: Appearance of "pre-discharge current impulses" as a function of ice surface condition ( $\sigma=30 \times 10^{4} \mathrm{~S} / \mathrm{m} ; T=-12^{\circ} \mathrm{C} ; d=18 \mathrm{~mm} ; \mathrm{r}=6 \mathrm{~mm}$; orient.=hor.)

\begin{tabular}{|c|ccc|}
\hline & No air gap & $\begin{array}{c}\text { Central } \\
\text { air gap }\end{array}$ & $\begin{array}{c}\text { Air gap at } \\
\text { HV }\end{array}$ \\
\hline $\begin{array}{c}\text { Total number of } \\
\text { experiments }\end{array}$ & 15 & 15 & 15 \\
\hline $\begin{array}{c}\text { No pre-discharge } \\
\text { current impulse }\end{array}$ & 9 & 10 & 8 \\
$\begin{array}{c}\text { Pos. voltage applied } \\
\text { Pos. current impulse }\end{array}$ & 2 & 3 & 3 \\
$\begin{array}{c}\text { Pos. voltage applied } \\
\text { Neg. current impulse }\end{array}$ & 1 & - & 1 \\
$\begin{array}{l}\text { Neg. voltage applied } \\
\text { Pos. current impulse } \\
\text { Neg. voltage applied }\end{array}$ & 1 & 1 & 1 \\
Neg. current impulse & 2 & 1 & 2 \\
\hline
\end{tabular}


Current impulses of opposite polarity than the applied voltage were first attributed to charge accumulation at the borders of the air gap, leading to partial discharges between one electrode and the edge of the air gap. This explanation would only be valid for ice surfaces with artificial air gap, whereas the predischarge current impulses were also observed for ice surfaces without an artificial air gap (Fig. 6-5).

Another hypothesis is proposed attributing these partial discharge activities to charge accumulation on dry ice surfaces, which was already indicated by several other observations (Sections 4.3.10, 5.4.2.5, and 5.5.2.5). Such surface charge accumulations were also found on various synthetic materials [14] [85] [103] [117]. Previous studies revealed that charges can be accumulated in the ice and on its surface [48] [78] [104]. Locally limited areas along the dry ice surface between the two electrodes may accumulate charges of a certain polarity, while charges of opposite polarity are trapped at another location. If sufficient charges are accumulated, a discharge process may take place only between the two locations, or one of these locations and an electrode, without creating total breakdown. An example for such a process, called "back-discharge" was reported between a rod electrode and space charge deposit on an acrylic plate [101].

Even if the ice surface seems relatively uniform to the human eye, it may show a certain roughness on a microscopic level, due to the fact that the 
uppermost layer of water molecules has no neighbouring water molecules above them, thus they tend to interact with other molecules in the atmosphere [74] [112]. Also, the surface layer contains a significant number of enclosed impurities due to the particular freezing process of ice, where pollution particles in the water will be ejected to the surface during the freezing process [11] [99]. These impurities may present propitious locations for charge accumulations. In order to gain reliable data on this subject, more experiments will be necessary. A promising methodology would be surface charge measurements, which was already proposed as a tool to explain discharge development on non-uniform ice surfaces (Sections 4.3.10, 5.4.2.5, and 5.5.2.5).

Another proposal for future investigations concerns the measuring circuit. As the focus in the present project was directed towards photographic observation of the visible discharge phenomena, the elaboration of the experimental set-up for the waveform measurements was limited. In particular, no measure was applied to suppress the dielectric displacement current that appears during voltage application. As this current impulse may cover weak pre-discharge processes in the early stages of the discharge process, it would be necessary to introduce a differential circuit to suppress the dielectric displacement current, in order to obtain measurements of the precise discharge current values. Previous investigations in the field of gaseous discharges may give examples on how to construct this circuit [46] [117]. The connection of the current shunt to the oscilloscope caused some 
reflections. Therefore, it is proposed to change the value of the current shunt to $50 \Omega$ or to use an optical link between shunt and measuring apparatuses. The second measure would also help to avoid any electromagnetic interference from the HV-generator to the measuring circuit.

\subsection{Conclusions of Chapter 6}

Several voltage and current waveform recordings were carried out to study both the breakdown process and pre-discharge activity prior to breakdown. The experimental set-up was found to be unsuitable for quantitative current measurements. The current measuring system may obscure the earlier current pulses due to the larger magnitude of the displacement current. Nevertheless, it helped to provide evidences for two questions that remained open after the preceding experiments:

1) An increase in ice surface conductivity (due to increased freezing water conductivity or increased ice temperature near the melting point leading to the appearance of a water film on the ice surface) leads to critical current values at lower voltages. Therefore, a correlation between increase in ice surface conductivity and decrease in critical breakdown voltage can be identified. 
2) The detection of current impulses, detached from later breakdown processes, gives evidence of non-visible (with the means of the used ultra high-speed camera systems) pre-discharges before the occurrence of breakdown. This pre-breakdown activity is supposed to alter and prepare the surface. As experiments on various insulating surfaces proved the existence of surface charge accumulation, it may be assumed that these processes also take place on dry ice surfaces (under low temperature and low conductivity conditions). Clusters of surface charges change the electric field distribution locally and may enhance the ionisation processes in the gaseous space next to the ice-air interface, which can explain discharge onset at lower voltages and faster discharge propagation respectively. 


\section{CHAPTER 7}

\section{GENERAL CONCLUSIONS AND RECOMMENDATIONS FOR FUTURE WORK}




\section{CHAPTER 7}

\section{GENERAL CONCLUSIONS AND RECOMMENDATIONS FOR FUTURE WORK}

\subsection{General Conclusions}

In the framework of the present Ph.D. Thesis, the first nanoseconds of visible discharge initiation and development on ice surfaces were studied, using various experimental methodologies, in particular a streak camera to study visible discharge processes. To the best knowledge of the author, this is the first application of ultra high-speed streak photography to observe the first nanoseconds of the electrical discharge development on ice surfaces. It was found that this technique is an adequate method for such an application. It was also shown that the method of ice sample preparation has no effect on discharge initiation and development. The effects of various experimental parameters on the discharge process on ice surfaces were determined. The parameters investigated can be classified as follows: Environmental parameters (freezing water 
conductivity, ice temperature, ice surface uniformity, cooling rate, ice accumulation process), electrical parameters (voltage polarity, voltage waveform, electric field during cooling period), and geometrical parameters (electrode distance, electrode curvature radius, electrode axis orientation). Furthermore, data on time to breakdown and discharge propagation velocity along the ice surface is provided. The results can be concluded as follows:

\section{1) General nature of discharge process}

The presence of an ice surface has a clearly deteriorating effect on withstand performance, similar to the effect of other dielectric surfaces - it leads to a significant decrease in critical breakdown voltage, combined with an increase in discharge propagation velocity, compared to an air gap with similar dimensions. However, under normal atmospheric conditions, the breakdown process on an ice surface exhibits important changes, depending on ice surface conditions:

a) On a clean ice surface $\left(\sigma \leq 2.5 \times 10^{-4} \mathrm{~S} / \mathrm{m}\right)$ at cold temperatures $\left(T \leq-12^{\circ} \mathrm{C}\right)$, the discharge is in some aspects similar to an air gap discharge, i.e. discharge initiation appears in front of the electrodes and then the visible discharges develop gradually along the ice surface. However, the critical breakdown voltage is lower (decrease of about $40 \%$ for the $7-\mathrm{mm}$ model), and the velocity of discharge development is greater (decrease of time to breakdown of about $50 \%$ ) than in the case of an air gap. 
b) For polluted ice $\left(\sigma \geq 160 \times 10^{-4} \mathrm{~S} / \mathrm{m}\right)$, or for temperatures near or at the melting point, the processes of discharge initiation and development are comparable to those observed previously on solid insulating surfaces: Visible discharge activity can start anywhere on the surface. It bridges very rapidly the whole electrode distance, so that no distinct discharge development can be identified even by the means of ultra high-speed photography in the range of nanoseconds. Critical breakdown voltage is significantly lower in this case, (decrease of about $40 \%$ in comparison with the case of dry, clean ice surface conditions).

\section{2) Freezing water conductivity}

Increasing freezing water conductivity leads to a gradual increase in the velocity of discharge development (decrease of time to breakdown from $\mathrm{t}_{\text {breakdown }}\left(\sigma=2.5 \times 10^{-4} \mathrm{~S} / \mathrm{m}\right)=14 \mathrm{~ns}$ to $\mathrm{t}_{\text {breakdown }}\left(\sigma=160 \times 10^{-4} \mathrm{~S} / \mathrm{m}\right)=5 \mathrm{~ns}$ for $18-\mathrm{mm}$ model $)$, combined with a simultaneous decrease in critical breakdown voltage $\left(U_{50 \%}\left(\sigma=2.5 \times 10^{-4} \mathrm{~S} / \mathrm{m}\right)=43.7 \mathrm{kV}\right.$ decreases to $U_{50 \%}\left(\sigma=160 \times 10^{-4} \mathrm{~S} / \mathrm{m}\right)=25.8 \mathrm{kV}$ for $18-$ $\mathrm{mm}$ model), for ice surfaces without artificial air gap. The reason for these two phenomena is the gradual increase in ice surface conductivity with increasing freezing water conductivity due to the fact that impurities diffuse to the liquid surface layer during the freezing process. With increasing ice surface conductivity, a critical leakage current value leading to ice surface breakdown is reached at lower voltage levels. The effect tends to saturate for higher values of freezing water 
conductivity. As the surface layer of the ice has a quasi-liquid characteristic, even for temperatures far below the melting point, the behaviour is also observed for dry ice surface conditions at low temperatures.

\section{3) Ice temperature}

Increasing ice temperatures, from below freezing towards the melting point, have a comparable effect to that of increasing freezing water conductivity: In the case of a weakly polluted ice surface $\left(\sigma=30 \times 10^{-4} \mathrm{~S} / \mathrm{m}\right)$ without artificial air gap, decreasing critical breakdown voltage $\left(\mathrm{U}_{50 \%}\left(T=-12^{\circ} \mathrm{C}\right)=41.9 \mathrm{kV}\right.$ decreases to $\mathrm{U}_{50 \%}\left(T=0^{\circ} \mathrm{C}\right)=24.3 \mathrm{kV}$ for $18-\mathrm{mm}$ model $)$ is concurrent with increasing velocity of discharge development $\left(t_{\text {breakdown }}\left(T=-12^{\circ} \quad C\right)=13 \quad\right.$ ns decreases to $t_{\text {breakdown }}\left(T=0^{\circ} \mathrm{C}\right)=9 \mathrm{~ns}$ for $18-\mathrm{mm}$ model). However, the effect is not gradual, but appears abruptly for a certain temperature value located between $T_{\text {ice }}=-12^{\circ} \mathrm{C}$ and $T_{\text {ice }}=-4^{\circ} \mathrm{C}$. This behaviour is caused by the formation of a water film on the ice surface, leading in turn to a significant increase in ice surface conductivity. A combination of increased ice temperature and increased freezing water conductivity increases the deteriorating effect on the critical breakdown voltage.

\section{4) Uniformity of Ice Surface}

The present study shows that the introduction of air gaps in the ice cover may not automatically lead to an increase in withstand performance of the whole electrode configuration. Very small air gaps may act as initiators of partial 
discharge activity, due to the discontinuity of the electric permittivity constants. The size of voids seems to be a decisive factor: They may act as discharge initiators decreasing the breakdown voltage, or improve the withstand performance.

\section{5) Discharge Propagation Velocity}

The velocity of discharge propagation is affected by ice surface conductivity (latter influenced by the environmental parameters such as freezing water conductivity and ice temperature), as well as the ice surface uniformity. Different characteristics can be identified:

a) In the case of ice surfaces without artificial air gap, the discharge propagation velocity is directly correlated with ice surface conductivity: Increased ice surface conductivity leads to an increased speed of discharge development. As the discharge develops faster it leads to a lower critical breakdown voltage.

b) In the case of ice surfaces with air gaps, the discharge propagation velocity depends strongly on the ice morphology, in particular on the number and size of air gaps at the ice surface. The discharge activity can bridge microscopic gaps immediately, whereas it develops first along the ice surface before leading to breakdown inside larger gaps. Thus, a void of sufficient size (in the present case $\mathrm{g}=1.6 \mathrm{~mm}$ ) delays the discharge development, but this delaying effect is not directly correlated with an increase in critical breakdown voltage. 


\section{6) Surface charging}

It may be assumed that a dry ice surface (at low temperature and low conductivity conditions) accumulates surface charges as previously observed on various other solid insulating materials, as the process of discharge development in the presence of an ice surface between the electrodes changes clearly in comparison with an air gap alone. The accelerated discharge developments, as well as waveform recordings of current impulses prior to breakdown, provide some evidence of such phenomena. However, no published information was found to substantiate surface charge accumulation on ice at any temperature or surface conductivity.

\section{7) Influence of distance}

Two distinct patterns of discharge development are observed as a function of electrode distance: In the case of very short electrode distance, $d=7 \mathrm{~mm}$, the visible discharge first appears in front of the electrodes. On the other hand, discharge may be initiated at any location along the ice surface for an electrode distance of $d=18 \mathrm{~mm}$. The differing observations for very short electrode distances are attributed to the lack of non-visible pre-breakdown phenomena leading to surface charge accumulation on dry ice surfaces. The minimal distance value for appearance of pre-breakdown activities on the ice surface is situated between the two chosen values of electrode distance, $d=7 \mathrm{~mm}$ and $d=18 \mathrm{~mm}$. 
As a first step towards the establishment of a theory on initiation and development of electrical discharges on ice surfaces, it is proposed to distinguish different regimes for the process of ice surface breakdown:

Two different regimes depending on the ice surface condition:
A) Dry ice surface $\left(T_{\text {ice }}=-12^{\circ} \mathrm{C}\right)$
B) Wet ice surface (ice surface covered with a water film for $\left.-4^{\circ} \mathrm{C} \leq \mathrm{T}_{\text {ice }} \leq 0^{\circ} \mathrm{C}\right)$

Two different sub-regimes in the case of dry ice surface depending on the electrode distance:

A.1) Very short distances (experimental value $d=7 \mathrm{~mm}$ )

A.2) Short distances (experimental value $d=18 \mathrm{~mm}$ )

A change in freezing water conductivity does not seem to alter the regime of discharge process, but the critical breakdown voltage is gradually reduced as conductivity increases. Investigations on the determination of the critical breakdown voltage were carried out only for electrode distance $d=18 \mathrm{~mm}$, thus, equations are given for the two regimes "A.2" and "B".

The regimes can be characterised as follows:

\section{A.1 Discharge initiation for very short distances on dry ice surface}

Visible discharge activity starts in front of the electrodes and grows continuously along the surface into the space between the electrodes. It is 
assumed that no surface charge accumulation on the ice occurs attributed to the lack of pre-cursor activity at very short electrode distances. The velocity of discharge propagation increases at the end of discharge development. With increasing conductivity of the ice surface, the speed of discharge propagation increases.

\section{A.2 Discharge initiation for short distances on dry ice surface}

Visible discharge activity may be initiated anywhere along the ice surface between the two electrodes, or at several places at the same time due to nonvisible pre-cursor activity, which in turn leads to charge accumulation on the ice surface. At first appearance, the discharge activity immediately covers a part of the electrode distance. A growing process follows to bridge the whole space between the electrodes, causing breakdown. Increasing conductivity of the ice surface leads to an increased velocity of discharge propagation. The lightning impulse breakdown voltage, $\mathrm{U}_{50 \%}$, can be described as a function of freezing water conductivity, $\sigma$ :

$$
\begin{aligned}
& U_{50 \%}=116.55 \cdot \sigma^{-0.31} \\
& \left(30 \times 10^{-4} \mathrm{~S} / \mathrm{m}<\sigma<160 \times 10^{-4} \mathrm{~S} / \mathrm{m} ;\right. \\
& \left.T_{\text {ice }}=-12^{\circ} \mathrm{C} ; \mathrm{d}=18 \mathrm{~mm} ; \mathrm{r}=6 \mathrm{~mm}\right)
\end{aligned}
$$




\section{B Discharge initiation on wet ice surface}

Due to the presence of a water film on the ice surface, leading to increased surface conductivity, the discharge bridge the entire space between the electrodes almost immediately, so that no gradual discharge development can be resolved with nanosecond streak photography. The $U_{50 \%}$ lightning impulse breakdown voltage can be described as a function of freezing water conductivity, $\sigma$ :

$$
\begin{gathered}
U_{50 \%}=50.73 \cdot \sigma^{-0.20} \\
\left(2.5 \times 10^{-4} \mathrm{~S} / \mathrm{m}<\sigma<160 \times 10^{-4} \mathrm{~S} / \mathrm{m} ;\right. \\
\left.\mathrm{T}_{\mathrm{ke \theta}} \geq-4^{\circ} \mathrm{C} ; \mathrm{d}=18 \mathrm{~mm} ; \mathrm{r}=6 \mathrm{~mm}\right)
\end{gathered}
$$

Despite the fact that the experimental conditions (simplified physical models under impulse voltage) did not portray perfectly the actual situation on power networks under icing conditions (complex-shaped insulators under ac or dc voltages), good concordance between certain field observations of power failures and the present laboratory investigations can be identified:

- The present study provides an explanation for the increased number of power failures during nice weather periods after icing events, due to the presence of a water film on the ice cover, which considerably increases surface conductivity. It is shown that a different regime governs the discharge process for wet ice surface conditions. 
- The present study shows that the particular characteristics of the ice surface layer and the freezing process of water lead to an increase in surface conductivity due to increasing pollution content of the freezing water, even for low temperatures. If partial discharge activity is initiated on power network equipment, it may quickly lead to local melting, which in turn further increases the danger of flashover and consequent power outages when significant pollution levels are present, also for temperatures well below the melting point.

Furthermore, the present study provides numerical data on critical conditions of discharge initiation, on time delay between start of pre-discharge activities and occurrence of breakdown, as well as on velocity of discharge development. This data may be integrated into software codes in order to develop numerical tools for flashover prediction and for new insulator design for application to power networks in cold regions. It is revealed that any model that aims to reproduce the complete ice surface breakdown process has to consider different regimes for discharge initiation and development, depending on ice surface conditions. 


\subsection{Recommendations for Future Work}

The present investigations can hopefully contribute to further the understanding of ice surface discharge processes, but several aspects still remain unexplained as the time frame of a Ph.D. project sets some limits. Four fields are identified, where further research is expected to reveal more worthwhile data:

1) In the present study, the size of the air gap was identified as an important parameter (Sections 4.3.8 and 5.5.2). Therefore, it is proposed to investigate different ratios $\mathrm{g} / \mathrm{d}$ (air gap length in relation to the electrode distance) in order to determine the critical air gap length, at which the void would increase the withstand performance of insulating devices.

2) This study provides some evidence of surface charge accumulation on dry, low conductive ice surfaces (Sections 4.3.10, 5.4.2.5, 5.5.2.5 and 6.3.2), but the experimental methods used did not permit to quantify the processes of surface charging. Therefore, it is proposed to measure surface charge deposits for the different discharge regimes of dry and wet ice surfaces. The experiments may analyse the influence of various parameters, i.e. freezing water conductivity, ice temperature, and ice surface uniformity. Experimental methods to measure surface charges have already been elaborated in the 
fields of surface discharges on synthetic insulating surfaces (for example [14] [52] [117]) and may be adapted to the field of ice surface discharges.

3) The investigations of visible discharge phenomena are powerful tools to explain the processes of partial discharges. However, in the early stages of discharge development, phenomena that show only very weak light emission or no emission in the visible electromagnetic spectrum may exist (Section 6.3.2). Therefore, it is proposed to carry out experiments on pre-discharge current measurements in order to obtain more precise data on non-visible discharge modes. Sophisticated measuring instruments will be necessary to detect the very weak current signals and to resolve the fast running processes. So as to concentrate on the current signals originating from partial discharge phenomena, it is proposed to integrate a differential circuit in the measuring set-up to suppress the dielectric displacement current (Section 6.3.2).

4) Investigations with simplified physical models enable the study of each individual experimental parameter, but the question remains how the knowledge obtained may be applied to complex systems, where several processes may interact and create synergetic effects. Effects by geometric form and orientation may appear, which could not be studied using simplified models (Sections 4.3.7 and 5.4.2.7). Therefore, it is proposed to carry out 
such fundamental experiments on the discharge processes using larger physical models and small HV insulators covered with atmospheric ice, in order to verify the results of basic studies under experimental conditions that closely resemble conditions on actual power network equipment. As a discharge process cannot be limited to a one-dimensional path for such complex-shaped test objects, it will be necessary to use framing photographic technologies with two-dimensional representation of the dynamic processes. The use of a streak camera may still be recommended for continuous observations of limited regions on a complex-shaped test object, for example the air gap next to the HV terminal on an ice-covered insulator. New numerical framing cameras with faster framing rates and "stand-by" modes will be available in the near future. Thereby, the trigger signal stops the continuous recording and images for the time period before the trigger moment are obtained. These new technologies will be very helpful for the study of the fast processes along ice surfaces under impulse as well as under power frequency voltages. The necessary infrastructure to provide realistic atmospheric icing conditions in a controlled laboratory environment, in combination with sufficient high voltage power supplies, is already available at the new icing research pavilion at the University of Quebec in Chicoutimi.

Finally, other experimental tools may be chosen. As the research field of electric discharge initiation and development along ice surfaces is very young, we 
still need to advance our knowledge in many aspects. It is conceivable to calculate the energy of the current pulses during partial discharge activity in order to find out if local melting of the ice surface occurs. Surface temperature measurements and the use of infrared cameras may also provide data for this question. Spectral analysis of the light emitted may yield more information about which molecules contribute to the ionisation processes and thus may help to clarify the question of whether the discharge processes take place in the gaseous space in the vicinity of or directly on the ice surface. Simultaneous measurements of discharge current and light emission using photomultiplier technology may give more information on the correlation between discharge current and the intensity of the visible phenomena, which will help with the interpretation of the ultra high-speed recordings. 


\section{REFERENCES}




\section{REFERENCES}

[1] N.L.Allen, P.N.Mikropoulos, "Streamer Propagation along Insulating Surfaces", IEEE Transactions on Dielectrics and Electrical Insulation, Vol.6, No.3, pp.357-362, June 1999.

[2] T.Asokan, T.S.Sudarshan, "Role of Coulombic Centers on Insulator Surface Breakdown Characteristics", IEEE Transactions on Electrical Insulation, Vol.El-27, No.5, pp.1040-1049, October 1992.

[3] T.Asokan, T.S.Sudarshan, "Insulator Surface Flashover Conditioning: A Streak Photographic Investigation", IEEE Transactions on Plasma Science, Vol.21, No.3, pp.298-304, June 1993.

[4] R.Badent, "Hochspannungstechnik I+II", Course Notes, 1995/96.

[5] R.BAdent, K.KIST, A.J.Schwab, "Streamer Inception and Propagation in Transformer Oil at $\mathrm{kHz}$ and $\mathrm{MHz}$ Frequencies", Proceedings of $9^{\text {th }}$ International Symposium on High-Voltage Engineering (ISH), Vol.1, pp.1024.1-1024.4, Graz, Austria, August 1995.

[6] H.W.Bandel, "Corona from Ice Points", Journal of Applied Physics, Vol.22, pp.984-985, 1951.

[7] A.Beroual, M.Zahn, A.Badent, K.KIST, A.J.SchwaB H.Yamashita, K.Yamazawa, M.Danikas, W.G.Chadband, Y.Torshin, "Propagation and Structure of Streamers in Liquid Dielectrics", IEEE Electrical Insulation Magazine, Vol.14, No.2, pp.6-17, March/April 1998.

[8] M.Beyen, W.Boeck, K.Moeller, W.ZAengl, "Hochspannungstechnik", Springer-Verlag, Berlin, 1986.

[9] J.Boulllot, M.Farzaneh, E.C.Svensson, R.L.Donaberger, Y.Teisseyre, "Modifications structurales induites dans la glace déposée sur les lignes 
électriques à très haute tension par la présence du champ électrique local", Présentation at $67^{\text {th }}$ ACFAS, Ottawa, Canada, Mai1998.

[10] F.D.A.BoYLeTt, I.G.MACLEAN, "The propagation of electric discharges across the surface of an electrolyte", Proc. Roy. Soc., 324 A, pp.469-489, 1971.

[11] P.G.Buchan, "Electrical Conductivity of Insulator Surface Ices", Ontario Hydro Internal Report, May 1989.

[12] H.T.Bul, "Contribution á l'étude du mécanisme de développement de la décharge électrique en arc de contournement sur la surface de la glace conductrice", Master Thesis, Université du Québec à Chicoutimi, Canada, June 1984.

[13] X.Chen, M.Farzaneh, J.ZHANG, "Factors Influencing Flashover Characteristics along lce Surfaces", Proceedings of $7^{\text {th }}$ International Workshop on Atmospheric Icing of Structures, pp.77-81, Chicoutimi, Canada, June 1996.

[14] S.E.Cherukupalul, "Surface Charge Accumulation on Spacers Under Switching Impulses in Sulphur Hexafluoride Gas", Ph.D. Thesis, University of British Columbia, Canada, July 1987.

[15] W.A.Chisholm, Y.T.Tam, T.O.Melo, I.K.PaVers, C.C.Erven, "60-Hz Performance of 500-kV Insulators under Light Contamination, Ice, Fog and Rising Temperatures: Operating Experience and Field Studies", IEEE Power Engineering Summer Meeting, pp.1-8, 1993.

[16] B.CIESLIK, Hamamatsu, Private Communication, 1999.

[17] J.D.Cross, "The Electret Effect in Ice", Journal Electrochem. Society, Vol.115, pp.42-45, 1968.

[18] J.D.Cross, B.MAzUREK, "Fast Cathode Processes in Conditioning of Vacuum Electrodes", IEEE Transactions on Electrical Insulation, Vol.23, No.1, pp.8789, January 1988.

[19] G.DJoGo, "Transient Behaviour of Vacuum Gaps during Electrical Breakdown", Ph.D. Thesis, University of Waterloo, Canada, 1995.

[20] DRS Hadland, "IMACON 468", Product Brochure. 
[21] H.Engelhardt, N.RIEHL, "Space-charge limited proton currents in ice", Phys. Lett., Vol.14, pp.20-21, 1965.

[22] W.N.English, "Corona from a Water Drop", Physical Review, New York, pp.179, 1948.

[23] M.FARZANEH, G.BouchaRD, "A Major Infrastructure for Meeting a World-wide Need in the Field of Atmospheric Icing Research and Development", Proceedings of $9^{\text {th }}$ International Workshop on Atmospheric Icing of Structures, Chester, United Kingdom, June 2000.

[24] M.Farzaneh, X.Chen, J.Zhang, "A Study of Surface Conductivity and Flashover Voltage of Ice Samples Formed Under Various Freezing Conditions", International Journal of Offshore and Polar Engineering, Vol.6, No.4, pp.298-303, December 1996.

[25] M.Farzaneh, J.F.Drapeau, "AC Flashover Performance of Insulators Covered with Artificial Ice", IEEE Transactions on Power Delivery, Vol.10, No.2, pp.1038-1051, April 1995.

[26] M.Farzaneh, J.KIernicki, "Flashover Problems Caused by Ice Build-up on Insulators", IEEE Electrical Insulation Magazine, Vol.11, No.2, pp.5-17, March/April 1995.

[27] M.Farzaneh, J.KIERNICKI, "Contournement électrique des isolateurs recouverts de glace", Canadian Journal of Electrical and Computer Engineering, Vol.22, No.3, pp.95-109, July 1997.

[28] M.Farzaneh, J.KIERNICKI, "Flashover Performance of IEEE Standard Insulators under Ice Conditions", IEEE Transactions on Power Delivery, Vol.12, No.4, pp.1602-1613, October 1997.

[29] M.Farzaneh, J.KIERnicki, J.F.Drapeau, "AC Flashover Performance of Icecoated Post Insulators", Proceedings of $6^{\text {th }}$ International Workshop on Atmospheric Icing of Structures, Budapest, Hungary, pp.253-257, September 1993.

[30] M.FARzANeh, J.L.LAfORTE, "The Effect of Voltage Polarity on Ice Accretion on Short String Insulators", Journal of Offshore Mechanics and Arctic Engineering, Vol.113, pp.179-184, May 1991. 
[31] M.Farzaneh, J.L.LAforTe, "Effect of Voltage Polarity on Icicles Grown on Line Insulators", International Journal of Offshore and Polar Engineering, Vol.2, pp.297-302, December 1992

[32] M.FARzaneh, J.L.LAFORTE, "Ice Accretion on Conductors Energized by AC or $D C$ : A Laboratory Investigation of Ice Treeing", Proceedings of $3^{\text {rd }}$ International Offshore and Polar Engineering Conference, Singapore, pp.663673, June1993.

[33] M.Farzaneh, S.Y.LI, K.D.SRivastava, "Flashover on Ice Surface", Atmospheric Research, Vol.46, pp.37-47, 1998.

[34] M.Farzaneh, O.T.Melo, "Properties and Effect of Freezing Rain and Winter Fog on Outline Insulators", Cold Regions Science and Technology, Vol.19, pp. 33-46, 1990.

[35] M. Farzaneh, C. Volat and A. Gakwaya, "Electric Field Calculation around Ice-covered Insulator Using Boundary Element Method". Proceedings of IEEE International Symposium on Electrical Insulation ISEI2000, Anaheim, California, pp.349-355, April 2000.

[36] M.Farzaneh, J.ZHANG, "Propagation of AC Arc on Ice Surfaces", Proceedings of IEEE International. Symposium on Electrical Insulation 1998, Washington, DC. USA, June 1998.

[37] M.Farzaneh, J.Zhang, S.Brettschneider, A.M.MiRI, "DC Flashover Performance of Ice-Covered Insulators", Proceedings of $10^{\text {th }}$ International Symposium on High-Voltage Engineering (ISH), Montreal, Canada, Vol.3, pp.77-80, August 1997.

[38] M.FARZANeh, J.Zhang, X.Chen, "Modelling of the AC Discharge on Ice Surfaces", IEEE Transactions on Power Delivery, Vol.12, No.1, pp.325-338, January 1997.

[39] S.M.FIKKE, J.E.HANSSEN, L.ROLFSENG, "Long Range Transported Pollutants and Conductivity of Atmospheric Ice on Insulators", IEEE Transactions on Power Delivery, Vol.PWRD-8, No.3, pp.1311-1321, July 1993.

[40] N.H.Fletcher, "The Surface of Ice", Proceedings of the International Symposium on Physics and Chemistry of Ice, Ottawa, Canada, pp.132-136, August 1972. 
[41] V.Gagliardo, "Discharges in Very-short Air Gaps in Plane-parallel Electrodes and under ac Voltage", IEEE Transactions on Dielectrics and Electrical Insulation, Vol.1, No.6, pp.1156-1166, December 1994.

[42] I.M.Gavrilov, V.R.KuKhta, V.V.Lopatin, P.G.Petrov, "Dynamics of Prebreakdown Phenomena in a Uniform Field in Water", IEEE Transactions on Dielectrics and Electrical Insulation, Vol.1, No.3, pp.496-502, June 1994.

[43] H.H.R.Gaxiola, J.M.Wetzer, "Prebreakdown Phenomena in Dry Air along PTFE Spacers", Proceedings of $8^{\text {th }}$ International Symposium on Gaseous Dielectrics, Virginia Beach, USA, pp.57.I-57.VI, June 1998.

[44] H.Gelin, R.Stubis, "Ice Electrets", Journal chem. Phys, Vol.42, pp.967-971, 1965.

[45] A.I.Grigor'Ev, "Some Features of the Corona Discharge from the Surface of Snow and Ice", Sov. Tech. Phys. Letters, Vol.11, No.8, pp.415-417, August 1985.

[46] H.Hiesinger, "Statistical Time-Lag in Case of Very Fast Transient Breakdown", $6^{\text {th }}$ International Symposium on High Voltage Engineering, New Orleans, USA, Paper 32.23, pp.1-4, August/September 1989

[47] A.v.HIPPEL, "The Dielectric Relaxation Spectra of Water, Ice and Aqueous Solutions, and their Interpretation - 3. Proton Organization and Proton Tranfer in Ice", IEEE Transactions on Electrical Insulation, Vol.23, No.5, pp.825-840, October 1988.

[48] P.V.Hobss, "Ice Physics", Clarendon Press, Oxford, 1974.

[49] N.IKeda, I.Kitamura, K.IWazumi, T.Kashio, T.OHaRa, S.Yoshino, T.Tamura, "Influence of Water Drops for AC Flashover Voltage on Porcelain Surface and Silicone Rubber Surface", Poster presented at Tenth International Symposium on High Voltage Engineering (ISH), Montreal, Canada, Août 1997.

[50] International Electrotechnical Commission, "High-Voltage Test Techniques - Part 2: Test Procedures", International Standard IEC 60-2, 1973.

[51] International Electrotechnical Commission, "Artificial Pollution Tests on High Voltage Insulators to be Used on AC Systems", International Standard IEC 507, April 1991. 
[52] N.C.JaitLY, T.S.SudARSHAN, "In-situ Surface Charge Measurement in Dielectric Bridged Vacuum Gaps", IEEE Transactions on Electrical Insulation, Vol.23, pp.261-273, 1988.

[53] K.Kannus, K.Laht, K.Nousiainen, "Comparisons between Experiments and Calculations of the Electrical Behaviour of Ice-Covered High Voltage Insulators", Proceedings of the $8^{\text {th }}$ International Workshop on Atmospheric Icing of Structures, Iceland, pp. 325-331, June 1998.

[54] K.Kannus, V.VerkKonen, E.Lakervi, "Effects of Ice Coating on the AC Performance of Medium Voltage Insulators", Proceedings of Nordic Symposium of Electrical Insulation, NORD-IS 86, Esbo, Finland, pp.1-11, June 1986.

[55] M.KAWAl, "AC Flashover Test at Project UHV on Ice-Coated Insulators", IEEE Transactions on Power Apparatus \& Systems, Vol.PAS-89, No.8, pp.18001804, December 1970.

[56] E.F.Kelley, M.Nehmad, R.E.Hebner, M.O.Pace, A.L.WintenberG, T.V.BLALOCK, J.V.Foust, "Measurement of Partial Discharges in Hexane under dc Voltages", IEEE Transactions on Electrical Insulation, Vol.24, No.6, pp.1109-1119, December 1989.

[57] M.S.KHALIL, B.S.HanSEN, "Investigation of Space Charge in Low-Density Polyethylene Using a Field Probe Technique", IEEE Transactions on Electrical Insulation, Vol.23, No.3, pp.441-445, June 1988.

[58] Kuffel, Zaengl, "High Voltgae Engineering", Pergamon Press, 1985.

[59] J.L.LAFORTE, C.L.PhAN, J.Druez, "Ice Accretion on Conductors Energized by $A C$ or $D C$ ", Proceedings of $6^{\text {th }}$ International Conference on Port and Oncean Engineering and Arctic Conditions, pp.1057-1066. 1983.

[60] G.Le Roy, C.Gary, B.HutzleR, J.Lalot, C.Dubanton, "Les propriétés diélectriques de l'air et les très hautes tensions", Éditions Eyrolles, Paris, 1984.

[61] S.Y.LI, K.D.Srivastava, G.D.TheOPHILUS, "Nanosecond Streak Photography of Discharges on Spacer Surface in Gases", IEEE Transactions on Dielectrics and Electrical Insulation, Vol.2, No.1, pp.-114-120, February 1995. 
[62] S.Y.LI, G.D.TheOPhiLus, K.D.SRIVAStaVA, "Early Stages of Discharge Development on Insulating Spacers in Gases - A Photographic Study", Proceedings of $5^{\text {th }}$ International Conference on Conduction and Breakdown in Solid Electrics", United Kingdom, pp. 1-5, July 1995.

[63] S.Y.LI, G.D.TheophILUS, K.D.SRIVAStava, "Photographic Observations of Discharge development on Spacers under Combined DC and Impulse Voltages in $S_{6}{ }^{\prime \prime}$, Private Communication, 1998.

[64] K.Libbrecht, "Snow Crystals - Ice Crystal Surface Physics", California Institute of Technology, http://www.its.caltech.edu/ atomic/snowcrystals/surface/surface.htm.

[65] I.V.LISITSYN, H.Nomiyama, S.KatsuKI, H.AkiYama, "Thermal Processes in a Streamer Discharge in Water", IEEE Transactions on Dielectrics and Electrical Insulation, Vol.6, No.3, pp. 351-356, June 1999.

[66] L.B.LoEB, "Electrical Breakdown of Gases with Steady or Direct Current Impulses Potentials", Handbuch der Physik, Springer-Verlag, Berlin, Band XXII, pp.445-530, 1956.

[67] L.B.LoEB, "Electrical Coronas - Their Basic Physical Mechanisms", University of California Press, Berkeley, 1965.

[68] V.Lopatin, M.D.Noskov, R.Badent, K.KIST, A.J.SchwaB, "Positive Discharge Development in Insulating Oil", IEEE Transactions on Dielectrics and Electrical Insulation, Vol.5, No.2, pp.250-255, April 1998.

[69] N.MaEno, "Measurements of Surface and Volume Conductivities of Single Ice Crystals", Proceedings of the International Symposium on Physics and Chemistry of Ice, Ottawa, Canada, pp.140-143, August 1972.

[70] C.Magano, H.Sho, "Frictional Electrification of Ice and Change in its Contact Surface", Physics of Snow and Ice, pp.137-150, 1967.

[71] H.MATSUDA, H.Komuro, K.TAKasu, "Withstand Voltage Characteristics of Insulator String Covered with Snow or Ice", IEEE Transactions on Power Delivery, Vol.PWRD-6, No.3, pp.1243-1250, July 1991.

[72] T.Matsumoto, M.Ishil, T.Kawamura, "Optoelectronic Measurement of Partial Arcs on a Contaminated Surface", IEEE Transactions on Electrical Insulation, Vol.El-19, No.6, pp.543-544, December 1984. 
[73] Max Plank Institut fuer FestKoerperforschung, "Ich bin schon da - Die Diffusion des Protons im Wasser", Spektrum der Wissenschaft, http://www.spektrum.de/themen/Proton-text.html.

[74] Max Planck Society, "Why is Ice so Slippery? Mysteries of the Invisible Ice Surface", http://www.mpg.de/ice2.htm.

[75] J.McNamara, "The Structure of Ice and its Role in Stratospheric", University of Manchester, http://mchhpi.ch.man.ac.uk/ mbdtsma/poster.ice.html.

[76] J.M.MeeK, J.D.Craggs, "Electrical Breakdown of Gases", Wiley-Interscience Publication, Chichester, 1978.

[77] A.Meier, W.M.Niggli, "The Influence of Snow and lce Deposit on Supertensison Transmission Line Insulator Strings with Special Reference to High Altitude Operation", IEEE Conference Publ.44, London, England, pp.386-395, September 1968.

[78] M.MelloR, "Properties of Snow", Cold Regions Science and Engineering, Part III, Sec.A1, December 1964.

[79] B. Michel, "Éléments de la physique de la neige et de la glace", Les presses de l'Université Laval, Québec, 1964.

[80] Microsoft encarta Online encyclopedia 2000, "Ice", http://encarta.msn.com, (20 July 2000).

[81] H.C.MilLeR, "Surface Flashover of Insulators", IEEE Transactions on Electrical Insulation, Vol.24, No.5, pp.765-786, October 1989.

[82] Y.NakaO, H.ITOH, Y.Sakal, H.TAGashiRa, "Studies of the Creepage Discharge on the Surface of Liquids", IEEE Transactions on Electrical Insulation, Vol.23, No.4, pp.677-687, August 1988.

[83] E.NASSER, "Fundamentals of Gaseous Ionization and Plasma Electronics", Wiley-Interscience, New York, 1971.

[84] W.Pfeiffer, M.Giesselmann, P.Volken, "Predischarge Development at Interface between Gaseous and Solid Dielectrics", IEEE International Symposium Electrical Insulation, Philadelphia, USA, pp.216-219, 1982.

[85] W.PFEIFFeR, D.Schoen, L.Z.Tong, "Simulation of Prebreakdown Phenomena at a Gas/Solid Inferface in a 10\% SF6/N2 Mixture Stressed by Very Fast 
Transient Voltages", Proceedings of IEEE International Symposium on Electrical Insulation ISEI2000, Anaheim, USA, paper 14-7,pp.408-411, April 2000.

[86] W.Pfeiffer, D.Schoen, C.Zender, "Dielectric Strength of $S F_{6} / N_{2}$ Mixtures for Nonuniform Field Distribution and Very Fast Transient Voltage Stress", Private Communication, 1997.

[87] L.C.Phan, J.-L.LAForTe, D.D.NguYen, "The Lobe Structure in Ice Accreted on an Aluminium Conductor in the Presence of a DC Electric Field", Annals of Glaciology, Vol.4, pp.228-235, 1983.

[88] A.J.Phillips, I.R.JAndrell, J.P.Reynders, "The Effect of Corona in Volume and Air-Density on the Corona Onset Potential of Water Drops", Proceedings of $9^{\text {th }}$ International Symposium on High Voltage Engineering, Graz, pp.21661-4, August 1995.

[89] M.PIDWIRny, "Introduction to Physical Geography 1, Physical Properties of Water", Okanagan University College, http://www.geog.ouc.bc.ca/conted/onlinecourses/geog_111/6a.html.

[90] E.R.PoundeR, "Physics of Ice", Pergamon Press ,Oxford, 1965

[91] S.E.REYNOLDS, M.BRooK, M.F.GouRLeY, "Thunderstorm Charge Separation", Journal. Met., Vol.14, pp.426-436, 1957.

[92] N.Rieht, B.Bullemer, H.Engelhardt, "Physics of Ice", Plenum Press, New York 1969

[93] M.Roulleau, "The Influence of an Electric Field on the Freezing of Water", Proceedings of the International Symposium on Physics of Ice, Munich, Germany, pp.631-640, September 1968.

[94] R.Rupp, "Electrical Properties of Ice Ih Single Crystals", Proceedings of the International Symposium on Physics and Chemistry of Ice, Ottawa, Canada, August 1972.

[95] M.Sato, H.Saito, A.Kaga, H.Akagami, "Fundamental Characteristics of AC Flashover on Contaminated Insulators Covered with Ice", Japanese Journal of Applied Physics, Vol.28, No.5, pp.889-896, May 1989. 
[96] H.M. SchNeIDer, "Artificial Ice Tests on Transmission Line Insulators - A Progress Report", IEEE/PES Summer Meeting, San Francisco, USA, Paper A75-491-1, pp.347-353, July 1975.

[97] G.SCHROEDER, "SF$F_{6}-N_{2}$ Gas Mixtures - Electrical Insulation and Discharge Development under Fast Oscillating Impulse Conditions in a Non-Uniform Gap", Proceedings of IEEE International Symposium on Electrical Insulation ISEI 2000, Anaheim, USA, paper 10-1, pp.280-283, April 2000.

[98] Scientific Visualization Laboratory, "Water and Ice", New York University, http://cwis.nyu.edu/pages/mathmol/modules/water/info_water.html.

[99] T.Seelig, J.Pilling, L.BerndT, "Physikalische Zusammenhänge beim Gefrieren und Schmelzen wäßriger Elektrolytlösungen an Freiluftisolatoren", Wiss. Berichte THZ 1234, pp.34-38, 1990.

[100]T.ShImazaKI, I.TsuneYasu, "Flashover Processes on the Surface of Solid Insulators under Positive Impulse Voltage in the Atmosphere", IEEE Transactions on Electrical Insulation, Vol.25, No.6, pp.1161-1169, December 1990.

[101]T.ShimazaKl, "Flashover Characteristics and Surface Processes under Negative Impulse Voltage in Atmospheric Air", IEEE Transactions on Electrical Insulation, Vol.27, No.3, pp.488-495, June 1992.

[102] M.L.-A.SJOeberG, H.J.BlenNow, S.M.GubanSKI, M.A.S.LelJon, "On Discharge Phenomena in a Covered Electrode System in Air", Proceedings of IEEE International Symposium on Electrical Insulation ISEI 2000, Anaheim, USA, paper 12-3, pp.345-348, April 2000.

[103] T.S.SudarShan, R.A.DougaL, "Mechanism of Surface Flashover along Solid Dielectrics in Compressed Gases: A Review", IEEE Transactions on Electrical Insulation, Vol.El-21, No.5, pp.727-746, October 1986.

[104]T.TAKahaSH, "Electric Potential of Liquid Water on an Ice Surface", Journal atmospheric Science, Vol.26, pp.1253-1258, 1969.

[105]T.TAKahaSH, "Electric Potential of a Rubbed Ice Surface", Journal atmos.Science, Vol.26, pp.1259-1265, 1969.

[106] Y.TeisseYre, M.Farzaneh, "Effect of Corona Discharge on the Ice Accretion", Proceedings of $4^{\text {th }}$ Conference on Atmospheric Icing of Structures, Paris, France, paper B5.5, pp.1-4, September 1988. 
[107] S.TenBoHLEN, "Particle-Initiated Surface Discharges in $\mathrm{SF}_{6}$ under Fast Oscillating Impulse Voltages", Proceedings of $10^{\text {th }}$ International Symposium on High-Voltage Engineering (ISH), Montreal, Canada, Vol.2, pp.101-104, August 1997.

[108]C.Volat, Internal Research Report, University of Québec in Chicoutimi, Canada, 1998.

[109]Z.Vuckovic, Z.Zdravkovic, S.Plazinic, G.Hrabak-Tumpa, "Effect of Polluted Ice and Snow Accretions on High-Voltage Transmission Line Insulators", Proceedings of $5^{\text {th }}$ International Workshop on Atmospheric Icing of Structures, Tokyo, Paper B4-3, pp.1-6, October/November 1990.

[110]D.WU, R.HARTINGS, S.M.FIKKE, "The Performance of Vertically Installed Insulator Strings under Ice and Snow Conditions", Proceedings of $8^{\text {th }}$ International Workshop on Atmospheric Icing of Structures, Iceland, pp. 205208, June 1998.

[111] T.Yamashita, G.Satoh, T.Fujishima, H.Matsuo, T.Shibata, "Propagation Characteristics of a Surface Discharge on Covered Conductors and Cylindrical Dielectric Materials", Proceedings of $10^{\text {th }}$ International Symposium on High-Voltage Engineering (ISH), Montreal, Canada, Vol.2, pp.145-148, August 1997.

[112]L.YARRIS, "Theory on Antarctic Ozone Hole Boosted by New Observations Confirming Wet Surface of Ice", Berkley Lab, http://www.lbl.gov/ScienceArticles/Archive/ice-ozone-link.html.

[113] M.Yashima, T.KaWamoto, H.Fujinami, T.Takuma, "A Study on Breakdown Characteristics of Hybrid Gas Insulated Transmission Line (H-GIL)", Proceedings of $10^{\text {th }}$ International Symposium on High-Voltage Engineering (ISH), Montreal, Canada, Vol.2, pp.5-8, August 1997.

[114]Z.YOSHIDA, "The Mechanism of Charge Generation in Friction and Destruction of Ice and in Thunderclouds", Low Temp. Science, A1, pp.149-187, 1944.

[115] M.Yumuto, T.SaKal, "Photo Electron Emission from Dielectric Materials by Ultra-violet-ray Irridiation", Annual Report of Conference on Electrical insulation and Dielectric Phenomena, Boston, USA, pp.75-81, 1981. 
[116]J.Zhang, M.Farzaneh, "Propagation of DC Arc on Ice Surfaces", Proceedings of $8^{\text {th }}$ International Offshore and Polar Engineering Conference, Montréal, Canada, Vol.2, pp.5547-550, May 1998.

[117]J.ZHOU, "A Study of Charge Accumulation and Spacer Flashover in Compressed Gas Insulation", Ph.D. Thesis, University of British Columbia, Canada, June 1991.

[118] http://www.geo.fmi.fi/ hlaakso/Rosetta/Complex.GIF, "Complex Permittivity" 
APPENDICES 


\section{APPENDIX 1}

PHASE DIAGRAMS OF ICE

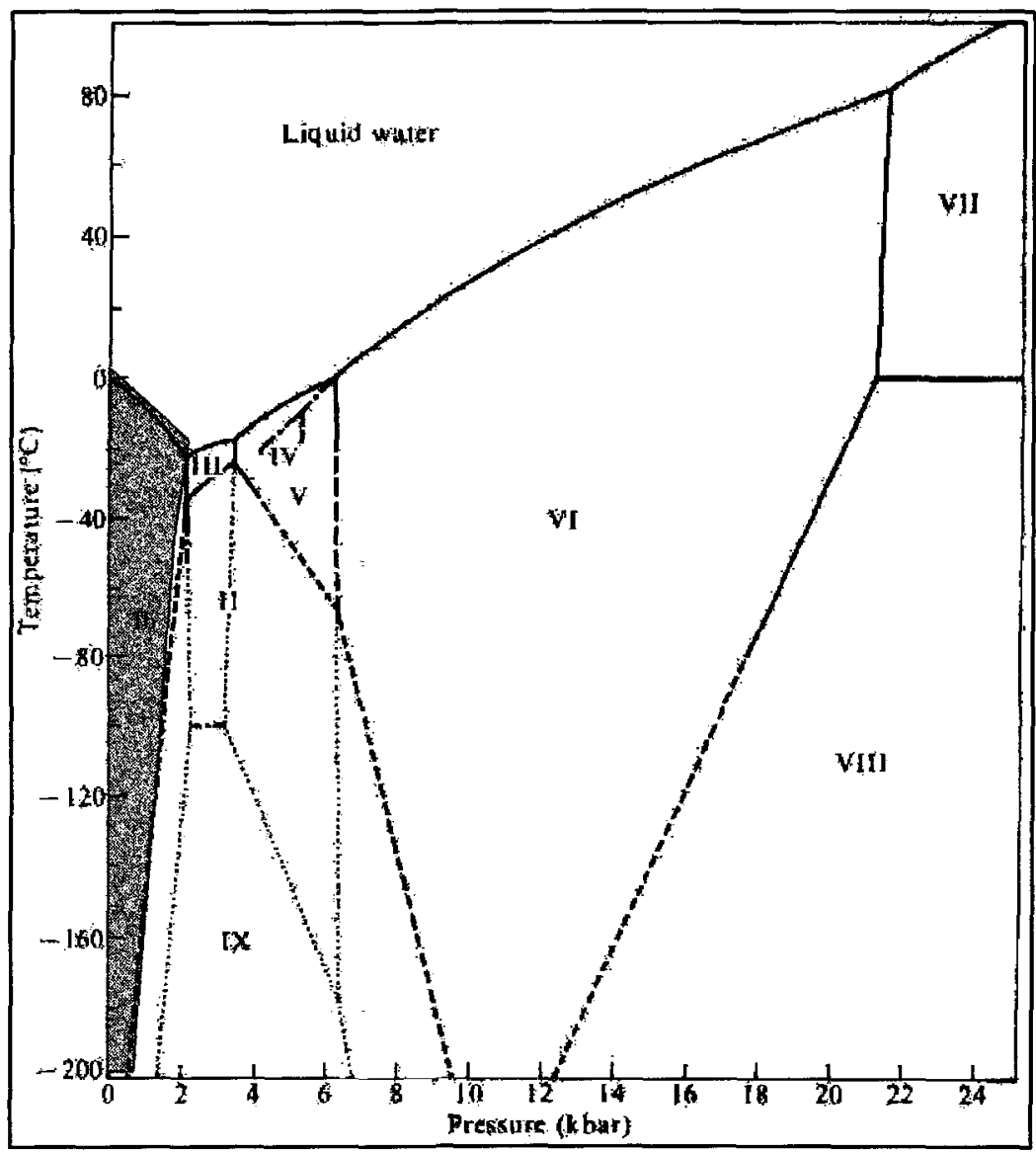

Fig. A-1: Phase diagram of ice as a function of pressure (showing the different crystalline ice structures) [48] 


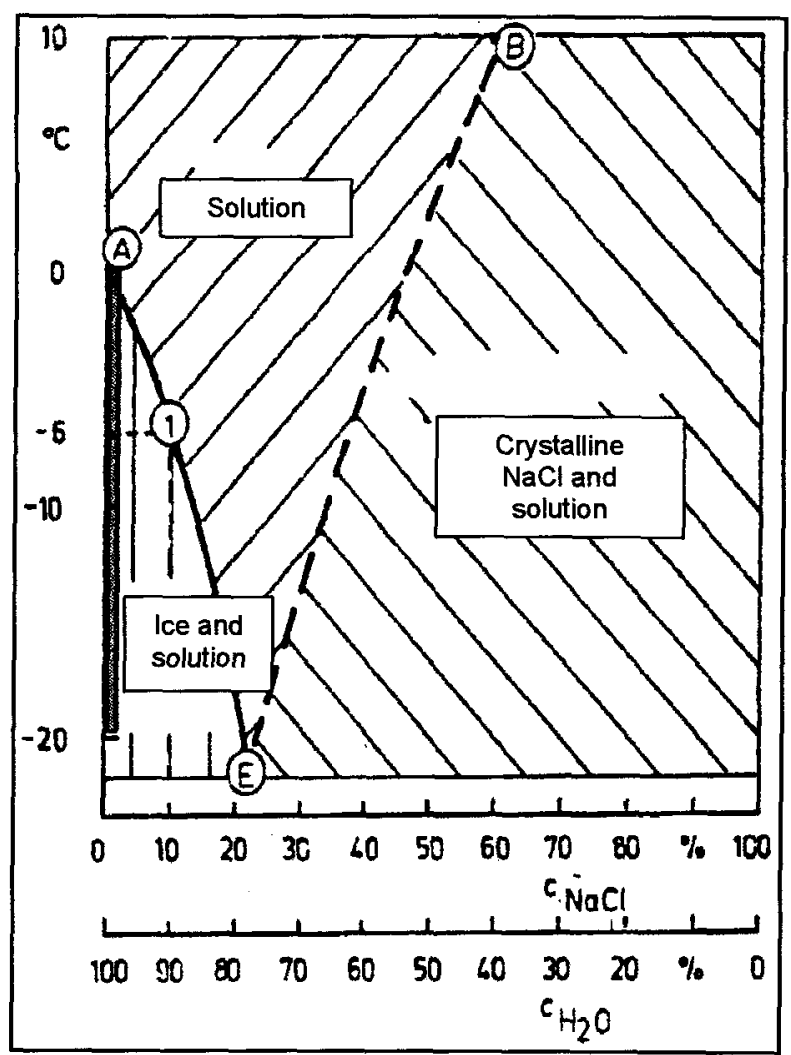

Fig. A-2: Phase diagram of a water/NaCl-solution as a function of $\mathrm{NaCl}$ concentration [99]

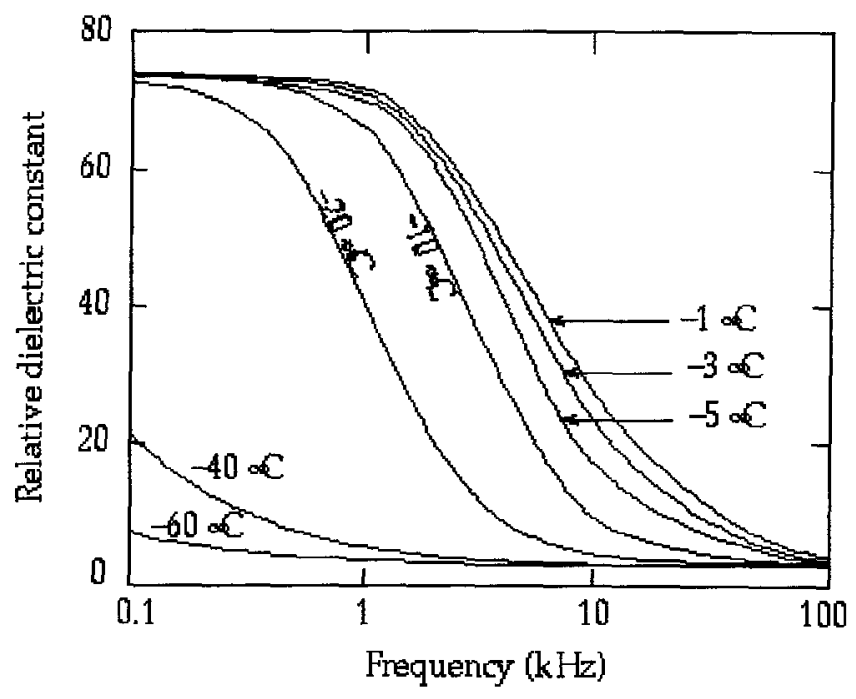

Fig. A-3: Relative permittivity of ice as a function of temperature and frequency [118] 


\section{APPENDIX 2}

\section{TECHNICAL DATA OF CLIMATE CHAMBER}

The climate chamber used in all experiments of this study is a type "Envirotronics EH40-2-3". The technical characteristics are:

- Workspace of about $1.5 \mathrm{~m}^{3}$

- Dual air circulation fans

- Air cooled cascade refrigeration system

- Microprocessor based temperature-humidity programmer controller

- Temperature measurement by thermocouple sensor

- $28 \mathrm{~cm}$ by $28 \mathrm{~cm}$ viewing window in front door

- Stainless steel interior

The data for the temperature control are presented in Table A-1.

Table A-1: Temperature range of climate chamber

\begin{tabular}{|c|c|}
\hline$T_{\max }$ & $+177^{\circ} \mathrm{C}$ \\
$T_{\min }$ & $-73^{\circ} \mathrm{C}$ \\
$\delta T_{\text {control }}$ & $+/-1.1 \mathrm{C}^{\circ}$ \\
\hline
\end{tabular}




\section{APPENDIX 3}

\section{TECHNICAL DATA OF STREAK CAMERA}

Table A-2: Technical data of streak camera

\begin{tabular}{|lll|}
\hline General Characteristics & & \\
\hline Steak unit (type M2548) & Sweep times & $10 \mathrm{~ns} \sim 1 \mathrm{~ms}$ (16 steps) \\
& Trigger delay time & approx. $60 \mathrm{~ns}$ at $\mathrm{t}_{\text {sweop }}=10 \mathrm{~ns}$ \\
& Time resolution & $100 \mathrm{ps}$ at $\mathrm{t}_{\mathrm{swesp}}=10 \mathrm{~ns}$ \\
& Gate time & $300 \mathrm{~ns} \sim 100 \mu \mathrm{s}$ \\
& Extinction ratio & minimum $1: 10^{6}$ \\
& Gate method & Photocathode-accel.-relating \\
& & electrode \\
& & MCP, simultaneous gate \\
\hline Electrical Characteristics & & \\
\hline Trigger & Streak trigger signal input & $+5-+40 \mathrm{~V}_{\mathrm{pp}} / 50 \Omega$ \\
& Gate trigger signal input & $+2-+40 \mathrm{~V}_{\mathrm{pp}} / 50 \Omega$ \\
& Trigger jitter & within $+/-50 \mathrm{ps}$
\end{tabular}




\begin{tabular}{|c|c|c|}
\hline \multicolumn{3}{|l|}{ Optical Characteristics } \\
\hline & Lens configuration & $35 \mathrm{~mm}, \mathrm{~F} 4.5$ \\
\hline & Image magnification & $1: 1$ \\
\hline & Slit width & $\begin{array}{l}0 \sim 5 \mathrm{~mm} \text { (continuously variable, } \\
\text { accuracy } 0.005 \mathrm{~mm} \text { ) }\end{array}$ \\
\hline & Slit length & $0 \sim 15 \mathrm{~mm}$ (continuously variable) \\
\hline \multicolumn{3}{|c|}{ Streak tube } \\
\hline & Photocathode & Multi-alkali S-20 \\
\hline & Faceplate material & UV glass \\
\hline & Fluorescent screen & P-20 \\
\hline & Spectral sensitivity & $200 \sim 850 \mathrm{~nm}$ \\
\hline & Size of photocathode & $1.5 \sim 8 \mathrm{~mm}$ \\
\hline & $\begin{array}{l}\text { Useful phosphor screen } \\
\text { size }\end{array}$ & $15 \mathrm{~mm}$ diameter \\
\hline & Light gain & approx. $3 \times 10^{3}$ \\
\hline & Image magnification & approx. 1:1.5 \\
\hline & Time resolution & $\min .10 \mathrm{ps}$ \\
\hline \multicolumn{3}{|c|}{ Format of streak photographs } \\
\hline & internal image format & $\begin{array}{l}\text { ".xif" (only for internal use, } \\
\text { coloured image) }\end{array}$ \\
\hline & format for image export & ".tif" as b/w-image \\
\hline
\end{tabular}




\section{APPENDIX 4}

\section{ELEMENTS OF HV IMPULSE GENERATOR}

Table A-3: Elements of high voltage generator

\begin{tabular}{|c|c|c|}
\hline Symbol & Designation & Value \\
\hline TEO & Test transformer & $\begin{array}{l}2 * 220 \mathrm{~V} / 100 \mathrm{kV} / \\
220 \mathrm{~V} \\
5 \mathrm{kVA}\end{array}$ \\
\hline Rs & Protective resistor & $10 \mathrm{M} \Omega$ \\
\hline GS1, GS2 & Selenium rectifier & $\mathrm{I}_{\text {nom }}=5 \mathrm{~mA}$ each \\
\hline $\begin{array}{l}\text { RGS1, } \\
\text { RGS2 }\end{array}$ & Serial rectifier resistance & $500 \mathrm{k} \Omega$ each \\
\hline KF & Sphere gap & $\begin{array}{l}\text { distance }=0 \text { to } \\
80 \mathrm{~mm} \\
\text { diameter }=100 \mathrm{~mm}\end{array}$ \\
\hline Cs & Impulse capacitor & $6000 \mathrm{pF}$ \\
\hline $\mathrm{Cb}$ & $\begin{array}{l}\text { Load capacitor (and high voltage } \\
\text { capacitor of voltage divider) }\end{array}$ & $1200 \mathrm{pF}$ \\
\hline $\mathrm{Ct}$ & low voltage capacitor of voltage- & $4.61 \mu \mathrm{F}$ \\
\hline
\end{tabular}




\begin{tabular}{|l|ll|}
\hline (modified) & divider \\
Re1, Re2 & $\begin{array}{l}\text { Discharging resistor (two resistors in } \\
\text { series) }\end{array}$ & $6100 \Omega$ each \\
Rd & Damping resistor & $375 \Omega$ \\
\hline
\end{tabular}




\section{APPENDIX 5}

\section{TECHNICAL DATA OF DIGITISING OSCILLOSCOPE}

The oscilloscope used for all voltage and current waveform measurements in this study is a "Hewlett Packard HP-54111D" digitising oscilloscope.

Table A-4: Technical specifications of oscilloscope

\begin{tabular}{|c|c|c|}
\hline \multicolumn{3}{|l|}{ Vertical } \\
\hline Channels & 2 & \\
\hline Bandwidth & real-time & repetitive \\
\hline dc-coupled & dc to $250 \mathrm{MHz}$ & dc to $500 \mathrm{MHz}$ \\
\hline ac-coupled & $10 \mathrm{~Hz}$ to $250 \mathrm{MHz}$ & $10 \mathrm{~Hz}$ to $500 \mathrm{MHz}$ \\
\hline $\begin{array}{l}\text { Transition time ( } 10 \% \text { to } \\
90 \% \text { ) }\end{array}$ & $<700$ ps & $700 \mathrm{ps}$ \\
\hline $\begin{array}{l}\text { Deflection factor (full scale } \\
=8 \mathrm{div})\end{array}$ & \multicolumn{2}{|c|}{$1 \mathrm{mV} /$ div to $5 \mathrm{~V} /$ div continuos } \\
\hline Resolution ( $\%$ of full scale) & 8 bits to $25 \mathrm{MHz}(0.4 \%)$ & 6 bits $(1.6 \%)$ \\
\hline
\end{tabular}




\begin{tabular}{|c|c|c|}
\hline $\begin{array}{l}\text { DC gain accuracy } \\
\text { DC offset accuracy }\end{array}$ & $\begin{array}{l}7 \text { bits to } 100 \mathrm{MHz}(0.8 \%) \\
6 \text { bits to } 250 \mathrm{MHz}(1.6 \%) \\
+/-2 \% \text { of full scale } \\
+/-1.5 \% \text { of setting }+/-0.2\end{array}$ & $\begin{array}{l}8 \text { bits with averaging to } \\
500 \mathrm{MHz}(0.4 \%)\end{array}$ \\
\hline \multicolumn{3}{|l|}{ DC measurement accuracy } \\
\hline $\begin{array}{l}\text { single data point } \\
\text { between data points on } \\
\text { same waveform } \\
\text { DC offset range } \\
\text { Input coupling } \\
\text { Max. safe voltage input }\end{array}$ & \multicolumn{2}{|c|}{$\begin{array}{l}+/- \text { gain acc. +/-offset acc. +/- resolution } \\
+/- \text { gain acc. +/-2 * resolution } \\
+/-200 \mathrm{mV}(1 \mathrm{mV} / \text { div to } 4 \mathrm{mV} / \mathrm{div}) \\
+/-1 \mathrm{~V}(5 \mathrm{mV} / \mathrm{div} \text { to } 49 \mathrm{mV} / \mathrm{div}) \\
+/-10 \mathrm{~V}(50 \mathrm{mV} / \text { div to } 499 \mathrm{mV} / \mathrm{div}) \\
+/-40 \mathrm{~V}(500 \mathrm{mV} / \mathrm{div} \text { to } 5 \mathrm{~V} / \mathrm{div}) \\
\text { ac/dc/dc }-50 \Omega / \mathrm{ground} \\
+/-40 \mathrm{~V} \text { at } 1 \mathrm{M} \Omega \text { (dc and peak ac) } \\
5 \mathrm{~V} \text { rm } \text { at } 50 \Omega\end{array}$} \\
\hline \multicolumn{3}{|l|}{ Horizontal } \\
\hline Deflection factor & $\begin{array}{l}\text { real-time } \\
1 \text { gigasamples } / \mathrm{s} \text { to } 50 \\
\text { samples/s } \\
500 \mathrm{ps} / \mathrm{div} \text { to } 1 \mathrm{~s} / \mathrm{div}\end{array}$ & repetitive \\
\hline $\begin{array}{l}\text { Memory depth (per chan.) } \\
\text { Pre-trigger delay range }\end{array}$ & $\begin{array}{l}8 \mathrm{k} \\
-8 \mu \mathrm{s} \text { at timebase settings }\end{array}$ & 501 \\
\hline
\end{tabular}




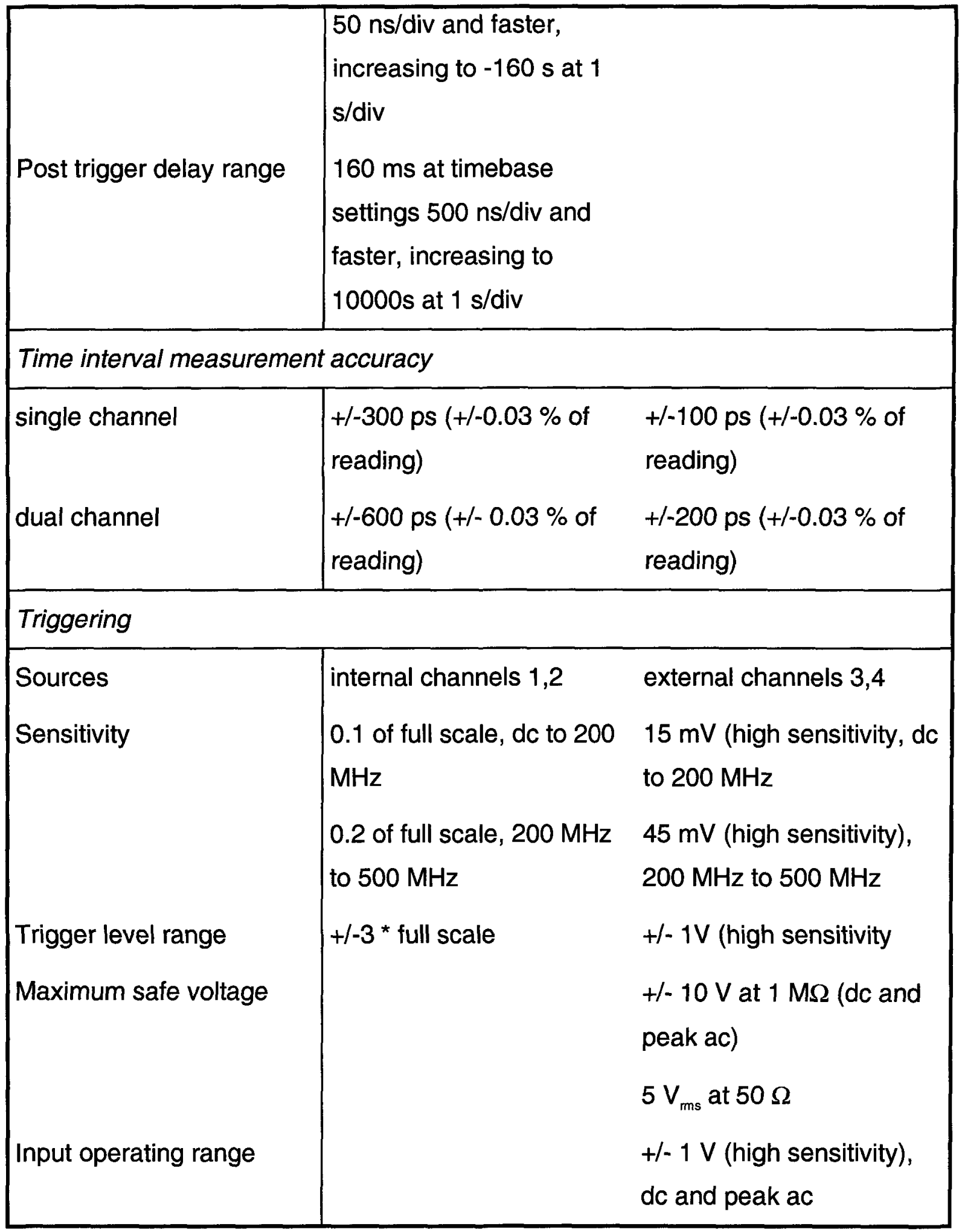




\section{APPENDIX 6}

\section{SPECIFICATIONS OF OVERVOLTAGE PROTECTION}

Table A-5: Specifications of overvoltage suppressor

\begin{tabular}{|l|l|}
\hline Type of protection & Philips ECG 4927 \\
Rated maximum voltage & $\mathrm{V}_{\text {rated }}=15.3 \mathrm{~V}$ \\
Measured maximum voltage & $\mathrm{V}_{\max }=19.4 \mathrm{~V}$ \\
for a lightning impulse $(1.2 / 50 \mu \mathrm{s})$ & \\
\hline
\end{tabular}




\section{APPENDIX 7}

\section{DESIGN PARAMETERS FOR CAPACITIVE HV MEASURING DIVIDER}

Table A-6: Design parameters for the low voltage capacitor of capacitive voltage divider

\begin{tabular}{|l|l|}
\hline Parameter & Value \\
\hline Number of capacitors & 10 \\
Value of each capacitor & $0.47 \mu \mathrm{F}+/-10 \%$ \\
Type of capacitor & Philips MKT \\
& $250 \mathrm{~V}$ \\
Total value of low voltage unit (measured at $\left.25^{\circ} \mathrm{C}\right)$ & $4,62 \mu \mathrm{F}$ \\
Divider factor & 3850 \\
\hline
\end{tabular}




\section{APPENDIX 8}

\section{DESIGN PARAMETERS FOR CURRENT SHUNTS}

Two different resistances were made in a coaxial low-impedance design. The resistance with the lower value $\left(R_{\text {stunt }}=1.4 \Omega\right)$ was used for flashover tests, whereas the second resistance with an increased value $\left(R_{\text {shunt } 2}=1.2 \mathrm{k} \Omega\right)$ was used for partial discharges tests, at lower voltages, without flashover event. To obtain the desired value, several components were connected in parallel. Figure A-3 shows a photograph of the coaxial design. As an additional security, the current signal was passed through a 10:1 probe to limit the maximum values of the incoming signal.

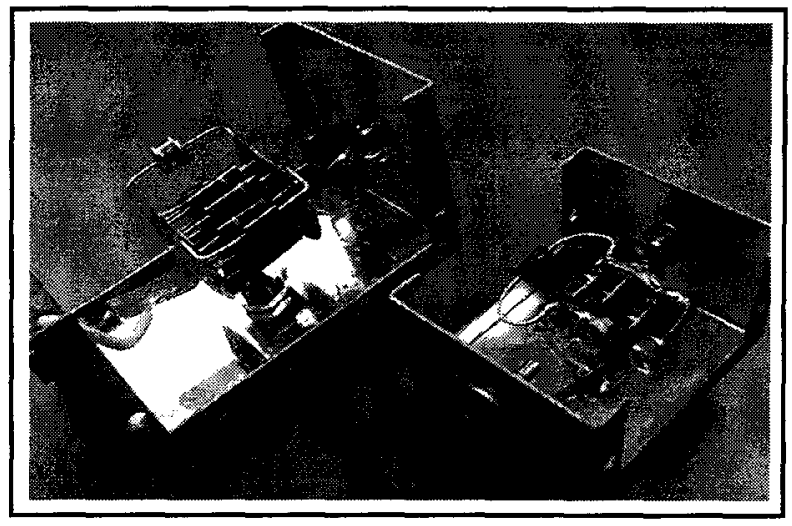

Fig. A-4: Coaxial design of current shunts 


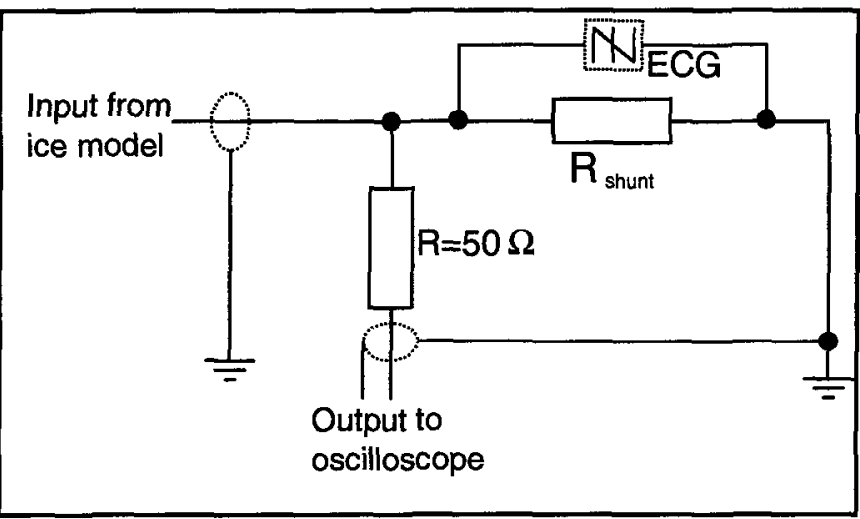

Fig. A-5: Internal circuit of the current shunt

Table A-7: Specifications for the current shunt

\begin{tabular}{|c|c|c|}
\hline Element & Parameter & Value \\
\hline $7 \mathrm{R} 1$ & $\begin{array}{c}\text { number of parallel resistances } \\
\text { value of each resistance } \\
\text { total value } \mathrm{R}_{\text {stunt } 1} \\
\text { (measured at } 25^{\circ} \mathrm{C} \text { ) }\end{array}$ & $\begin{array}{c}11 \\
15 \Omega+/-5 \% \\
1.45 \Omega\end{array}$ \\
\hline $\mathrm{R} 2$ & $\begin{array}{l}\text { number of parallel resistances } \\
\text { value of each resistance } \\
\text { total value } R_{\text {shunt } 2} \\
\text { (measured at } 25^{\circ} \mathrm{C} \text { ) }\end{array}$ & $\begin{array}{c}8 \\
10 \mathrm{k} \Omega+/-5 \% \\
1.245 \mathrm{k} \Omega\end{array}$ \\
\hline Overvoltage protection & & $\begin{array}{c}\text { Philips } \\
\text { ECG } 4927\end{array}$ \\
\hline Coupling resistance & & $47 \Omega+/-5 \%$ \\
\hline
\end{tabular}




\section{APPENDIX 9}

\section{CONNECTION OF THE SUB-SYSTEMS IN THE EXPERIMENTAL TEST SET-UP}

Figure A-5 shows a photograph of the experimental set-up in the laboratory for discharge physics at the University of Quebec in Chicoutimi. The main components are identified and Fig. A-6 shows the detailed equivalent electric circuit of the interconnection of the different systems for the experimental test setup.

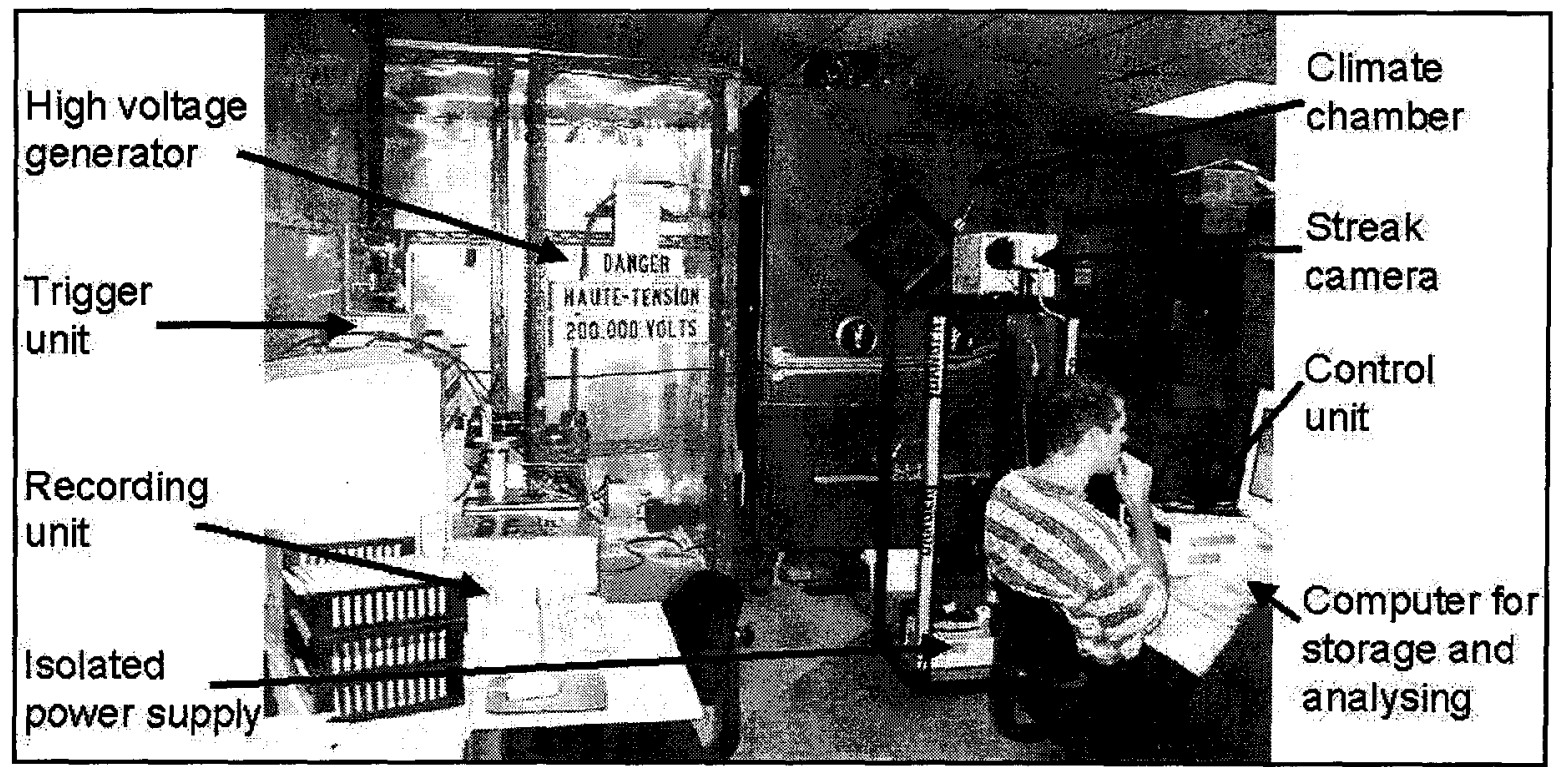

Fig. A-6: Actual experimental set-up in the laboratory 


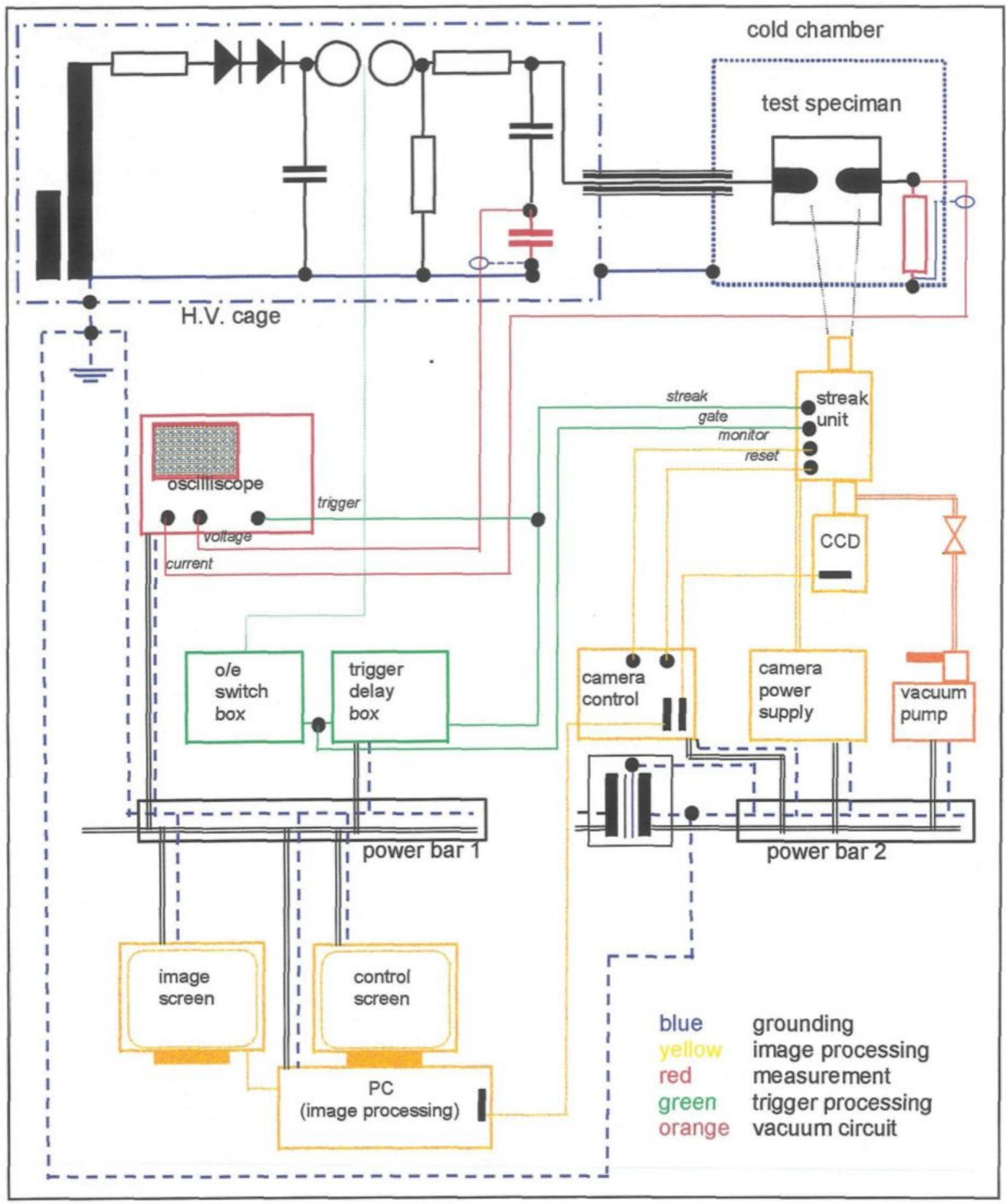

Fig. A-7: Complete experimental set-up with the interconnection of the different systems 


\section{APPENDIX 10}

\section{CORRECTION OF FREEZING WATER CONDUCTIVITY IN FUNCTION OF TEMPERATURE}

An equation does exist for the calculation of the electric conductivity of water at a temperature other than $20^{\circ} \mathrm{C}$ :

$$
\begin{aligned}
& \sigma_{T_{x}}=\sigma_{20^{\circ} \mathrm{C}} \cdot \delta \\
& \delta=\frac{0.45 \cdot T_{x}}{20}+0.55
\end{aligned}
$$

For the daily work in the laboratory, a table was established for the correlation factor $\delta$, which is presented in Table A-8. 
Table A-8: Correction factor $\delta$ for water conductivity as a function of the temperature

\begin{tabular}{|c|c|c|c|}
\hline Temperature $\left({ }^{\circ} \mathrm{c}\right)$ & $\delta$ & Temperature $\left({ }^{\circ} \mathrm{c}\right)$ & $\delta$ \\
\hline 15.0 & 089 & 21.0 & 1.02 \\
\hline 15.5 & 0.90 & 21.5 & 1.03 \\
\hline 16.0 & 0.91 & 22.0 & 1.05 \\
\hline 16.5 & 0.92 & 22.5 & 1.06 \\
\hline 17.0 & 0.93 & 23.0 & 1.07 \\
\hline 175 & 094 & 23.5 & 1.08 \\
\hline 18.0 & 0.96 & 24.0 & 1.09 \\
\hline 18.5 & 0.97 & 24.5 & 1.10 \\
\hline 19.0 & 0.98 & 25.0 & 1.11 \\
\hline 19.5 & 0.99 & 25.5 & 1.12 \\
\hline 20.0 & 1.00 & 26.0 & 1.14 \\
\hline 20.5 & 1.01 & 26.5 & 1.15 \\
\hline
\end{tabular}

To give an idea of the concentration of added sodium chloride $(\mathrm{NaCl})$ in the freezing water, the increase of the electric conductivity of water was measured with the conductivity meter type "Yokogawa SC82" before and after adding $0.2 \mathrm{~g}$ of $\mathrm{NaCl}$ to $0.25 \ell$ of de-ionised water. Tab. A-9 shows the measured values:

Table A-9: Measured conductivity values before and after adding $0.2 \mathrm{~g}$ of $\mathrm{NaCl}$ to $0.25 \mathrm{\ell}$ of de-ionised water

\begin{tabular}{|c|c|}
\hline Moment of conductivity measurement & $\sigma$ \\
\hline before adding salt & $2.20 \times 10^{-4} \mathrm{~S} / \mathrm{m}$ (at $\left.19.4^{\circ} \mathrm{C}\right)$ \\
after adding salt & $1.709 \times 10^{-1} \mathrm{~S} / \mathrm{m}\left(\right.$ at $19.3^{\circ}$ \\
& $\mathrm{C})$ \\
\hline
\end{tabular}




\section{APPENDIX 11}

\section{NON-LINEAR REGRESSION ANALYSIS OF THE EFFECT OF FREEZING WATER CONDUCTIVITY ON CRITICAL BREAKDOWN VOLTAGE}

The experimental results give evidence that different regimes for the breakdown process exist depending on parameters "ice surface condition" and "electrode distance". On the other hand, the parameter "freezing water conductivity" does not seem to provoke the change of the regime of the discharge process, but it influences the velocity for the execution of discharge development. Therefore, a regression analysis of the effect of freezing water conductivity was carried out in order to determine the relation between the critical breakdown voltage and the freezing water conductivity in form of a mathematical equation. Due to the non-linear characteristic of the results, a regression type "power" was used.

The experimental values used for the regression analysis are presented in Tables 4-1 to 4-3. Table A-10a shows the different results for each value of the 
parameters "ice temperature" and "voltage polarity". In addition, results of regression analysis based on the average values from the results of both voltage polarities are presented in Table A-10b for the three different temperature values. It is interesting to observe the accordance of the results for the two equations based on mean values for the two temperature values $T=-4^{\circ} \mathrm{C}$ and $\mathrm{T}=0^{\circ} \mathrm{C}$, whereas the results for a temperature $T=-12^{\circ} \mathrm{C}$ is significantly different. This may be seen as confirmation of the hypothesis that the discharge process appears in two different regimes: one for temperatures far below the melting point, were the ice surface conditions can be identified as "dry", the second for temperatures near and at the melting point, where a water film exists on the ice surface.

In the case of temperature $\mathrm{T}=-12^{\circ} \mathrm{C}$, the regression type "power" showed significant deviation from the experimental results for low values. As the results for the lowest freezing water conductivity $\left(\sigma=2.5 \times 10^{-4} \mathrm{~S} / \mathrm{m}\right)$ was excluded, a quite good regression agreement of regression and measurements could be obtained. Table A-11 finally presents the two retained equations describing the effect of the freezing water conductivity on the critical breakdown voltage for the two different discharge regimes. The curves for the different measurements and the two retained equations are presented in Fig. A-7. 
Table A-10: Equations resulting from regression analysis of the effect of freezing water conductivity on critical breakdown voltage

\begin{tabular}{|cc|l|}
\hline Temperature & Polarity & \multicolumn{1}{|c|}{ Equation } \\
\hline$-12^{\circ} \mathrm{C}$ & pos. & $U_{50 \%}=52.18 \cdot \sigma^{-0.11}$ \\
& neg. & $U_{50 \%}=58.22 \cdot \sigma^{-0.16}$ \\
& pos. & $U_{50 \%}=45.81 \cdot \sigma^{-0.19}$ \\
& neg. & $U_{50 \%}=54.74 \cdot \sigma^{-0.21}$ \\
$0^{\circ} \mathrm{C}$ & pos. & $U_{50 \%}=50.48 \cdot \sigma^{-0.20}$ \\
& neg. & $U_{50 \%}=51.90 \cdot \sigma^{-0.20}$ \\
\hline
\end{tabular}

a) Analysis based on experimental values

\begin{tabular}{|c|l|}
\hline Averaging parameter & Equation \\
\hline$-12^{\circ} \mathrm{C}$ & $U_{50 \%}=55.11 \cdot \sigma^{-0.14}$ \\
$-4^{\circ} \mathrm{C}$ & $U_{50 \%}=50.25 \cdot \sigma^{-0.20}$ \\
$0^{\circ} \mathrm{C}$ & $U_{50 \%}=51.18 \cdot \sigma^{-0.20}$ \\
\hline
\end{tabular}

b) Analysis based on mean values grouped according to various temperatures

Table A-11: Final results of non-linear regression analysis

\begin{tabular}{|c|c|}
\hline Ice surface condition & Equation \\
\hline dry ice surface & $U_{50 \%}=116.55 \cdot \sigma^{-0.31}$ \\
$\left(30 \times 10^{4} \mathrm{~S} / \mathrm{m} \leq \sigma \leq 160 \times 10^{4} \mathrm{~S} / \mathrm{m}\right)$ & \\
wet ice surface & $U_{50 \%}=50.73 \cdot \sigma^{-0.20}$ \\
$\left(2.5 \times 10^{-4} \mathrm{~S} / \mathrm{m} \leq \sigma \leq 160 \times 10^{4} \mathrm{~S} / \mathrm{m}\right)$ & \\
\hline
\end{tabular}



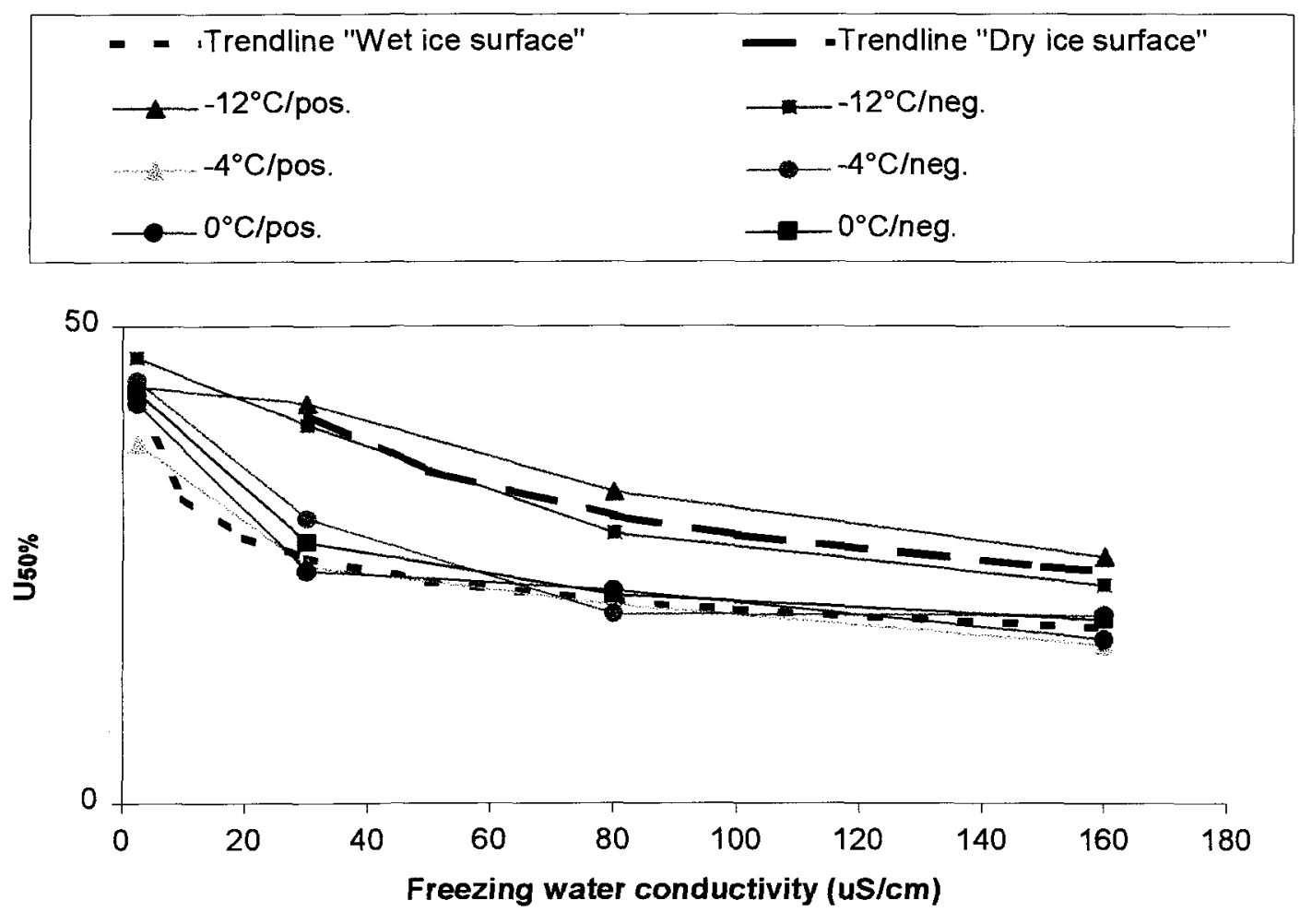

a) Presentation with linear scales

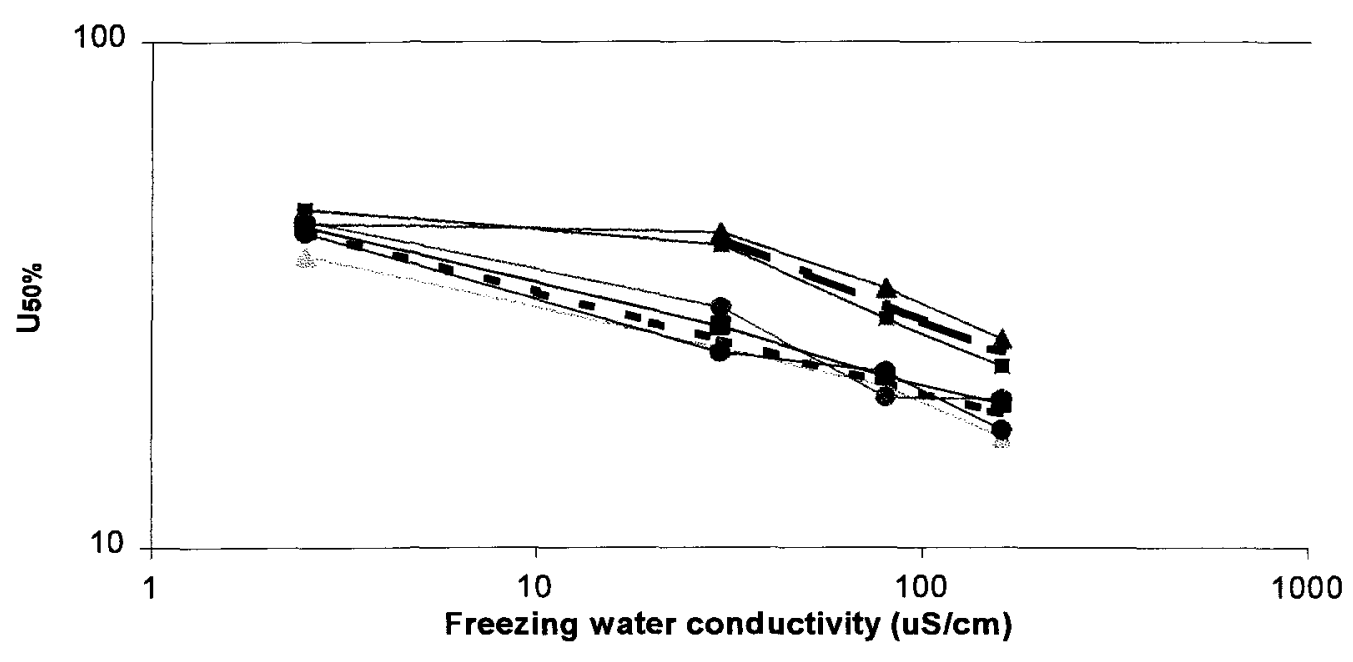

b) Presentation with logarithmic scales

Fig. A-8: Curves of measurement and equations resulting from regression analysis for critical breakdown voltage as a function of freezing water conductivity 